\title{
Modelagem computacional para reconhecimento de emoções baseada na análise facial
}

\author{
Giampaolo Luiz Libralon
}



Data de Depósito:

Assinatura:

\title{
Modelagem computacional para reconhecimento de emoções baseada na análise facial
}

\author{
Giampaolo Luiz Libralon
}

Orientadora: Profa. Dra. Roseli Aparecida Francelin Rome ro

Tese apresentada ao Instituto de Ciências Matemáticas e de Computação - ICMC-USP, como parte dos requisitos para obtenção do título de Doutor em Ciências - Ciências de Computação e Matemática Computacional. VERSÃO REVISADA. 
Ficha catalográfica elaborada pela Biblioteca Prof. Achille Bassi e Seção Técnica de Informática, ICMC/USP, com os dados fornecidos pelo(a) autor(a)

\begin{tabular}{|c|c|}
\hline \multirow[t]{3}{*}{$\mathrm{L} 697 \mathrm{~m}$} & $\begin{array}{l}\text { Libralon, Giampaolo Luiz } \\
\quad \text { Modelagem computacional para reconhecimento de } \\
\text { emoções baseada na análise facial / Giampaolo Luiz } \\
\text { Libralon; orientadora Roseli Aparecida Francelin } \\
\text { Romero. -- São Carlos, } 2014 \text {. } \\
\quad 196 \text { p. }\end{array}$ \\
\hline & $\begin{array}{l}\text { Tese (Doutorado - Programa de Pós-Graduação em } \\
\text { Ciências de Computação e Matemática Computacional) -- } \\
\text { Instituto de Ciências Matemáticas e de Computação, } \\
\text { Universidade de São Paulo, } 2014 .\end{array}$ \\
\hline & $\begin{array}{l}\text { 1. Reconhecimento de emoções. 2. Interação homem- } \\
\text { máquina. 3. Expressões faciais. 4. Inteligência } \\
\text { Artificial. I. Romero, Roseli Aparecida Francelin, } \\
\text { orient. II. Título. }\end{array}$ \\
\hline
\end{tabular}


À minha amada esposa Andreia, à minha família, e a Deus. Meus pilares de sustentação! 


\section{Agradecimentos}

Agradeço especialmente à minha amada esposa Andreia, que me fez seguir firme neste trabalho, nas várias vezes em que desanimei. Sem duvida ela é a principal responsável pela conclusão de mais este projeto em minha vida. Agradeço também pela paciência, entendendo e aceitando meus momentos de irritação.

Agradeço muito minha família, pelo apoio recebido. Em especial à minha querida mãe, pela dedicação, carinho e preocupação que sempre demonstrou para que eu concluísse este trabalho.

Agradeço à minha orientadora, Profa. Dra. Roseli, pela oportunidade, orientação, confiança e paciência para conduzir esta pesquisa.

Meu profundo agradecimento a Deus, que me envia forças para lutar, além de capacidade e determinação para atingir meus objetivos.

A todos aqueles que, em algum momento, me auxiliaram direta ou indiretamente para a conclusão deste trabalho, deixo também meus agradecimentos.

Para finalizar, agradeço aos apoios financeiros recebidos, durante parte deste doutorado, das agências de fomento CAPES e FAPESP. 


\section{Resumo}

As emoções são objeto de estudo não apenas da psicologia, mas também de diversas áreas como filosofia, psiquiatria, biologia, neurociências e, a partir da segunda metade do século XX, das ciências cognitivas. Várias teorias e modelos emocionais foram propostos, mas não existe consenso quanto à escolha de uma ou outra teoria ou modelo. Neste sentido, diversos pesquisadores argumentam que existe um conjunto de emoções básicas que foram preservadas durante o processo evolutivo, pois servem a propósitos específicos. Porém, quantas e quais são as emoções básicas aceitas ainda é um tópico em discussão. De modo geral, o modelo de emoções básicas mais difundido é o proposto por Paul Ekman, que afirma a existência de seis emoções: alegria, tristeza, medo, raiva, aversão e surpresa. Estudos também indicam que existe um pequeno conjunto de expressões faciais universais capaz de representar as seis emoções básicas. No contexto das interações homem-máquina, o relacionamento entre ambos vem se tornando progressivamente natural e social. Desta forma, à medida que as interfaces evoluem, a capacidade de interpretar sinais emocionais de interlocutores e reagir de acordo com eles de maneira apropriada é um desafio a ser superado. Embora os seres humanos utilizem diferentes maneiras para expressar emoções, existem evidências de que estas são mais precisamente descritas por expressões faciais. Assim, visando obter interfaces que propiciem interações mais realísticas e naturais, nesta tese foi desenvolvida uma modelagem computacional, baseada em princípios psicológicos e biológicos, que simula o sistema de reconhecimento emocional existente nos seres humanos. Diferentes etapas são utilizadas para identificar o estado emocional: a utilização de um mecanismo de pré-atenção visual, que rapidamente interpreta as prováveis emoções, a detecção das características faciais mais relevantes para o reconhecimento das expressões emocionais identificadas, e a análise de características geométricas da face para determinar o estado emocional final. Vários experimentos demonstraram que a modelagem proposta apresenta taxas de acerto elevadas, boa capacidade de generalização, e permite a interpretabilidade das características faciais encontradas. 


\section{Abstract}

Emotions are the object of study not only of psychology, but also of various research areas such as philosophy, psychiatry, biology, neuroscience and, from the second half of the twentieth century, the cognitive sciences. A number of emotional theories and models have been proposed, but there is no consensus on the choice of one or another of these models or theories. In this sense, several researchers argue that there is a set of basic emotions that have been preserved during the evolutionary process because they serve specific purposes. However, it is still a topic for discussion how many and which the accepted basic emotions are. In general, the model of basic emotions proposed by Paul Ekman, which asserts the existence of six emotions - happiness, sadness, fear, anger, disgust and surprise, is the most popular. Studies also indicate the existence of a small set of universal facial expressions related to the six basic emotions. In the context of human-machine interactions, the relationship between human beings and machines is becoming increasingly natural and social. Thus, as the interfaces evolve, the ability to interpret emotional signals of interlocutors and to react accordingly in an appropriate manner is a challenge to surpass. Even though emotions are expressed in different ways by human beings, there is evidence that they are more accurately described by facial expressions. In order to obtain interfaces that allow more natural and realistic interactions, a computational modeling based on psychological and biological principles was developed to simulate the emotional recognition system existing in human beings. It presents distinct steps to identify an emotional state: the use of a preattentive visual mechanism, which quickly interprets the most likely emotions, the detection of the most important facial features for recognition of the identified emotional expressions, and the analysis of geometric facial features to determine the final emotional state. A number of experiments demonstrated that the proposed computational modeling achieves high accuracy rates, good generalization performance, and allows the interpretability of the facial features revealed. 


\section{Sumário}

Lista de Figuras $\ldots \ldots \ldots \ldots \ldots \ldots$. . . . . . . . . . . . . . . . . . . . . . .

Lista de Tabelas . . . . . . . . . . . . . . . . . . . . . xxiv

1 Introdução 1

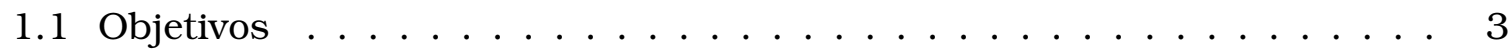

1.2 Principais Contribuições . . . . . . . . . . . . . . . 4

1.3 Organização do Texto . . . . . . . . . . . . . . . . . 5

2 O Estudo das Emoções $\quad 7$

2.1 As Emoções Humanas . . . . . . . . . . . . . . . . . . . . . . . . 9 9

2.1.1 Neurofisiologia das Emoções . . . . . . . . . . . . . . . . . . 14

2.2 Considerações Finais . . . . . . . . . . . . . . . 17

3 Robótica Sociável $\quad 19$

3.1 Robôs Sociáveis . . . . . . . . . . . . . . . . . . 20

3.2 As Emoções e a Robótica Sociável . . . . . . . . . . . . . . . . . . . . 24

3.3 Considerações Finais . . . . . . . . . . . . . . . . . . . . 29

4 Expressões Faciais $\quad 31$

4.1 Análise de Expressões Faciais . . . . . . . . . . . . . . . . . . 32

4.1.1 Sistema de Codificação de Ações Faciais . . . . . . . . . . . . . . . 35

4.2 Expressões Faciais Emocionais . . . . . . . . . . . . . . . 38

4.3 Trabalhos sobre Reconhecimento Emocional . . . . . . . . . . . . . 45

4.4 Considerações Finais . . . . . . . . . . . . . . . . . . 53

5 Algoritmos e Métodos $\quad 55$

5.1 Mecanismo de Pré-atenção Visual . . . . . . . . . . . . . . . . . 56

5.1 .1 Mapa de Saliência . . . . . . . . . . . . . . . . . 57

5.1 .2 Histograma de Gradientes Orientados . . . . . . . . . . . . . . . 59

5.1 .3 Entropia, Variância e Desvio-padrão . . . . . . . . . . . . . 60

5.2 Aprendizado de Máquina . . . . . . . . . . . . . . . . . . . 62 
5.2.1 Support Vector Machines . . . . . . . . . . . . . . . . 64

5.2 .2 Algoritmo C4.5 . . . . . . . . . . . . . . . . . 64

5.2 .3 Redes Neurais Artificiais . . . . . . . . . . . . . . . 65

5.2.4 Algoritmos de Agrupamento de Dados . . . . . . . . . . . . . 66

5.3 Seleção de Características . . . . . . . . . . . . . . . 70

5.3 .1 Algoritmos Selecionados . . . . . . . . . . . . . 74

5.3.2 Combinação de Algoritmos para Seleção de Características . . . 76

5.4 Considerações Finais . . . . . . . . . . . . . . . . . . 77

6 Modelagem para o Reconhecimento das Emoções 79

6.1 Modelagem Computacional Proposta . . . . . . . . . . . . . . 79

6.1.1 Abordagem para o Mecanismo de Pré-atenção Visual . . . . . . . . 81

6.1.2 Representações Faciais para o Reconhecimento de Emoções . . . 84

6.1.3 Abordagem para a Identificação das Características Faciais . . . . 89

6.2 Considerações Finais . . . . . . . . . . . . . . . . . . . 91

7 Identificação das Características de Diagnóstico 95

7.1 Bases de Dados Avaliadas . . . . . . . . . . . . . . . . . 95

7.2 Experimentos e Resultados . . . . . . . . . . . . . . . . . . . . 97

7.2.1 Resultados do Reconhecimento Emocional . . . . . . . . . . . . 97

7.2.2 Resultados da Identificação de Características Faciais . . . . . . . 129

7.3 Considerações Finais . . . . . . . . . . . . . . . . . . . . . . . 144

8 Análise das Imagens Térmicas $\quad 145$

8.1 Base de Dados Investigada . . . . . . . . . . . . . . . . . 145

8.2 Experimentos e Resultados . . . . . . . . . . . . . . . . 147

8.2.1 Resultados do Mecanismo de Pré-atenção Visual . . . . . . . . . 148

8.2.2 Resultados obtidos com a Modelagem Proposta . . . . . . . . . . . 167

8.3 Considerações Finais . . . . . . . . . . . . . . . . . . . 179

9 Conclusões e Trabalhos Futuros $\quad 181$

9.1 Trabalhos Futuros . . . . . . . . . . . . . . . . . 183

$\begin{array}{ll}\text { Referências } & 184\end{array}$ 


\section{Lista de Figuras}

2.1 Emoções básicas propostas por Ekman . . . . . . . . . . . . 11

2.2 Modelo Circumplexo proposto por Russel _ . . . . . . . . . . . . . . . 12

2.3 Roda de Emoções de Plutchik . . . . . . . . . . . . . . . . . . . 13

2.4 Representação do Sistema Límbico . . . . . . . . . . . . . . . 15

3.1 Robô Kismet . . . . . . . . . . . . . . . . . . . 21

3.2 Robô Maggie . . . . . . . . . . . . . . . . . . 21

3.3 Personificação corporal . . . . . . . . . . . . . . . . 23

3.4 Face renderizada do robô Valerie . . . . . . . . . . . . . . . 25

3.5 Robô Barthoc . . . . . . . . . . . . . . . . . . . . . . 27

3.6 Robô Probo e seu espaço emocional . . . . . . . . . . . . . . . . . 28

3.7 Emoções do robô Ifbot . . . . . . . . . . . . . . . . . . . . 28

4.1 Exemplos de unidades de ação do sistema FACS . . . . . . . . . . . 36

4.2 Músculos da face humana . . . . . . . . . . . . . . . . . . 37

4.3 Alterações na configuração dos elementos faciais . . . . . . . . . . . . . 41

4.4 Comparação entre mapas de fixação do olhar e de saliência . . . . . . . . . 52

4.5 Comparação entre as regiões faciais obtidas pelos experimentos psicológicos, e pela técnica Bubbles . . . . . . . . . . . . . . . . 53

5.1 Exemplo de mapa de saliência . . . . . . . . . . . . . . . . . 59

5.2 Exemplo de aplicação do método HOG . . . . . . . . . . . . . . . . 61

5.3 Entropia de uma imagem . . . . . . . . . . . . . . . 6 61

6.1 Modelagem desenvolvida . . . . . . . . . . . . . . . 80

6.2 Aplicação do algoritmo de segmentação facial em imagens térmicas . . . 83

6.3 Faces recortadas . . . . . . . . . . . . . . . . . . 83

6.4 Máscara aplicada às faces . . . . . . . . . . . . . . . 83

6.5 Mapeamento facial obtido pelo Face Tracker . . . . . . . . . . . . . . . . . 85

6.6 Apresentação gráfica das representações faciais . . . . . . . . . . . 86 
6.7 Fluxograma da seleção de características . . . . . . . . . . . . . . 92

6.8 Fluxo interno da seleção de características . . . . . . . . . . . . . 93

7.1 Exemplos de imagens encontradas nas bases de dados CK+ e RaFD . . . 96

7.2 Gráfico comparativo entre Emoções separadas x Emoções em conjunto . 118

7.3 Gráfico comparativo da utilização do Modelo de Face Neutra . . . . . . . 128

7.4 Características de diagnóstico para a emoção de tristeza . . . . . . . . 133

7.5 Características de diagnóstico para a emoção de raiva . . . . . . . . . . 135

7.6 Características de diagnóstico para a emoção de aversão . . . . . . . . 136

7.7 Características de diagnóstico para a emoção de surpresa . . . . . . . 137

7.8 Características de diagnóstico para a emoção de alegria . . . . . . . . . 140

7.9 Características de diagnóstico para a emoção de medo . . . . . . . . . . . 142

8.1 Exemplos de imagens existentes na base de dados USTC-NVIE . . . . . 146

8.2 Pontos anotados nas imagens térmicas da base de dados USTC-NVIE . . 147

8.3 Processo de registro das imagens visíveis e térmicas . . . . . . . . . . . 147

8.4 Médias do índice silhueta obtidas para os mapas de saliência dos conjuntos 1 a $10 \ldots \ldots$. . . . . . . . . . . . . . . . 152

8.5 Médias do índice silhueta obtidas para os mapas de saliência dos conjuntos 11 a $20 \ldots \ldots$. . . . . . . . . . . . . . . . . . . . . . . . . . . . . .

8.6 Médias do índice silhueta obtidas para os mapas de saliência dos conjuntos 21 a $31 \ldots \ldots \ldots \ldots$. . . . . . . . . . . . . . . . . . . . . . . . .

8.7 Médias do índice Jaccard obtidas para os mapas de saliência dos conjuntos 1 a $10 \ldots \ldots \ldots$. . . . . . . . . . . . . . . . . . . . . . . . . . . . . . .

8.8 Médias do índice Jaccard obtidas para os mapas de saliência dos conjuntos 11 a $20 \ldots \ldots$. . . . . . . . . . . . . . . . . 154

8.9 Médias do índice Jaccard obtidas para os mapas de saliência dos conjuntos 21 a $31 \ldots \ldots$. . . . . . . . . . . . . . . . . . 154

8.10 Exemplo de agrupamento obtido . . . . . . . . . . . . . . . 155

8.11 Médias do índice silhueta obtidas para as imagens térmicas dos conjuntos 1 a $10 \ldots \ldots$. . . . . . . . . . . . . . . . . . . . . . . . . . . . . . .

8.12 Médias do índice silhueta obtidas para as imagens térmicas dos conjuntos 11 a $20 \ldots \ldots$. . . . . . . . . . . . . . . . . . . . . . . . . . . . . .

8.13 Médias do índice silhueta obtidas para as imagens térmicas dos con-

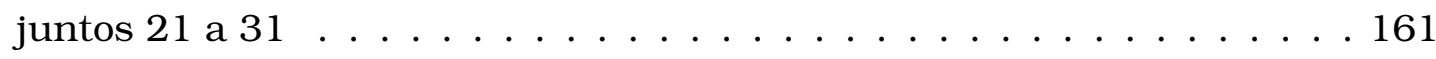

8.14 Médias do índice Jaccard obtidas para as imagens térmicas dos con-

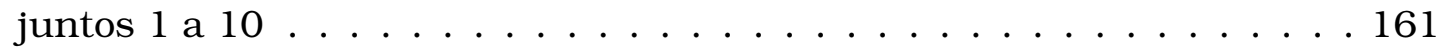

8.15Médias do índice Jaccard obtidas para as imagens térmicas dos conjuntos 11 a $20 \ldots \ldots$. . . . . . . . . . . . . . . . . . 162

8.16 Médias do índice Jaccard obtidas para as imagens térmicas dos conjuntos 21 a $31 \ldots \ldots \ldots \ldots$. . . . . . . . . . . . . . . . . . . . . . . 
8.17 Médias do índice silhueta obtidas pela união dos mapas de saliência com as imagens térmicas . . . . . . . . . . . . . . . . . . 165

8.18Médias do índice Jaccard obtidas pela união dos mapas de saliência com as imagens térmicas . . . . . . . . . . . . . . . . . 165

8.19 Melhor agrupamento obtido para os experimentos realizados . . . . . . 168

8.20 Etapas realizadas pela modelagem proposta para a identificação emocional . . . . . . . . . . . . . . . . . . . . . 169

8.21 Modos diferentes de expressar a tristeza . . . . . . . . . . . . . 177 


\section{Lista de Tabelas}

4.1 Mapeamento dos músculos faciais (UAs) para emoções de acordo com o sistema FACS. A $\|$ B significa "A ou B". . . . . . . . . . . . . . . . . . . 37

4.2 Relação existente entre as UAs definidas pelo sistema FACS e os músculos faciais. . . . . . . . . . . . . . . . . 38

7.1 Taxas de acerto obtidas pelas SVMs para a base RaFD com as emoções positivas e a expressão neutra. . . . . . . . . . . . . . . . . 99

7.2 Taxas de acerto obtidas pelas SVMs para a base RaFD com as emoções negativas. . . . . . . . . . . . . . . . . 100

7.3 Taxas de acerto obtidas pelo algoritmo $\mathrm{C} 4.5$ para a base RaFD com as emoções positivas e a expressão neutra. . . . . . . . . . . . . . 100

7.4 Taxas de acerto obtidas pelo algoritmo C4.5 para a base RaFD com as emoções negativas. . . . . . . . . . . . . . . . . . 100

7.5 Taxas de acerto obtidas pelas MLPs para a base RaFD com as emoções positivas e a expressão neutra. . . . . . . . . . . . . . . 101

7.6 Taxas de acerto obtidas pelas MLPs para a base RaFD com as emoções negativas. . . . . . . . . . . . . . . . . 101

7.7 Taxas de acerto obtidas pelas SVMs para a base CK+ com as emoções positivas e a expressão neutra. . . . . . . . . . . . . . 103

7.8 Taxas de acerto obtidas pelas SVMs para a base CK+ com as emoções negativas. . . . . . . . . . . . . . . . . 103

7.9 Taxas de acerto obtidas pelo algoritmo $\mathrm{C} 4.5$ para a base $\mathrm{CK}+\mathrm{com}$ as emoções positivas e a expressão neutra. . . . . . . . . . . . . 103

7.10Taxas de acerto obtidas pelo algoritmo $\mathrm{C} 4.5$ para a base $\mathrm{CK}+\mathrm{com}$ as emoções negativas. . . . . . . . . . . . . . . . . . . . 104

7.11 Taxas de acerto obtidas pelas MLPs para a base CK+ com as emoções positivas e a expressão neutra. . . . . . . . . . . . . . . . . . . 104

7.12Taxas de acerto obtidas pelas MLPs para a base CK+ com as emoções negativas. . . . . . . . . . . . . . . . . . . . 104 
7.13Taxas de acerto obtidas pelas SVMs para as emoções positivas e a expressão neutra, quando treinadas com a base RaFD e avaliadas com a base $\mathrm{CK}+\ldots \ldots \ldots \ldots$. . . . . . . . . . . . . . . 106

7.14Taxas de acerto obtidas pelas SVMs para as emoções negativas, quando treinadas com a base RaFD e avaliadas com a base CK+. . . . . . . . . 106

7.15Taxas de acerto obtidas pelo algoritmo C4.5 para as emoções positivas e a expressão neutra, quando treinado com a base RaFD e avaliado com a base CK+. . . . . . . . . . . . . . . . . . . . . . . . . 107

7.16Taxas de acerto obtidas pelo algoritmo $\mathrm{C} 4.5$ para as emoções negativas, quando treinado com a base RaFD e avaliado com a base CK+. . . . . . . 107

7.17Taxas de acerto obtidas pelas MLPs para as emoções positivas e a expressão neutra, quando treinadas com a base RaFD e avaliadas com a base CK+. . . . . . . . . . . . . . . . . . . . . . . . . 107

7.18Taxas de acerto obtidas pelas MLPs para as emoções negativas, quando treinadas com a base RaFD e avaliadas com a base CK+. . . . . . . . . . 108

7.19Taxas de acerto obtidas pelas SVMs para as emoções positivas e a expressão neutra, quando treinadas com a base CK+ e avaliadas com a base RaFD. . . . . . . . . . . . . . . . . . . . . . . . . . . 108

7.20Taxas de acerto obtidas pelas SVMs para as emoções negativas, quando treinadas com a base CK+ e avaliadas com a base RaFD. . . . . . . . . . 108

7.21 Taxas de acerto obtidas pelo algoritmo $\mathrm{C} 4.5$ para as emoções positivas e a expressão neutra, quando treinado com a base $\mathrm{CK}+\mathrm{e}$ avaliado com a base RaFD. . . . . . . . . . . . . . . . . . . . . . . . . . . . . . . 109

7.22 Taxas de acerto obtidas pelo algoritmo $\mathrm{C} 4.5$ para as emoções negativas, quando treinado com a base $\mathrm{CK}+$ e avaliado com a base RaFD. . . . . . . 109

7.23Taxas de acerto obtidas pelas MLPs para as emoções positivas e a expressão neutra, quando treinadas com a base $\mathrm{CK}+\mathrm{e}$ avaliadas com a base RaFD. . . . . . . . . . . . . . . . . . . . . . . . . . . 109

7.24 Taxas de acerto obtidas pelas MLPs para as emoções negativas, quando treinadas com a base CK+ e avaliadas com a base RaFD. . . . . . . . . . 110

7.25Taxa de acerto média obtida para as emoções positivas com os experimentos entre as bases de dados. . . . . . . . . . . . . . . . . . . 110

7.26 Taxa de acerto média obtida para as emoções negativas com os experimentos entre as bases de dados. . . . . . . . . . . . . . . . . . . 110

7.27Taxas de acerto obtidas para a base RaFD e as emoções em conjunto. . 112

7.28 Taxas de acerto obtidas para a base CK+ e as emoções em conjunto. . . 112

7.29 Taxa de acerto média obtida para as emoções positivas e a expressão neutra com a base RaFD, quando analisadas em conjunto. . . . . . . . . 114

7.30 Taxa de acerto média obtida para as emoções negativas com a base RaFD, quando analisadas em conjunto. . . . . . . . . . . . . . . . 114 
7.31 Taxa de acerto média obtida para as emoções positivas com a base $\mathrm{CK}^{+}$, quando analisadas em conjunto. . . . . . . . . . . . . . . . . . 115

7.32 Taxa de acerto média obtida para as emoções negativas com a base $\mathrm{CK}+$, quando analisadas em conjunto. . . . . . . . . . . . . . . 115

7.33Taxas de acerto obtidas para as emoções em conjunto, quando treinadas com a base CK+ e avaliadas com a base RaFD. . . . . . . . . . . . 116

7.34Taxas de acerto obtidas para as emoções em conjunto, quando treinadas com a base RaFD e avaliadas com a base CK+. . . . . . . . . . . . 117

7.35Taxa de acerto média obtida para as emoções positivas, quando analisadas em conjunto, para os experimentos entre as bases de dados. . . . 117

7.36Taxa de acerto média obtida para as emoções negativas, quando analisadas em conjunto, para os experimentos entre as bases de dados. . . . 118

7.37Taxas de acerto obtidas pelas SVMs para a base RaFD com as emoções positivas e a expressão neutra, utilizando o modelo de face neutra que tem a distância euclidiana média como métrica. . . . . . . . . . . . . . 120

7.38Taxas de acerto obtidas pelas SVMs para a base RaFD com as emoções negativas, utilizando o modelo de face neutra que tem a distância euclidiana média como métrica. . . . . . . . . . . . . . . . . . . . . . 120

7.39Taxas de acerto obtidas pelo algoritmo $\mathrm{C} 4.5$ para a base RaFD com as emoções positivas e a expressão neutra, utilizando o modelo de face neutra que tem a distância euclidiana média como métrica. . . . . . . 120

7.40Taxas de acerto obtidas pelo algoritmo C4.5 para a base RaFD com as emoções negativas, utilizando o modelo de face neutra que tem a distância euclidiana média como métrica. . . . . . . . . . . . . . . . 121

7.41 Taxas de acerto obtidas pelas MLPs para a base RaFD com as emoções positivas e a expressão neutra, utilizando o modelo de face neutra que tem a distância euclidiana média como métrica. . . . . . . . . . . . . . 121

7.42 Taxas de acerto obtidas pelas MLPs para a base RaFD com as emoções negativas, utilizando o modelo de face neutra que tem a distância euclidiana média como métrica. . . . . . . . . . . . . . . . 121

7.43Taxas de acerto obtidas pelas SVMs para a base RaFD com as emoções positivas e a expressão neutra, utilizando o modelo de face neutra que tem a quantidade de pontos próximos como métrica. . . . . . . . . . . . 122

7.44 Taxas de acerto obtidas pelas SVMs para a base RaFD com as emoções negativas, utilizando o modelo de face neutra que tem a quantidade de pontos próximos como métrica. . . . . . . . . . . . . . . . . . . . 122

7.45Taxas de acerto obtidas pelo algoritmo $\mathrm{C} 4.5$ para a base RaFD com as emoções positivas e a expressão neutra, utilizando o modelo de face neutra que tem a quantidade de pontos próximos como métrica. . . . . . 123 
7.46Taxas de acerto obtidas pelo algoritmo C4.5 para a base RaFD com as emoções negativas, utilizando o modelo de face neutra que tem a quantidade de pontos próximos como métrica. . . . . . . . . . . . . . 123

7.47Taxas de acerto obtidas pelas MLPs para a base RaFD com as emoções positivas e a expressão neutra, utilizando o modelo de face neutra que tem a quantidade de pontos próximos como métrica. . . . . . . . . . . . . 123

7.48Taxas de acerto obtidas pelas MLPs para a base RaFD com as emoções negativas, utilizando o modelo de face neutra que tem a quantidade de pontos próximos como métrica. . . . . . . . . . . . . . . . . . . . . 123

7.49Taxas de acerto obtidas pelas SVMs para a base CK+ com as emoções positivas e a expressão neutra, utilizando o modelo de face neutra que tem a distância euclidiana média como métrica. . . . . . . . . . . . . . . 124

7.50Taxas de acerto obtidas pelas SVMs para a base CK+ com as emoções negativas, utilizando o modelo de face neutra que tem a distância euclidiana média como métrica. . . . . . . . . . . . . . . . . . . . . . . . . . 124

7.51 Taxas de acerto obtidas pelo algoritmo $\mathrm{C} 4.5$ para a base $\mathrm{CK}+$ com as emoções positivas e a expressão neutra, utilizando o modelo de face neutra que tem a distância euclidiana média como métrica. . . . . . . . . 125

7.52 Taxas de acerto obtidas pelo algoritmo $\mathrm{C} 4.5$ para a base $\mathrm{CK}+\mathrm{com}$ as emoções negativas, utilizando o modelo de face neutra que tem a distância euclidiana média como métrica. . . . . . . . . . . . . . . . . . . 125

7.53Taxas de acerto obtidas pelas MLPs para a base CK+ com as emoções positivas e a expressão neutra, utilizando o modelo de face neutra que tem a distância euclidiana média como métrica. . . . . . . . . . . . . . . 125

7.54 Taxas de acerto obtidas pelas MLPs para a base CK+ com as emoções negativas, utilizando o modelo de face neutra que tem a distância euclidiana média como métrica. . . . . . . . . . . . . . . . . . . . . 126

7.55Taxas de acerto obtidas pelas SVMs para a base CK+ com as emoções positivas e a expressão neutra, utilizando o modelo de face neutra que tem a quantidade de pontos próximos como métrica. . . . . . . . . . . . . 126

7.56Taxas de acerto obtidas pelas SVMs para a base CK+ com as emoções negativas, utilizando o modelo de face neutra que tem a quantidade de pontos próximos como métrica. . . . . . . . . . . . . . . . . 126

7.57Taxas de acerto obtidas pelo algoritmo $\mathrm{C} 4.5$ para a base $\mathrm{CK}+\mathrm{com}$ as emoções positivas e a expressão neutra, utilizando o modelo de face neutra que tem a quantidade de pontos próximos como métrica. . . . . . 126

7.58Taxas de acerto obtidas pelo algoritmo $\mathrm{C} 4.5$ para a base $\mathrm{CK}+\mathrm{com}$ as emoções negativas, utilizando o modelo de face neutra que tem a quantidade de pontos próximos como métrica. 
7.59Taxas de acerto obtidas pelas MLPs para a base CK+ com as emoções positivas e a expressão neutra, utilizando o modelo de face neutra que tem a quantidade de pontos próximos como métrica. . . . . . . . . . . . 127

7.60Taxas de acerto obtidas pelas MLPs para a base CK+ com as emoções negativas, utilizando o modelo de face neutra que tem a quantidade de pontos próximos como métrica. . . . . . . . . . . . . . . . 127

7.61 Melhores resultados obtidos pela seleção de características para as emoções positivas e a expressão neutra, com a base de dados RaFD. . . 130

7.62 Melhores resultados obtidos pela seleção de características para as emoções negativas e a base de dados RaFD. . . . . . . . . . . . . . 130

7.63 Melhores resultados obtidos pela seleção de características para as emoções positivas e a expressão neutra, com a base de dados CK+. . . . 130

7.64 Melhores resultados obtidos pela seleção de características para as emoções negativas e a base de dados CK+. . . . . . . . . . . . . . 131

7.65Apresentação das características selecionadas para representar a alegria, com a base de dados RaFD. . . . . . . . . . . . . . . . . . 139

7.66Apresentação das características selecionadas para representar a ale-

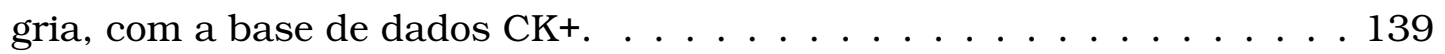

7.67 Apresentação das características selecionadas para representar a expressão de medo, com a base de dados RaFD. . . . . . . . . . . . . . . . 140

7.68Apresentação das características selecionadas para representar a expressão de medo, com a base de dados CK+. . . . . . . . . . . . . . . . 141

7.69Apresentação das características selecionadas para representar a expressão neutra, com a base de dados RaFD. . . . . . . . . . . . . . . . 143

7.70Apresentação das características selecionadas para representar a expressão neutra, com a base de dados CK+. . . . . . . . . . . . . . . . . 143

8.1 Conjuntos de dados avaliados. . . . . . . . . . . . . . . . . 149

8.2 Valores das médias obtidas para o índice silhueta com os mapas de saliência, para os diferentes conjuntos de dados avaliados. . . . . . . . . 150

8.3 Valores das médias obtidas para o índice Jaccard com os mapas de saliência, para os diferentes conjuntos de dados avaliados. . . . . . . . 151

8.4 Comparação estatística entre os conjuntos de dados utilizados, considerando o índice silhueta e os mapas de saliência. . . . . . . . . . . . . 156

8.5 Comparação estatística entre os conjuntos de dados utilizados, considerando o índice Jaccard e os mapas de saliência. . . . . . . . . . . . 157

8.6 Valores das médias obtidas para o índice silhueta com as imagens térmicas, para os diferentes conjuntos de dados avaliados. . . . . . . 158

8.7 Valores das médias obtidas para o indice Jaccard com as imagens térmicas, para os diferentes conjuntos de dados avaliados. . . . . . . . 159 
8.8 Comparação estatística entre os conjuntos de dados utilizados, considerando o índice silhueta e as imagens térmicas. . . . . . . . . . . . . 163

8.9 Comparação estatística entre os conjuntos de dados utilizados, considerando o índice Jaccard e as imagens térmicas. . . . . . . . . . . . . 163

8.10 Novos conjuntos de dados avaliados. . . . . . . . . . . . . . . . 164

8.11 Valores das médias obtidas para o índice silhueta com mapas de saliência e imagens térmicas analisados em conjunto. . . . . . . . . . . . . . 164

8.12 Valores das médias obtidas para o índice Jaccard com mapas de saliência e imagens térmicas analisados em conjunto. . . . . . . . . . . . . . 164

8.13Comparação estatística obtida para os conjuntos de dados avaliados, considerando o índice silhueta e a análise conjunta dos mapas de saliência e imagens térmicas. . . . . . . . . . . . . . . . . . 166

8.14 Comparação estatística obtida para os conjuntos de dados avaliados, considerando o índice Jaccard e a análise conjunta dos mapas de saliência e imagens térmicas. . . . . . . . . . . . . . . . . . . . . 167

8.15Desempenho obtido pelo mecanismo de pré-atenção visual. . . . . . . . 170

8.16 Guantidade de vetores de características considerada para representar as diferentes expressões emocionais. . . . . . . . . . . . . . . . . 171

8.17 Análise das características de diagnóstico, direcionadas pelo mecanismo de pré-atenção visual, para identificar as expressões emocionais. . . . . . 172

8.18Reconhecimento, pela análise das características de diagnóstico, das expressões emocionais que apresentam resultados divergentes. . . . . . 173

8.19 Classificação final das expressões emocionais investigadas, obtida pela modelagem proposta. . . . . . . . . . . . . . . . . 173

8.20Reconhecimento das expressões emocionais pela análise das características de diagnóstico, sem a utilização do mecanismo de pré-atenção. . 174

8.21 Resultados obtidos com as representações faciais desenvolvidas, para as emoções positivas e a expressão neutra. . . . . . . . . . . . . . . . . . 175

8.22 Resultados obtidos com as representações faciais desenvolvidas, para as emoções negativas. . . . . . . . . . . . . . . . . 176

8.23Tempos de execução das diferentes etapas da modelagem. . . . . . . . . 178 

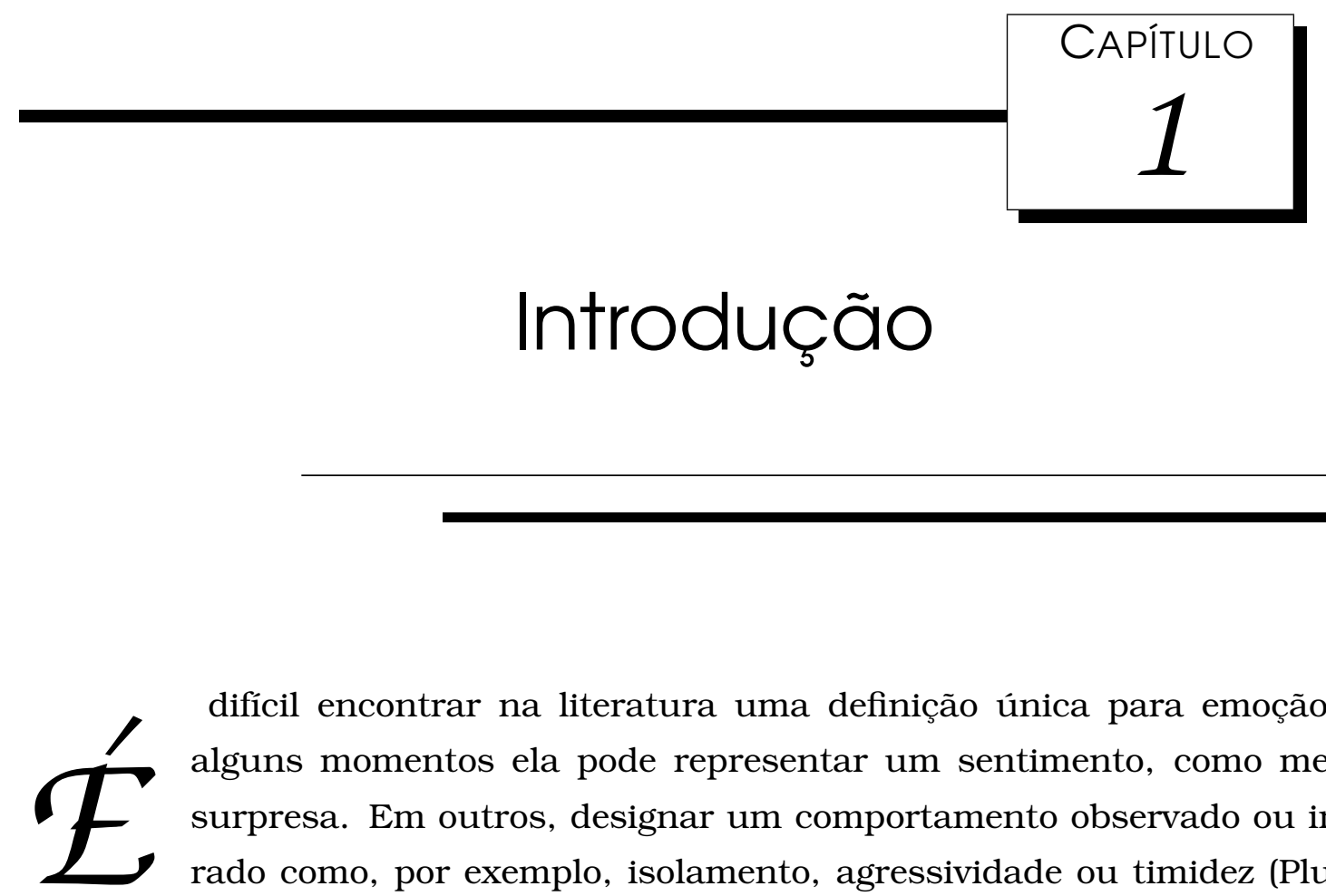

difícil encontrar na literatura uma definição única para emoção. Em alguns momentos ela pode representar um sentimento, como medo ou surpresa. Em outros, designar um comportamento observado ou inesperado como, por exemplo, isolamento, agressividade ou timidez (Plutchik, 1980).

Em um dos primeiros trabalhos relacionados ao tema, Darwin (1872) defende a presença de emoções no cérebro animal utilizando a teoria evolucionista: as emoções se estabeleceram para propiciar melhores condições de sobrevivência e reprodução àqueles que reagiram a eventos e mudanças ambientais. Porém, em seres humanos, conclui que as emoções e sua expressão são comportamentos equivalentes a órgãos vestigiais, decorrentes do desenvolvimento individual, e que estão presentes na vida adulta, sejam úteis ou não.

Mais recentemente, as ciências cognitivas demonstraram que as emoções não são irracionais e disfuncionais. Ao contrário, desempenham papel ativo nos processos cognitivos e sociais, colaborando com os processos racionais (Damasio, 1994).

Uma análise dos estudos sobre emoções permite notar que existem diversos modelos e teorias propostos. Neste sentido, os modelos emocionais mais difundidos são os discretos e os contínuos. Basicamente, enquanto os modelos discretos preocupam-se em agrupar as emoções em diferentes categorias, os modelos contínuos buscam também descrever a relação entre tais categorias. Do mesmo modo, inexiste uma teoria unificada e amplamente aceita sobre as emoções humanas.

Do ponto de vista computacional, a capacidade de interpretar sinais emocionais de interlocutores e reagir de acordo com eles em um contexto apropriado é eleita como um grande desafio a ser superado nos paradigmas de interação homem-máqui- 
na (Picard, 2003; Breazeal, 2003a). Neste sentido, Picard (2003) destaca a importância da compreensão emocional. Segundo a autora, o relacionamento entre o homem e a máquina vem se tornando progressivamente natural e social. Desta forma, à medida que as interfaces evoluem, elas enfrentam as mesmas expectativas presentes no relacionamento interpessoal. Se tais expectativas não são correspondidas, o usuário pode vir a sentir-se frustrado.

Diversas são as maneiras dos seres humanos manifestarem suas emoções, e mais variados ainda são os métodos para captar e reconhecer a emoção transmitida. Diferentes sinais emocionais podem ser utilizados tais como expressões faciais, fala, postura, gestos, movimentos corporais, dados fisiológicos, dentre outros. Porém, embora os seres humanos utilizem diferentes maneiras para expressar emoções, estudos evidenciam que elas são mais precisamente descritas por expressões faciais, sem a necessidade de análises complementares (Ekman and Friesen, 2003).

As expressões faciais são formas de comunicação não verbal amplamente utilizadas no cotidiano dos seres humanos. Elas externam, consciente ou inconscientemente, nossas manifestações em relação aos estímulos sociais a que somos submetidos. Seres humanos e a maioria dos mamíferos utilizam expressões faciais para demonstrar estados emocionais. Com a popularização dos sistemas de detecção de faces devido, em grande parte, ao algoritmo de Viola-Jones (Viola and Jones, 2004), os sistemas de detecção de expressões faciais vêm se popularizando. As possibilidades de utilização destes sistemas e seus impactos na atual sociedade são inúmeros.

Sistemas para reconhecimento e análise emocional por meio de expressões faciais podem ser utilizados em segurança, na psiquiatria e ciências comportamentais humanas, além de jogos interativos, entretenimento, telecomunicações, aprendizado, dentre outras aplicações que utilizem interação homem-máquina (Tong et al., 2010). Como alguns exemplos, é possível citar sistemas educacionais para tutoria, em que o tutor virtual pode interativamente ajustar o conteúdo e a velocidade da disciplina de acordo com o estado emocional do usuário, assim como recomendar uma pausa, se detectado cansaço. A utilização em serviços automáticos prestados ao consumidor, como call centers ou assistentes pessoais, para detectar frustrações e evitar irritação com o serviço. A aplicação em automóveis para detectar sinais de stress ou raiva no motorista e alertá-lo para ser mais cauteloso, ou em teleconferências, nas quais as informações emocionais dos participantes podem melhorar a interação com o interlocutor, permitindo a ele modificar sua atitude de acordo com estas informações e se comportar como se estivesse presente no ambiente (Fragopanagos and Taylor, 2005).

Ademais, sistemas para reconhecer emoções podem ser utilizados em uma grande variedade de estudos psicológicos, psiquiátricos e neuro-fisiológicos sobre expressões emocionais que hoje dependem de auto-relatos dos participantes para 
classificar seus estados emocionais, aumentando a confiabilidade dos resultados obtidos (Fragopanagos and Taylor, 2005).

Neste sentido, o entendimento dos processos emocionais pode auxiliar na criação de faces ou vozes dotados de qualidades emocionais convincentes, semelhantes às humanas, elevando a imersão da interação homem-máquina a patamares semelhantes a interações reais entre seres humanos (Fragopanagos and Taylor, 2005).

\subsection{Objetivos}

Dada a atual importância na identificação e entendimento das emoções humanas, esta tese apresenta uma modelagem computacional, baseada em princípios biológicos e teorias psicológicas, do sistema de reconhecimento emocional existente nos seres humanos. Diferentes conceitos biológicos e psicológicos são utilizados nas distintas etapas de desenvolvimento realizadas. A abordagem empregada para o reconhecimento emocional se vale da análise de expressões faciais. Uma discussão detalhada sobre a fundamentação teórica, trabalhos relacionados e resultados obtidos pode ser encontrada nos demais capítulos. A seguir, um breve resumo descrevendo os principais objetivos pretendidos é apresentado.

- Identificação das teorias e conceitos relacionados à análise de expressões faciais para reconhecer as emoções humanas;

- Reconhecimento emocional, baseado em conceitos psicológicos, das seis emoções básicas propostas por Ekman (1999). A hipótese é que uma modelagem semelhante à maneira como os seres humanos interpretam as emoções confira maior robustez a um sistema computacional para este fim;

- Identificação das características faciais relevantes para o reconhecimento das emoções investigadas. Embora a psicologia tenha identificado as regiões faciais que recebem o maior foco da atenção, a determinação das características específicas envolvidas neste processo ainda não é possível. Deste modo, identificar prováveis características candidatas pode auxiliar os estudos psicológicos sobre este tema. Ainda, do ponto de vista computacional, é possível citar benefícios em áreas como animação de faces virtuais, identificação dos músculos com maior envolvimento na expressão de uma determinada emoção, dentre outros;

- Desenvolvimento de uma modelagem completa que simule os mecanismos reais de reconhecimento emocional existentes nos seres humanos. Deste modo, esta modelagem pode ser inserida em diferentes sistemas, como parte de um mecanismo mais complexo, para obter interações homem-máquina mais realísticas. Espera-se que um agente computacional ou robótico utilizando esta modelagem possa assemelhar seu comportamento ao observado nos seres humanos. 


\subsection{Principais Contribuições}

Como resultado das atividades realizadas, as principais contribuições desta tese de doutorado são descritas a seguir.

- Modelagem para o reconhecimento das emoções pela simulação de mecanismos psicológicos encontrados nos seres humanos

- Inspiração psicológica e biológica permite que sistemas ou robôs adquiram comportamento semelhante às pessoas;

- Facilidade encontrada para o reconhecimento das emoções é semelhante ao descrito pela psicologia.

- Desenvolvimento de um modelo facial que representa a expressão neutra

- Permite a utilização em aplicações reais;

- É baseado em fundamentos psicológicos;

- Apresenta flexibilidade para utilização com diferentes raças de quaisquer culturas.

- Identificação de características faciais de diagnóstico

- Importantes para reconhecer as diferentes expressões investigadas;

- Selecionadas para que sejam menos dependentes dos métodos computacionais;

- Podem ser utilizadas pela psicologia e aplicações de diversas áreas.

- Abordagem híbrida para a representação da face

- Emprego de modelos faciais geométricos e baseados em aparência com o objetivo de melhorar a identificação das emoções analisadas.

- Abordagem híbrida que analisa imagens térmicas e visíveis para o reconhecimento emocional

- Informações complementares são obtidas destas imagens;

- Recentemente explorada, de acordo com a literatura.

- Desenvolvimento de seis representações faciais

- Exploração de grande variedade de atributos e relações da face, com o objetivo de disponibilizar um conjunto representativo de características. 


\subsection{Organização do Texto}

Este trabalho está organizado da seguinte maneira. O Capítulo 2 explica conceitos psicológicos sobre as emoções humanas, considerados relevantes para o desenvolvimento desta tese. O Capítulo 3 apresenta uma sub-área da Robótica, denominada Robótica Sociável, e os trabalhos desta área que exploram a incorporação de emoções nas interações sociais, que serviram de motivação para a proposta apresentada. O Capítulo 4 descreve os conceitos e trabalhos relacionados à análise e interpretação de emoções em expressões faciais. No Capítulo 5 são apresentados os algoritmos investigados para o desenvolvimento desta proposta. O Capítulo 6 detalha a metodologia adotada para o desenvolvimento das diferentes etapas que compõem a modelagem proposta para a identificação das emoções humanas. Nos Capítulos 7 e 8 são descritos os experimentos realizados, com a análise e discussão dos principais resultados e contribuições. Finalmente, no Capítulo 9, são apresentadas as considerações finais deste trabalho, assim como os trabalhos futuros. 


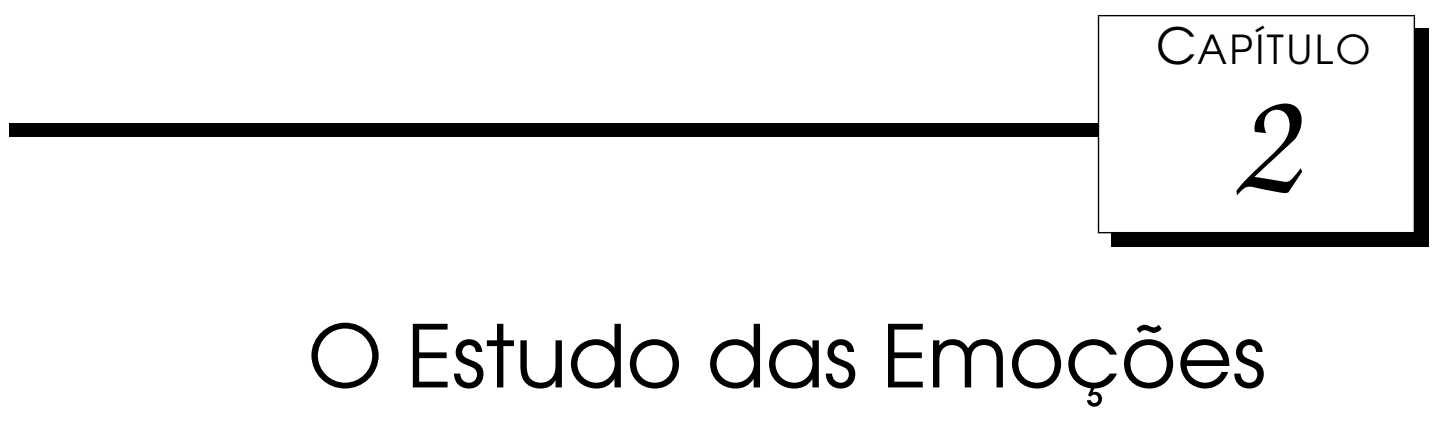

$\mathcal{A}$ s emoções estão presentes no cotidiano dos seres humanos. Sejam elas resultantes da interação com o mundo, do choque entre expectativa e realidade, da antecipação de ações e comportamentos, de mecanismos de autopreservação ou da presença de consciência, as emoções apresentam-se como característica da espécie. Ainda assim, emoções são tratadas com certo estigma pela ciência, cujo método remete ao pensamento racional (Picard, 2003).

Embora a existência de emoções seja uma característica comum aos mamíferos, presente no Homo Sapiens e seus ancestrais, somente com as escolas filosóficas helênicas a cultura ocidental passa a oferecer explicações formais sobre o papel que as emoções desempenham no cotidiano humano (Damasio, 1994). Desde então, elas vêm sendo objeto de estudo de áreas como a filosofia, psicologia, psiquiatria, biologia, neurociências e, a partir da segunda metade do século XX, das ciências cognitivas.

As emoções são fundamentais para a experiência humana, influenciando a cognição, a percepção, e as tarefas diárias, tais como o aprendizado e a comunicação (Damasio, 1994). Entender como as emoções são representadas e reconhecidas é essencial para a compreensão do comportamento e da cognição humanos e desempenha um papel importante nos estudos da evolução e consciência (Martinez and Neth, 2010).

Do ponto de vista computacional, a compreensão das emoções refere-se à capacidade de uma máquina não apenas detectar a informação emocional, mas também armazenar, processar, construir e manter um modelo emocional do usuário. O objetivo da compreensão emocional é entender as informações contextuais sobre o indivíduo e seu ambiente, e formular uma resposta apropriada. Isto é uma tarefa árdua, pois as emoções humanas surgem de contextos externos e internos complexos. Uma possivel característica de sistemas com capacidade de compreender 
as emoções é a apresentação de comportamentos adaptativos como, por exemplo, evitar a interação com um usuário que aparente estar com raiva. Nestas situações, a compreensão emocional é importante para identificar o estado emocional do usuário e adaptar as variáveis de ambiente de acordo com o estado reconhecido. Questões relacionadas com os fundamentos teóricos para a análise dos dados coletados, e as possiveis saídas para este processo interativo são de fundamental importância (Malatesta, Murray, Raouzaiou, Hiolle, Canamero, and Karpouzis, Malatesta et al.).

De acordo com Picard (2003), para as máquinas se tornarem efetivamente inteligentes e conseguirem, assim, interagir de maneira natural com os seres humanos, elas precisam obter a habilidade de reconhecer, entender ou mesmo expressar emoções. Além disso, as emoções podem atuar como mecanismos de controle e aprendizado, direcionando o comportamento e refletindo como o sistema é afetado, e se adapta, a diferentes fatores durante a interação.

Diversos trabalhos na área de reconhecimento emocional unimodal, em que apenas uma única forma de expressar emoções é analisada, investigam diferentes características como expressões faciais, fala, postura, gestos, movimentos corporais, dados fisiológicos, dentre outros. Porém, cada vez mais, o foco dos trabalhos está no desenvolvimento de interfaces multimodais para o reconhecimento de emoções, integrando principalmente a análise de expressões faciais e com a análise da fala (Caridakis et al., 2007).

O reconhecimento de emoções pela investigação de expressões faciais tem sido investigado em três tipos principais de bases de dados: emoções representadas, nas quais, quando solicitado, a expressão facial correspondente é produzida; emoções induzidas, por exemplo, ao assistir um vídeo; e emoções espontâneas ou naturais. Os melhores resultados são geralmente obtidos com as emoções representadas, pois o processo de reproduzi-las evidencia as características do estado emocional investigado. Para o reconhecimento de emoções pela análise da fala, os dois principais tipos de bases de dados utilizadas incluem a análise da fala espontânea e da fala representada, na qual a emoção também é expressa quando solicitado (Caridakis et al., 2007).

Os métodos atuais de reconhecimento emocional pelo computador se aproximam e, em alguns casos, superam o reconhecimento humano. Enquanto o reconhecimento de expressões faciais emocionais pelos seres humanos é de aproximadamente $87 \%$, alguns algoritmos computacionais, em ambientes controlados, obtêm taxa de acerto entre $74 \%$ e $98 \%$ (Sebe et al., 2005). Na análise da fala, existe equilíbrio entre seres humanos e computadores, com aproximadamente $65 \%$ de acerto. Entretanto, alguns algoritmos já obtiveram quase $80 \%$ de acerto (Sebe et al., 2005). Um problema que pode ocorrer na identificação das emoções pela fala é a interferência de sons externos (ruídos) durante a captação sonora, em ambientes não controlados. Resultados ainda melhores de identificação emocional 
podem ser obtidos utilizando combinações de mecanismos de reconhecimento, como as expressões faciais e a fala, que são considerados os principais meios utilizados pelos seres humanos para reconhecer emoções.

A compreensão do funcionamento das emoções é um aspecto importante para a saúde individual e social dos seres humanos. No entanto, existem diversas dificuldades na realização de estudos psicológicos sobre emoções. O estado emocional de um indivíduo pode ser influenciado por inúmeras situações, e diferentes pessoas têm distintas experiências emocionais em resposta a um mesmo estímulo. Por isto, analisar objetivamente o estado emocional de um indivíduo e descobrir as áreas funcionais do processamento emocional humano tem recebido grande atenção nas pesquisas psicológicas recentes (Cowie et al., 2001).

Este capítulo apresenta uma introdução sobre as emoções do ponto de vista psicológico. Neste sentido, a Seção 2.1 apresenta definições e conceitos sobre as emoções humanas e, na Subseção 2.1.1, são discutidos aspectos neurofisiológicos das emoções. Por fim, na Seção 2.2, são feitas as considerações finais deste capítulo.

\subsection{As Emoções Humanas}

Em uma definição mais geral, uma emoção é um impulso neural que move um organismo para uma determinada ação. Ela não deve ser confundida com o humor, que consiste em estados emocionais mais difusos e duradouros que influenciam o pensamento e o comportamento. O humor reflete a percepção que temos de possuir ou não os recursos necessários para atender às demandas ambientais. Já a emoção é uma força primária que motiva comportamentos adaptativos e desencoraja comportamentos não adaptativos. Elas são respostas imediatas a eventos ambientais (Gazzaniga and Heatherton, 2005).

As emoções são adaptativas porque preparam e orientam comportamentos motivados. Elas fornecem informações sobre a importância de um estímulo recebido e possibilitam a adaptação do comportamento dos organismos a diversas situações com as quais se deparam diariamente (Ekman, 1999; Gazzaniga and Heatherton, 2005). Além disso, os seres humanos interpretam as expressões faciais de emoção para predizer o comportamento futuro. Neste sentido, as expressões faciais emocionais fornecem diversas informações sobre o comportamento humano e comunicam as emoções daqueles com quem interagimos (Gazzaniga and Heatherton, 2005).

As emoções têm importante influência sobre os processos cognitivos, particularmente aqueles que envolvem tomada de decisão e resolução de problemas (Damasio, 1994). Além disso, possuem um papel fundamental na memória, comportamento e interação em sociedade (Ekman, 1999), sendo uma das maneiras mais efetivas de comunicação (Breazeal, 2003a). Estudos psicológicos afirmam que elas são constituídas por três componentes: o estado de sentimento, que é uma experiência subjetiva. As mudanças fisiológicas, como o aumento da temperatura da 
pele, dos batimentos cardíacos ou da ativação cerebral. E a interpretação cognitiva, que envolve crenças e entendimentos dos seres humanos sobre por que eles se sentem da maneira como se sentem (Gazzaniga and Heatherton, 2005).

Dentre as diversas teorias propostas, três podem ser consideradas as mais aceitas para explicar as emoções, que diferem na ênfase dada a cada um destes componentes. A teoria de James-Lange afirma que padrões distintos de mudanças físicas dão origem à percepção de emoções específicas, por exemplo, se uma pessoa moldar sua face para uma expressão de tristeza, ela sentirá esta emoção, o mesmo vale para qualquer outro padrão de expressão física adotado, que resultará no ato de sentir a emoção especificada. A teoria de Cannon-Bard afirma que existem duas vias separadas de emoção. Sendo assim, a mente e o corpo atuam de modo independente provocando a experiência de duas sensações separadas praticamente ao mesmo tempo: uma emoção e uma reação física. Por fim, a teoria dos dois fatores de Schachter enfatiza que emoções são a interação de excitação fisiológica com avaliações cognitivas (Gazzaniga and Heatherton, 2005). Vale destacar que nenhuma destas teorias é totalmente aceita ou rejeitada.

Diversos modelos emocionais também foram propostos ao longo da história dos estudos sobre emoções. Dentre estes modelos, existem duas vertentes principais para a modelagem emocional: teorias cognitivas das emoções e teorias dimensionais das emoções. A primeira delas resultou nos modelos discretos, ao passo que a segunda nos modelos contínuos. Enquanto os modelos discretos preocupam-se em agrupar rótulos semelhantes sob uma mesma categoria emocional, os modelos contínuos visam também descrever a relação entre tais categorias. Estes dois modelos têm sido utilizados em várias aplicações de computação e robótica sociável, e a escolha de um ou outro não parece ter um efeito importante na maneira como os seres humanos interpretam as emoções apresentadas pelas máquinas (Gockley et al., 2006).

Dentre os modelos discretos, o mais difundido é o modelo de emoções básicas proposto por Ekman (1999), que afirma a existência de seis emoções básicas: alegria, tristeza, medo, raiva, aversão e surpresa. Todas as demais categorias emocionais são, então, construídas a partir de combinações destas emoções básicas. As emoções básicas são representadas por seis distintas expressões faciais universais, pois são compreensiveis por todas as pessoas em diferentes localidades, independente da cultura. O termo universal indica que os mesmos movimentos musculares são produzidos ao realizar as expressões faciais.

O modelo proposto por Ekman (1999) baseia-se diretamente nas observações de Darwin (1872) nas quais animais e seres humanos apresentam expressões semelhantes quando confrontados com situações similares, e busca evidências da universalidade das expressões de emoção em seres humanos, afirmando que as expressões faciais emocionais são resultado da evolução (Valstar, 2008). É importante 
ressaltar que este modelo apresenta seis emoções básicas universalmente reconhecidas e produzidas pelos seres humanos, por meio das respectivas expressões faciais emocionais que as descrevem, mas não afirma que estas são as únicas emoções ou expressões faciais emocionais existentes. Um exemplo de expressões faciais para as seis emoções básicas pode ser visto na Figura 2.1.

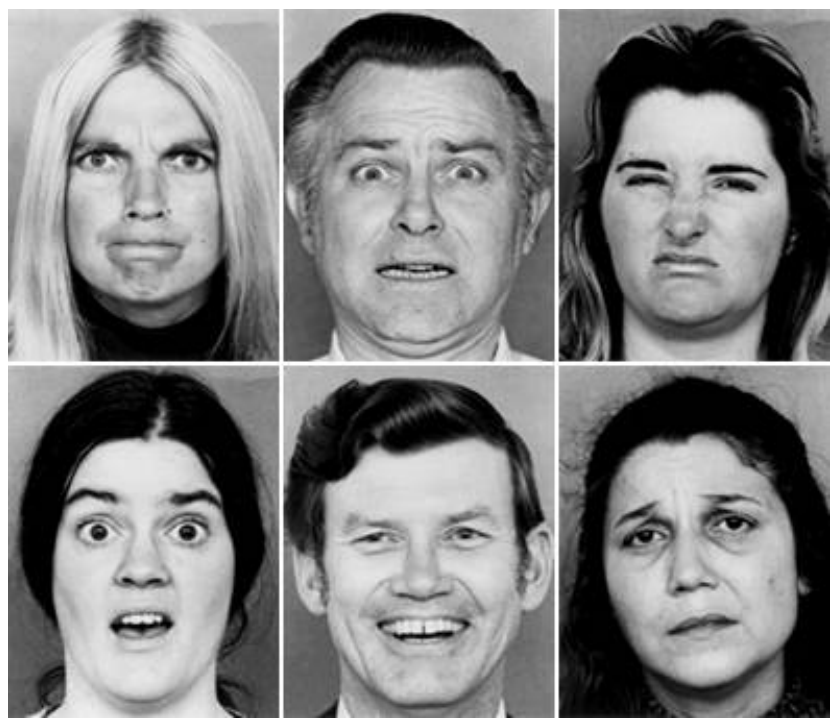

Figura 2.1: Seis emoções básicas propostas por Ekman (1999), na sequência Raiva, Medo, Aversão, Surpresa, Alegria e Tristeza.

Uma das principais vantagens dos modelos discretos é a comprovação, por meio de diversos experimentos psicofísicos, que a percepção das emoções pelos seres humanos é discreta. Estudos em neurociências sugerem ainda que distintas regiões (ou caminhos) no cérebro são utilizadas para reconhecer a maioria das emoções e expressões faciais que as representam. Isto não é necessariamente prova de um modelo emocional discreto, mas sugere fortemente que existem grupos diferentes de emoções que seguem interpretações distintas. Além disso, existem também evidências da ciência cognitiva que sugerem que as seis emoções básicas são categorias importantes utilizadas como referência pelos seres humanos para descrever as expressões emocionais observadas no cotidiano (Zeng et al., 2009; Martinez and Du, 2012). Sendo assim, estes modelos permitem facilmente associar as emoções com expressões faciais que as representam. Como desvantagens, os modelos discretos precisam definir uma quantidade finita de emoções, falhando em descrever todas as emoções que podem ser demonstradas durante as interações entre seres humanos (Zeng et al., 2009).

Dentre os modelos contínuos, um dos mais difundidos é o Modelo Circumplexo proposto por Russell (1980). Em que as emoções não são discretas e independentes entre si, ao contrário, estão relacionadas umas com as outras e são descritas por pontos em um espaço bidimensional. Mais detalhadamente, as emoções estão dispostas em um círculo e são representadas por duas dimensões, valência e excitação, representadas em um espaço cartesiano, no qual a coordenada $x$ representa 
a valência e a coordenada $y$ representa a excitação. Dessa forma, cada emoção $e(v$, a) corresponde a um ponto no plano cartesiano. A valência corresponde ao tipo de emoção, e representa como um ser humano se sente. Ela varia de tristeza (valência negativa - emoções desagradáveis) à alegria (valência positiva - emoções agradáveis). A excitação corresponde à intensidade da emoção, e mede a propensão dos seres humanos em realizar uma ação desencadeada pelo estado emocional. Ela varia de abatido ou sonolento (baixa intensidade - passivo) até super estimulado ou em pânico (alta intensidade - ativo), conforme pode ser observado na Figura 2.2.

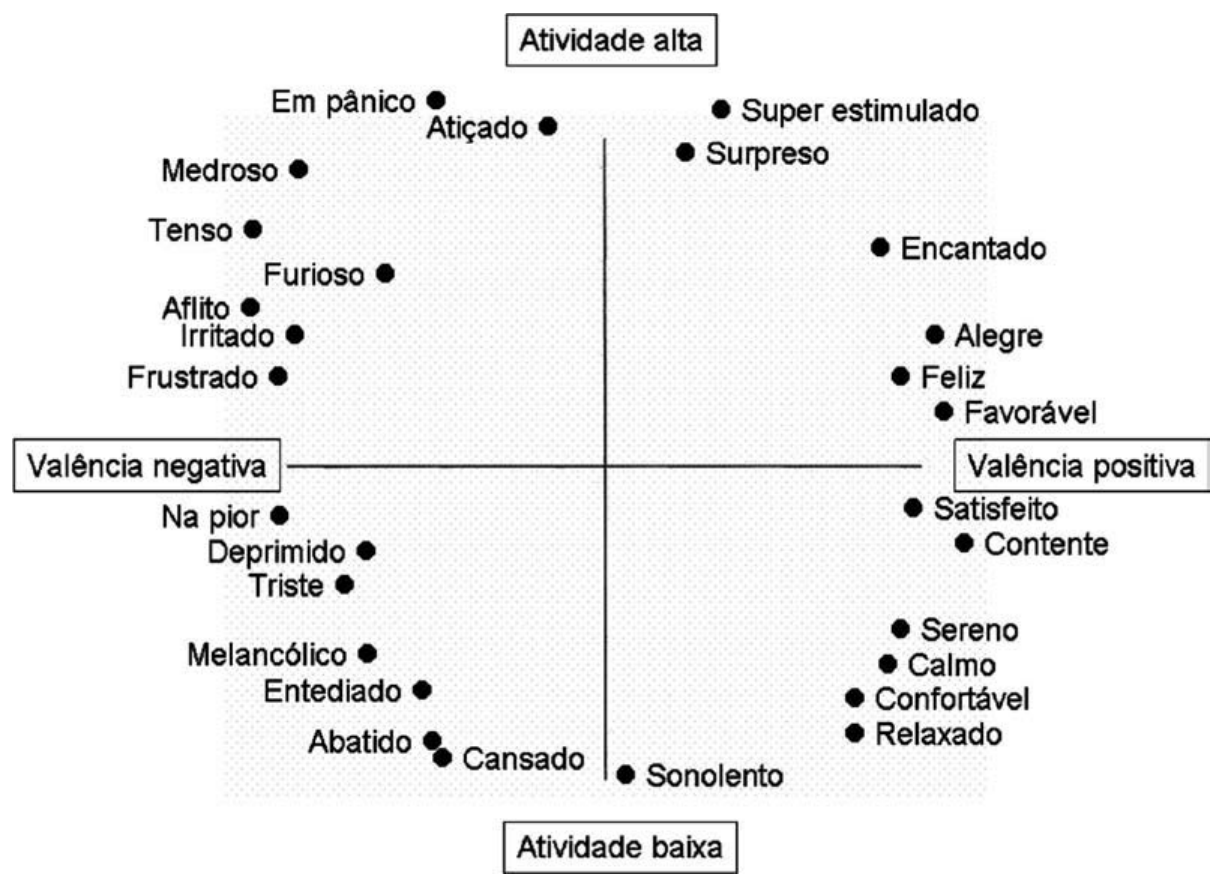

Figura 2.2: Modelo Circumplexo proposto por Russell (1980).

Estudos em neurociências também abrem precedente para a justificativa de que os modelos emocionais são contínuos. Neste contexto, estes modelos são melhor explicados pelo chamado Modelo Límbico, que afirma existir um único mecanismo neural no Sistema Límbico humano que é responsável pelo reconhecimento de todas as expressões faciais emocionais (Martinez and $\mathrm{Du}, 2012$ ). A vantagem dos modelos contínuos é que podem justificar a percepção de diversas emoções. Além disso, permitem identificar a intensidade de uma emoção de maneira direta, pela simples interpretação do modelo. Como desvantagens, está a dificuldade em mapear todas as emoções produzidas com expressões faciais que as representam. Outro problema está relacionado ao espaço bidimensional destes modelos, que é insuficiente para modelar com precisão todas as emoções representadas, sendo proposto, por diversos autores, a expansão deste espaço para três dimensões a fim de resolver esta dificuldade (Zeng et al., 2009).

Os modelos emocionais podem também ser híbridos, como exemplo temos a Roda Emocional de Plutchik (1980). Ela define um conjunto de emoções discretas que são mapeadas em um espaço dimensional contínuo. Diferente do modelo de 
Ekman (1999), o modelo de Plutchik propõe oito emoções primárias, sendo elas aceitação, raiva, antecipação, aversão, medo, alegria, tristeza e surpresa, que possuem uma relação direta com processos biológicos adaptativos. Este modelo circumplexo tridimensional descreve as relações entre os conceitos de emoção, com cada emoção sendo suavemente transformada em outra ao se percorrer um caminho na superfície do cone tridimensional, apresentado na Figura 2.3.

A dimensão vertical do cone representa a intensidade de uma emoção e a posição sobre o círculo define a localização em um dos setores que representa uma das emoções primárias. Oito setores são projetados para indicar que existem oito dimensões de emoções primárias, constituídas por quatro pares de emoções opostas, a saber: alegria e tristeza, raiva e medo, aprovação e aversão, surpresa e antecipação. Neste modelo, as emoções secundárias podem ser produzidas por uma mistura de emoções primárias adjacentes, por meio da roda emocional. Como exemplo, pode-se citar a emoção de submissão, que é uma combinação das emoções primárias de aprovação e medo.

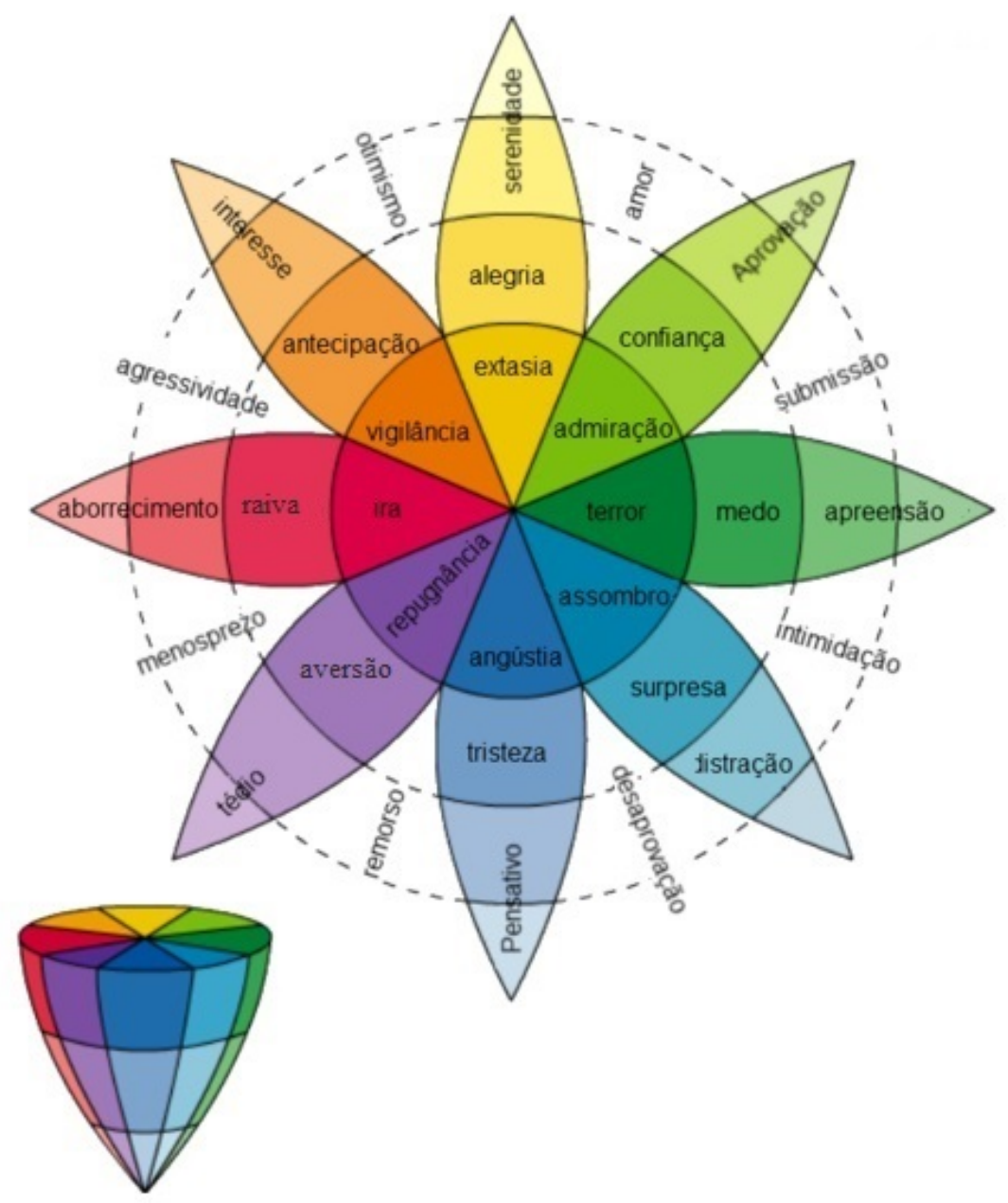

Figura 2.3: Roda de Emoções de Plutchik (1980).

Além dos modelos apresentados, existem modelos emocionais mais recentes baseados em uma nova vertente, as teorias de avaliação. Teorias de avaliação 
concentram-se nos processos internos de eliciação de respostas emocionais a partir da avaliação de eventos, em contraste com as abordagens mencionadas anteriormente que enfatizam sobre as consequências ou sintomas de um episódio emocional (Grizard and Lisetti, 2006). Os trabalhos realizados por Scherer são os precursores das teorias de avaliação. Scherer define o comportamento emocional como um processo dinâmico, em vez de um estado estacionário. Os componentes envolvidos são: relevância do evento para um indivíduo e como este pode afetá-lo (relevância), consequências do evento sobre os objetivos do indivíduo (implicações), o modo como um indivíduo reage a esse evento (potencial de atuar) e se o evento respeita as normas sociais do indivíduo (significado normativo). Para cada componente, Scherer define as intensidades das respostas emocionais que variam em função das emoções expressadas. As respostas emocionais dependem dos indivíduos e de como eles avaliam os eventos que ocorrem. Assim, cabe às teorias de avaliação o papel de realizar uma abordagem funcional das emoções, de forma que estas passam a ser explicadas como reações cuja função principal é lidar com situações dotadas de significado ao indivíduo (Grizard and Lisetti, 2006).

Uma outra questão que pode ser encontrada na literatura sobre as emoções é a discussão se elas são inatas, ou se são aprendidas por meio da convivência social. A primeira hipótese é amparada pelos teóricos evolucionários, que acreditam na tradição Darwiniana (Darwin, 1872) de que a evolução moldou as emoções no cérebro como o resultado de uma adaptação orientada pelo ambiente, para melhor atender às necessidades comportamentais de nossos ancestrais. A segunda hipótese defende uma abordagem social construtivista. Segundo esta abordagem, a influência social modela a resposta emocional e isto, por si só, justifica a variação emocional existente entre diferentes culturas. Como consequência, os indivíduos de uma mesma população devem perceber as emoções de maneira semelhante. Independente da hipótese defendida, o que é possível notar, mesmo dentro de uma mesma cultura, é que existem diferenças sutis na maneira como distintos indivíduos interpretam as emoções daqueles com quem convivem (Fragopanagos and Taylor, 2005).

\subsubsection{Neurofisiologia das Emoções}

Considerando as emoções do ponto de vista neurofisiológico, mesmo com os recentes avanços obtidos, ainda são necessário muitos estudos para entender o funcionamento completo do processamento emocional nos seres humanos. Um grande número de diferentes estruturas cerebrais podem ser associadas às emoções. Neste sentido, pesquisadores identificaram que estados emocionais específicos estão associados a padrões singulares de ativação cerebral, embora muitas destas estruturas cerebrais estejam envolvidas em diferentes experiências emocionais (Gazzaniga and Heatherton, 2005).

O estímulo emocional parece ter prioridade no cérebro, comandando um rede 
de neurônios distribuída constituída por estruturas corticais e subcorticais para representar diferentes expressões faciais e determinar respostas adaptativas a este estímulo. Como observado por análise celular, neuro-imagens e estudos de pacientes com lesões cerebrais, a via cortical occipito-temporal parece estar envolvida em uma percepção prévia do estímulo, que é essencial para diferenciar entre as expressões faciais de emoção. Além disso, indícios da existência de uma via subcortical são relatados, em parte, pelo fato da percepção emocional ocorrer mesmo de forma inconsciente. Porém, este é ainda um tópico controverso (Schyns et al., 2009). Neste sentido, a análise de imagens cerebrais indica que tanto as redes corticais quanto as subcorticais estão envolvidas no rápido processamento das emoções. Ainda, existem evidências que, na via cortical, a identificação das emoções ocorre no intervalo entre 140 e 200ms após o início do estímulo emocional (Schyns et al., 2009).

O sistema do corpo humano responsável pelas interpretações e respostas emocionais é o Sistema Límbico. Ele é constituído pelo lobo límbico (componente cortical) e pelas estruturas subcorticais a ele relacionadas. São funções deste sistema a regulação dos processos emocionais, do Sistema Nervoso Autônomo, do Sistema Endócrino e dos processos motivacionais como fome, sede, sexo, dentre outros, além da participação nos mecanismos de memória. No Sistema Límbico, as emoções são mediadas por vários sistemas neurais, incluindo o hipotálamo, o tálamo, o giro cingulado, o hipocampo, a amígdala, o córtex orbito-frontal, porções dos gânglios basais, e diversos outros, que diferem entre si na influência sobre os processos emocionais. A Figura 2.4 apresenta a estrutura deste sistema. Sabe-se que a amígdala e o córtex orbito-frontal são consideradas as estruturas mais importantes (Gazzaniga and Heatherton, 2005).

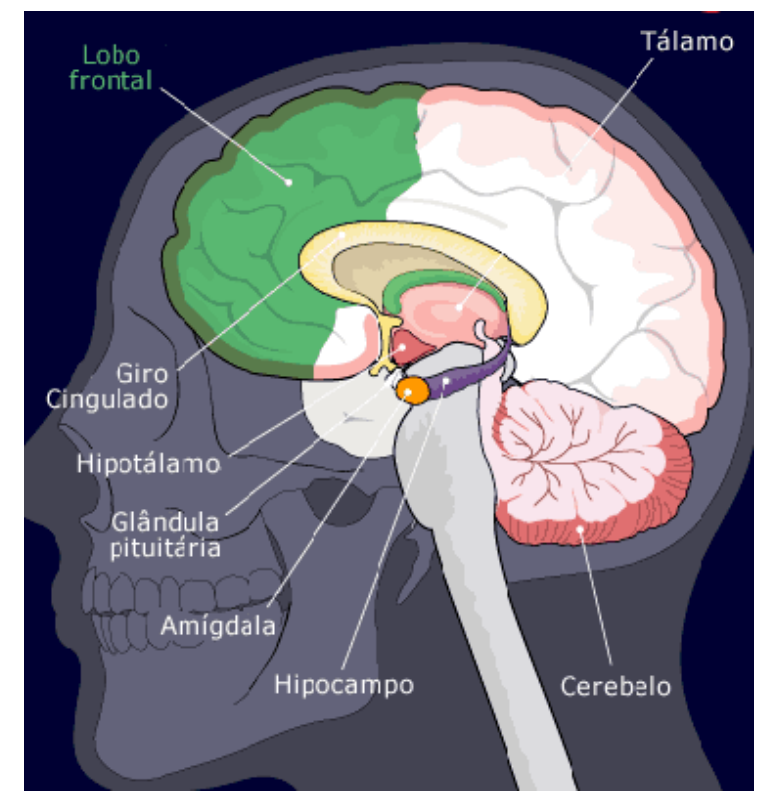

Figura 2.4: Sistema Límbico Humano.

A amígdala é responsável pelo desenvolvimento de respostas de medo para 
proteger os animais do perigo. A informação atinge a amígdala através de duas vias separadas. A primeira via é um sistema rápido, que processa a informação sensorial quase instantaneamente. A informação sensorial percorre rapidamente pelo tálamo até a amígdala para um processamento prioritário. A segunda via é um pouco mais lenta, mas é responsável por avaliações mais deliberadas e cuidadosas. O material sensorial percorre do tálamo ao córtex, onde a informação é analisada antes de ser enviada à amígdala. A via mais rápida é responsável por preparar o animal para uma resposta caso a via mais lenta confirme a ameaça (Gazzaniga and Heatherton, 2005).

Outro papel da amígdala no processamento de emoções é seu envolvimento na percepção de estímulos sociais. Ela é capaz de identificar o significado emocional das expressões faciais, sendo especialmente sensivel a faces que demonstram expressões de medo de diferentes intensidades. Lesões na amígdala causam a perda do reconhecimento das expressões emocionais de raiva e medo (Cowie et al., 2001).

O córtex orbito-frontal está envolvido no processamento emocional relacionado às interações interpessoais, sendo responsável pelas respostas comportamentais e também por algumas respostas automáticas. Lesões nessa região tornam os seres humanos insensiveis às expressões emocionais dos outros, além de aumentarem a agressividade do indivíduo, sugerindo dificuldades no controle das emoções (Gazzaniga and Heatherton, 2005).

A identificação de uma grande diferenciação dos estados emocionais dentro do Sistema Límbico dão apoio à ideia de que as emoções são inatas, seguindo a abordagem Darwiniana. No entanto, os defensores da abordagem social construtivista contestam esta hipótese, afirmando que o Sistema Límbico apresenta áreas com diferentes sensibilidades aos níveis de excitação e valência do estímulo ao qual o indivíduo é exposto, atribuindo aos processos corticais mais sofisticados como, por exemplo, aqueles envolvidos nos comportamentos sociais complexos, a responsabilidade por diferenciar a percepção das emoções (Fragopanagos and Taylor, 2005).

Outra característica associada a estados emocionais específicos é a ativação desigual dos lobos frontais direito e esquerdo. A maior ativação do córtex pré-frontal direito está associada a emoções negativas, enquanto a maior ativação no hemisfério esquerdo está associada a emoções positivas. Evidências neuroquímicas sugerem que as emoções positivas estão associadas a um aumento da dopamina, e que as emoções negativas estão associadas a um aumento da noradrenalina, estas evidências apóiam a probabilidade de que emoções positivas e negativas são independentes (Gazzaniga and Heatherton, 2005). Além disso, pesquisas demonstram que o hemisfério direito está mais envolvido que o esquerdo na interpretação e compreensão das emoções. Embora a ativação emocional ocorra em ambos os hemisférios, a ativação é muito maior no lado direito. O hemisfério direito também é mais exato ao detectar 
emoções na fala, ao passo que o hemisfério esquerdo é mais exato para detectar o conteúdo semântico (Gazzaniga and Heatherton, 2005). Adicionalmente, o lobo frontal direito contém uma área sensível à identificação de faces. A degeneração desta área pode levar à incapacidade de reconhecer rostos (Cowie et al., 2001).

Estudos também demonstraram que as emoções de aversão, alegria e tristeza ativam o tálamo e o córtex pré-frontal, mas mesmo entre elas há uma certa diferenciação na forma de ativação. Ao passo que alegria e tristeza aumentam a ativação do hipotálamo, isso não ocorre com a aversão. Considerando os processos fisiológicos, também são encontradas distinções, por exemplo, quando uma pessoa está excitada, quer devido à raiva, quer devido à atração sexual, o rosto fica corado, mas as pupilas se contraem durante a raiva e se dilatam durante a excitação sexual. Além disso, padrões diferenciais de batimentos cardíacos e pressão sanguínea foram registrados. Medo e raiva aumentam os batimentos cardíacos, mas a raiva também é acompanhada de aumento na temperatura da pele (Gazzaniga and Heatherton, 2005).

\subsection{Considerações Finais}

A análise computacional das emoções humanas possui uma grande variedade de aplicações que auxiliam na melhoria das interações homem-máquina, tais como cuidados de saúde, aprendizagem assistida por computador, detecção de eventos anômalos, e melhoria na interatividade de jogos de computador. Dentre as várias modalidades que são utilizadas para expressar a emoção humana, informações não verbais, como as expressões faciais, desempenham um papel importante para a análise do comportamento humano.

Embora algum progresso já tenha sido feito, diferentes estudos psicológicos continuam sendo realizados com o objetivo de entender os mecanismos emocionais humanos de modo mais completo. Várias teorias e modelos emocionais já foram propostos, porém, não foram encontradas, até o momento, evidências científicas que justifiquem a escolha de uma ou outra teoria ou modelo existente. Além disso, diversas questões como, por exemplo, se as emoções são inatas ou aprendidas por meio da convivência social, ainda estão em aberto.

O que os estudos psicológicas já demonstraram é que existe uma grande quantidade de sistemas relacionados ao processamento de emoções no cérebro. As informações relativas à identificação das emoções por meio de expressões faciais são processadas em locais diferentes de onde se processa as informações sobre a identidade de um individuo. Isso indica a importância das emoções na vida humana e também a dimensão do esforço computacional necessário para o desenvolvimento de sistemas que identifiquem, ou mesmo simulem, emoções (Cowie et al., 2001).

Uma nova sub-área da Robótica, denominada Robótica Sociável, que busca desenvolver robôs ou sistemas computacionais com interfaces homem-máquina ami- 
gáveis, para que a interação com os seres humanos aconteça da maneira mais natural possível vêm, cada vez mais, incorporando emoções em suas pesquisas. Acredita-se que, somente com o desenvolvimento de componentes emocionais, as interações sociais serão efetivas. Porém, para o desenvolvimento de tais mecanismos, inúmeras complicações devem ser solucionadas como, por exemplo, a escolha de qual o modelo ou teoria psicológica deve ser utilizada na modelagem do sistema. Neste sentido, esta área é apresentada em maiores detalhes no próximo capítulo. 


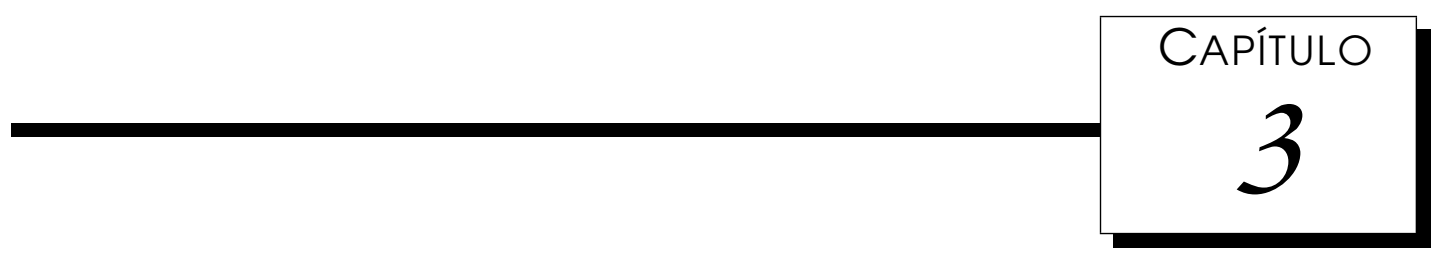

\section{Robótica Sociável}

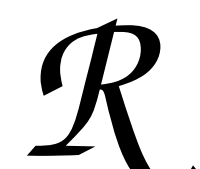

obótica Sociável é a denominação de uma sub-área da robótica que estuda e desenvolve Robôs Sociáveis. Estes robôs devem ser capazes de reconhecer outros robôs ou seres humanos e aprender novos conceitos durante uma interação social. Para isso, devem possuir percepções, conseguir interpretar o ambiente no qual estão inseridos, além de se comunicar, aprender e relacionar com seres humanos de uma maneira natural, ou seja, apresentando comportamentos socialmente adequados, que incluem expressões faciais, gestos, atenção e fala (Breazeal, 2002; 2003b; Berlin et al., 2005; Bennewitz et al., 2007; Kasap and Magnenat-Thalmann, 2010; Mohameda and Capi, 2012).

Existem motivações científicas e práticas para o desenvolvimento de robôs sociáveis. De uma perspectiva científica, pode-se aprender muito sobre a natureza social dos seres humanos com a realização de estudos e experimentos utilizando estes robôs (Breazeal, 2002; 2003b). Por exemplo, modelos computacionais de nossas habilidades sociais podem ser implementados, testados e analisados por meio da inserção de um robô em ambientes sociais controlados (Breazeal, 2003b; Sidner et al., 2005; Bennewitz et al., 2007; Park et al., 2008; Vanderborght et al., 2012). Esses robôs podem, também, ser utilizados como modelos para testar hipóteses de controle e comportamento de criaturas vivas (Grizard and Lisetti, 2006).

De uma perspectiva prática, com o progresso das pesquisas na área de robótica sociável e o potencial que estes robôs oferecem, espera-se o aumento de sua utilização no auxílio aos seres humanos em um número cada vez maior de tarefas como, por exemplo, como mediadores de interações em terapias com crianças autistas (Vanderborght et al., 2012), aprendizado e execução de tarefas para organização e cuidado de uma casa (Park et al., 2008), na área de entretenimento (Grizard and Lisetti, 2006), cuidados médicos para pessoas doentes (Saldien et al., 2008), atuação 
em locais públicos (Bennewitz et al., 2007), dentre outras.

Este capítulo apresenta a sub-área de Robótica Sociável. A Seção 3.1 introduz as principais características dos robôs sociáveis. A utilização de emoções em robótica sociável, com a descrição dos trabalhos existentes, que motivaram a realização desta pesquisa, são apresentados na Seção 3.2. Para finalizar, na Seção 3.3, são feitas as considerações finais deste capítulo.

\subsection{Robôs Sociáveis}

A qualidade das interações humano-robô possui um importante papel para o aumento da utilização de robôs sociáveis pela sociedade. O sucesso de uma interação não depende apenas dos mecanismos e estruturas desenvolvidos, mas também da robustez do robô em termos de membro da sociedade (Itoh et al., 2009). A incorporação de princípios relevantes do comportamento social humano e o entendimento do contexto sócio-cultural no qual ocorrerão as interações são de extrema importância. Neste sentido, o desenvolvimento de agentes sociáveis precisa ser balanceado em termos de cognição, aquisição de experiências, credibilidade e incorporação, dentre outros aspectos (Breazeal, 2002).

Os robôs sociáveis precisam perceber e entender o comportamento humano para interagir com estes (Sidner et al., 2005). Eles devem ser capazes de rastrear características humanas, interpretar a fala, além de incorporar mecanismos para o reconhecimento de expressões faciais, gestos e atividades humanas (Breazeal, 2002; Salichs et al., 2006; Spexard et al., 2007; Kim et al., 2008; Itoh et al., 2009). Para isso, necessitam de interfaces multimodais que permitam a interação e, muitas vezes, o aprendizado em tempo real e integrem percepções visuais e auditivas.

O trabalho desenvolvido por Breazeal (2002) é um dos pioneiros na área. Nele é apresentado Kismet, que pode ser visto na Figura 3.1. Este robô possui um sistema que integra diferentes percepções visuais: detecção de movimento, cores e faces humanas, juntamente com efeitos de habituação. Cada percepção visual produz um mapa de características que são combinadas por meio de uma soma ponderada. Esse sistema influencia e é influenciado por um sistema de comportamento e por um sistema motivacional, provendo um sistema de atenção dependente do contexto do ambiente e das necessidades do robô. Desta forma, o sistema combina as diversas características obtidas por meio do sistema perceptual em conjunto com os estados atuais de motivação e comportamento do robô para direcionar seus recursos computacionais durante as interações sociais.

Um robô denominado Maggie, que permite a interação multimodal utilizando expressões faciais e corporais, comunicação verbal e toques, é apresentado em Salichs et al. (2006). A base de Maggie é equipada com duas rodas, dois motores com encoders e também com 12 para-choques, 12 sensores ópticos infravermelhos e 12 sensores de ultrassom. Sobre a base, existe um sensor laser para buscas e 


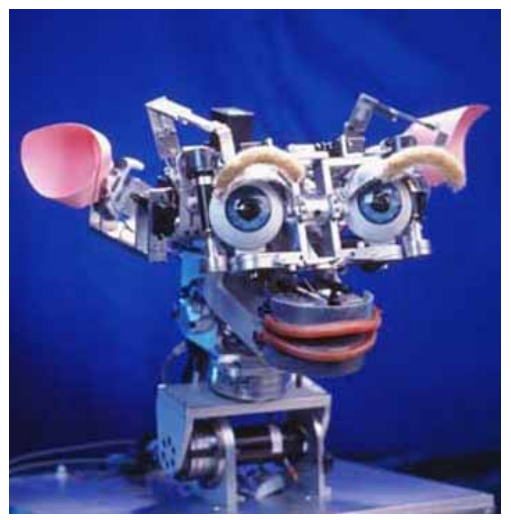

Figura 3.1: Aparência do robô Kismet (Breazeal, 2002).

mapeamento do ambiente. A parte superior do robô incorpora os mecanismos de interação. Sobre a plataforma, foi adicionada uma cabeça com aspectos antropomórficos com uma aparência atraente. A cabeça possui dois graus de liberdade permitindo movimentos básicos na vertical e horizontal, dois olhos, boca, câmeras ocultas nos olhos e duas pálpebras móveis e controláveis. Maggie possui dois braços com um grau de liberdade cada, para prover expressões não verbais por meio de movimentos do corpo. O sistema de voz permite que o robô fale e reconheça falas em castelhano. Este robô possui também uma câmera auxiliar para localizar e rastrear pessoas próximas a ele, e pode ser visto na Figura 3.2.

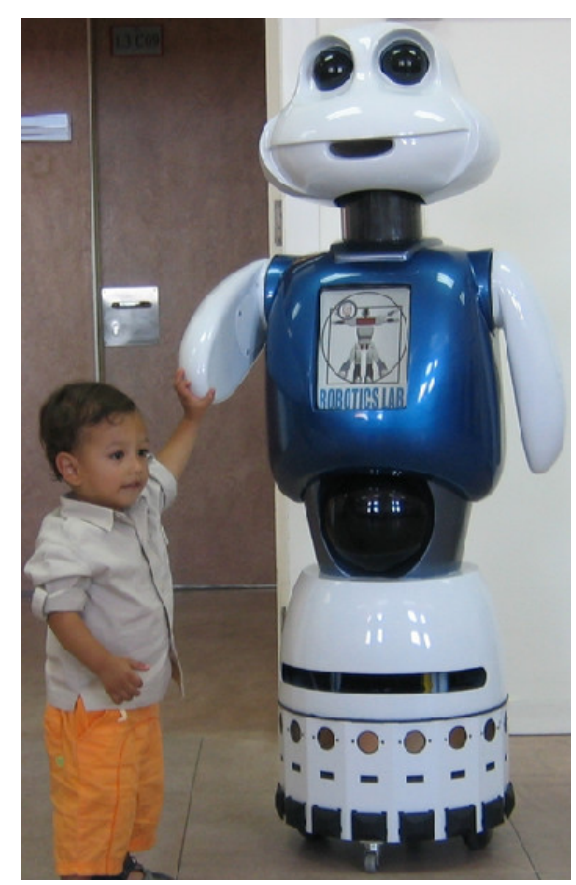

Figura 3.2: O robô Maggie (Salichs et al., 2006).

O desenvolvimento de mecanismos de atenção compartilhada é outro grande desafio a ser solucionado. Atenção compartilhada é definida como a capacidade de utilizar gestos e contato ocular para coordenar a atenção de outros agentes de maneira a compartilhar experiências sobre objetos ou eventos interessantes, 
possibilitando o aprendizado do que é importante no ambiente (Deák and Triesch, 2005).

Na literatura podem ser encontrados diversos trabalhos sobre atenção compartilhada (Deák and Triesch, 2005; Bennewitz et al., 2007; Hanheide and Sagerer, 2008; Policastro et al., 2009). Por exemplo, o robô Fritz (Bennewitz et al., 2007) pode caminhar e interagir por meio de gestos, expressões faciais, direção do olhar e fala, sendo capaz de direcionar sua atenção para múltiplas pessoas em paralelo. Para isso, possui um sistema de localização de voz, que possibilita direcionar sua atenção, por meio da movimentação de seu corpo, para a pessoa que fala. O robô foca sua atenção na pessoa que está conversando em determinado momento, fixando o olhar nela. Enquanto a atenção principal é dada à pessoa que fala, o robô também direciona sua atenção (olhar) diversas vezes para as distintas pessoas que estão interagindo simultaneamente, de modo a envolvê-las na conversa. Durante a interação, o robô movimenta seus braços ou executa gestos de apontamento utilizando seus olhos, cabeça e braços para direcionar a atenção dos usuários a objetos ou eventos de interesse. O foco da atenção também pode mudar durante o diálogo com diferentes pessoas. Se uma pessoa que está fora do campo visual começa uma conversa com ele, Fritz reage virando-se em direção a esta pessoa. Dessa forma, o robô atualiza seu foco de atenção, mantendo interatividade durante a conversa.

Para a obtenção de interações humano-robô mais realísticas, acredita-se que os robôs devem ser ensinados da mesma maneira que ensinamos outras pessoas ou da forma mais semelhante possível. Assim, os robôs sociáveis devem ser capazes de aprender e se adaptar a novas experiências a partir das interações com o ambiente ou com os seres humanos, adquirindo novos conhecimentos e adaptando seus comportamentos em resposta aos estímulos recebidos (Breazeal, 2002).

Na literatura, os trabalhos de Berlin et al. (2005); Gockley et al. (2006); Spexard et al. (2007); Hanheide and Sagerer (2008); Policastro et al. (2009), dentre outros, são alguns dos exemplos que podem ser citados. Neste sentido, Hanheide and Sagerer (2008) propõem um aprendizado por interações para o robô Biron, que deve interagir com o usuário executando tarefas em um apartamento.

Biron utiliza a fala para interagir com as pessoas e, por meio dela, armazenar as informações em sua memória. Para permitir o aprendizado em tempo real, o conceito de memória ativa é utilizado para reger as regras de funcionamento da memória do robô, que se vale de imagens detectadas em sua câmera para interagir com as pessoas presentes no ambiente. Basicamente, o conceito de memória ativa segue a ideia de integração direcionada a eventos. Para cada evento é criada uma representação XML que é armazenada em um servidor, que possui todas as informações presentes na memória do robô. Este servidor de memória ativa, no qual as informações são armazenadas de modo persistente, pode ser facilmente manipulado, permitindo a recuperação, remoção ou adição de informações. Isto possibilita, como 
ressaltam os autores, simular no robô, por exemplo, o comportamento de esquecer um determinado evento, que pode acontecer quando uma informação está há muito tempo armazenada no servidor, sem utilização, ou quando um evento armazenado pode prejudicar a execução de outros comportamentos mais frequentemente utilizados.

A personificação corporal também deve ser empregada para melhorar as interações com o ser humano, já que auxilia a entender e produzir o comportamento inteligente (Breazeal, 2002; 2003b). Da perspectiva do robô, seu corpo provê um meio para experimentar e interagir com o ambiente e interpretar suas experiências dentro deste ambiente. Da perspectiva do ser humano também é benéfico para o robô ter um corpo, uma vez que os humanos evoluíram para interagir socialmente com criaturas personificadas (Breazeal, 2002).

Os sistemas personificados possuem a vantagem de serem capazes de se comunicar de forma paralinguística, emitindo sinais como gestos, expressões faciais, entonação de voz, direção de olhar, orientação e postura corporal. Estes sinais são importantes para complementar e aprimorar a mensagem do robô durante uma interação (Breazeal, 2003a). Diversos pesquisadores exploram a personificação corporal em seus trabalhos (Berlin et al., 2005; Salichs et al., 2006; Spexard et al., 2007; Bennewitz et al., 2007; Itoh et al., 2009; Vanderborght et al., 2012). Como exemplos, a Figura 3.3 apresenta os robôs Leonardo e Fritz.
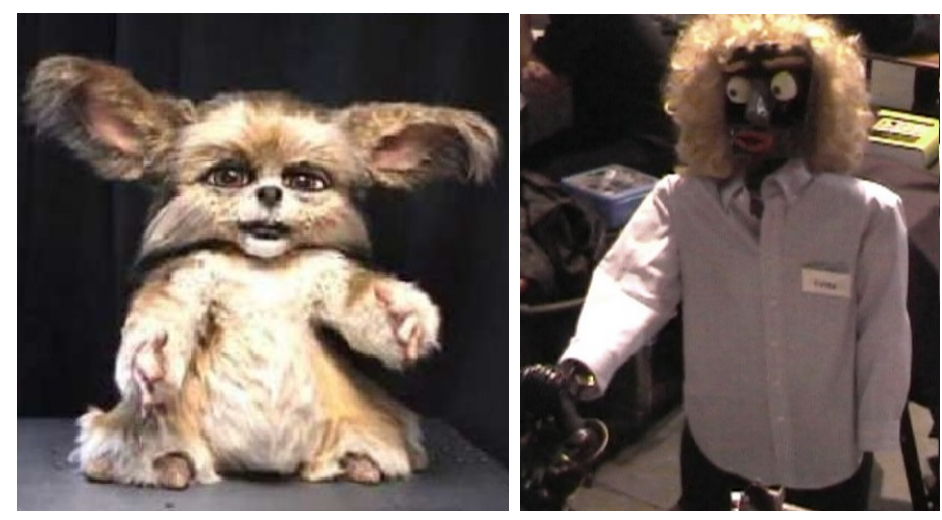

Figura 3.3: Exemplos de personificação corporal. Robô Leonardo (Berlin et al., 2005), à esquerda, e robô Fritz (Bennewitz et al., 2007), à direita.

Recentemente, a robótica sociável elegeu a capacidade de interpretar sinais emocionais de interlocutores e reagir de acordo com eles em um contexto apropriado como desafios a serem superados nos paradigmas de interação homem-máquina (Picard, 2003; Breazeal, 2003a). Sendo assim, para que as interações se tornem efetivamente naturais e inteligentes acredita-se que seja necessário que os robôs possam reconhecer as emoções humanas e responder a elas de maneira adequada, ou seja, possuir também a capacidade de expressá-las (Yang et al., 2009). 


\subsection{As Emoções e a Robótica Sociável}

Sistemas emocionalmente inteligentes devem ser capazes de criar uma interação afetiva com os seres humanos: eles devem ser dotados com a habilidade de perceber, interpretar, expressar e regular emoções. Sendo assim, reconhecer o estado emocional de um indivíduo é um dos principais requisitos para as máquinas interagirem, de maneira satisfatória, com os seres humanos (Picard, 2003).

Diversos autores (Breazeal, 2002; Cañamero, 2003; Picard, 2003) expõem distintas razões para justificar que a utilização de emoções em robótica sociável traz vários benefícios. Picard (2003), por exemplo, apresenta três motivos para atribuir habilidades emocionais às máquinas. O primeiro é a construção de robôs ou agentes sintéticos que possam emular seres humanos ou animais. O segundo trata do desenvolvimento de máquinas que possam apresentar comportamento inteligente. Como terceiro é citada a necessidade de compreender as emoções humanas e modelá-las para as máquinas.

Cañamero (2003) considera que as emoções, ou ao menos um sub-conjunto delas, são mecanismos existentes nos organismos vivos para que possam confrontar o ambiente em que vivem, propiciando autonomia e maior facilidade de adaptação ao meio. Por esse motivo, a autora considera ser necessário explorar emoções no desenvolvimento de mecanismos para robôs autônomos, para permitir que estes apresentem reações mais rápidas, contribuir para a escolha de qual ação tomar dentre as muitas possibilidades existentes, e chamar a atenção de outros agentes para eventos importantes do ambiente.

Assim, é possivel encontrar, cada vez mais, trabalhos que utilizam emoções para obtenção de interações sociais mais amigáveis entre seres humanos e robôs. Somente por meio de interações mais realísticas e duradouras será possível a inserção de robôs sociáveis em diversas tarefas para auxiliar no cotidiano das pessoas.

As pesquisas que exploram emoções em robótica sociável começaram na década de 90. No entanto, o desenvolvimento do robô Kismet (Breazeal, 2002; 2003a) impulsionou os trabalhos recentes. Na concepção deste robô, um sistema emocional que influencia suas expressões faciais foi desenvolvido. Desta forma, os humanos podem interpretar os sentimentos e necessidades internas do robô para interagir de maneira mais natural. O sistema emocional é projetado para ser um sistema flexível que coordena e recebe informações sobre estímulos do ambiente e estados internos para produzir uma resposta que atenda ao propósito de comportamento sociável apropriado, além de manter o estado interno do robô em níveis aceitáveis. As emoções podem ser ativadas por diversos eventos que são avaliados como sendo significativos para o "bem estar" do robô. Uma vez ativa, uma emoção serve a um conjunto particular de funções ou comportamentos que poderão atuar para estabelecer a relação desejada entre o robô e seu ambiente. As emoções motivam o robô a entrar em contato com o que pode lhe promover "bem estar" e a evitar o contato com 
aquilo que não lhe fazem bem. A face de Kismet possui 15 atuadores, muitos dos quais trabalham em conjunto para permitir a exibição de emoções específicas como felicidade, angústia, raiva, medo, dentre outras.

Em Gockley et al. (2006), um robô recepcionista é apresentado pelos autores, e pode ser visto na Figura 3.4. Esse robô explora o uso de expressões faciais por meio de uma face gráfica renderizada em 3D, e possui um conjunto básico de emoções, sendo elas felicidade, tristeza, frustração e raiva. Cada emoção é associada a um nível de intensidade, representado como um número real que varia entre 0 (não existente) e 1 (intensidade mais alta), como também um valor de valência, que indica o campo no qual essa emoção se enquadra, podendo ser positivo ou negativo. Para cada emoção, são definidas expressões de diferentes intensidades que podem ser exibidas pela face do robô. Este modelo é integrado a um sistema de reconhecimento de voz, de forma que certas declarações podem disparar emoções específicas diretamente, como elogios que causam felicidade ou insultos que resultam em tristeza. Para torná-lo uma presença natural, ele recebeu algumas características humanas como uma personalidade, uma história prévia de vida e diversos enredos que são encenados durante as interações, além de um nome: Valerie. A verbalização do robô é sincronizada com movimentos dos lábios e demais musculaturas de face.

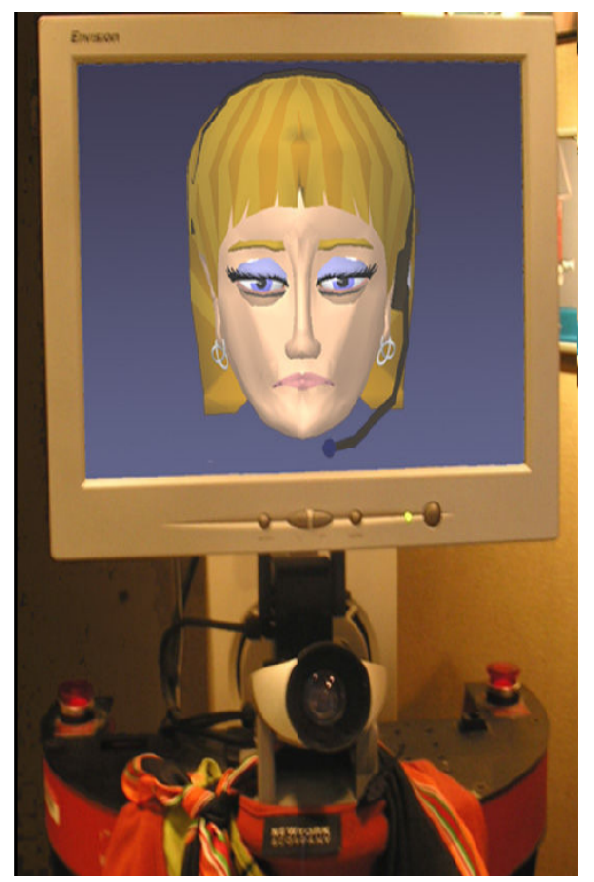

Figura 3.4: Face renderizada 3D do robô Valerie (Gockley et al., 2006).

Os trabalhos apresentados baseiam-se fortemente em expressões faciais para reconhecer e expressar emoções. Porém, os seres humanos também utilizam diferentes maneiras como, por exemplo, a entonação da voz e gestos, para este fim. Nesse sentido, diversos mecanismos que exploram distintas maneiras de expressar emoções utilizando, para isso, expressões faciais, gestos, movimentos do corpo, postura, orientação, cor e sons, vêm sendo cada vez mais desenvolvidos na literatura 
(Bethel and Murphy, 2008). Vale ressaltar que a utilização de sons inclui não apenas a fala, mas também sons não verbais.

Uma análise da literatura permite identificar que a maneira mais empregada para reconhecer e expressar emoções é a análise de expressões faciais. A entonação da voz aparece como a segunda forma mais utilizada. Em seguida, pode-se citar a análise de dados fisiológicos, como transpiração, batimentos cardíacos, pressão sanguínea, temperatura da pele, dentre outros. A utilização de gestos, movimentos corporais, orientação, postura e semântica são apenas parcialmente explorados (Paleari et al., 2010).

Pesquisadores argumentam que a utilização de gestos, movimentos do corpo, orientação e postura melhoram a interação social, pois os movimentos praticados pelo robô influenciam fortemente sua percepção e aceitação. Além disso, os gestos praticados por um robô transferem informações sobre seu estado emocional, influenciando nas impressões transmitidas aos seres humanos (Kim et al., 2008).

Embora poucos trabalhos utilizem cores e sons não verbais para expressar emoções, estudos psicológicos indicam que diferentes cores podem induzir a distintos estados emocionais como, por exemplo, a cor vermelha leva a sentimentos de amor ou raiva, as cores roxa ou preta estão associadas à ideia de tristeza, etc. Neste sentido, a utilização de sons não verbais também resulta no mesmo efeito, com sons mais altos associados a emoções negativas e, mais baixos, a positivas. A utilização de sons é, em geral, empregada como forma suplementar para a identificação do estado emocional (Bethel and Murphy, 2008).

Spexard et al. (2007) é um exemplo de trabalho que utiliza diferentes modalidades para expressar emoções. Nele, é apresentado o robô Barthoc, que está equipado com sensores que simulam as capacidades perceptuais dos seres humanos, ou seja, duas câmeras no local dos olhos, dois microfones, um em cada orelha, e uma máscara de látex para sua face se assemelhar à face humana. Para garantir uma interação efetiva, este robô utiliza, como entrada de dados, a fala, o reconhecimento de gestos de apontamento, a direção do olhar e informações emocionais do usuário. As emoções são produzidas com base na entonação da voz do usuário e no conteúdo semântico da fala. Para auxiliar na identificação emocional, os autores desenvolveram um software para classificar o significado das palavras encontradas no diálogo. Estas podem ser classificadas nos estados emocionais de alegria, raiva, medo, tristeza, surpresa, aversão e aborrecimento. Assim, o robô pode, por exemplo, perceber quando um usuário está ficando nervoso e agir pró-ativamente de modo a se desculpar.

As expressões faciais que podem ser produzidas pelo robô representam as emoções de alegria, tristeza, medo, raiva e surpresa, além da expressão pensativo, que indica que o sistema está processando as informações obtidas. O modelo também considera o humor do robô, que é alterado pouco a pouco durante a interação, 
e influencia no modo como as expressões faciais são apresentadas. Para auxiliar nas interações sociais, o robô também é capaz de utilizar seu braços e mãos para interagir por meio de gestos.

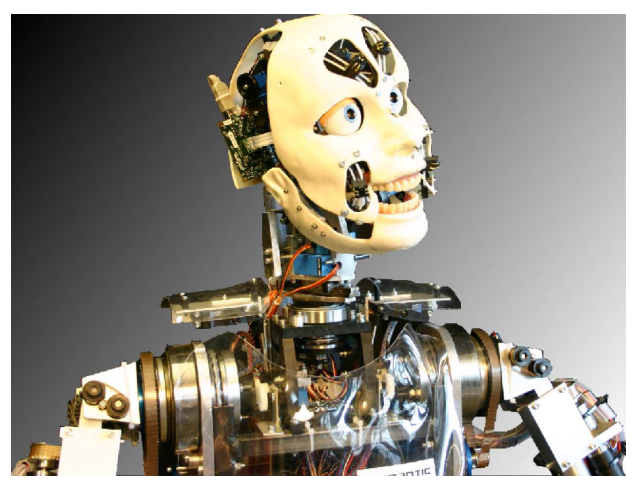

Figura 3.5: Robô Barthoc, que representa uma pessoa adulta (Spexard et al., 2007).

Em um outro trabalho, os autores apresentam o robô Probo (Saldien et al., 2008), desenvolvido para ser utilizado em hospitais como auxiliar no tratamento de crianças, em substituição às terapias com animais. O robô tem a habilidade de expressar emoções por meio de diferentes expressões faciais, que são enfatizadas por diferentes entonações em sua fala. O reconhecimento das emoções do usuário é feito pela análise da fala, assim como pela detecção da intensidade dos sons. O robô possui também sensibilidade ao toque em algumas partes do corpo. Para realizar as expressões faciais, a maioria dos graus de liberdade da face do robô são baseados em unidades de ação (UA) definidas pelo Sistema de Codificação de Ações Faciais (FACS) proposto por Ekman (Ekman et al., 2002). Para controlar o comportamento apresentado pelo robô, um modelo que foca na interação entre emoções, motivação e cognição é desenvolvido. O espaço emocional criado é baseado no modelo afetivo definido por Russell (1980), que permite às emoções apresentar diferentes graus de intensidades. O robô Probo e seu espaço emocional são apresentados na Figura 3.6.

Existem também autores (Lohse et al., 2008; Kim et al., 2008; Itoh et al., 2009) que procuram utilizar as emoções para atribuir uma personalidade específica ao robô, com o objetivo de que o ser humano possa criar laços de confiança e amizade com seus robôs, assim como faz com outros seres humanos ou animais de estimação. A argumentação é a de que associar uma personalidade facilita as interações sociais, pois auxilia o ser humano a predizer e entender o comportamento e características específicas, aumentando a percepção de humanidade (Kim et al., 2008). Dentre diversos atributos que podem ser investigados para conferir personalidade a um robô, os principais estão relacionados à aparência, atitudes, comportamentos, gestos, fala e tarefas realizadas (Kim et al., 2008).

Como exemplo, em Itoh et al. (2009) é apresentado o robô Ifbot. O estado afetivo deste robô é dividido em humor e emoção, o humor é um estado afetivo duradouro que influencia as emoções, dessa forma, diferentes intensidades para uma 


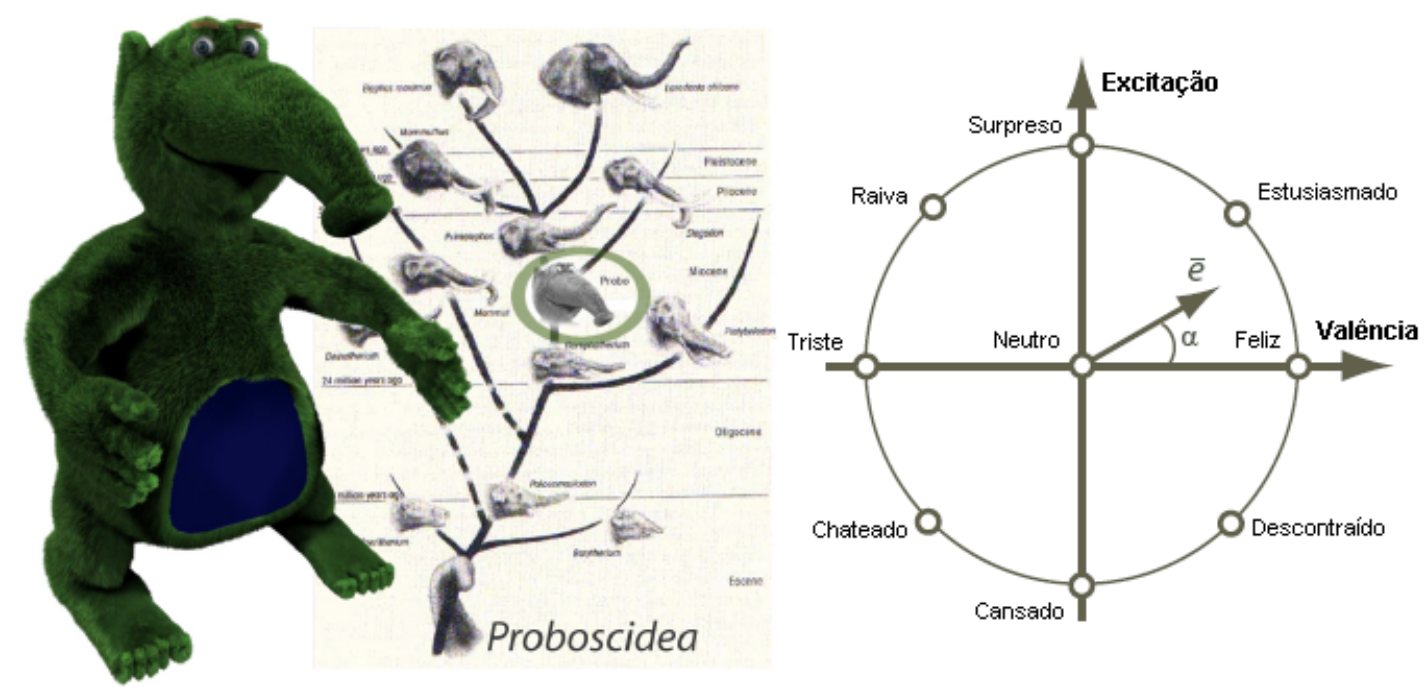

Figura 3.6: À esquerda é apresentado o robô Probo, e à direita o mapeamento de seu espaço emocional (Saldien et al., 2008).

mesma emoção podem ser apresentadas, de acordo com o humor atual do robô. A emoção é um estado afetivo curto, bem definido e diretamente apresentável por meio de gestos e expressões faciais, que são complementadas por 101 luzes auxiliares. Uma emoção é avaliada pela quantidade de prazer ou aversão do robô, e é ativada de acordo com a influência de seu humor. Por outro lado, o humor é dinamicamente alterado por meio do acúmulo de emoções passadas. A alteração do humor confere características específicas ao robô, que demonstra individualidade pela capacidade de apresentar uma ampla gama de comportamentos, produzindo uma personalidade própria. A personalidade consiste da análise de três componentes: o esquecimento, a suscetibilidade ao seu humor, e a submissão aos caprichos de seu humor. As expressões emocionais de felicidade, descontração, agradecimento, ânimo, encantamento, alarmado, nervoso, tristeza, aborrecimento, sonolência/desinteresse e aflição podem ser simuladas pelo robô. Exemplos de expressões que representam diferentes intensidades para a emoção "nervoso" podem ser vistos na Figura 3.7.

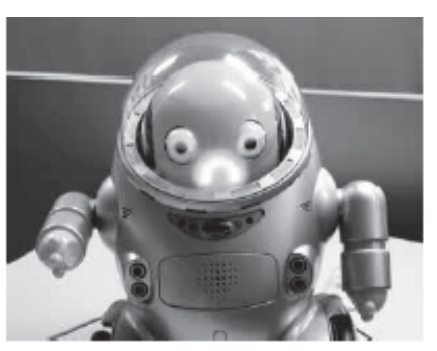

Nervoso

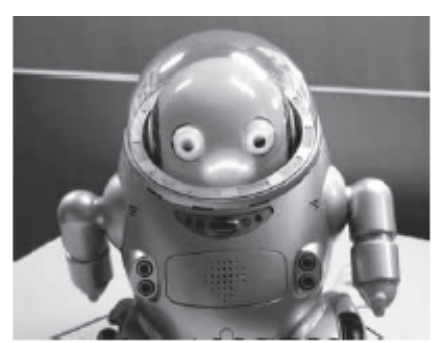

Muito nervoso

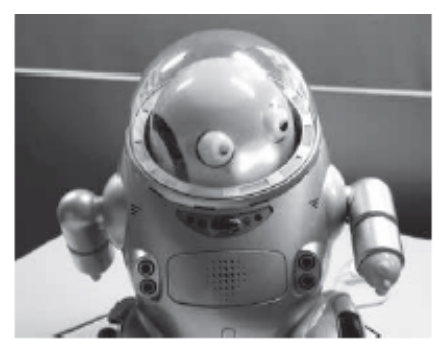

Extremamente nervoso

Figura 3.7: Da esquerda para a direita são apresentadas as diferentes expressões para a emoção "nervoso", realizadas pelo robô Ifbot. De acordo com o grau de intensidade da emoção, diferentes gestos, expressões faciais e luzes são utilizados (Itoh et al., 2009).

Embora progressos tenham sido feitos para o reconhecimento das emoções, 
existem vários problemas não resolvidos. Por exemplo, é ainda uma questão em aberto quais as características faciais mais importantes para a identificação de diferentes emoções. Este é um tema pouco estudado em computação, embora seja possivel encontrar diversos trabalhos em psicologia que o abordam (Yang et al., 2009). De acordo com estes trabalhos, informações obtidas de distintas regiões faciais têm diferentes efeitos no reconhecimento de expressões emocionais.

\subsection{Considerações Finais}

Uma diferença fundamental entre robôs sociáveis e outros tipos de robôs é a capacidade de interagir com os seres humanos de uma maneira mais natural. Recentemente, pesquisadores da Robótica Sociável entenderam que, para tornar as interações sociais mais realísticas, faz-se necessário o desenvolvimento de robôs que entendam e expressem as emoções humanas.

A incorporação de emoções em robôs ou sistemas computacionais não é uma tarefa simples, um grande desafio é mensurar uma emoção, que é algo abstrato, com o objetivo de desenvolver métodos computacionais que a representem. Neste sentido, diferentes algoritmos e modelos foram desenvolvidos na literatura, cada qual buscando uma maneira de permitir ao robô reconhecer e expressar emoções que auxiliem no entendimento de seus estados internos e produzam interações saudáveis em tempo real.

Este projeto investiga o desenvolvimento de uma modelagem que possa conferir a um sistema computacional, ou robótico, a capacidade de identificar as emoções humanas. Adicionalmente, esta modelagem deve ser fundamentada por teorias e conceitos biológicos e psicológicos, para que a identificação das emoções se assemelhe aos processos de reconhecimento emocional existentes nos seres humanos, objetivando propiciar maior naturalidade nas interações homem-máquina.

De acordo com o Capítulo 2, não existe um consenso de quais teorias ou modelos melhor descrevem o mecanismo emocional humano. Por isto, para desenvolver a modelagem computacional proposta, é necessário escolher os princípios biológicos ou psicológicos que serão utilizados. Deste modo, o modelo discreto proposto por Ekman (1999) é adotado. Este modelo afirma que existem seis emoções básicas inatas e universais, ou seja, reconhecidas por todos os povos, independente da cultura. Ainda, como os seres humanos utilizam diversas maneiras para expressar emoções, a modelagem proposta é baseada na análise de expressões faciais. Esta escolha é feita pois estudos demonstram que as expressões faciais são uma forma robusta para identificar as emoções humanas. Vale ressaltar que, para a análise de expressões faciais, é importante a utilização de um modelo facial apropriado. Também, para identificar as prováveis características faciais relevantes ao processo de reconhecimento emocional, é interessante que o modelo facial proposto seja relativamente simples. 
Um modelo facial simplificado, porém robusto, possui a vantagem de facilitar a identificação das principais características faciais necessárias para o reconhecimento de uma determinada emoção. Este tema vem recebendo cada vez mais destaque nas pesquisas psicológicas, que indicam a importância de distintas regiões da face no processo de reconhecimento de diferentes expressões emocionais. Sendo assim, um estudo mais aprofundado das expressões faciais humanas se mostra fundamental. Neste sentido, o próximo capítulo apresenta os fundamentos teóricos necessários para a análise das expressões faciais humanas, assim como um maior detalhamento psicológico sobre os processos de reconhecimento de emoções por meio de expressões faciais. 


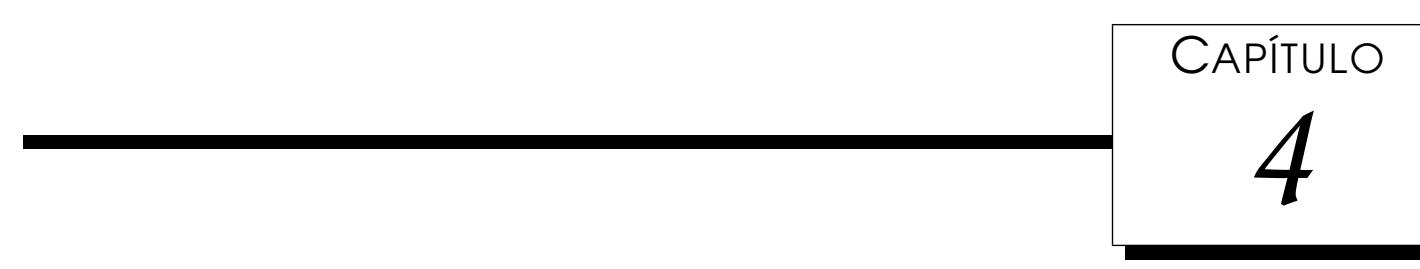

\section{Expressões Faciais}

$\mathcal{A}$

s expressões faciais têm sido foco de interesse em pesquisas relacionadas às emoções por mais de cem anos (Darwin, 1872), estando presentes em estudos que envolvem praticamente todos os aspectos emocionais, incluindo psicofisiologia, percepção, distúrbios emocionais, dentre outros (Cohn et al., 2007; Lee et al., 2007). Estudos psicológicos realizados com pessoas de diferentes culturas também indicam a existência de um pequeno conjunto de expressões faciais relacionado às seis emoções básicas (Ekman, 1973).

O reconhecimento automático de emoções é uma tarefa multidisciplinar que envolve diferentes áreas de pesquisa, como a psicologia, visão computacional, análise de discurso e aprendizado de máquina. Diferentes maneiras, como a entonação de voz, movimentos corporais e expressões faciais são naturalmente utilizados pelos seres humanos para expressar emoções. No entanto, estas ações humanas requerem cálculos complexos para serem executadas por máquinas. Por este motivo, pesquisadores investigam diferentes abordagens e técnicas para identificar e expressar emoções (Lee et al., 2007). Embora os seres humanos utilizem diferentes maneiras para expressar emoções, estudos evidenciam que estas são mais precisamente descritas por expressões faciais, sem a necessidade de análises complementares (Ekman and Friesen, 2003).

Este capítulo trata das expressões faciais humanas, assim como apresenta os trabalhos da literatura relacionados à proposta desta tese. Neste sentido, a Seção 4.1 apresenta definições e conceitos sobre a análise de expressões faciais, ao passo que a Seção 4.2 descreve as principais características das expressões faciais emocionais, além de apresentar a fundamentação psicológica envolvida na percepção delas. Em seguida, podem ser vistos, na Seção 4.3, alguns exemplos de trabalhos que reconhecem as emoções pela análise de expressões faciais. As considerações 
finais deste capítulo são feitas na Seção 4.4.

\subsection{Análise de Expressões Faciais}

Embora os seres humanos tenham adquirido a capacidade de se expressar por meio da linguagem falada, a importância das expressões faciais durante uma interação social ainda é considerável. Elas são manifestações visíveis, automáticas ou voluntárias, que podem ser medidas (Schyns et al., 2009). A face é o nosso principal meio de interação com o mundo que nos rodeia. Ela é utilizada para reconhecer pessoas, determinar a idade, o grupo étnico, a beleza e o sexo de um indivíduo, sendo uma das maneiras mais importantes de comunicação não verbal, com uma riqueza de sinais comunicativos provenientes das expressões faciais, movimentos de cabeça e direção do olhar (Ekman, 1973).

Expressões faciais são mudanças na face em resposta a estados emocionais, intenções ou interações sociais de um ser humano. Desde o trabalho de Darwin (1872), a análise de expressões faciais tem sido um tópico ativo de pesquisas para cientistas de análise do comportamento. Darwin (1872) estudou as semelhanças e diferenças na maneira como humanos e animais expressam as emoções, concluindo que "os jovens e os velhos de diferentes raças, independente se homem ou animal, expressam o mesmo estado de espírito com os mesmos movimentos". Estes estudos impulsionaram grande interesse entre psicólogos e cientistas cognitivos, com o surgimento de diversos estudos relacionando as expressões faciais às emoções e à comunicação interpessoal. Foi em um destes estudos que Ekman (1973) afirmou a existência de seis emoções básicas, que são produzidas e reconhecidas independentemente do contexto cultural.

A partir do trabalho de Parke (1974) teve início a análise de expressões faciais pela Ciência da Computação que, inspirada pelas descobertas dos cientistas cognitivos, buscou automatizar esta análise a partir de vídeos ou imagens estáticas, com o objetivo inicial de identificar um conjunto de expressões faciais prototípicas que represente as seis emoções básicas. Diversas abordagens, que variam desde métodos globais de análise facial, baseados em cores ou intensidades, até abordagens baseadas em características, que utilizam as posições de pontos faciais, foram propostas (Valstar, 2008). Mais tarde, alguns pesquisadores iniciaram estudos na detecção de ações faciais atômicas, relacionadas a movimentos de áreas ou músculos faciais, de acordo com o Sistema de Codificação de Ações Faciais (FACS) e os conceitos de unidades de ação (UAs) (Ekman et al., 2002). Recentemente, dois novos aspectos da análise de expressões faciais começaram a ser abordados: a análise de expressões emocionais espontâneas e a análise da dinâmica temporal destas expressões (Lucey et al., 2007; Valstar, 2008; Tong et al., 2010; Baltrusaitis et al., 2011).

A análise de expressões faciais pode ser aplicada a diversas áreas como comunicação emocional e paralinguística, psicologia clínica, psiquiatria, neurologia, 
avaliação da dor, detecção de mentiras, construção de ambientes inteligentes e desenvolvimento de interfaces homem-máquina. A maioria dos sistemas existentes visa reconhecer um pequeno conjunto de expressões faciais emocionais prototípicas relacionadas às seis emoções básicas ou a um subconjunto delas (Tian et al., 2005; Khan et al., 2006; Kotsia and Pitas, 2007; Valstar, 2008; Khan et al., 2011; 2013). Embora algum progresso tenha sido feito no reconhecimento de emoções pela análise de expressões faciais, vários problemas ainda não foram resolvidos, sendo assim, podem ser encontrados na literatura diversos trabalhos com o objetivo de encontrar maneiras mais eficientes para a análise destas expressões.

Três etapas distintas compõem o processo de análise automática de expressões faciais: detecção da face, extração de características e classificação (Valstar, 2008). Na etapa de detecção, o objetivo é encontrar a região da imagem em que a face está localizada. A detecção de faces em cenas complexas é ainda motivo de estudos devido aos inúmeros problemas que podem existir. Nesse sentido, a maioria dos sistemas existentes demanda que a face esteja em posição frontal. Ainda, a localização da face, sua escala e orientação precisam ser determinados manualmente ou por um sistema auxiliar de rastreamento automático. Movimentos de cabeça, oclusões, alterações na iluminação, presença de cabelo ou óculos sobre a face, dentre outros, são exemplos de possíveis dificuldades encontradas durante a utilização do sistema.

Para identificação do estado emocional, diferentes tipos de estímulos perceptivos são exibidos pela face, tais como deslocamentos (sobrancelhas erguidas), alterações de textura na superfície da pele (franzir a testa), mudanças na cor da pele (rubor), dentre outros. A maneira como a face e sua expressão são modelados influencia diretamente nas características que devem ser selecionadas. Além disso, estas características serão responsáveis pela qualidade final obtida pelo classificador, já que uma correta representação facial é muito importante para produzir resultados finais satisfatórios (Tian et al., 2005). Neste sentido, duas abordagens principais são utilizadas na extração de características faciais: métodos baseados em características geométricas e métodos baseados em aparência.

Os primeiros utilizam características geométricas da face como as posições e as distâncias entre pontos faciais, a velocidade de separação destes, dentre outras. As características faciais mais comumente utilizadas são o formato de boca, olhos, sobrancelhas e nariz, e a localização de pontos salientes, como cantos dos olhos, da face e da boca. Os componentes faciais são, então, representados por um vetor de características que contém informações sobre a geometria da face modelada. Os baseados em aparência utilizam propriedades fotométricas das imagens, como cores, textura, intensidade, assim como a presença de cantos ou bordas para a análise de deformações faciais. As características faciais de aparência representam as mudanças físicas, como o surgimento de rugas ou marcas de expressão, que 
podem ser observadas pela textura da pele. Nestes métodos, a face pode ter suas características representadas por mapas de intensidade, de cores, pela aplicação de filtros, dentre outros, que podem ser aplicados na face inteira ou em regiões específicas. Em geral, a transformada wavelet de Gabor é utilizada para analisar a aparência da face (Tian et al., 2005).

As duas abordagens de extração de características apresentadas podem, também, ser utilizadas em conjunto para complementar as informações utilizadas na modelagem facial, resultando numa abordagem híbrida. Estudos indicam que uma abordagem híbrida pode melhorar a acurácia no reconhecimento de algumas das expressões faciais emocionais. Ainda, para remover os efeitos de variações na escala, posição e distância da face com relação à câmera, iluminação, dentre outros fatores, pode-se primeiro alinhar e normalizar a face analisada com base em um modelo facial já existente (Tian et al., 2005). Exemplos de trabalhos que utilizam métodos baseados em características geométricas são Cohen et al. (2003); Kotsia and Pitas (2007) e Valstar (2008). Para métodos baseados em aparência, alguns exemplos são Anderson and McOwan (2006) e Sarvadevabhatla et al. (2011). Ainda, o trabalho de Lucey et al. (2007) pode ser apresentado como um exemplo de abordagem híbrida.

A classificação da expressão facial é a última etapa. As deformações faciais podem ser identificadas como movimentos musculares ou expressões emocionais prototípicas. Dependendo se a dinâmica temporal é ou não utilizada, as abordagens de reconhecimento são classificadas como baseadas em quadros ou baseadas em sequência. A abordagem baseada em quadros utiliza apenas informação do quadro atual da imagem, baseando-se ou não em uma imagem de referência, que normalmente representa a face neutra, para reconhecer as expressões daquele quadro. A abordagem baseada em sequência utiliza a informação temporal da sequência de quadros que representa uma expressão, para reconhecer as expressões presentes em um ou mais quadros. Muitos classificadores têm sido aplicados nesta etapa, como redes neurais (RNs), máquinas de vetores suporte (SVMs), análise de discriminante linear (LDA), $k$-vizinhos mais próximos, modelos ocultos de Markov (HMM), dentre outros (Tian et al., 2005).

Do ponto de vista do reconhecimento das expressões faciais, duas abordagens podem ser identificadas. A primeira avalia o reconhecimento do estado afetivo ou da emoção, ao passo que a segunda analisa a movimentação muscular (Pantic and Rothkrantz, 2003; Tian et al., 2005). Estas abordagens têm relação direta com as duas principais vertentes psicológicas que estudam expressões faciais (Cohn, 2006): análise do significado facial e análise dos sinais faciais. Enquanto a primeira busca inferir o significado de uma expressão facial, como a emoção ou personalidade, a segunda descreve a aparência física da expressão apresentada, como o movimento dos músculos ativados ou mudanças na configuração ou formato dos elementos que a compõem (Valstar, 2008). 
A análise do significado facial depende de interpretações subjetivas, já a análise dos sinais faciais é agnóstica e independente de qualquer tentativa de interpretação. As seis emoções básicas (Ekman, 1999) e o modelo circumplexo de Russell (1980) são os modelos comumente utilizados para análise do significado das expressões faciais. Já para a análise de sinais, o sistema FACS (Ekman et al., 2002) e o sistema MPEG-4 (Tekalp and Ostermann, 2000) são os mais comumente empregados.

Enquanto a análise do significado facial é capaz de distinguir um conjunto predefinido de expressões faciais, a análise dos sinais faciais pode utilizar o sistema FACS, por exemplo, para identificar diferentes expressões pela decomposição em específicas UAs. Como as UAs representam movimentos musculares faciais que independem de qualquer interpretação cultural, elas também podem ser utilizadas para a identificação das seis emoções básicas (Ekman et al., 2002).

Os sistemas FACS e MPEG-4 têm muitos elementos em comum. No entanto, o FACS é utilizado para descrever movimentos musculares faciais, sendo popular entre cientistas da computação e psicólogos. Já o sistema MPEG-4 foi criado para a animação de faces virtuais e codifica o movimento real de componentes faciais, sendo utilizado exclusivamente por cientistas da computação. Como o trabalho desenvolvido nesta tese utiliza indiretamente o sistema FACS, pois analisa as características faciais mais relevantes encontradas em cada expressão emocional para identificar quais as UAs ativadas pela respectiva configuração facial, ele será apresentado em maiores detalhes.

\subsubsection{Sistema de Codificação de Ações Faciais}

Na vida cotidiana, as expressões prototípicas ocorrem com pouca frequência. Em vez disso, uma emoção é mais frequentemente comunicada por mudanças sutis em uma ou poucas características faciais distintas, como abaixar os cantos dos lábios na tristeza ou o aperto dos lábios na raiva (Tian et al., 2005). As alterações destas características isoladas, especialmente nas áreas das sobrancelhas ou pálpebras, são típicos exemplos de sinais paralinguísticos, como a elevação das pálpebras, que indica uma saudação. Para capturar a sutileza das emoções humanas e da comunicação paralinguística, é necessário o reconhecimento automático de mudanças sutis na expressão facial.

O Sistema de Codificação de Ações Faciais (FACS) (Ekman et al., 2002) é um sistema projetado para detectar estas mudanças sutis nas características faciais. Ele associa alterações na expressão facial com a ação dos músculos responsáveis por produzi-las. Os movimentos musculares são representados por unidades de ação (UAs), que podem ocorrer individualmente ou em combinações.

O sistema FACS é composto por 32 UAs anatomicamente relacionadas à contração de um conjunto específico de músculos faciais, sendo nove localizadas 
na parte superior da face, que é constituída por olhos (pálpebras), sobrancelhas e testa, 18 na parte inferior, onde são consideradas as bochechas, queixo, nariz e boca (lábios) e cinco que não podem ser classificadas como pertencentes à parte superior ou inferior da face. Além das UAs, existem também 11 descritores de ação para as diferentes posições da cabeça, nove para as posições dos olhos e 14 para ações diversas, em que a base anatômica não é especificada. Todas as UAs são atômicas, ou seja, são consideradas os menores movimentos faciais visualmente discerniveis. Como exemplo, tem-se que as UA12, UA17, UA23, UA24, UA25 e UA27 são relativas a movimentos dos lábios, assim como as UA1, UA2 e UA4 estão relacionadas a movimentos das sobrancelhas (Tong et al., 2010).

O sistema FACS também possui regras que permitem identificar os segmentos temporais (início, ápice e término) de uma determinada UA. Além disso, existem UAs que podem ser codificadas como simétricas ou assimétricas, assim como diversas UAs variam em intensidade, em que uma escala ordinal com cinco graus de intensidade é utilizada para medir o grau de contração muscular (Tian et al., 2005).

É importante destacar que as UAs podem ser utilizadas para o reconhecimento de emoções, já que Ekman et al. (2002) encontraram combinações específicas de UAs que representam cada uma das seis emoções básicas. Neste sentido, uma expressão emocional nada mais é que um conjunto de UAs, permitindo relacionar movimentos musculares a específicas expressões emocionais.

Alguns exemplos de UAs podem ser vistos na Figura 4.1 e, na Tabela 4.1, podem ser vistas as possíveis configurações de UAs que representam cada uma das seis emoções básicas investigadas neste trabalho.

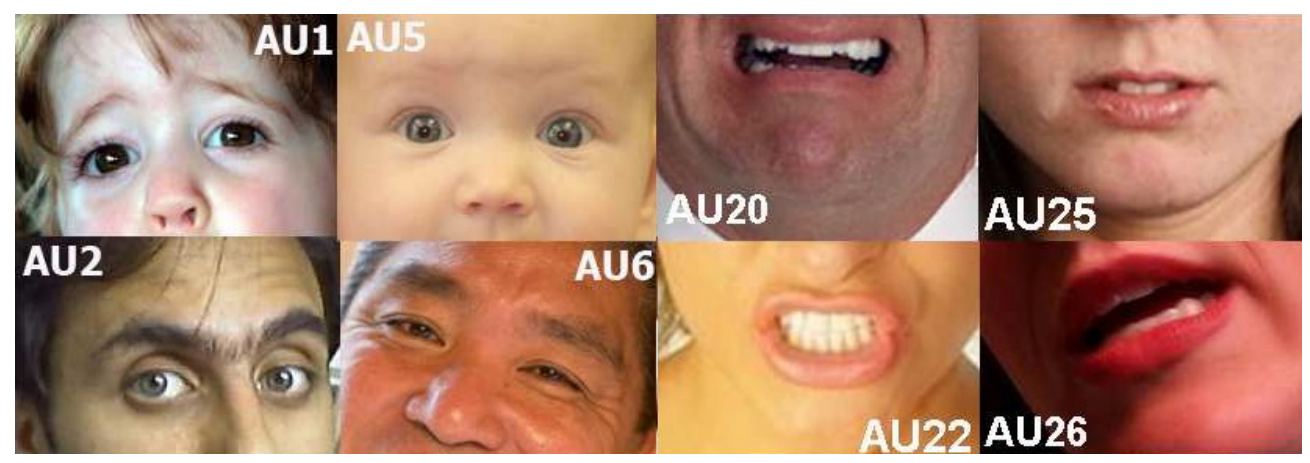

Figura 4.1: Exemplos de unidades de ação (UAs), adaptado de Valstar (2008).

Os principais músculos faciais responsáveis pela produção de expressões faciais são apresentados na Figura 4.2. Uma descrição mais detalhada destes músculos pode ser encontrada em Faigan (1990). Na Tabela 4.2, a relação entre os músculos faciais e as UAs codificadas pelo sistema FACS é apresentada. Esta tabela é utilizada para mapear as características faciais selecionadas pela abordagem proposta, apresentada em detalhes no Capítulo 6, nas respectivas UAs ativadas. 
Tabela 4.1: Mapeamento dos músculos faciais (UAs) para emoções de acordo com o sistema FACS. A || B significa "A ou B".

\begin{tabular}{|c|c|c|}
\hline Raiva & Tristeza & Medo \\
\hline$\{4,5,7,10,22,23,25 \| 26\}$ & $\{1,4\}$ & $\{1,2,4\}$ \\
$\{4,5,7,10,23,25 \| 26\}$ & $\{1,4,11 \| 15\}$ & $\{1,2,4,5,20,25\|26\| 27\}$ \\
$\{4,5,7,17,23 \| 24\}$ & $\{1,4,15,17\}$ & $\{1,2,4,5,25\|26\| 27\}$ \\
$\{4,5,7,23 \| 24\}$ & $\{6,15\}$ & $\{1,2,4,5\}$ \\
$\{4,5 \| 7\}$ & $\{11,17\}$ & $\{1,2,5,25\|26\| 27\}$ \\
$\{17,24\}$ & $\{1\}$ & $\{5,20,25\|26\| 27\}$ \\
& & $\{5,20\}$ \\
& & $\{5\}$ \\
\hline Alegria & Surpresa & Aversão \\
\hline$\{12\}$ & $\{1,2,5,26 \| 27\}$ & $\{9 \| 10,17\}$ \\
$\{6,12\}$ & $\{1,2,5\}$ & $\{9 \| 10\}$ \\
& $\{1,2,26 \| 27\}$ & $\{9\|10,16,25\| 26\}$ \\
\hline & $\{5,26 \| 27\}$ & \\
\hline
\end{tabular}

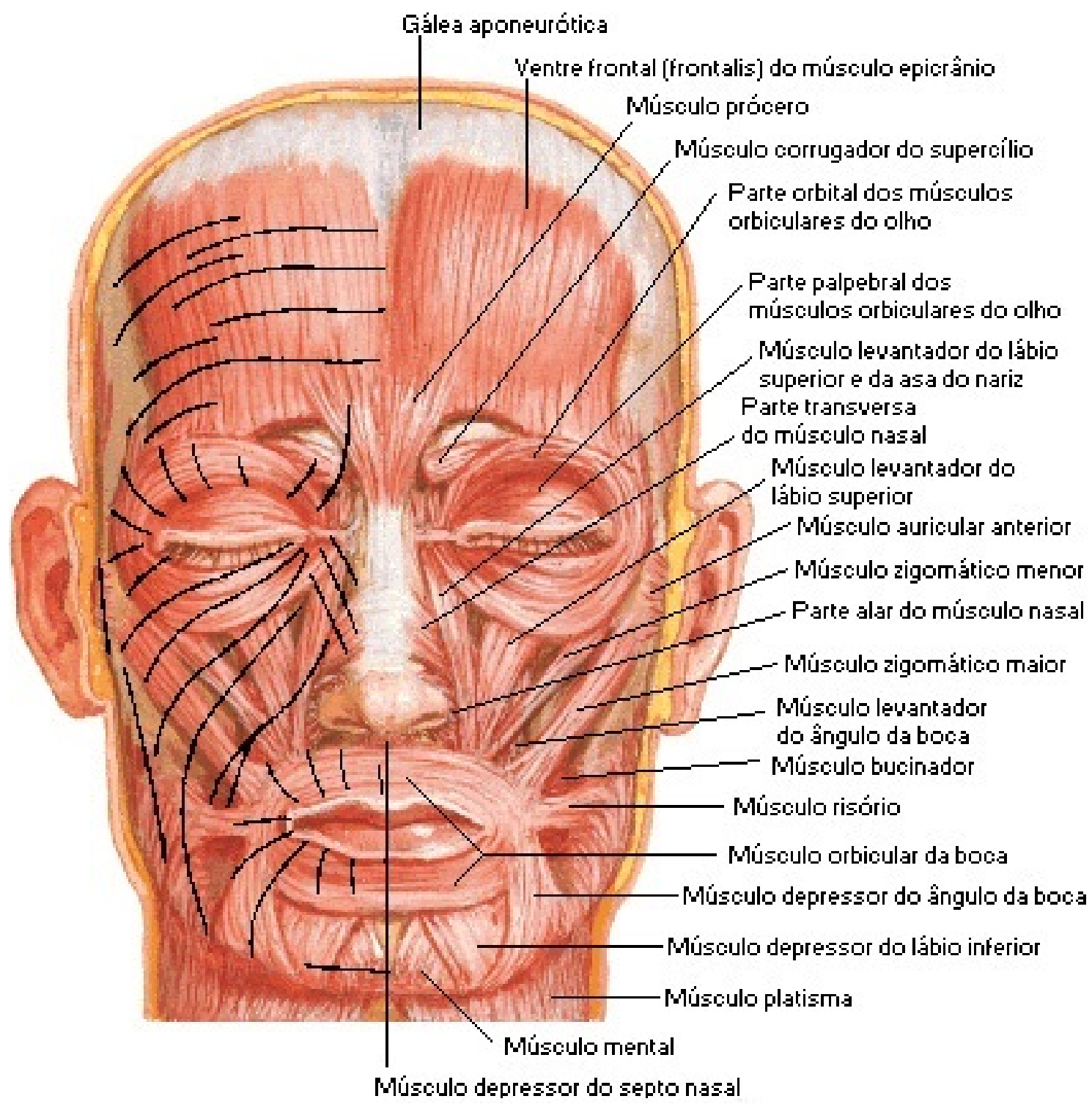

Figura 4.2: Principais músculos faciais representados pelas UAs. 
Tabela 4.2: Relação existente entre as UAs definidas pelo sistema FACS e os músculos faciais.

\begin{tabular}{|c|c|c|c|}
\hline UA & Músculos & UA & Músculos \\
\hline 1 & Frontalis (central) & 2 & Frontalis (lateral) \\
\hline 4 & Corrugador do supercílio, Prócero & 5 & Levantador da pálpebra \\
\hline 6 & Orbicular do olho (parte orbital) & 7 & Orbicular do olho (parte palpebral) \\
\hline 8 & Orbicular da boca & 9 & $\begin{array}{c}\text { Levantador do lábio superior e } \\
\text { asa do nariz }\end{array}$ \\
\hline 10 & Levantador do lábio superior & 11 & Zigomático menor \\
\hline 12 & $\begin{array}{l}\text { Zigomático maior, } \\
\text { Levantador do ângulo da boca }\end{array}$ & 13 & Canino, levantador do ângulo da boca \\
\hline 14 & Bucinador & 15 & Depressor do ângulo da boca (triangular) \\
\hline 16 & Depressor do lábio inferior & 17 & Mental \\
\hline 18 & Incisivo do lábio & 20 & Risório, Platisma \\
\hline 22 & $\begin{array}{l}\text { Orbicular da boca (parte externa), } \\
\text { Bucinador }\end{array}$ & 23 & Orbicular da boca (parte interna) \\
\hline 24 & Orbicular da boca (parte interna) & 25 & $\begin{array}{c}\text { Depressor do lábio inferior, mental, } \\
\text { Orbicular da boca }\end{array}$ \\
\hline 26 & Temporal, Masseter & 27 & Digástrico, temporal, masseter \\
\hline 28 & Orbicular da boca & 38 & Nasal (parte alar) \\
\hline 39 & $\begin{array}{l}\text { Nasal (parte transversal), } \\
\text { Depressor do septo nasal }\end{array}$ & 43 & Orbicular do olho \\
\hline 45 & Levantador da pálpebra, orbicular do olho & 46 & Orbicular do olho \\
\hline
\end{tabular}

\subsection{Expressões Faciais Emocionais}

Expressões faciais emocionais são produzidas pelo movimento de cada um dos músculos faciais para uma posição específica. Isto faz com que as características da face e da pele formem configurações que podem ser interpretadas como uma emoção (Martinez and Neth, 2010). Pela análise delas, é possivel obter o estado emocional de uma pessoa e, assim, ajustar um sistema computacional para que apresente comportamento apropriado. Além disso, estudos evidenciam que as expressões faciais emocionais ocupam importante papel na evolução e comunicação diária dos seres humanos (Martinez and Du, 2012). Nesse sentido, o desenvolvimento de modelos computacionais para corretamente representá-las é de extrema importância para diversas áreas de pesquisa.

$\mathrm{Na}$ vida cotidiana, oclusões e detecções imprecisas dos elementos característicos da face, dentre diversos outros fatores, afetam o reconhecimento. Mais importante, ainda, é o fato de que os seres humanos não são bons em reconhecer diversas expressões faciais de emoção, mesmo sob condições favoráveis (Du and Martinez, 2011). Os seres humanos facilmente reconhecem as expressões de alegria e surpresa, independente das condições ou resolução da imagem. No entanto, não são muito bons em reconhecer a raiva e a tristeza e são ainda piores com as expressões de medo e aversão. Estas evidências psicológicas sugerem que podem existir três grupos distintos de expressões emocionais. O primeiro é destinado a transmitir emoções aos observadores. Sendo assim, estas expressões evoluíram para serem facilmente detectadas a curtas ou longas distâncias. Expressões deste grupo são a 
alegria e a surpresa. O segundo grupo, composto por raiva e tristeza, é constituído por expressões que são razoavelmente reconhecidas somente a curtas distâncias. O terceiro e último grupo é composto por expressões que os seres humanos têm dificuldades de reconhecer. Isto inclui as expressões de medo e aversão (Martinez and Du, 2012). É possível que as expressões deste grupo evoluíram para propósitos que não estão relacionados à comunicação interpessoal (Du and Martinez, 2011).

A existência de ambiguidades nas expressões emocionais é também destacada no trabalho de Sebe et al. (2005). Nele, os autores observam que, mesmo no trabalho realizado por Ekman (1973), é possível identificar que os seres humanos confundem as expressões de raiva e aversão. O mesmo é também observado para as expressões de surpresa e medo. O fato destas expressões produzirem movimentos faciais semelhantes pode ser o motivo dos seres humanos as confundirem. Curiosamente, uma análise dos sistemas de detecção automática de emoções baseados na análise de expressões faciais indica que estes sistemas apresentam dificuldades em discernir as expressões de raiva e aversão, porém esta mesma dificuldade não é encontrada para as expressões de medo e surpresa. Em vez disso, é possível notar, de acordo com a literatura, que estes sistemas costumam confundir a expressão de medo com alegria ou raiva, e a expressão de tristeza com raiva. Ademais, alegria e surpresa são as expressões emocionais mais facilmente identificáveis (Bettadapura, 2012).

Dadas as limitações de reconhecimento apresentadas pelos seres humanos, espera-se que sistemas de visão computacional biologicamente inspirados possam reconhecer as expressões de alegria e surpresa a quaisquer distâncias, independente da qualidade da imagem analisada. Para as expressões de tristeza e raiva, espera-se que possam ser reconhecidas a curtas distâncias em imagens com boa resolução. Já para as expressões de medo e aversão, é aceitável a ocorrência de falhas, pois os seres humanos também apresentam dificuldades em identificá-las (Martinez and Du, 2012).

Os primeiros trabalhos desenvolvidos na área de reconhecimento de expressões faciais emocionais valeram-se de métodos baseados em características geométricas (Kanade, 1973; Marr, 1976). Pouco tempo depois, os métodos baseados em aparência começaram a ser empregados (Sirovich and Kirby, 1987). Com os avanços nas pesquisas, estes métodos se popularizaram nas últimas duas décadas, seja para a análise de emoções ou de UAs (Martinez and Du, 2012). A principal vantagem dos métodos baseados em aparência é não ser necessário definir um modelo específico, automaticamente produzido pelo método, porém exigido para a utilização dos métodos baseados em características geométricas. Estes métodos produzem ótimos resultados em imagens com boa resolução, nas quais a face se encontra praticamente na posição frontal. Em outras situações, porém, apresentam diversos problemas.

A principal desvantagem é a sensibilidade na manipulação das imagens. A 
escala, além de mudanças na iluminação ou postura da face são alguns exemplos. A maioria destes problemas é intrínseca à própria definição do método, que não é capaz de generalizar seus resultados para condições não previstas no conjunto de treinamento. Uma solução seria ampliar o número de imagens do conjunto de treinamento. No entanto, o aprendizado a partir de grandes conjuntos de dados (da ordem de milhões de amostras) é, em sua maioria, sem solução (Martinez and $\mathrm{Du}, 2012)$. Neste sentido, em situações nas quais existe grande movimentação da face, oclusões ou problemas de iluminação, os métodos baseados em características geométricas são capazes de superar o desempenho obtido pelos métodos baseados em aparência (Valstar, 2008).

Estudos psicológicos sugerem que a face humana é processada de forma diferente que outros objetos, e estudos neurofisiológicos confirmam este ponto de vista (Martinez and Neth, 2010). A maioria destes estudos conclui que, seja para o reconhecimento da identidade ou da expressão emocional de um indivíduo, o foco da atenção é a percepção de alterações na configuração (ou disposição) dos elementos faciais. Sendo assim, estes estudos indicam que o algoritmo do cérebro humano não é baseado em aparência. Parece que, com o tempo, foi identificado um conjunto de características geométricas que facilitam a rápida categorização das faces humanas (Martinez and Neth, 2010). Neste sentido, estudos comportamentais mostram que a diferença fundamental no modo como as faces são processadas em comparação com outros objetos é que as informações dos elementos faciais e da configuração espacial destes elementos são processadas em conjunto, como um todo integrado, denominado de processamento global ou representação holística (Zhang et al., 2012).

Ademais, a psicologia encontrou uma região do cérebro, denominada Área Fusiforme da Face, responsável por detectar os elementos faciais e extrair características com base nas informações da configuração destes elementos (relação espacial entre as distintas regiões da face) (Zhang et al., 2012). Esta região do cérebro reconhece que a disposição de olhos, nariz e boca seguem o formato de um "T", o que recebeu a nomenclatura de relação de primeira ordem. Adicionalmente, por meio do que é denominado relação de segunda ordem, esta região também é responsável por identificar o formato da face e de seus elementos específicos, como a boca, olhos e nariz, identificando métricas precisas (por exemplo, posição, distância) entre eles.

Estas evidências psicológicas foram determinantes na escolha de métodos baseados em características geométricas para a modelagem da face humana proposta nesta tese, uma vez que o objetivo é desenvolver uma abordagem biologicamente inspirada, fundamentada em conceitos da psicologia e biologia. É importante destacar também que a análise computacional de alterações na disposição dos elementos faciais é mais vantajosa, pois estas podem ser facilmente obtidas, independente da resolução da imagem analisada, e não dependem de mudanças na textura da face, o que muitas vezes é de difícil detecção (Martinez and Neth, 2010). 
A Figura 4.3 exemplifica a maneira como os seres humanos interpretam as expressões faciais emocionais. Ela mostra diferentes imagens da expressão neutra mas, por apresentarem alterações na configuração espacial de seus elementos, os seres humanos as percebem, respectivamente, como expressando raiva, tristeza, surpresa e aversão. Isto porque o sistema visual humano aprendeu que as faces geralmente não têm a aparência apresentada nesta figura. Pelo contrário, as distâncias entre as sobrancelhas, o nariz, a boca e o contorno da face seguem um padrão, que não está sendo obedecido. Por exemplo, na face supostamente triste, a distância entre as sobrancelhas e a boca é maior que o normal e a face é mais fina que o usual. Isto a deixa fora do padrão facial de pessoas caucasianas. A percepção de raiva é aumentada quando, de acordo com este padrão, a face é mais larga e a distância entre sobrancelhas e boca é menor. A face com aparência de surpresa está mais fina que o esperado, e apresenta uma distância maior entre olhos e sobrancelhas, ao passo que a face de aversão possui distâncias menores entre sobrancelhas, olhos, nariz e boca.

Apesar da grande influência da configuração dos elementos da face na percepção das expressões emocionais, é possivel observar que apenas alterações na configuração destes elementos muitas vezes não são suficientes para a obtenção de expressões realísticas, sendo necessário, em alguns casos, mudanças no formato dos elementos faciais. Como exemplo, pode-se citar a inclusão dos olhos bem abertos na expressão de surpresa, que não ficou natural na imagem apresentada na Figura 4.3, demonstrando também a sensação de desinteresse ou sonolência (Martinez and Du, 2012).
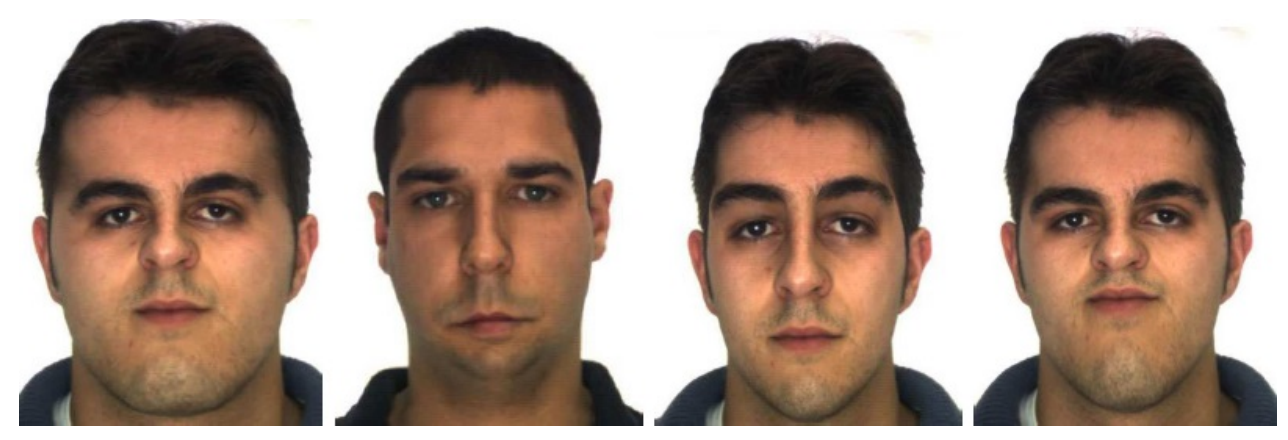

Figura 4.3: As quatro imagens são da expressão neutra, porém, a maioria da pessoas as interpretam, respectivamente, como expressões de raiva, tristeza, surpresa e aversão (Martinez and Du, 2012).

No trabalho de Martinez and Neth (2010), os autores demonstraram que a distância vertical entre as sobrancelhas e a boca influencia na percepção das expressões de raiva e tristeza. Quando esta distância é menor que o padrão, aumenta a percepção de raiva, quando é maior que o padrão, a percepção de tristeza é aumentada. O mesmo é verdade para a proporção entre a largura e a altura de uma face. Quando a distância vertical entre a parte superior e inferior da face diminui, a percepção de raiva é aumentada e de tristeza é diminuída. Neste sentido, os 
autores concluíram que as alterações na configuração dos elementos faciais (relação de segunda ordem) compõem, ao menos, uma parte do espaço computacional que pode ser utilizado para representar as expressões faciais de emoção. É importante notar que estas alterações na configuração estão relacionadas com a movimentação muscular e, portanto, podem ser utilizadas para determinar uma emoção ou uma UA facial, sem prejuízo de análise.

Diversos estudos psicológicos (Joyce et al., 2006; Schyns et al., 2009; Martinez and Neth, 2010; Martinez and Du, 2012; Scheller et al., 2012) evidenciam também que os seres humanos olham para locais específicos da face para identificar as emoções. Estes locais apresentam características de diagnóstico, ou seja, características que são importantes para a análise de expressões emocionais. Adicionalmente, estudos demonstram que estas características são diferentes para cada uma das seis emoções básicas. Por exemplo, os olhos bem abertos têm maior relação com a expressão de medo, o enrugamento dos cantos do nariz com a aversão e a boca aberta com a alegria. Neste sentido, os olhos bem abertos são suficientes para a expressão de medo quando o objetivo é discriminá-la da expressão de alegria, mas os olhos e a boca devem ser analisados se o objetivo é discriminar o medo da surpresa (Smith et al., 2005).

No trabalho de Joyce et al. (2006), a importância das características de diagnóstico é analisada. Para isso, faces compostas apenas pelas características de diagnóstico, e faces que possuem apenas o complemento destas características, foram apresentadas aos participantes, que precisavam identificar a expressão facial emocional de um indivíduo. As características de diagnóstico foram obtidos utilizando a técnica Bubbles (Smith et al., 2005). Os experimentos demonstraram que a apresentação das características de diagnóstico melhora não apenas a capacidade de identificação das expressões, mas também o tempo de resposta.

Os autores também procuraram identificar o momento que as características de diagnóstico são processadas durante a execução da tarefa. Para isso, eles analisaram uma grande negatividade occipito-temporal, comumente denominada N170 ou occipito-temporal $\mathrm{N} 1$, que estudos indicam estar relacionada com os processos iniciais de categorização visual. De acordo com os experimentos, quando uma face é apresentada, as concentrações de N170 são fortemente aumentadas se comparadas com a apresentação de estímulos visuais não faciais. Desse modo, o N170 aparenta ser o responsável por discriminar as faces de outros objetos, sugerindo que existe um conjunto de processos iniciais relacionados com a identificação da face que, independentemente da tarefa em questão e da expressão emocional observada, direciona a atenção para características de diagnóstico específicas.

De acordo com Schyns et al. (2009), o processo de escaneamento facial para reconhecer emoções apresenta um padrão pré-definido: A primeira etapa começa aproximadamente 140ms após o início do estímulo, e a atenção é direcionada aos 
olhos, independente da expressão. Em torno de 156ms, uma segunda etapa direciona a atenção para a face como um todo, também independente da expressão. Em seguida, em torno de $180 \mathrm{~ms}$, a atenção é direcionada a diferentes regiões da face identificando, assim, as características de diagnóstico. Nesta terceira etapa, diferentes características são codificadas para cada expressão emocional.

Os autores concluíram que o direcionamento da atenção para extrair as características faciais de diagnóstico é controlado por algum mecanismo cognitivo top-down. O foco da atenção é um conjunto de características relevantes como, por exemplo, o enrugamento dos cantos do nariz para a expressão de aversão. Analisando informações cerebrais, os autores encontraram ainda mais evidências para orientação top-down da atenção para as características de diagnóstico, pois identificaram que o processo de representar as expressões faciais no cérebro termina com o reconhecimento das características de diagnóstico, de forma independente, nos hemisférios esquerdo e direito.

Em outro trabalho (Scheller et al., 2012), é feita uma análise se as características faciais de diagnóstico continuam sendo o foco da atenção mesmo quando são irrelevantes para a tarefa a ser executada, ou quando as faces estão localizadas em diferentes regiões do campo visual. Para este objetivo, foram monitorados os movimentos dos olhos e padrões de fixação do olhar. Dois experimentos distintos foram realizados, nos quais os participantes teriam que classificar as expressões faciais neutra, de medo ou de alegria. No primeiro experimento, as faces foram apresentadas em um mesmo local do campo visual, ao passo que no segundo experimento, elas foram apresentadas em diferentes localizações do campo visual, para verificar se a atenção dos participantes era direcionada para as características de diagnóstico encontradas, ou se apenas existia um padrão natural de fixação do olhar para posições específicas do campo visual.

Como resultado dos experimentos, os participantes fixaram a região dos olhos por muito mais tempo que qualquer outra região da face. Neste sentido, a região dos olhos teve maior foco de atenção quando as expressões neutra e de medo eram apresentadas, ao passo que o foco da atenção foi também direcionado para a boca quando da análise de faces alegres. Este comportamento indica um padrão, no qual a região dos olhos sempre obtém o maior foco de atenção para, em seguida, a atenção ser direcionada para as características de diagnóstico de cada uma das expressões avaliadas.

Os autores analisaram também se este comportamento pode ter sido induzido por características das imagens utilizadas. Para isso, repetiram os experimentos mas, desta vez, garantindo que todas as regiões das imagens possuíam valores semelhantes de saliência. No entanto, para estas imagens, os mesmos resultados foram obtidos, indicando que os participantes realmente direcionam a atenção do olhar de acordo com as diferentes características de diagnóstico encontradas nas 
expressões faciais em análise. Ainda, mesmo quando as faces eram rapidamente apresentadas, não propiciando tempo hábil aos participantes para mudar a fixação inicial do olhar antes do término do estímulo, o número de classificações corretas das expressões emocionais pouco foi alterado, demonstrando que a face como um todo é percebida.

Deste modo, os autores destacam que as expressões emocionais são detectadas muito rapidamente, mesmo quando o olhar não pode ser direcionado para as características de diagnóstico. No entanto, a tendência natural de direcionar o olhar para estas características mostra que a atenção visual é automaticamente orientada para elas mesmo quando a mudança da fixação do olhar não contribui diretamente para o reconhecimento emocional. Assim, como o foco de atenção fica evidente logo no início do estímulo visual, e é semelhante mesmo quando os participantes não puderam mudar a direção inicial do olhar, é possivel afirmar que os seres humanos possuem um mecanismo de pré-atenção visual, que detecta a expressão emocional para, em seguida, direcionar a atenção para as características faciais relevantes. Ainda, notou-se que as expressões faciais emocionais recebem maior foco de atenção que as expressões neutras. Neste sentido, os autores concluíram que as características de diagnóstico são o foco de atenção principal do olhar, independente da tarefa executada ou localização que a face ocupa no campo visual.

Com o objetivo de simular o mecanismo de reconhecimento das expressões emocionais evidenciado pela psicologia, que faz com que os seres humanos direcionem a atenção do olhar para regiões específicas da face, procurando pelas características de diagnóstico que melhor identificam o estado emocional de um indivíduo, este trabalho propõe a utilização de técnicas de seleção de características.

Espera-se que estas técnicas atuem como um mecanismo top-down de direcionamento da atenção para as características de diagnóstico. Vale lembrar que, embora a psicologia tenha identificado as regiões faciais que recebem o maior foco da atenção e influenciam, de maneiras distintas, no processo de reconhecimento de emoções por meio da análise de expressões faciais, a determinação das características específicas envolvidas neste processo ainda não é possível. Ademais, embora existam diversos estudos psicológicos sobre este tema, ele ainda é pouco investigado em computação (Yang et al., 2009).

Além disso, podem ser encontradas evidências psicológicas demonstrando que, mesmo quando as faces são rapidamente observadas pelos seres humanos e o olhar não é direcionado para as características de diagnóstico, as emoções já são percebidas. Provavelmente isto acontece devido à existência de um mecanismo de pré-atenção visual que automaticamente detecta as características faciais relevantes. Sendo assim, este trabalho investiga a utilização de mapas de saliência e imagens térmicas para simular este mecanismo. 


\subsection{Trabalhos sobre Reconhecimento Emocional}

Como a modelagem proposta utiliza diferentes teorias psicológicas para reconhecer as expressões emocionais investigadas, não foram encontrados, na literatura, trabalhos que utilizem os mesmos conceitos para identificar as emoções humanas. No entanto, exemplos de propostas semelhantes podem ser vistos em Khan et al. (2011) e Khan et al. (2013).

Deste modo, Khan et al. (2013) desenvolveram uma arquitetura inspirada no funcionamento do sistema de visão humano que reconhece as seis emoções básicas. Para isso, um experimento foi realizado com o aparelho de eye-tracker, identificando as diferentes regiões faciais associadas às expressões investigadas. Em seguida, a análise das texturas destas regiões foi feita pela aplicação do método Pyramid of Local Binary Patterns (PLBP), produzindo a representação da face.

Nesta arquitetura, as emoções foram analisadas em duas etapas. Inicialmente, o classificador deve escolher entre as emoções de alegria, tristeza e surpresa, que possuem apenas a região da boca como saliente, ou as emoções de raiva, medo e aversão, com duas ou mais regiões salientes. Se um exemplo for atribuído ao primeiro grupo, uma análise subsequente é realizada para decidir entre as três opções emocionais, e apenas as características da região da boca são extraídas. Caso o exemplo seja classificado como pertencente ao segundo grupo, a emoção é obtida pela análise de características da região dos olhos e sobrancelhas, avaliadas em conjunto com as previamente encontradas para a região da boca.

As taxas médias de acerto obtidas pelos experimentos realizados com a base $\mathrm{CK}+\mathrm{e}$ cinco diferentes classificadores foram de 94,7\%, 96,2\%, 97,9\% e 90,2\%, respectivamente, para os algoritmos C4.5, Random Forest (RF), 2-Nearest Neighbor (2NN) e Nä̈ve Bayes (NB), e de 96,7\% para as SVMs, com desempenho médio de $95,1 \%$. Já no teste de generalização da arquitetura, para o treinamento realizado com a base $\mathrm{CK}+\mathrm{e}$ os testes com a base FG-NET, os resultados encontrados foram, respectivamente, para as SVMs e algoritmos C4.5, RF e 2NN, de 81,9\%, 74,8\%, $79,5 \%$ e $83,1 \%$. Apresentando desempenho médio de 79,8\%. Considerando o treinamento com a base FG-NET e os testes com a base $\mathrm{CK}+$, as taxas de acerto foram 80,5\%, 77,3\%, 79\% e 84,7\%, respectivamente, para as SVMs e os algoritmos C4.5, RF e $2 \mathrm{NN}$, com acerto médio de $80,4 \%$.

Khan et al. (2011) também propuseram uma arquitetura baseada no sistema de visão humano, que analisa somente as regiões faciais salientes identificadas pelo eye-tracker. Para obter a saliência, o algoritmo Frequency-tuned Salient Region Detection foi aplicado. Em seguida, as regiões do mapa de saliência que correspondem às obtidas pelo eye-tracker foram processadas para extrair as medidas de entropia e brilho, utilizadas nos vetores de características representativos da face.

Os experimentos foram feitos com o classificador SVM e a base de dados CK+. No primeiro deles, somente características da boca foram utilizadas para identificar 
a alegria, a surpresa e a tristeza, pois, de acordo com o eye-tracker, apenas esta região se mostrou saliente na análise das emoções citadas. O desempenho médio encontrado foi de $78,5 \%$, em que a surpresa obteve a melhor classificação, e a tristeza, a pior. No segundo experimento, os autores avaliaram as características das regiões dos olhos, nariz e boca, também definidas pelo eye-tracker, para reconhecer o medo, a raiva e a aversão. O acerto médio obtido foi de $70,8 \%$, e as três emoções investigadas apresentaram taxas de erro semelhantes.

Considerando os trabalhos que identificam as emoções pela análise da face, sem a necessidade de inspiração biológica ou psicológica, a utilização de algoritmos não supervisionados, abordagem empregada para o desenvolvimento do mecanismo de pré-atenção é, de acordo com a literatura, menos utilizada (Khan et al., 2004; Zhao et al., 2007; Zhou et al., 2008b;a; Ghahari et al., 2009; Mitra et al., 2011). Deste modo, a maioria se vale de algoritmos supervisionados (Caridakis et al., 2007; Valstar, 2008; Li et al., 2008; Shih et al., 2008; Shan et al., 2009; Paleari et al., 2010; Khan et al., 2011; Sarvadevabhatla et al., 2011; Khan et al., 2013), semelhante à proposta desta tese para a análise das características faciais de diagnóstico.

Assim, no contexto do paradigma não supervisionado, Khan et al. (2004) utilizaram testes estatísticos multivariados em imagens térmicas para identificar 75 pontos da face humana que, pela análise das variações de temperatura, foram capazes de representar as expressões neutra, de alegria, aversão e tristeza. Utilizando a técnica Linear Discriminant Analysis (LDA), os autores demonstraram que as três primeiras componentes produziram partições bem definidas para as expressões avaliadas.

No trabalho de Mitra et al. (2011), o algoritmo de fluxo ótico foi aplicado à face para encontrar regiões que se deformam devido à ativação muscular produzida pelas seis emoções básicas. De acordo com os resultados deste algoritmo, os autores obtiveram 13 diferentes regiões faciais de interesse (RFIs), que foram divididas em quatro quadrantes. A magnitude do fluxo ótico de cada quadrante foi utilizada para calcular medidas estatísticas como média, desvio-padrão, dentre outras, responsáveis pela representação facial. A base de dados avaliada era composta por 50 exemplos de expressões faciais de indianos, dez para cada emoção, e o algoritmo fuzzy c-means foi investigado para obter o agrupamento dos dados.

A análise das expressões emocionais consideradas, utilizando vetores de características com dados de todas as RFIs, resultou em baixo reconhecimento, de apenas 43,3\%. Para melhorar este desempenho, os autores definiram vetores distintos, em que diferentes subconjuntos destas RFIs foram associados a cada uma das expressões emocionais. Com isso, as taxas de acerto foram de $100 \%$ para a alegria, $70 \%$ para a tristeza, $90 \%$ para a raiva e $80 \%$ para as demais emoções, obtendo acerto médio de $83,3 \%$.

Ainda, em Zhou et al. (2008b), o algoritmo de agrupamento Support Vector 
Clustering (SVC) foi utilizado para identificar as expressões emocionais existentes na base de dados Japanese Female Facial Expression (JAFFE). A representação facial foi obtida pela aplicação da transformada de Gabor somente às regiões da boca, dos olhos e das sobrancelhas. Em seguida, os autores realizaram diferentes experimentos com o algoritmo SVC, até a obtenção de um conjunto de parâmetros capaz de produzir um agrupamento que adequadamente separasse as seis emoções básicas e a expressão neutra.

Podem ser encontrados também trabalhos que utilizam a abordagem não supervisionada para representar as expressões emocionais, empregando algoritmos supervisionados para classificá-las. Neste sentido, uma extensão do trabalho anterior pode ser vista em Zhou et al. (2008a), em que os autores desenvolveram o algoritmo Locally Constrained Support Vector Clustering (LCSVC) para agrupar as expressões emocionais em diferentes partições, e uma extensão supervisionada, denominada Locally Constrained Support Vector Clustering Neural Network (LCSVCNN), para realizar a classificação. A representação da face foi obtida pela aplicação do método Independent Component Analysis (ICA).

O algoritmo não supervisionado LCSVC minimiza os ruídos existentes nos dados analisados pela aplicação do método Mixture of Factor Analyzers (MFA) para, em seguida, aplicar o algoritmo SVC. Já o algoritmo supervisionado LCSVCNN funciona, basicamente, como uma rede neural que interpreta as informações das partições encontradas pelo algoritmo LCSVC e obtém a classificação das diferentes emoções avaliadas. O desempenho médio observado, considerando as sete expressões da base de dados JAFFE, foi de 96,2\%, com 100\% de reconhecimento para a alegria e a aversão.

Do mesmo modo, em Ghahari et al. (2009), um método para a extração das características faciais baseado em agrupamentos foi proposto. Neste trabalho, as características faciais foram extraídas pelo algoritmo Canny Edge, que utiliza o operador Nonmaxiam Suppression (NMS) e operações duplas de limiar para construir os agrupamentos de características. Assim, um procedimento semelhante ao realizado por algoritmos de agrupamento hierárquico foi executado, ou seja, as partições iniciais foram sucessivamente divididas até a obtenção de 15 a 30 partições, sem sobreposição, que eram unidas para compor o vetor de características representativo da face.

Com o objetivo de garantir este número de partições, a região retangular que delimita a face foi gradativamente reduzida, direcionando a busca do algoritmo Canny Edge para os elementos faciais mais relevantes. Como resultado deste procedimento, diferentes pontos característicos foram obtidos para representar cada uma das seis emoções básicas. Os experimentos realizados com a base de dados $\mathrm{CK}+$ e uma rede MLP como classificador apresentaram taxas de acerto de 79,6\% para a alegria, 97,9\% para a surpresa e a tristeza, e 100\% para as emoções de medo, raiva 
e aversão, com desempenho médio de 95,7\%.

Dentre os trabalhos em que a análise das emoções é feita por algoritmos supervisionados, os métodos baseados em aparência são mais predominantes (Anderson and McOwan, 2006; Hu et al., 2008; Wang et al., 2008; Li et al., 2008; Shih et al., 2008; Rabie et al., 2008; Shan et al., 2009; Orrite et al., 2009; Wang et al., 2010; Lucey et al., 2010; Dahmane and Meunier, 2011; Sarvadevabhatla et al., 2011; Khan et al., 2013; Chen et al., 2013) se comparados aos métodos baseados em geometria (Cohen et al., 2003; Khan et al., 2006; Kotsia and Pitas, 2007; Caridakis et al., 2007; Valstar, 2008; Khan et al., 2009; Yang et al., 2009; Paleari et al., 2010; Sheerman-Chase et al., 2013). Nesta tese, apenas métodos baseados em geometria são utilizados na etapa supervisionada e, por isso, alguns trabalhos que se valem destes métodos são descritos a seguir.

Considerando as imagens térmicas, Khan et al. (2006) empiricamente dividiram a face em diferentes quantidades de blocos e, pela análise das variações de temperatura, obtiveram 75 pontos relevantes para a identificação das expressões de alegria, tristeza e neutra. Neste trabalho, uma base de dados própria, composta por imagens térmicas de 16 participantes, foi avaliada pelos autores. As taxas de reconhecimento encontradas foram de $81,3 \%$ para a alegria e a tristeza, e de $87,5 \%$ para a expressão neutra, com desempenho médio de $83,4 \%$.

Uma extensão do trabalho anterior foi descrita em Khan et al. (2009). Nela, os autores desenvolveram diferentes classificadores para avaliar os mesmos 75 pontos, mas agora com uma base de dados obtida a partir de experimentos realizados com 10 participantes, contendo imagens térmicas de emoções espontâneas. Neste sentido, a análise das seis emoções básicas e da expressão neutra apresentou acerto médio de $57,2 \%$, em que os piores desempenhos foram observados para a raiva, a surpresa e a expressão neutra, e o melhor, de $87,5 \%$, foi encontrado para o medo. Na identificação somente das emoções de alegria, aversão, surpresa e raiva, um acerto médio de $67,2 \%$ foi obtido, com elevada taxa de reconhecimento para a surpresa, e baixa para a aversão. Em uma última análise, os autores avaliaram a expressão neutra e as emoções de alegria, tristeza, aversão e raiva. Neste experimento, a tristeza foi a emoção melhor classificada, ao passo que as demais apresentaram resultados semelhantes. Assim, um desempenho médio de $72 \%$ foi encontrado.

No contexto das imagens visiveis, Cohen et al. (2003) identificaram as seis emoções básicas a partir da análise de vídeos. Duas abordagens foram utilizadas: na primeira delas, cada frame do vídeo foi isoladamente classificado como uma emoção. Na segunda, a dinâmica temporal das expressões emocionais, ou seja, as relações entre as características faciais de cada frame do vídeo, foi considerada. Uma malha tridimensional composta por 16 superfícies contínuas, responsáveis pela modelagem das deformações produzidas pela movimentação muscular, foi utilizada para representar a face. Para esta malha construir um modelo facial adequado, 
era necessário que os autores manualmente indicassem informações como, por exemplo, a posição dos olhos, boca e contornos, para a obtenção de 12 vetores de deformação facial, que representavam a ativação, a direção e a intensidade dos diferentes movimentos mapeados.

Na primeira abordagem, foram avaliados o classificador Naïve Bayes com as distribuições gaussiana (NB-G) e de Cauchy (NB-C), além do classificador Gaussian Tree-Augmented Nä̈ve Bayes (TAN). Modelos Ocultos de Markov (HMMs) e HMMs multiniveis, desenvolvidos pelos autores, foram empregados na segunda abordagem. O melhor desempenho obtido com uma base de dados produzida pelos autores, composta por expressões emocionais de cinco pessoas, foi de 66,5\%, e um acerto de $73,2 \%$ foi encontrado para a base $\mathrm{CK}^{+}$, ambos observados com o algoritmo TAN. Nestes experimentos, a alegria e a surpresa apresentaram as melhores taxas de reconhecimento.

No trabalho proposto por Kotsia and Pitas (2007), vídeos também foram analisados para reconhecer as seis emoções básicas diretamente das características avaliadas, ou a partir de um conjunto de unidades de ação (UAs) faciais previamente obtidas. A face foi descrita pelo modelo deformável Candide que, inicialmente, precisa do posicionamento manual de alguns de seus nós em locais como os olhos, as sobrancelhas e a boca, por exemplo, para possibilitar o correto mapeamento. $\mathrm{O}$ deslocamento geométrico dos nós do modelo, definido como a diferença entre as coordenadas de um nó no primeiro frame, e do mesmo nó no frame que representa o ápice da expressão emocional, foi utilizado para a representação facial.

Em diversos experimentos realizados com a base de dados $\mathrm{CK}^{+}$, foram avaliados o algoritmo SVM, assim como versões deste mesmo algoritmo propostas pelos autores. O modelo Candide completo, com 104 nós, e uma versão simplificada, que apresenta 62 nós, também foram analisados, além de conjuntos que possuíam oito ou 17 UAs. Deste modo, os experimentos que utilizaram as SVMs propostas pelos autores, a versão simplificada do modelo Candide, e o conjunto composto por oito UAs produziram os melhores desempenhos. O reconhecimento emocional obtido pela análise das UAs apresentou acerto médio de 95,1\%, e as piores classificações foram observadas para aversão, raiva e tristeza. Já a identificação das emoções com base nas características faciais mapeadas foi de 99,7\%, em que raiva e tristeza apresentaram os piores desempenhos.

Um sistema para reconhecer as seis emoções básicas e movimentos faciais musculares, descritos por 23 UAs, foi apresentado em Valstar (2008). Vídeos da base de dados $\mathrm{CK}+$ foram avaliados. Para o reconhecimento emocional, 20 pontos característicos da face foram mapeados, e dois conjuntos de dados, construídos. O primeiro possuía as coordenadas destes pontos, assim como as distâncias e ângulos obtidos por todas as possíveis combinações existentes entre eles. O segundo apresentava as mesmas informações, mas considerando as diferenças entre o frame atual do vídeo 
em análise e o frame imediatamente anterior, assim como as diferenças entre o frame atual e o frame associado à expressão neutra.

Estes conjuntos de dados tiveram os principais atributos selecionados pelo algoritmo GentleBoost, e as SVMs foram utilizadas como classificadores. As melhores taxas de acerto obtidas foram de 94,8\% para raiva e aversão, 92,2\% para o medo, 96,7\% para a alegria, 93,5\% para a tristeza e 96,7\% para a surpresa, com desempenho médio de 94,8\%. A identificação das emoções também foi feita a partir das 23 UAs previamente encontradas. Para classificar as UAs, os conjuntos citados tiveram sua dimensionalidade reduzida pelo algoritmo GentleBoost e foram avaliados por Cascade-SVMs. Em seguida, para mapear as UAs em emoções, duas abordagens diferentes foram propostas: a primeira utilizava uma rede MLP, e a segunda, um sistema baseado em regras. Como resultado deste experimento, foi observado que a análise das características extraídas diretamente da face apresentou taxas de reconhecimento $2,2 \%$ superiores às obtidas pelo mapeamento das UAs em emoções, utilizando a rede MLP.

A identificação das regiões faciais mais significativas para o reconhecimento emocional é objeto de estudo de diversos trabalhos psicológicos. Deste modo, Smith et al. (2005); Calvo and Nummenmaa (2008); Schyns et al. (2009) e Scheller et al. (2012) são apenas alguns exemplos. Em computação, o desenvolvimento de algoritmos de seleção de características para a análise das expressões emocionais pode resultar, indiretamente, na obtenção de regiões faciais representativas (Ma and Wang, 2005; Shan et al., 2009; Orrite et al., 2009; Sarvadevabhatla et al., 2011). No entanto, a investigação específica deste tema ainda é recente, e um número menor de trabalhos pode ser encontrado (Yang et al., 2009; Paleari et al., 2010; Wang et al., 2012; Sheerman-Chase et al., 2013).

Assim, em Yang et al. (2009), os autores desenvolveram um algoritmo de seleção de características baseado na teoria matemática de rough sets, para identificar os principais elementos faciais que descrevem as seis emoções básicas e a expressão neutra. A modelagem geométrica foi utilizada e 52 pontos, relacionados a parâmetros de animação facial existentes no sistema MPEG-4, foram mapeados. A partir destes pontos, 33 características faciais, representadas por diferentes distâncias, foram obtidas, sendo 17 relativas aos olhos, seis associadas às bochechas e dez relacionadas à boca. As SVMs avaliaram os exemplos das bases de dados CK+, JAFFE e CQUPTE.

Quatro diferentes algoritmos de seleção: algoritmo genético (AG), CEBARKNC, MIBARK e SARA, este último proposto pelos autores, foram aplicados ao conjunto original, com 33 características. Ainda, dois novos conjuntos, que possuíam, respectivamente, todas as características, exceto aquelas encontradas na região da boca, e todas as características, exceto as que representam a região dos olhos, assim como o conjunto original, foram utilizados nos experimentos. A seleção de características considerou, para cada base de dados, todas as expressões emocionais, ou seja, 
não foi feita uma análise individual de cada expressão. Neste sentido, o melhor desempenho encontrado para as três bases de dados foi de $82,7 \%$, obtido com o conjunto original. Em seguida, o algoritmo SARA apresentou bons resultados, destacando-se com $79,3 \%$ de acerto.

Dentre as características selecionadas pela análise das diferentes bases consideradas, o AG não obteve características comuns a todas as bases de dados. Neste sentido, três foram encontradas pelo algoritmo SARA, duas pelo algoritmo CEBARKNC e outras duas pelo algoritmo MIBARK. Vale destacar que somente uma destas características pertencia à região dos olhos. Deste modo, os autores concluíram que a região da boca é a mais importante para o reconhecimento emocional, baseados não apenas nas características evidenciadas pelos algoritmos de seleção, mas também pelo fato do conjunto de dados que não considerou esta região ter apresentado desempenho próximo a 55\%, muito inferior a todos os demais. As três características obtidas pelo algoritmo SARA foram as distâncias entre os cantos direito e esquerdo da boca, entre os lábios superior e inferior, e entre o centro das narinas e o queixo.

Já no trabalho de Paleari et al. (2010), os autores apresentaram uma investigação detalhada sobre a importância de diferentes atributos na identificação emocional. A base de dados eNTERFACE'05, na qual as seis emoções básicas são representadas por áudio e vídeo, foi utilizada. As características relacionadas à análise da voz não serão discutidas pois fogem ao escopo desta tese. Para a análise das expressões faciais, métodos baseados em geometria foram empregados. Deste modo, 12 regiões de interesse foram obtidas, a partir das quais foi realizada a extração das características, que consistiram de 12 pontos, um para cada região de interesse, e de 14 distâncias, mapeadas entre estes pontos. Redes MLP foram utilizadas nos experimentos.

Para cada emoção, as coordenadas dos 12 pontos foram avaliadas separadamente, assim como mais quatro conjuntos de dados, que consistiam de pontos da região da boca, da região dos olhos, pontos que descreviam a região do nariz, e aqueles localizados na região central da face, que representam o nariz e a testa. Também foi feita uma análise individual das 14 distâncias, assim como de mais três conjuntos contendo, respectivamente, as distâncias pertencentes à região da boca, aquelas encontradas na região dos olhos, e as distâncias que representam movimentos da cabeça.

Dentre as características obtidas pelos autores, a região dos olhos melhor definiu as emoções de aversão e surpresa, embora, para esta última, vários atributos distribuídos pela face tenham apresentado bom desempenho. Os deslocamentos de cabeça, assim como o alinhamento das sobrancelhas, influenciaram no correto reconhecimento da raiva e do medo. Para a alegria, a região da boca foi de extrema importância e, na análise da tristeza, todas as características apresentaram bom de- 
sempenho. Uma descrição mais detalhada pode ser vista no trabalho dos autores. $\mathrm{O}$ sistema desenvolvido para identificar as emoções utilizou as melhores características encontradas na análise da voz e das expressões faciais, e obteve taxas de acerto de $99 \%$ para a alegria, $87 \%$ para a raiva, $75 \%$ para o medo, $64 \%$ para a tristeza, $60 \%$ para a aversão e $41 \%$ para a surpresa, com desempenho médio de $71 \%$.

Do ponto de vista psicológico, Scheller et al. (2012) avaliaram o direcionamento da atenção para as características de diagnóstico durante o reconhecimento emocional. As expressões neutra, de alegria e de medo foram consideradas. Com a utilização do aparelho de eye-tracker, mapas de fixação do olhar foram obtidos e comparados a mapas de saliência. As diferenças encontradas evidenciaram que o comportamento observado para a fixação do olhar não segue os padrões encontrados pelos mapas de saliência. Deste modo, os autores concluíram que a saliência não deve ser a única responsável pelo direcionamento da atenção durante a análise das expressões investigadas, e somente a existência de algum mecanismo cognitivo top-down permitiria justificar os padrões de fixação observados. A Figura 4.4 apresenta os distintos mapas de fixação e de saliência obtidos. Nela, quanto mais as cores se aproximam do vermelho, maior é o foco da atenção.

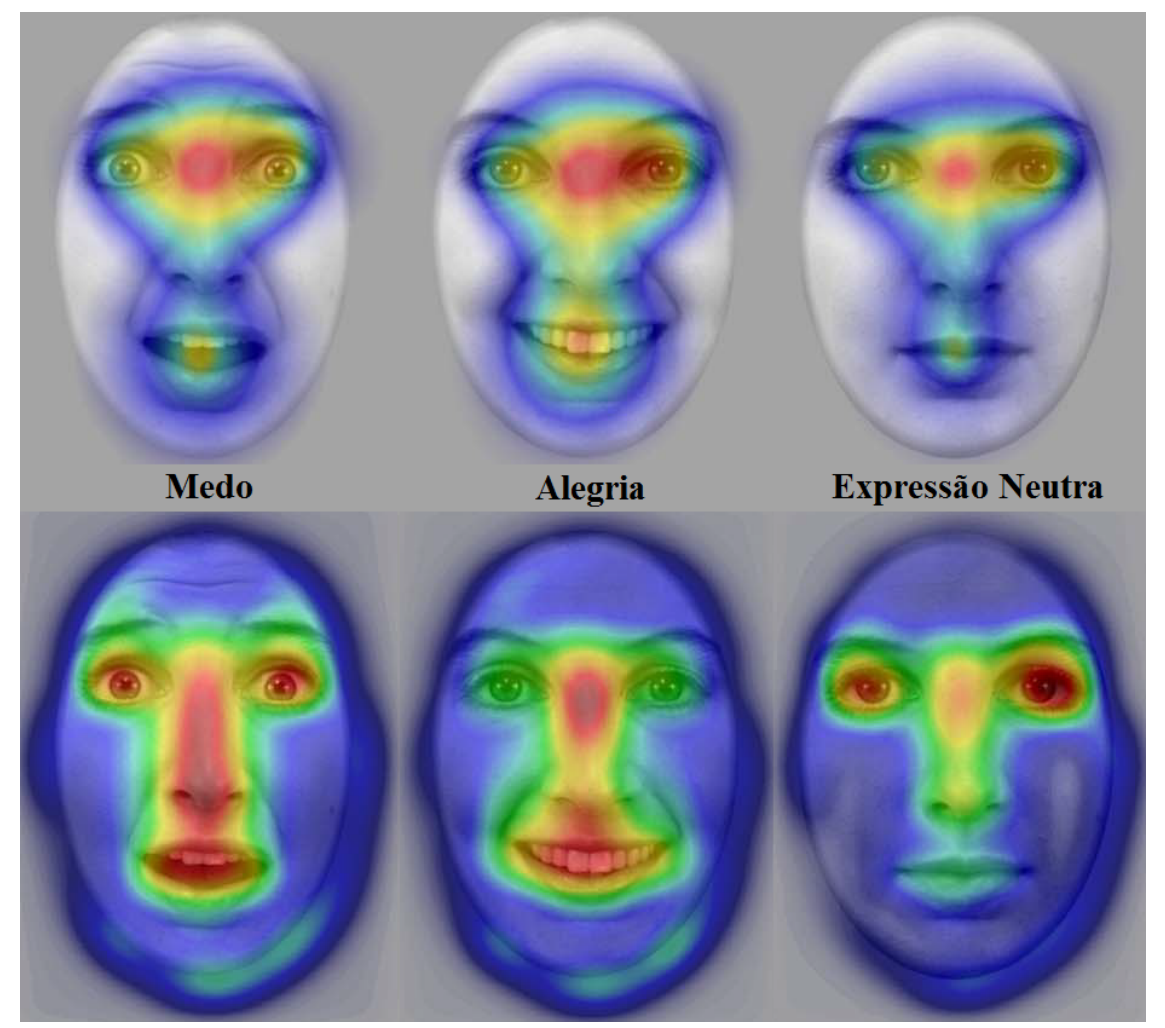

Figura 4.4: Acima são apresentados os mapas de fixação do olhar e, abaixo, os respectivos mapas de saliência (Scheller et al., 2012).

Do mesmo modo, Smith et al. (2005) e Schyns et al. (2009) também analisaram as diferentes regiões faciais de diagnóstico, mas agora para identificar a expressão neutra e as seis emoções básicas. Nestes trabalhos, com a utilização da técnica Bubbles, desenvolvida pelos autores, experimentos psicológicos foram 
realizados com diferentes participantes, em que regiões distintas da face eram, progressivamente, apresentadas, até que um acerto mínimo de $75 \%$ fosse observado para a categorização de cada expressão avaliada. Deste modo, as principais regiões necessárias para o reconhecimento emocional foram encontradas. Em seguida, um modelo facial para cada expressão em análise também foi produzido pela técnica Bubbles, garantindo 75\% de classificações corretas. Os resultados dos experimentos psicológicos, assim como os modelos definidos pelo Bubbles, podem ser vistos na Figura 4.5, em que é possivel notar que as regiões obtidas são semelhantes.
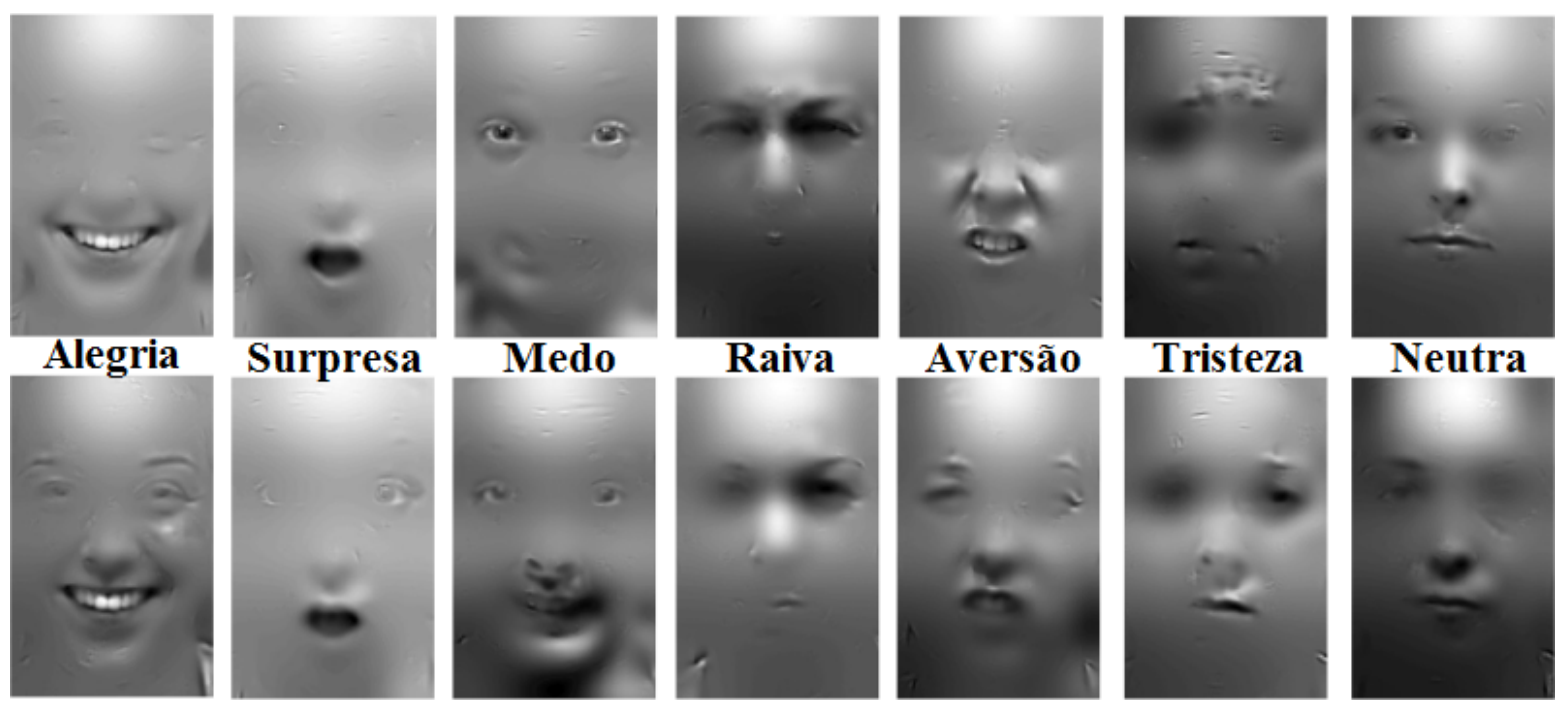

Figura 4.5: Comparação entre as regiões faciais obtidas pelos experimentos psicológicos (acima) e pela técnica Bubbles (abaixo) (Smith et al., 2005).

Considerando os trabalhos apresentados, que investigam os elementos faciais importantes para classificar as emoções, é possivel encontrar diferenças entre os estudos psicológicos e a análise computacional. Enquanto os primeiros são capazes de identificar as principais regiões envolvidas no reconhecimento das emoções, a computação, em geral, utiliza métodos baseados em geometria para modelar a face e, assim, precisamente encontrar as características que melhoram o desempenho dos classificadores avaliados. Neste sentido, dentre os trabalhos computacionais, cada abordagem proposta encontra distintas características de diagnóstico. Isto pode ser explicado por diferenças nas representações, algoritmos ou metodologias utilizados. Ainda, a maioria deles não se preocupa em validar os resultados obtidos com aqueles apresentados pela psicologia.

\subsection{Considerações Finais}

As expressões faciais são importantes mecanismos de interação interpessoal e convívio em sociedade. Se o objetivo é a identificação do estado afetivo de um indivíduo, existem evidências que a análise destas expressões é suficiente para realizar tal tarefa. Existem diferentes métodos de modelagem facial para a extração 
das características que serão utilizadas pelos algoritmos computacionais. Neste sentido, uma correta modelagem facial determina o grau de sucesso da abordagem proposta.

Os principais métodos utilizados são baseados em características geométricas ou em aparência. Neste trabalho, a escolha por métodos baseados em características geométricas para modelar a face humana advém da análise de estudos psicológicos que indicam que o sistema visual humano se baseia em alterações na configuração dos elementos faciais para categorizar as expressões faciais emocionais.

De forma complementar, durante o processo de reconhecimento emocional, os seres humanos direcionam o foco de atenção para locais específicos da face a procura das características de diagnóstico. Ainda, durante este processo, os estudos psicológicos apresentados também sugerem a utilização de um mecanismo de pré-atenção visual. Neste sentido, para simular o mecanismo de reconhecimento emocional humano, é proposta a utilização de técnicas de seleção de características e de imagens térmicas em conjunto com mapas de saliência.

Para finalizar, são descritos alguns trabalhos existentes na literatura que, assim como a modelagem desenvolvida, exploram a identificação de emoções pela análise facial. Deste modo, no próximo capítulo são apresentados os algoritmos utilizados nesta tese. 


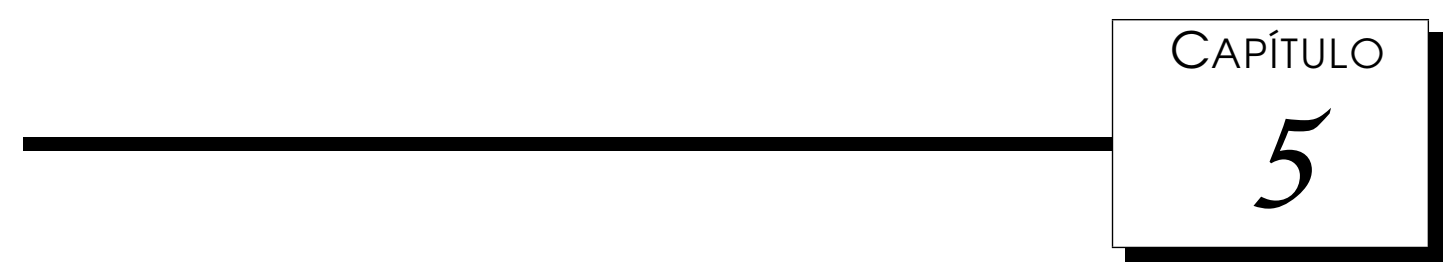

\section{Algoritmos e Métodos}

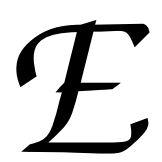

ste capítulo apresenta as diferentes técnicas computacionais e algoritmos de Aprendizado de Máquina (AM) investigados para o desenvolvimento de uma modelagem computacional, que se baseia em fundamentos biológicos e psicológicos, para simular o funcionamento do sistema de reconhecimento emocional dos seres humanos.

Para atuar de maneira semelhante ao sistema emocional humano, a modelagem computacional desenvolvida possui três partes distintas. A primeira representa a hipótese da existência de um mecanismo de pré-atenção visual que possibilita o reconhecimento emocional quase que instantaneamente, mesmo que a visualização da face aconteça por um curto espaço de tempo. A segunda etapa engloba as teorias psicológicas que sugerem a existência de características de diagnóstico distintas, que são o foco da atenção visual, ou seja, do direcionamento do olhar, para regiões específicas da face que possibilitam o reconhecimento de uma determinada emoção. Por fim, na terceira etapa, com base na modelagem geométrica da face, o reconhecimento emocional final é obtido.

O processo de reconhecimento emocional dos seres humanos é ainda foco de inúmeros estudos psicológicos para ser conhecido por completo. Portanto, diferentes algoritmos e métodos são utilizados para a modelagem computacional proposta. Deste modo, a Seção 5.1 descreve os métodos utilizados para simular o mecanismo de pré-atenção visual. Na Seção 5.2, são apresentados a área de AM, assim como os algoritmos investigados para a identificação das emoções por meio da análise facial. A Seção 5.3 explica conceitos sobre seleção de características e detalhes do procedimento empregado para obter as características faciais de diagnóstico. Finalmente, as considerações finais deste capítulo podem ser vistas na Seção 5.4. 


\subsection{Mecanismo de Pré-atenção Visual}

Podem ser encontrados estudos psicológicos que evidenciam a capacidade dos seres humanos de identificar a emoção de um usuário, mesmo quando a face é observada por um curto período de tempo e o foco da atenção, representado pela direção do olhar, não pode ser direcionado a regiões faciais específicas. Este comportamento pode ser atribuído possivelmente à existência de um mecanismo de pré-atenção visual.

A atenção visual geralmente é medida pelo mapa de saliência de uma imagem, uma vez que existem provas de que os objetos de interesse são visualmente salientes (Itti and Koch, 2001). Ademais, do ponto de vista neurobiológico, a saliência de todo um campo visual é alcançada de maneira pré-atencional, tornando-a um rápido mecanismo de atenção visual (Itti and Koch, 2001). Devido a esta característica, é possível que o mecanismo de pré-atenção visual humano utilize informações provenientes da saliência. Baseado nestas evidências, as imagens visíveis não são avaliadas. Em contrapartida, o mapa de saliência destas imagens é analisado pois a saliência representa a capacidade de regiões específicas da imagem atraírem a atenção visual, ou seja, a direção do olhar. Desta forma, pretende-se biologicamente fundamentar a modelagem do mecanismo de pré-atenção visual.

Adicionalmente, mapas de saliência vêm sendo utilizados em diversos trabalhos, como detecção de objetos ou de faces (Elazary and Itti, 2008; Wang et al., 2010; El-Barkouky et al., 2012), estimativa da direção do olhar (Valenti et al., 2012), descrição do comportamento da fixação do olhar durante o reconhecimento de expressões faciais emocionais (Boccignone and Ferraro, 2010), assim como para o reconhecimento de expressões faciais emocionais (Khan et al., 2011; Sarvadevabhatla et al., 2011).

Uma análise da literatura também permite notar que a maioria dos trabalhos utiliza vídeos ou imagens visíveis, ou seja, provenientes de uma câmera RGB, para a identificação das emoções por meio da análise facial (Kotsia and Pitas, 2007; Valstar, 2008; Khan et al., 2011). No entanto, o emprego de imagens térmicas, que medem variações na temperatura da pele, tem demonstrado que elas são adequadas para o reconhecimento de expressões faciais emocionais (Khan et al., 2004; 2006; Wang et al., 2008; Khan et al., 2009; Nhan and Chau, 2010; Wang et al., 2012). De fato, estas imagens complementam as principais deficiências encontradas na análise de imagens visíveis, pois são robustas a variações de luminosidade e à qualidade, ou resolução, da imagem, além do fato da detecção, localização e segmentação da face serem mais facilmente realizadas (Kong et al., 2005). Ainda, como o custo de aquisição das câmeras térmicas é cada vez menor, sua utilização têm se popularizado (Mekyska et al., 2010).

Com o objetivo de permitir à modelagem desenvolvida atuar com informações faciais complementares, que auxiliem na melhoria da identificação emocional, as 
imagens térmicas são utilizadas, embora esta escolha não tenha qualquer fundamentação psicológica. Estas imagens são avaliadas em conjunto com os mapas de saliência para aumentar a robustez do mecanismo de pré-atenção visual proposto. Vale destacar que abordagens híbridas, compostas por imagens térmicas e visíveis para o reconhecimento emocional, vêm sendo exploradas apenas recentemente pela literatura (Wang et al., 2014; Nguyen et al., 2014).

A seguir, são apresentadas em maiores detalhes as técnicas empregadas para a modelagem computacional do mecanismo de pré-atenção visual humano.

\subsubsection{Mapa de Saliência}

O termo "atenção" é o processo pelo qual um agente exclui todas as características do ambiente, exceto algumas de seu interesse, concentrando-se apenas nelas. A maioria dos modelos de atenção visual bottom-up inspirados biologicamente segue a hipótese de Koch and Ullman (1985), em que vários mapas de características alimentam um único mapa mestre ou mapa de saliência. Desta forma, o primeiro estágio de processamento em qualquer modelo de atenção bottom-up é a computação de características visuais primitivas (Itti and Koch, 2001).

O mapa de saliência é formado pela composição de vários mapas com características visuais primitivas da imagem como, por exemplo, cor, intensidade e orientação. Esta composição gera uma medida de saliência independente de qualquer dimensão de característica. As diversas regiões da cena visual disputam essa medida em várias escalas espaciais e a região vencedora é eleita como a mais saliente.

Neste trabalho é utilizado o modelo de saliência da atenção visual proposto por Itti and Koch (2001). O mapa de saliência é um mapa escalar bidimensional de atividade representado topograficamente pela conspicuidade ou saliência visual (Itti and Koch, 2001). Para a obtenção de um mapa de saliência, as seguintes etapas são necessárias: extração de características, filtragem linear, cálculo das diferenças centro-vizinhanças, soma dos mapas de características (combinação linear) e obtenção de regiões salientes.

A etapa de extração de características consiste na obtenção de três mapas de características visuais primitivas (cor, intensidades e orientação). O mapa de cor é gerado empregando os três canais das cores $r$ (vermelho), $g$ (verde) e $b$ (azul) da imagem de entrada. A partir destes canais obtém-se também o mapa de intensidades I, dado pela Equação 5.1, que define a imagem em tons de cinza.

$$
I=\frac{(r+g+b)}{3}
$$

Estes canais são, então, normalizados a partir de $I$, produzindo quatro canais de cores denominados $R$ para o vermelho, $G$ para o verde, $B$ para o azul, e $Y$ para o 
amarelo, representados, respectivamente, pelas equações 5.2, 5.3, 5.4 e 5.5.

$$
\begin{gathered}
R=r-\frac{(g+b)}{2} \\
G=g-\frac{(r+b)}{2} \\
B=b-\frac{(r+g)}{2} \\
Y=\frac{(r+g)}{2}-\frac{|r-g|}{2}-b
\end{gathered}
$$

$\mathrm{Na}$ segunda etapa, os canais de cores e o mapa de intensidades são submetidos a um processo de filtragem linear, que consiste na utilização progressiva de filtros passa-baixa e reescalonamento da imagem original, em que cada nível subsequente é reduzido pela metade. O objetivo é obter amostras da imagem nas quais detalhes indesejados e ruídos sejam suprimidos e características importantes realçadas. Deste modo, uma pirâmide Gaussiana composta por nove níveis, obtida de acordo com o algoritmo proposto em Burt and Adelson (1983), é gerada referente a cada canal, sendo: $I_{\sigma}, R_{\sigma}, G_{\sigma}, B_{\sigma}$ e $Y_{\sigma}$, onde $\sigma \in[0 . .8]$.

O modelo de Itti et al. (1998) também considera informações sobre orientações locais como uma característica importante para o desenvolvimento da atenção visual. Neste sentido, os mapas de orientações $O_{\sigma}(\theta)$ são criados através da convolução do mapa de intensidades $I_{\sigma}$, com filtros direcionais de Gabor para quatro orientações $\theta \in 0^{\circ}, 45^{\circ}, 90^{\circ}, 135^{\circ}$.

Em seguida, os mapas de características são obtidos por meio do cálculo das diferenças centro-vizinhança da pirâmide. Nesta subtração de imagens, o centro é um pixel da imagem na escala $c \in\{2,3,4\}$ e a vizinhança é o pixel correspondente em outra escala $s=c+\delta$, $\operatorname{com} \delta \in\{3,4\}$ da representação piramidal. Desta forma, obtêm-se sete tipos de características: uma para intensidade da imagem (On-Off), duas que codificam as diferenças Vermelho-Verde e Azul-Amarelo, e mais quatro para contraste local da orientação $\left(0^{\circ}, 45^{\circ}, 90^{\circ}, 135^{\circ}\right)$ (Itti et al., 1998).

$\mathrm{Na}$ quarta etapa, os mapas de características são individualmente somados $(\bigoplus$ ) nas diversas escalas, gerando três mapas de conspicuidades: $\overline{\mathcal{I}}$ para intensidade, $\overline{\mathcal{C}}$ para cor e $\overline{\mathcal{O}}$ para orientação. Entretanto, um fato importante a ser notado é que, previamente à somatória dos mapas de cada característica, Itti et al. (1998) propõem sua normalização $\mathcal{N}($.$) , com o objetivo de que uma região que apresente um nível$ de saliência contrastante com as demais seja amplificada e, por outro lado, regiões salientes não contrastantes sejam mutuamente inibidas. Deste modo, somente após o processo de normalização os mapas de características são combinados em três mapas de conspicuidades.

De acordo com Itti et al. (1998), a motivação para a criação dos três canais 
separados $(\overline{\mathcal{I}}, \overline{\mathcal{C}}, \overline{\mathcal{O}})$ é a hipótese de que características similares competem pela saliência, enquanto modalidades diferentes contribuem independentemente para o mapa de saliência. Por fim, os três mapas de conspicuidades são normalizados e somados, resultando no mapa de saliência $\mathcal{S}$, como apresentado na Equação 5.6.

$$
\mathcal{S}=\frac{1}{3}(\mathcal{N}(\overline{\mathcal{J}})+\mathcal{N}(\overline{\mathcal{C}})+\mathcal{N}(\overline{\mathcal{O}}))
$$

Na Figura 5.1 é possível visualizar um exemplo dos três mapas de conspicuidade, assim como do mapa de saliência obtido, para uma imagem da base de dados USTC-NVIE (Wang et al., 2010), utilizada neste trabalho.

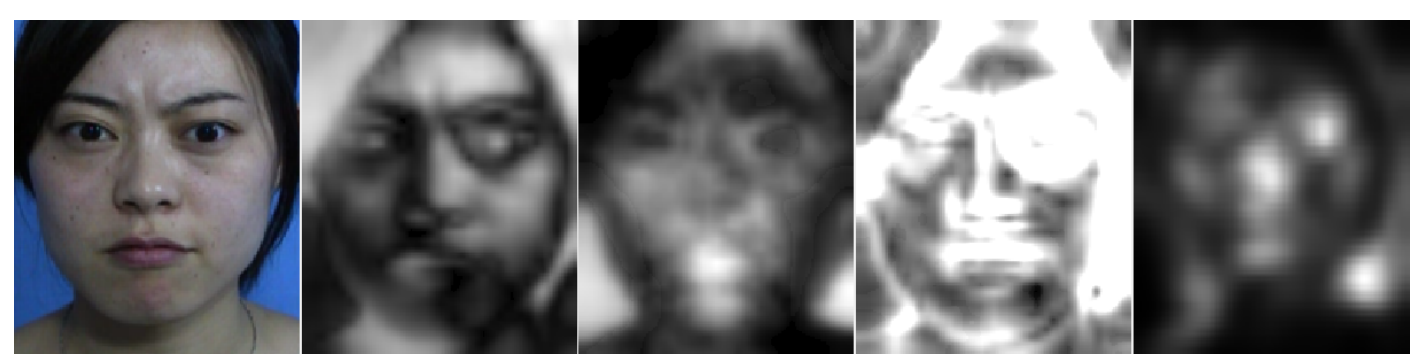

Figura 5.1: Da esquerda para a direita: imagem original, mapa de conspicuidade para intensidade $\overline{\mathcal{I}}$, mapa de conspicuidade para cor $\overline{\mathcal{C}}$, mapa de conspicuidade para orientação $\overline{\mathcal{O}}$ e mapa de saliência resultante.

De acordo com Itti and Koch (2001), a saliência é independente da natureza de um processo de busca pelo local de maior atenção, realiza-se de forma rápida e é dirigida principalmente de forma bottom-up. Entretanto, pode ser influenciada pelo contexto, como efeitos de plano de fundo, de modo que, se um estímulo é suficientemente saliente, se destacará automaticamente na cena.

\subsubsection{Histograma de Gradientes Orientados}

O Histograma de Gradientes Orientados (HOG), proposto por Dalal and Triggs (2005), pode ser considerado um método baseado em aparência, pois codifica a forma e a aparência visual de objetos. Inicialmente, o método HOG foi utilizado para detecção de pedestres (Dalal and Triggs, 2005). Posteriormente, passou a ser utilizado em diversas aplicações como reconhecimento de objetos, de faces e mesmo de expressões faciais emocionais (Hu et al., 2008; Orrite et al., 2009; Lucey et al., 2010; Dahmane and Meunier, 2011; Goswami et al., 2013; Chen et al., 2013).

A escolha por este método em contraposição aos métodos baseados em características geométricas, explorados para a modelagem da face, se baseia na vantagem de não ser necessário definir um modelo facial específico, que é automaticamente produzido. Ainda, a utilização de métodos baseados em aparência em conjunto com métodos baseados em geometria pode resultar em desempenho superior, dada a complementariedade existente entre eles (Lucey et al., 2007).

A ideia principal do método HOG está na caracterização da aparência pela 
distribuição, orientação e magnitude de gradientes de intensidade local. Assim, o HOG é um descritor de características que considera as ocorrências da orientação do gradiente em porções localizadas da imagem. De acordo com Dalal and Triggs (2005), o processo para produzir os descritores se divide em cinco etapas.

Primeiramente, é aplicada uma normalização na imagem projetada para reduzir a influência de efeitos de iluminação. Esta etapa, segundo o autor, é opcional, e pode utilizar as técnicas de compressão gama, o cálculo da raiz quadrada ou o registro de cada canal de cor. Em seguida, são calculados os gradientes de primeira ordem da imagem. Nesta etapa são capturados o contorno, a silhueta e algumas informações de textura, proporcionando uma maior tolerância a variações de iluminação.

O objetivo da terceira etapa é produzir uma codificação que seja sensível à imagem local, permanecendo tolerante a pequenas alterações de forma ou aparência. Esta etapa envolve a criação dos histogramas locais. Neste sentido, a janela de detecção da imagem é dividida em pequenas regiões espaciais denominadas "células". Para cada célula é calculado o gradiente de orientação local, ou seja, linhas de orientação sobre todos os pixels da célula. O conjunto de células constitui a representação do histograma orientado. Cada histograma orientado divide o intervalo de ângulos de inclinação em um número fixo de posições pré-determinadas. A magnitude do gradiente para cada posição de orientação é calculada para todos os pixels da célula. Estas magnitudes são utilizadas para selecionar a orientação do histograma por meio de um processo de eleição.

Na quarta etapa é feita a normalização, que considera grupos locais de células e de contraste para serem normalizados antes de realizar a etapa final. A normalização confere melhor invariância à iluminação, sombras, contraste e bordas. O cálculo é feito pelas medidas de energia local sobre grupos de células vizinhas denominados "blocos". O resultado é utilizado para normalizar cada célula do bloco. Tipicamente, cada célula individual é compartilhada entre vários blocos, ou seja, existe sobreposição de partes de diferentes blocos mas, como cada processo de normalização é dependente de seu bloco, as normalizações realizadas são diferentes. Ao final da normalização, os blocos normalizados são definidos como descritores do HOG.

Por fim, os descritores de todos os blocos são concatenados em um único vetor de características, que representa o descritor da imagem resultante da aplicação do método HOG. A aplicação do método HOG a uma imagem da base de dados USTC-NVIE pode ser observada na Figura 5.2.

\subsubsection{Entropia, Variância e Desvio-padrão}

A entropia (ou incerteza) $E_{I}$ de uma imagem $I$ é uma medida estatística definida como um quantificador da aleatoriedade da imagem. Quanto maior seu 


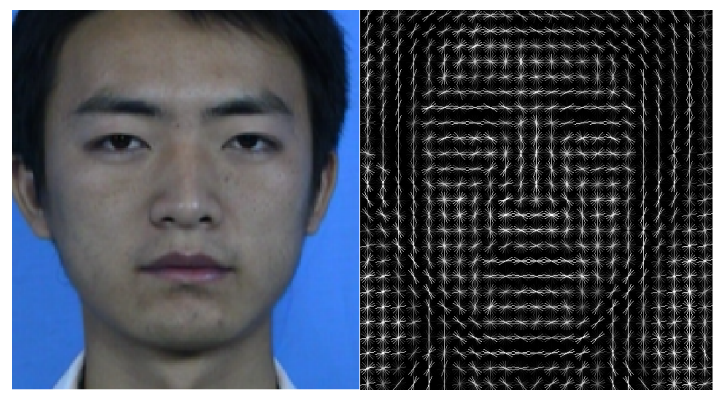

Figura 5.2: À esquerda tem-se a imagem original e, à direita, o resultado da aplicação do método HOG.

valor, mais irregular, atípica ou fora dos padrões se encontra a imagem em análise. Mais especificamente, a entropia representa o grau de dispersão dos níveis de cinza de uma imagem e, quanto maior é a entropia, maior é também a probabilidade de ocorrência de um determinado nível de cinza (Gualberto and Filho, 2007). Ademais, a análise visual do mapa de entropia permite caracterizar padrões de textura da imagem, de modo que pode ser utilizado para a extração de informações relevantes.

O cálculo da entropia é apresentado pela equação 5.7. Nela, p possui a contagem de pixels do histograma da imagem $I$, e $i$ percorre todos os 256 níveis de cinza existentes na imagem. Um exemplo da entropia de uma expressão facial da base de dados USTC-NVIE pode ser vista na Figura 5.3.

$$
E_{I}=-\sum p(i) * \log _{2} p(i)
$$

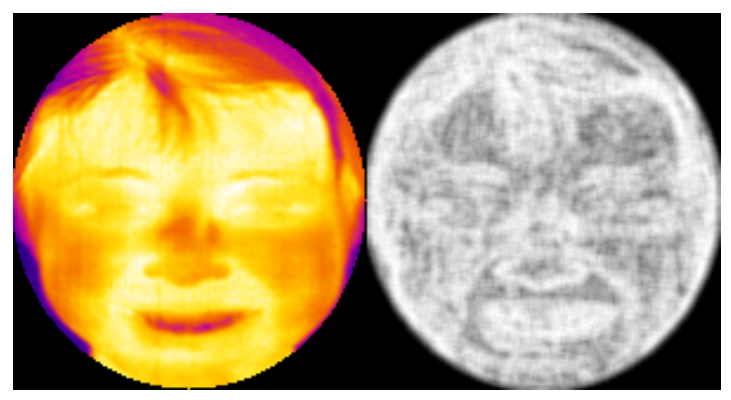

Figura 5.3: À esquerda tem-se a imagem original e, à direita, é possível visualizar sua entropia.

A variância $\sigma_{I}^{2}$ é uma medida de dispersão estatística e, para uma imagem $I$, representa o valor de desvio dos níveis de cinza da imagem em relação ao nível de cinza médio. O valor do nível de cinza médio $\mu_{I}$ de uma imagem é calculado pela somatória dos valores de níveis de cinza ( $\operatorname{cin}$ ) de todos os pixels da imagem, dividido pelo número total $n$ de pixels. Em que $n$ é dado por $n=$ nlin $*$ ncol, composto, respectivamente, pela quantidade de linhas e quantidade de colunas da imagem $I$ analisada. Este cálculo é obtido pela Equação 5.8 e, na Equação 5.9, é apresentado 
o cálculo da variância.

$$
\begin{gathered}
\mu_{I}=\sum_{k=1}^{n} \frac{\left(\operatorname{cin}_{k I}\right)}{n} \\
\sigma_{I}^{2}=\sum_{k=1}^{n} \frac{\left(\operatorname{cin}_{k I}-\mu_{I}\right)^{2}}{n-1}
\end{gathered}
$$

O desvio-padrão $\sigma_{I}$ é uma medida de dispersão estatística que mede a variabilidade dos dados de uma distribuição de frequências. Neste sentido, ele mede a dispersão dos valores individuais em torno da média. O desvio-padrão representa, como pode ser observado pela Equação 5.10, a raiz quadrada da variância, e informa sobre a maior ou menor homogeneidade, ou heterogeneidade, de uma imagem.

$$
\sigma_{I}=\sqrt{\sum_{k=1}^{n} \frac{\left(\operatorname{cin}_{k I}-\mu_{I}\right)^{2}}{n-1}}
$$

Estas medidas estatísticas são utilizadas pois existem diversos trabalhos na literatura que as aplicam para a análise de imagens térmicas ou mapas de saliência, com obtenção de bons resultados (Khan et al., 2004; 2006; Nhan and Chau, 2010; Wang et al., 2010; Khan et al., 2011; Wang et al., 2012).

\subsection{Aprendizado de Máquina}

Aprendizado de Máquina (AM) é um campo de pesquisas em Inteligência Artificial que estuda o desenvolvimento de métodos capazes de extrair conhecimento a partir de conjuntos de dados. Pesquisas nesta área têm por objetivo desenvolver novas técnicas computacionais de aprendizado, bem como construir sistemas capazes de adquirir conhecimento de modo automático (Mitchell, 1997). Neste sentido, AM estuda os processos de aprendizado humano com o objetivo de desenvolver métodos computacionais que simulem estas nossas habilidades.

Um problema importante da área de AM está relacionado com a representação dos dados. Existe consenso que, com uma representação adequada, a maioria dos algoritmos existentes obtém resultados satisfatórios. No entanto, a construção de uma boa representação para os dados que seja simples e, ao mesmo tempo, representativa, ou seja, revele os aspectos mais importantes do problema investigado, é ainda um tópico de pesquisas em aberto (Navot, 2006). Construir uma representação apropriada confere a oportunidade de inserir conhecimento específico do domínio aos dados, que é diferente para cada aplicação (Guyon and Elisseeff, 2003).

Apesar de AM possibilitar o desenvolvimento de ferramentas para a aquisição automática de conhecimento, deve-se observar que não existe um único algoritmo que apresente o melhor desempenho para todos os problemas. Neste sentido, é importante compreender o poder e a limitação dos diferentes algoritmos existentes, 
por meio de uma metodologia que permita avaliar os conceitos induzidos por estes algoritmos em diferentes problemas (Monard and Baranauskas, 2003).

De acordo com a literatura, três principais paradigmas de aprendizado, que definem o modo como se dará o aprendizado de um algoritmo de AM (Haykin, 1999), podem ser encontrados. Deste modo, no aprendizado supervisionado, um supervisor ou mentor externo representa o conhecimento do ambiente por meio de rótulos que indicam a resposta esperada para o problema. No aprendizado não supervisionado, os exemplos relacionados ao problema a ser aprendido não estão rotulados, e o algoritmo de AM aprende a representar ou agrupar os exemplos segundo alguma medida de similaridade (Lorena, 2003). Já o aprendizado por reforço ocorre por meio de punições e recompensas, que são utilizadas para ajustar o algoritmo de AM com base no desempenho apresentado.

Existem também algoritmos de AM que seguem o paradigma de aprendizado evolutivo, cujo principal representante são os algoritmos genéticos (AGs) (Goldberg, 1989). Este paradigma engloba algoritmos cujos conceitos e princípios se baseiam nas Teorias da Evolução e da Genética.

Para algoritmos que seguem o paradigma de aprendizado supervisionado, ou seja, a partir de um conjunto de dados inicial, um classificador (modelo ou hipótese) é treinado para predizer a classe de novos dados, a generalização deste classificador é definida como sua capacidade de prever corretamente a classe de novos exemplos, sendo avaliada por seu desempenho em conjuntos de teste.

No caso em que o modelo se especializa nos dados utilizados em seu treinamento, apresentando baixa taxa de acerto quando confrontado com novos dados, tem-se a ocorrência de overfitting. Existe também a possibilidade de se induzir hipóteses que apresentam baixa taxa de acerto mesmo no conjunto de treinamento. Esse fato é denominado underfitting. De acordo com Monard and Baranauskas (2003), esta situação pode ocorrer se os exemplos de treinamento disponíveis são pouco representativos ou o modelo obtido é demasiado simples.

Para a determinação das taxas de erro e acerto de um classificador tem-se, como regra geral, a divisão do conjunto de dados original em dois subconjuntos disjuntos: de treinamento e de testes. O subconjunto de treinamento é utilizado no aprendizado do problema, e o subconjunto de testes é utilizado para medir a efetividade do aprendizado. Dentre as metodologias existentes para obtenção das estimativas da taxa de acerto (ou da taxa de erro), as mais comumente utilizadas são as metodologias r-fold-cross-validation e bootstrap (Mitchell, 1997).

Na metodologia r-fold-cross-validation, empregada nos experimentos deste trabalho, os exemplos são aleatoriamente divididos em $r$ partições mutuamente exclusivas de tamanho aproximadamente igual. Os exemplos nas $(r-1)$ partições são utilizados para treinamento e a hipótese induzida é testada na partição remanescente (conjunto de validação). Este processo é repetido $r$ vezes, cada vez considerando 
uma partição diferente para teste. O erro final é a média dos erros calculados em cada uma das $r$ partições.

Os algoritmos de AM investigados para a tarefa de identificação das seis emoções básicas e da expressão neutra, por meio da análise de características faciais, são apresentados nas próximas subseções.

\subsubsection{Support Vector Machines}

As Support Vector Machines (SVMs) (Vapnik, 1995) representam uma classe de algoritmos de AM que se baseia na Teoria de Aprendizado Estatístico. Sua formulação resulta em um problema de otimização quadrática e envolve o princípio de Minimização do Risco Estrutural (Structural Risk Minimization - SRM), em vez do princípio de Minimização do Risco Empírico (Empirical Risk Minimization - ERM). SRM minimiza o erro de generalização, em oposição ao ERM, que minimiza o erro nos dados de treinamento, conferindo ao algoritmo SVM uma maior capacidade de generalização sobre o conjunto de dados.

As SVMs foram originalmente desenvolvidas para o reconhecimento de padrões. Neste caso, uma fronteira de decisão é representada em termos de um subconjunto dos exemplos de treinamento, tipicamente pequeno, chamado de vetores de suporte (support vectors). Basicamente, uma SVM realiza um mapeamento não linear dos dados em um espaço de elevada dimensionalidade em que um hiperplano ótimo (com a maior margem de separação possível) possa ser construído, de modo a permitir a separação das classes positivas e negativas.

As SVMs têm obtido desempenho comparável, ou mesmo superior, a técnicas clássicas de AM em diversos domínios. Por isso, cada vez mais são utilizadas na solução de diferentes problemas, tais como o reconhecimento e classificação de padrões, regressão de funções, processamento de sinais, dentre outros.

Dentre as vantagens, é possível citar a boa capacidade de generalização, mesmo em problemas que manipulam dados de elevada dimensionalidade. Suas principais deficiências encontram-se em sua sensibilidade na escolha dos parâmetros pelo usuário, e na dificuldade de interpretação do modelo produzido.

\subsubsection{Algoritmo C4.5}

O algoritmo C4.5 (Quinlan, 1993) é um algoritmo de aprendizado simbólico que produz árvores de decisão (ADs) a partir de um conjunto de treinamento utilizando, para isso, uma abordagem gulosa que progressivamente expande a AD.

As ADs são estruturas recursivas que organizam suas informações em uma árvore composta por nós e ramificações. Cada nó representa um atributo e está associado a um teste relevante para classificação dos dados, ou a uma classe, no caso do nó ser um nó-folha. As ramificações representam cada um dos possíveis resultados do teste aplicado. A complexidade de uma $\mathrm{AD}$ é avaliada de acordo com 
seu tamanho, quanto maior o tamanho da árvore, maior a complexidade. Para lidar com ruído e overfitting, este algoritmo possui um procedimento de poda da árvore produzida, que elimina os ramos considerados pouco representativos, com o objetivo de simplificar a $\mathrm{AD}$ e reduzir a taxa de erro.

Uma $\mathrm{AD}$ é produzida do seguinte modo: um atributo é escolhido e, de acordo com seu valor, o conjunto de treinamento é dividido. Para cada subconjunto criado, um novo atributo é escolhido para dividi-lo. Esse processo segue até que um subconjunto contendo somente exemplos de uma mesma classe seja obtido. Quando isso ocorre, um nó-folha é criado e rotulado com o mesmo nome da respectiva classe. A classificação de um exemplo se dá seguindo os nós e as ramificações existentes até que um nó-folha seja alcançado, ou seja, para classificar um novo exemplo, o algoritmo $\mathrm{C} 4.5$ percorre a $\mathrm{AD}$ produzida, começando pela raiz até alcançar um nó-folha. A classe do novo exemplo analisado será a mesma do rótulo do nó-folha alcançado.

Algumas vantagens das ADs são a compreensibilidade das regras de classificação produzidas, facilidade de manutenção, flexibilidade e velocidade de treinamento. Em contrapartida, são pouco robustas a exemplos de elevada dimensionalidade (com grande quantidade de atributos).

\subsubsection{Redes Neurais Artificiais}

As redes neurais artificiais (RNs) são técnicas computacionais baseadas em modelos matemáticos, inspiradas no sistema nervoso dos seres humanos. A principal característica delas é que não necessitam de programação prévia, pois adquirem conhecimento através da experiência (Haykin, 1999).

RNs podem ser definidas como sistemas paralelos distribuídos compostos por unidades de processamento simples (ou neurônios), altamente interconectadas, que computam determinadas funções matemáticas. Tais unidades são dispostas em uma ou mais camadas e interligadas por um grande número de conexões, geralmente unidirecionais. Na maioria dos modelos, estas conexões estão associadas a pesos, que armazenam o conhecimento representado no modelo e servem para ponderar a entrada recebida por cada neurônio da rede. Neste sentido, uma RN consiste em um conjunto de unidades individuais de processamento (neurônios) que se comunicam entre si através de conexões ponderadas (Haykin, 1999).

Cada unidade de processamento executa uma tarefa relativamente simples: recebe um conjunto de entradas de seus vizinhos ou fontes externas e as utiliza para computar um sinal de ativação que é propagado para os demais neurônios. Três tipos de unidades de processamento podem ser identificadas: neurônios de entrada, que recebem dados externos à rede, neurônios de saída, que enviam dados para fora da rede, e neurônios internos, cujas entradas e saídas permanecem dentro da rede. Cada neurônio contribui para a entrada do neurônio ao qual ele está conectado. 
Os modelos de RNs possuem regras de treinamento, nas quais os pesos de suas conexões são ajustados de acordo com certos padrões. O treinamento consiste em ajustes iterativos dos pesos das conexões, de forma a permitir o aprendizado através de exemplos. Este é concluído quando a rede estiver apta a obter uma solução generalizada para uma determinada classe de problemas.

O aprendizado das RNs pode ser categorizado em dois paradigmas distintos: o supervisionado e o não supervisionado (Haykin, 1999). Neste projeto de doutorado, são investigadas as redes Perceptron de Múltiplas Camadas (Multilayer Perceptron MLPs) (Haykin, 1999), apresentadas a seguir.

\section{Redes Multilayer Perceptron}

É o modelo de RN mais utilizado, que segue o paradigma de aprendizado supervisionado. Basicamente, esta rede consiste de um conjunto de unidades sensoriais (neurônios), que constituem uma camada de entrada, uma ou mais camadas intermediárias (ou escondidas) e uma camada de saída. As camadas intermediárias funcionam como extratores de características: os pesos codificam os padrões existentes nos dados de entrada, produzindo uma representação mais complexa do conjunto de dados. Não existe uma regra que determine quantos neurônios devem existir nas camadas intermediárias (Haykin, 1999).

O algoritmo mais comumente utilizado para o aprendizado destas redes é conhecido como back-propagation, que pode ser simplificado da seguinte forma: Primeiramente, um vetor de padrões é fornecido à rede por meio de sua camada de entrada. Este vetor é propagado entre as diferentes camadas intermediárias até produzir uma resposta na camada de saída. Esta etapa é conhecida como forward pass, pois a análise do conjunto de padrões é feita no sentido início $->$ final da rede, e os vetores de pesos permanecem inalterados. Na segunda etapa, conhecida como backward pass, a resposta obtida pela rede é subtraída da resposta esperada (correta) produzindo um erro, que é propagado no sentido inverso ao já citado. Os pesos de cada neurônio são alterados com base neste erro, com o objetivo de produzir uma nova resposta que seja mais próxima da esperada. Existem diversas variações deste algoritmo que podem ser aplicadas às redes MLP, e têm como objetivo acelerar o processo de treinamento e reduzir as taxas de erro obtidas.

\subsubsection{Algoritmos de Agrupamento de Dados}

O agrupamento de dados ou clusterização é um problema de aprendizado não supervisionado cujo objetivo é encontrar alguma estrutura ou padrão em uma base de dados, sem conhecimento prévio (Mitchell, 1997). Nesta estrutura, os exemplos pertencentes a cada grupo ou partição compartilham alguma característica ou propriedade relevante para o domínio do problema em estudo.

Os algoritmos de agrupamento exploram semelhanças entre dados e os di- 
videm em grupos ou partições que possuem características comuns. Nestes algoritmos, os dados são agrupados em conjuntos ou partições naturais. Métricas de similaridade ou medidas de associação são utilizadas para descrever a proximidade entre os dados analisados e, assim, realizar o particionamento. Dentre as métricas de similaridade mais difundidas na literatura, destacam-se a distância euclidiana e o coeficiente de Pearson (Lorena, 2003).

Deste modo, os algoritmos de agrupamento de dados selecionam os dados de uma amostra, definem o conjunto de variáveis que caracterizam as entidades na amostra, calculam as similaridades entre os dados, usam um método de análise de agrupamento criando partições de entidades similares e validam a solução encontrada. A natureza heurística destes algoritmos pode levar a resultados tendenciosos. Os resultados podem ser afetados por diferenças de escala nos dados, escolha das métricas de similaridade ou dos algoritmos, e até pela ordem de entrada dos dados (Faceli, 2001). A descrição dos algoritmos investigados neste trabalho é apresentada a seguir.

Algoritmo K-Médias: O algoritmo k-médias é um dos mais simples e populares algoritmos de agrupamento de dados que utiliza o conceito de centróides como protótipos representativos das partições. O centróide representa o centro de uma partição, sendo calculado pela média de todos os exemplos da partição. Quando na análise dos dados existem informações sobre o número de partições que devem ser produzidas, o algoritmo k-médias é uma boa alternativa. Neste algoritmo, os padrões são agrupados em um número fixo $(k)$ de partições, definido pelo usuário (Lorena, 2003).

$\mathrm{O}$ algoritmo k-médias divide o conjunto de entrada em $k$ subconjuntos disjuntos (clusters) (Faceli, 2001). O objetivo é encontrar a melhor divisão de $L$ dados em $M$ partições $C_{i}, i=1, \ldots, M$, de maneira que a distância total entre os dados de uma partição e o seu respectivo protótipo, somada por todas as partições, seja minimizada.

Intuitivamente, o algoritmo funciona da seguinte maneira. Após atribuir aleatoriamente os padrões do conjunto de treinamento a cada uma das $k$ partições, um conjunto de vetores, chamados protótipos, contendo a média dos vetores (padrões) pertencentes a cada partição, é calculado. Estes protótipos são utilizados para calcular as distâncias entre as partições. Os padrões são iterativamente deslocados entre partições, de acordo com as distâncias intra- e inter- partições. Padrões passam para uma nova partição se estiverem mais próximos desta nova partição que de sua partição atual. Após cada deslocamento, os protótipos para cada partição são recalculados. Este processo continua até que não haja alteração no conjunto de protótipos calculados (Lorena, 2003).

Como vantagens do algoritmo k-médias é possível citar a complexidade computacional linear, além de ser um algoritmo simples, intuitivo, e de fácil interpretação 
dos resultados obtidos. Dentre as deficiências, tem-se a dependência da escolha do número $k$ de partições, e a sensibilidade à inicialização dos protótipos, podendo levá-lo a ficar preso em mínimos locais. Ainda, este algoritmo se comporta melhor com dados que contenham partições esféricas. Portanto, partições com outra geometria podem não ser encontradas (Lorena, 2003).

Para suprir as deficiências apontadas, pode-se citar a utilização de heurísticas para estimar o número $k$ de partições e amenizar a sensibilidade do algoritmo à inicialização dos protótipos. Isto é feito, por exemplo, nos algoritmos bisecting $k$-means e $x$-means ou $\mathrm{x}$-médias.

Algoritmo X-Médias: O algoritmo x-médias foi proposto por Pelleg and Moore (2000) para minimizar as deficiências do algoritmo k-médias. Este algoritmo permite fornecer um intervalo com o número de partições $\left[k_{\min }, k_{\max }\right]$ a serem investigadas durante sua execução, e produz uma partição do conjunto de dados em análise pela utilização do algoritmo k-médias.

Primeiramente, o algoritmo x-médias é inicializado pela aplicação do algoritmo $\mathrm{k}$-médias para obter um agrupamento com $\mathbf{k}_{\min }$ partições. Este agrupamento é avaliado e armazenado. Em seguida, o algoritmo k-médias é novamente aplicado para dividir cada partição existente em outras duas. Cada divisão efetuada é avaliada e as divisões que produziram os melhores agrupamentos são mantidas, garantindo que um máximo de $k_{\max }$ partições sejam produzidas.

Se nenhum agrupamento é mantido, o algoritmo divide uma proporção das partições inicialmente produzidas, respeitando o limite de $k_{\max }$ partições, valendo-se das divisões que obtém as melhores avaliações. Em seguida, o algoritmo k-médias é aplicado para o refinamento do agrupamento obtido, que é armazenado caso obtenha uma avaliação superior às previamente encontradas para agrupamentos anteriores. Se este agrupamento possuir $k_{\max }$ partições, o algoritmo é finalizado, retornando o agrupamento melhor avaliado. Caso contrário, o algoritmo novamente utiliza o k-médias para dividir cada partição existente em duas novas, e o processo de execução continua até ser obtido um agrupamento com $k_{\text {max }}$ partições.

Durante a execução do algoritmo, os protótipos fornecidos ao k-médias são inicializados na mesma posição do centróide original da partição a ser dividida e, em seguida, são deslocados no sentido oposto de uma direção escolhida aleatoriamente dentro do espaço de dados. O valor do deslocamento deve ser proporcional ao tamanho da região da partição. Em geral, o índice de validação interno Bayesian Information Criterion (BIC) (Pelleg and Moore, 2000) é utilizado para avaliar estas divisões, e indicar se a divisão realizada melhora, ou não, a qualidade do agrupamento. 


\section{Índices de Validação}

Para determinar se as partições produzidas por um algoritmo de agrupamento de dados são significativas, o resultado obtido deve ser avaliado para aferir a qualidade da solução encontrada. Em geral, para validar os agrupamentos encontrados, índices estatísticos, que quantificam a qualidade de um agrupamento, são utilizados. Estes índices, conhecidos como índices de validação, podem ser divididos em três tipos (Jain and Dubes, 1988):

- Os índices externos medem a similaridade entre dois agrupamentos obtidos a partir de um mesmo conjunto de dados, e são geralmente utilizados para comparar o agrupamento produzido com a estrutura ou classificação real dos dados em análise. Deste modo, eles determinam quanto um agrupamento produzido se aproxima da estrutura conhecida dos dados;

- Os índices internos avaliam o agrupamento obtido, ou seja, a qualidade das partições produzidas, com base apenas nos dados originais, sem nenhum conhecimento externo ao agrupamento realizado;

- Os índices relativos comparam diversas partições para decidir qual delas é melhor, de acordo com algum critério. Estes critérios podem ser utilizados na comparação de algoritmos de agrupamento ou na definição do melhor valor para um parâmetro.

Neste trabalho, os índices de validação interno Silhueta e externo Jaccard são utilizados.

Índice Silhueta: O índice de validação silhueta (Rousseeuw, 1987) é calculado para cada exemplo de uma partição, identificando quais estão bem situados em suas partições e quais estão fora da partição apropriada. Este índice define a qualidade dos agrupamentos com base na proximidade entre os exemplos de uma partição e na distância destes em relação à partição mais próxima.

Para seu cálculo, podem ser utilizadas quaisquer medidas de dissimilaridade ou similaridade. Assim, seja um exemplo $x_{i}$ do conjunto de dados, e a partição $P_{A}$ tal que $x_{i} \in P_{A}$, e seja $a\left(x_{i}\right)$ a dissimilaridade média do exemplo $x_{i}$ em relação a todos os demais exemplos da partição $P_{A}$, e $b\left(x_{i}\right)$ a menor dissimilaridade média de $x_{i}$ em relação aos exemplos de uma outra partição $P_{b}$, tal que $P_{b} \neq P_{A}$. A silhueta do exemplo $x_{i}$ é dada pela Equação 5.11.

$$
\operatorname{silhueta}\left(x_{i}\right)=\frac{b\left(x_{i}\right)-a\left(x_{i}\right)}{\max \left\{a\left(x_{i}\right), b\left(x_{i}\right)\right\}}
$$

O resultado desta equação é um valor no intervalo [-1,1]. Se um exemplo está bem situado em sua partição, sua silhueta será positiva, caso contrário, se estiver mais próximo de outra partição, ela será negativa. Logo, para o algoritmo de 
agrupamento garantir que os exemplos estejam na partição apropriada, a silhueta deve apresentar valores no intervalo $[0,1]$.

O índice silhueta depende apenas do agrupamento resultante e não do algoritmo de agrupamento utilizado. Ele é apropriado para a identificação de partições compactas e separadas. Porém, não apresenta bons resultados para partições com formatos arbitrários (Rousseeuw, 1987).

Índice Jaccard: Para estabelecer a equivalência entre partições de agrupamentos distintos, faz-se necessário considerar a relação entre seus exemplos. Por este motivo, os índices externos consideram a relação entre pares de exemplos para determinar esta equivalência. Neste sentido, dado o par de exemplos $x_{i}$ e $x_{j}$, pertencente ao conjunto de dados $X$, tal que $i \neq j$, e as partições $C_{r} \in \pi_{r}$ e $C_{g} \in \pi_{g}$, em que $\pi_{r}$ é o agrupamento obtido e $\pi_{g}$ é o agrupamento ou classificação real dos dados, considere as quatro situações apresentadas:

- 11: $\left(x_{i} \in C_{r}\right)$ e $\left(x_{j} \in C_{r}\right)$ em $\pi_{r},\left(x_{i} \in C_{g}\right)$ e $\left(x_{j} \in C_{g}\right)$ em $\pi_{g}$

- 01: $\left(x_{i} \in C_{r}\right)$ e $\left(x_{j} \notin C_{r}\right)$ em $\pi_{r},\left(x_{i} \in C_{g}\right)$ e $\left(x_{j} \in C_{g}\right)$ em $\pi_{g}$

- 10: $\left(x_{i} \in C_{r}\right)$ e $\left(x_{j} \in C_{r}\right)$ em $\pi_{r},\left(x_{i} \in C_{g}\right)$ e $\left(x_{j} \notin C_{g}\right)$ em $\pi_{g}$

- 00: $\left(x_{i} \in C_{r}\right)$ e $\left(x_{j} \notin C_{r}\right)$ em $\pi_{r},\left(x_{i} \notin C_{g}\right)$ e $\left(x_{j} \in C_{g}\right)$ em $\pi_{g}$

Sabendo que $n p_{t}=n(n-1) / 2$ é o número de todas as possiveis combinações de pares de exemplos do conjunto de dados $X$ que possui $n$ exemplos, que $n p_{11}$ é o número de pares de exemplos na situação 11, np $p_{01}$ é o número de pares de exemplos na situação 01, e $n p_{10}$ e $n p_{00}$ são os números de pares de exemplos nas situações 10 e 00, respectivamente, é possível descrever o índice Jaccard ou coeficiente de similaridade de Jaccard (Jaccard, 1908).

Neste sentido, trata-se de um índice utilizado para comparar a similaridade entre conjuntos de amostras. Guando utilizado para calcular a probabilidade de dois exemplos pertencerem a uma mesma partição em ambos os agrupamentos $\pi_{r}$ e $\pi_{g}$, pode ser obtido pela Equação 5.12.

$$
\operatorname{Jaccard}\left(\pi_{r}, \pi_{g}\right)=\frac{n p_{11}}{n p_{11}+n p_{01}+n p_{10}}
$$

Este índice resulta em valores entre [0,1], de modo que, quanto mais diferentes os agrupamentos, mais próximo de 0 é o valor obtido. Deste modo, agrupamentos idênticos resultam no valor 1 .

\subsection{Seleção de Características}

A psicologia sugere que o reconhecimento emocional nos seres humanos é realizado pela identificação de características de diagnóstico, que são específicas 
para cada emoção. Deste modo, algoritmos de seleção de características são utilizados para identificar as possíveis características faciais de diagnóstico que representam cada expressão facial analisada. Espera-se que estes algoritmos simulem o mecanismo humano, identificado por estudos psicológicos, que direciona o foco de atenção para locais específicos da face com o objetivo de reconhecer as expressões emocionais.

A seleção de características investiga a utilização de técnicas de pré-processamento para identificar quais os atributos importantes, e quais os redundantes, existentes em conjuntos de dados que apresentam elevada dimensionalidade. Um atributo é considerado relevante se não pode ser substituído por outro atributo, ou conjunto de atributos, existente no conjunto de dados analisado (Navot, 2006). De modo mais abrangente, as pesquisas sobre seleção de características também envolvem pesquisas relacionadas à construção de representações apropriadas para os dados em análise, pois permite selecionar uma pequena quantidade de dados que confere bom desempenho ao classificador (Navot, 2006).

É importante notar que a seleção de características é também um processo de aprendizado, estando sujeita a overfitting. Sendo assim, os resultados obtidos devem ser avaliados antes de aceitos. Podem ser enumeradas quatro razões principais para justificar a utilização de seleção de características (Navot, 2006):

- Redução da complexidade computacional, pela seleção de um pequeno conjunto representativo de características, que produz um modelo mais simplificado para o problema em análise;

- Economia, pela diminuição do custo computacional (tempo e armazenamento), uma vez que apenas as características relevantes são analisadas, ignorando as demais existentes;

- Melhoria, em muitos casos, do desempenho final obtido pelo classificador;

- Entendimento do problema, pois uma análise das características selecionadas pode facilitar a compreensão da natureza do problema abordado. Isto é de extrema importância já que, em diversas situações, a capacidade de reconhecer as características mais informativas é mais relevante que a obtenção de uma boa resposta preditiva do classificador.

De acordo com o paradigma de seleção mais usual, uma função de avaliação é utilizada para atribuir pontuações a características ou subconjuntos destas, e um algoritmo de busca é utilizado para procurar pela característica ou subconjunto que possua a maior pontuação. Assim, os diferentes algoritmos de seleção existentes possuem variações na escolha da função de avaliação e do método de busca utilizados (Navot, 2006). 
Os procedimentos para seleção de características são divididos em três abordagens principais: wrappers, filtros e métodos embarcados. A abordagem por wrappers utiliza o desempenho de um classificador específico, que é visto como uma "caixa preta", para pontuar os subconjuntos de características.

Os filtros são aplicados em uma fase de pré-processamento, na qual os subconjuntos de características são selecionados de maneira independente do classificador que será utilizado. Métodos embarcados realizam a seleção de características automaticamente durante o processo de treinamento, o nome embarcado indica que o classificador possui, durante seu processo de aprendizado, a capacidade de selecionar as características mais relevantes, de acordo com algum critério (Guyon and Elisseeff, 2003).

A abordagem por wrappers oferece uma maneira simples e robusta para o problema de seleção de características, independente do classificador utilizado. De modo geral, esta abordagem consiste em utilizar o desempenho preditivo do classificador escolhido para identificar a importância de diferentes subconjuntos de características. Na prática, faz-se necessária a definição da maneira como o espaço de possíveis subconjuntos de características será percorrido, o modo como utilizar o desempenho preditivo do classificador para direcionar a busca no espaço de possibilidades e terminá-la no momento adequado, e a escolha de qual classificador utilizar (Guyon and Elisseeff, 2003).

Esta abordagem é criticada pois aparenta ser uma metodologia de "força bruta", mas isto não é necessariamente verdade. A utilização de estratégias de busca adequadas reduzem a complexidade computacional desta abordagem sem prejudicar o desempenho do classificador. De fato, estratégias de busca gulosa, tais como forward selection e backward elimination, se mostram adequadas em termos de complexidade da abordagem, além de robustez ao problema de overfitting (Guyon and Elisseeff, 2003).

A principal vantagem de utilizar wrappers está no fato da otimização ser feita com base no desempenho final do classificador. Em contrapartida, a principal desvantagem encontra-se na complexidade computacional, que limita a quantidade de subconjuntos de dados que podem ser avaliados. A complexidade computacional é elevada pois é preciso realizar um novo treinamento do classificador a cada novo subconjunto de características candidatas que será avaliado (Navot, 2006).

A abordagem por filtros utiliza diferentes métricas para avaliar a relevância dos subconjuntos de características em análise. Dentre estas métricas, pode-se citar a variância condicional dos atributos em relação à classe a que pertencem, o coeficiente de correlação, dentre outras (Navot, 2006). Diferentemente dos wrappers, esta abordagem não se limita apenas na seleção de um subconjunto de características. Filtros para o ranqueamento de atributos analisam individualmente cada característica do conjunto de dados, e são muito utilizados devido à simplicidade, 
escalabilidade e obtenção de bons resultados.

O ranqueamento de atributos calcula a importância individual das características presentes no conjunto de dados, atribuindo uma pontuação a cada uma delas e as ranqueando em ordem decrescente. Considere um conjunto com $m$ exemplares $x_{k}, y_{k}(k=1, \ldots, m)$ consistindo de $n$ atributos de entrada $x_{k, i}(i=1$, $\ldots, n)$ e um atributo de saída $y_{k}$. O ranqueamento de atributos utiliza uma função de pontuação $S(i)$ que é calculada a partir dos valores das características consideradas. Por convenção, assume-se que uma pontuação alta indica que aquele atributo é importante.

Ao utilizar o ranqueamento de atributos, são definidos subconjuntos aninhados incorporando, progressivamente, mais e mais atributos com relevância decrescente. O ranqueamento de atributos pode, considerando certas hipóteses de independência ou de ortogonalidade, obter o desempenho ótimo de um classificador. Porém, mesmo quando isto não ocorre, ele é vantajoso com relação a outros métodos que selecionam subconjuntos de características por ser robusto a overfitting e computacionalmente eficiente, já que requer apenas a realização dos cálculos de $n$ pontuações, ordenando-as adequadamente.

Uma crítica comum ao ranqueamento de atributos é que este leva à seleção de um subconjunto redundante. O mesmo resultado poderia ser obtido com um subconjunto menor de variáveis complementares (Guyon and Elisseeff, 2003). Vale ressaltar também que estes métodos são mais rápidos, mas falham em situações em que apenas uma combinação de características é capaz de conferir desempenho satisfatório ao classificador (Navot, 2006).

Em comparação com os wrappers, os filtros possuem como vantagem o menor tempo computacional de execução, obtido apenas por métodos embarcados recentes. Adicionalmente, como os filtros são utilizados em uma etapa de pré-processamento, isto reduz a dimensionalidade dos dados, diminui a probabilidade de overfitting e produz uma seleção de características genérica, não especializada para um classificador específico (Guyon and Elisseeff, 2003).

Os métodos embarcados, ao incorporarem a seleção de características em seu processo de aprendizado, se mostram mais eficientes que os wrappers em muitos aspectos. Os dados são utilizados de modo mais eficiente, sem a necessidade de dividir o conjunto de treinamento em duas partições, uma para treinamento e outra para validação. Além disso, as características são selecionadas de modo mais rápido, pois não é necessário treinar novamente o classificador a cada apresentação de um novo subconjunto de características. Como exemplos de métodos embarcados é possível citar os algoritmos CART e C4.5, baseados em ADs (Guyon and Elisseeff, 2003). 


\subsubsection{Algoritmos Selecionados}

Para a tarefa de seleção de características, são investigados nove diferentes algoritmos que seguem a abordagem por wrappers ou filtros, com o objetivo de explorar diferentes paradigmas de aprendizado, funções de avaliação e métodos de busca, na tentativa de obter uma boa generalização dos resultados. A descrição destes algoritmos é apresentada a seguir.

- Algoritmo Genético: Os AGs (Goldberg, 1989) são técnicas de busca heurística aleatória. Eles atuam sobre uma população de possiveis soluções aplicando o princípio da diversidade e da sobrevivência dos indivíduos mais adaptados ao ambiente, que se reproduzem através de operadores que imitam os conceitos genéticos, gerando descendentes que mais se aproximam da solução do problema. A técnica de seleção de características por AGs envolve a atribuição de um peso para cada característica, que corresponde à relevância ou importância na tarefa de inferência. Seja $\mu(S)$ a medida de desempenho usada para avaliar um subconjunto de características $S$, a seleção de características é essencialmente um problema de otimização que envolve a busca, no espaço de possíveis subconjuntos de características, de soluções que maximizem a precisão no teste do modelo de inferência, isto é, que identifiquem a solução ótima ou perto da ótima com respeito a $\mu$. A seleção de características utilizando AGs é efetiva na busca global rápida de grandes espaços de soluções em difíceis problemas de otimização. Entretanto, esta técnica é computacionalmente custosa, pois a seleção de características envolve executar o algoritmo para várias gerações.

- Forward Selection: É uma técnica de busca "gulosa" que tem início com um subconjunto vazio, ao qual as demais características são progressivamente inseridas, uma a uma. A cada iteração, a característica adicionada é aquela que confere melhor desempenho à função de avaliação (Navot, 2006). Isto garante um melhor tempo de processamento se comparada com a técnica Backward Elimination, que pode ser intratável se for aplicada a conjuntos de dados com dimensionalidade extremamente alta.

- Backward Elimination: Trata-se de uma técnica de busca "gulosa" que, inicialmente, analisa o subconjunto formado por todas as características existentes no conjunto principal e, progressivamente, vai eliminando, uma a uma, aquelas que não prejudicam o desempenho da função de avaliação. Isto permite que características irrelevantes sejam eliminadas, e que as complementares sejam mantidas (Navot, 2006). Esta técnica apresenta maior robustez que a técnica Forward Selection pois possui a vantagem de, ao avaliar a importância de uma determinada característica, considerar todas as demais existentes no conjunto. Já na técnica Forward Selection, uma característica adicionada em algum momento da busca pode se tornar irrelevante ou mesmo prejudicar o 
desempenho do subconjunto final selecionado. Assim como uma característica eliminada pode vir a ser importante para o subconjunto final, mas não poderá ser novamente adicionada.

- Linear Forward Selection: É uma extensão do algoritmo Best First, que utiliza uma função heurística para expandir uma busca entre os possíveis nós candidatos de um grafo. A heurística é aplicada globalmente, isto é, o caminho a ser percorrido é selecionado considerando todos os nós conhecidos, sendo escolhido para a expansão o nó de menor custo associado. A versão utilizada neste trabalho é a encontrada no simulador Weka, e permite que o usuário defina uma quantidade $n$ de passos backward a serem executados pelo algoritmo (Frank and Witten, 2005).

- Enxame de Partículas: O algoritmo Particle Swarm Optimization (PSO) modela o "comportamento social" observado em muitas espécies de pássaros, cardumes de peixes, e até mesmo dos seres humanos. A definição de enxame pode ser considerada como um conjunto de indivíduos que interagem localmente entre si, regidos por um comportamento global buscando, de modo distribuído, a solução para um problema. Desta forma, não há centralização de controle e o grupo consegue atingir as soluções desejadas de forma igualitária (Frank and Witten, 2005). Cada indivíduo de uma população possui sua própria experiência e é capaz de estimar a qualidade desta experiência, assim como também conhece o comportamento de seus vizinhos. Esses dois tipos de informação correspondem, respectivamente, à aprendizagem individual (cognitiva) e à transmissão cultural (social). Portanto, a probabilidade de que um determinado indivíduo tome uma certa decisão será em função de seu desempenho no passado e do desempenho de seus vizinhos, ou seja, o comportamento de cada partícula é influenciado pelo comportamento de todas as demais partículas. A posição de uma partícula representa uma solução candidata, enquanto a topologia do espaço de busca é dada pela função objetivo do problema. A cada partícula é atribuída uma velocidade, que representa as informações de direção e taxa de mudança de posição em função do tempo, e um atributo de desempenho ou adequação, obtido pela avaliação da função objetivo na posição da partícula. O processo de evolução da população de partículas conduz à obtenção de uma possivel solução ótima.

- Busca Scatter Search: É um método evolutivo que utiliza estratégias que se mostraram efetivas na resolução de diversos problemas de otimização, para diversificar e melhorar a busca. Com base em um conjunto de pontos de referência, que representam boas soluções obtidas em resoluções prévias do problema, o algoritmo sistematicamente explora o espaço de busca para encontrar uma solução ótima. Neste sentido, assim como ocorre nos demais 
algoritmos que seguem o paradigma evolutivo, ele trabalha com um conjunto (população) de soluções por iteração, e não apenas com uma única solução. Além disso, também combina as soluções existentes para obter novas soluções candidatas. No entanto, para a obtenção destas novas soluções, o algoritmo explora o conhecimento do contexto do problema, ou seja, utiliza métodos sistemáticos para a obtenção de novas soluções candidatas, não recorrendo a processos aleatórios. O algoritmo de busca Scatter Search é muito flexível, permitindo que cada um de seus elementos seja implementado de diferentes formas ou graus de sofisticação. A implementação utilizada neste trabalho é a disponibilizada pelo simulador Weka (Frank and Witten, 2005).

- Ranqueamento de Atributos: A utilização de filtros para o ranqueamento de atributos é também investigada, motivada pela simplicidade desta abordagem e da obtenção, em geral, de bons resultados. Para este trabalho, o ranqueamento é realizado pelos algoritmos SVM, ReliefF e Chi-Squared.

- SVM: Utiliza o classificador SVM para avaliar cada um dos atributos, que são ordenados com base no peso atribuído pela SVM. A seleção de atributos para problemas multi-classe é obtida pela ordenação dos atributos para cada classe separadamente, utilizando a metodologia "um-contra-todos".

- ReliefF: O algoritmo ReliefF é uma extensão do algoritmo Relief, capaz de lidar com ruído, dados incompletos e problemas multi-classes (Frank and Witten, 2005). A diferença principal entre ambos está no fato do algoritmo ReliefF, ao avaliar um atributo, considerar a distância deste à instância mais próxima pertencente à mesma classe dele, e também a uma classe diferente, para escolher a classificação correta do mesmo.

- Chi-Squared: Este algoritmo é baseado na estatística qui-quadrado, e avalia cada atributo de modo independente, pelo cálculo do valor desta estatística com relação aos rótulos das classes que representam o problema. Quanto maior o valor da estatística qui-quadrado obtido, maior a relevância de um determinado atributo para a classe analisada.

\subsubsection{Combinação de Algoritmos para Seleção de Características}

De acordo com Prampero (1998), o desenvolvimento de uma combinação de algoritmos tem como objetivo resolver problemas mais gerais, que envolvem diferentes tipos de dados, ou aqueles que não são resolvidos satisfatoriamente por um único algoritmo e/ou em que o desempenho apresentado pelo módulo de classificação deve ser estável.

A escolha de quantos e quais algoritmos serão combinados depende do problema em análise. Para que a combinação seja bem sucedida é aconselhável utilizar algoritmos de diferentes características que possam se complementar, ou seja, a 
ênfase da combinação deve estar na exploração da similaridade ou da diferença de cada um dos algoritmos envolvidos. Da similaridade porque oferece mais garantias de que a decisão indicada por um algoritmo foi correta, da diferença porque dados classificados incorretamente por um algoritmo podem ser classificados corretamente por outro(s).

As principais estratégias utilizadas para a combinação de algoritmos são a votação por maioria ou por consenso. Na primeira delas, para $n$ algoritmos avaliados, se ao menos $m$ deles, em que $m$ é maior que $n / 2$, classificarem o exemplar como pertencente a uma determinada categoria, esta será a classificação escolhida. Quanto maior o valor atribuído a $m$, mais conservador se torna o método, uma vez que mais algoritmos devem classificar um exemplar como pertencente a uma categoria. Na estratégia por consenso, para que um exemplar seja considerado de uma categoria específica, é preciso que todos os $n$ algoritmos empregados classifiquem-no como pertencente a ela. Nesse sentido, a estratégia de votação por consenso, em oposição à combinação por maioria, resultará em um resultado mais conservador.

Como os algoritmos de seleção de características selecionados para utilização neste trabalho seguem diferentes paradigmas de aprendizado, funções de avaliação e métodos de busca, uma combinação destes pode trazer vantagens. O objetivo da combinação desenvolvida é garantir que as características faciais selecionadas sejam efetivas não apenas para o reconhecimento de emoções, mas também confiram independência do algoritmo de seleção ou do classificador utilizado. Ainda, as combinações desenvolvidas podem refinar o processo de seleção de características, facilitando a compreensão das similaridades ou diferenças existentes entre distintas expressões faciais emocionais.

\subsection{Considerações Finais}

Neste capítulo são descritos os algoritmos empregados para modelar o sistema de reconhecimento emocional humano. Mapas de saliência, imagens térmicas, métodos baseados em aparência e medidas estatísticas são utilizados na modelagem do mecanismo de pré-atenção visual.

São também apresentados, para facilitar o entendimento dos algoritmos investigados para o reconhecimento emocional por meio da análise da face humana, os conceitos principais relacionados à área de AM, uma linha de pesquisa da Inteligência Artificial que estuda o desenvolvimento de métodos capazes de extrair conhecimento a partir de conjuntos de dados.

Para permitir a identificação das características de diagnóstico das expressões faciais emocionais investigadas, uma etapa de seleção de características é realizada. Para facilitar a análise dos módulos de combinação desenvolvidos, fundamentos sobre seleção de características, com a apresentação dos algoritmos utilizados, e conceitos sobre combinação de algoritmos de seleção de características, são também 
apresentados. Deste modo, a modelagem proposta por este projeto, bem como os experimentos realizados e os resultados obtidos, são apresentados nos próximos capítulos. 


\section{Modelagem para 0}

\section{Reconhecimento das Emoções}

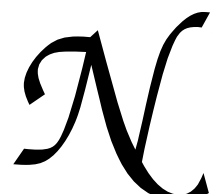

este capítulo, o desenvolvimento de uma modelagem computacional, baseada em evidências psicológicas e conceitos biológicos para simular o sistema de identificação emocional humano, é detalhado na Seção 6.1. Especificamente, a Subseção 6.1.1 apresenta a abordagem para simular a existência do mecanismo de pré-atenção visual presente nos seres humanos. Na Subseção 6.1.2, as representações faciais propostas para a identificação do estado emocional de um indivíduo, que seguem a modelagem geométrica, são descritas e, na Subseção 6.1.3, é explicada a abordagem computacional desenvolvida para a identificação das características faciais de diagnóstico. Concluindo, as considerações finais são encontradas na Seção 6.2 .

\subsection{Modelagem Computacional Proposta}

Diferentes evidências psicológicas e biológicas são utilizadas para modelar computacionalmente o sistema de reconhecimento emocional humano. Neste sentido, para modelar os mecanismos de pré-atenção visual e de identificação das características faciais mais importantes para o reconhecimento das emoções, duas teorias são utilizadas. A primeira propõe a existência de um mecanismo de pré-atenção visual, que permite aos seres humanos interpretar as expressões faciais emocionais, mesmo que o foco da atenção aconteça por um curto período de tempo. A segunda defende a existência de características de diagnóstico, diferentes para cada emoção, e responsáveis pelo direcionamento do olhar (foco da atenção) a regiões específicas da face. A identificação destas características pelos seres humanos possibilita o 
reconhecimento de uma emoção específica.

Estas duas teorias se complementam, pois a pré-atenção visual é um mecanismo rápido de reconhecimento emocional, e a identificação das características de diagnóstico visa assegurar que a emoção previamente identificada está correta, ou permite a escolha de outra emoção que se mostre mais adequada de acordo com o observado.

Vale destacar que as teorias psicológicas apresentadas não permitem especificamente identificar as regiões ou características faciais de diagnóstico utilizadas no processo de reconhecimento emocional. Neste sentido, utilizando a hipótese psicológica de que o cérebro humano se baseia na percepção de alterações na configuração (ou disposição) dos elementos faciais para o reconhecimento da expressão emocional de um indivíduo, representações geométricas da face são desenvolvidas. Estas representações mapeiam diferentes relações entre os elementos faciais, disponibilizando um conjunto de atributos que podem ser utilizados como características de diagnóstico emocionais.

Ainda, diferentes teorias psicológicas discutem sobre a utilização de modelos discretos ou contínuos para a modelagem emocional e, mesmo dentre os modelos discretos, não existe consenso de quais emoções considerar como básicas. Deste modo, para identificação das emoções, este trabalho adota o modelo discreto proposto por Ekman (1999), que afirma a existência de seis emoções básicas, a saber: alegria, tristeza, raiva, medo, surpresa e aversão. Para facilitar a compreensão da modelagem, a representação gráfica da mesma é apresentada na Figura 6.1.

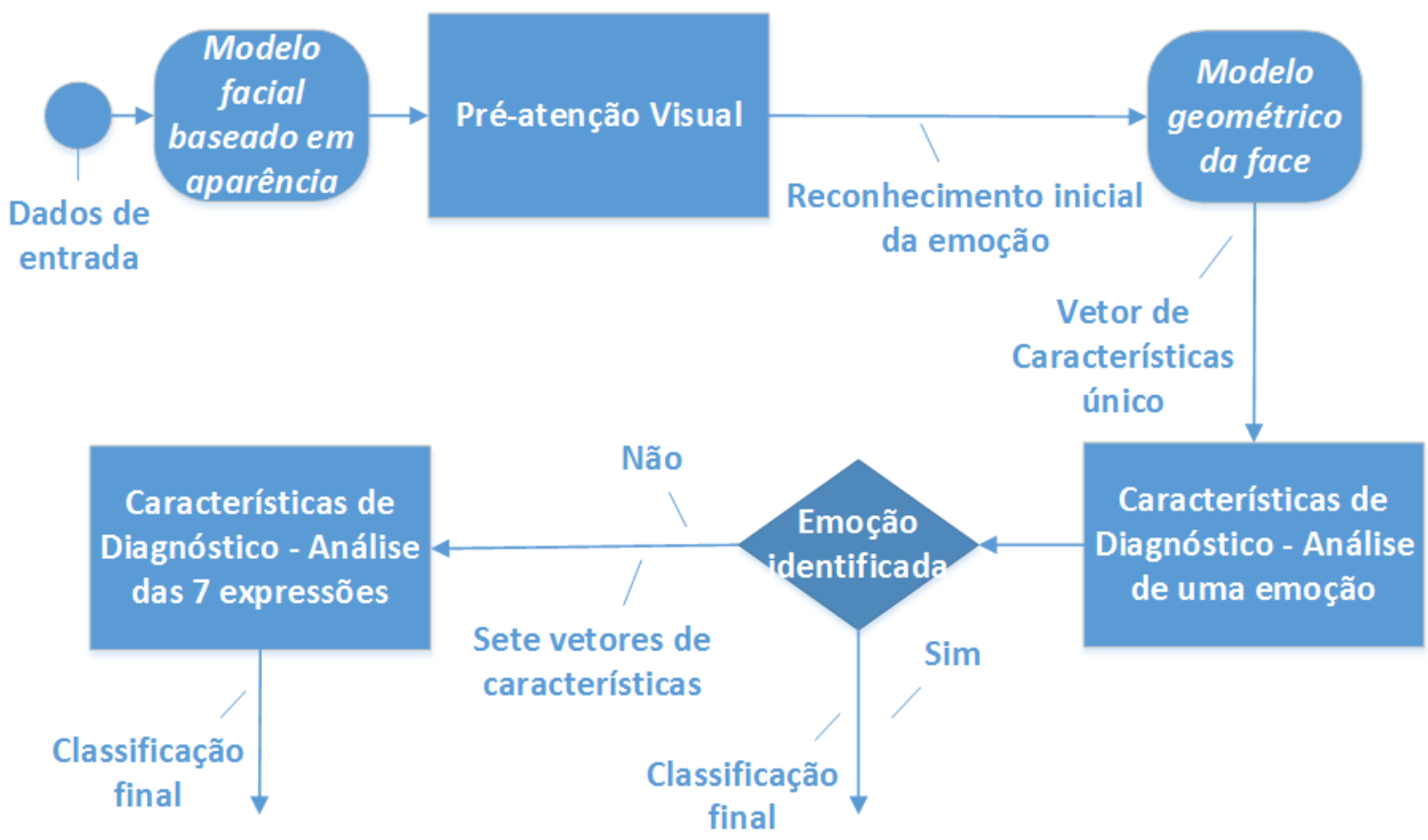

Figura 6.1: Representação gráfica da modelagem desenvolvida.

Como pode ser observado, uma abordagem híbrida para a representação da 
face é desenvolvida. A motivação para esta escolha é o fato de que métodos baseados em aparência e em geometria podem, de acordo com a literatura (Tian et al., 2005), melhorar o reconhecimento de algumas das expressões emocionais avaliadas quando utilizados em conjunto. Ainda, o modelo baseado em aparência desenvolvido, que fornece informações de características da face para a pré-atenção visual, é também híbrido, e composto por imagens térmicas e vísiveis com o objetivo de minimizar problemas de qualidade e luminosidade encontrados em imagens provenientes de câmeras RGB.

A modelagem computacional reconhece, como dados de entrada válidos, faces na posição frontal. Deste modo, uma face é identificada e o reconhecimento inicial da emoção é realizado pela pré-atenção visual. Em seguida, os vetores que contêm as características geométricas de diagnóstico da emoção identificada são avaliados para validar o reconhecimento prévio, que é rápido porém menos preciso, no intuito de obter uma classificação final confiável. Caso isto não aconteça, ou seja, se as características de diagnóstico e a pré-atenção divergem sobre a emoção que o usuário expressa, vetores de características das seis emoções básicas e da expressão neutra são avaliados em um etapa mais lenta, capaz de identificar a emoção em análise.

Ainda, os paradigmas de aprendizado supervisionado e não supervisionado são empregados para identificar a expressão emocional. Estes dois paradigmas já foram aplicados no reconhecimento de emoções pela análise da face com a obtenção de bons resultados. No entanto, de acordo com a literatura, o paradigma não supervisionado possui uma quantidade menor de trabalhos que o exploram. Do mesmo modo, trabalhos que se valem de ambos são ainda menos encontrados. Na modelagem desenvolvida, o mecanismo de pré-atenção visual é responsável pela etapa não supervisionada, e as características de diagnóstico são avaliadas pelos algoritmos supervisionados.

Vale destacar que, além do benefício de utilizá-los em conjunto para explorar as complementariedades existentes entre eles, o emprego do paradigma não supervisionado no mecanismo de pré-atenção visual possibilita a utilização da modelagem em aplicações reais, nas quais é desconhecida, a priori, a emoção do usuário e, portanto, os algoritmos supervisionados, que necessitam de informações sobre a classe dos dados, não podem ser aplicados de modo eficiente. Desta forma, os algoritmos não supervisionados associam a expressão inicialmente reconhecida a uma das partições existentes e, pela análise desta partição, a emoção é identificada.

\subsubsection{Abordagem para o Mecanismo de Pré-atenção Visual}

Para simular o mecanismo de pré-atenção visual humano, imagens térmicas e mapas de saliência são utilizados. O objetivo é, de forma rápida e eficiente, identificar o estado emocional de uma pessoa. A utilização de mapas de saliência adiciona, além de conceitos psicológicos, uma fundamentação biológica para a modelagem 
computacional desenvolvida.

Os mapas de saliência destacam elementos da cena que atraem a atenção visual de um observador. Do ponto de vista neurobiológico, a saliência de um campo visual é alcançada de maneira pré-atencional (Itti and Koch, 2001). Uma vez que não é conhecido o funcionamento do mecanismo de pré-atenção visual dos seres humanos, a proposta de incorporação de mapas de saliência pode resultar em uma modelagem que se assemelhe a seu real funcionamento. Já as imagens térmicas são investigadas para aumentar a confiabilidade deste sistema pois complementam as principais deficiências encontradas com a utilização de imagens visíveis (Kong et al., 2005; Mekyska et al., 2010).

A variância e o desvio-padrão, medidas estatísticas de dispersão, além da entropia, uma medida estatística de incerteza, são utilizados para extração de informações relevantes das expressões faciais avaliadas. Esta escolha se baseia no fato destas medidas terem sido aplicadas, com a obtenção de bons resultados, em diferentes trabalhos encontrados na literatura. Ainda, o método de histograma de gradientes orientados (HOG), baseado em aparência, também é utilizado. O emprego de métodos baseados em aparência em conjunto com métodos baseados em geometria, utilizados na modelagem das seis representações faciais desenvolvidas neste trabalho, visa obter melhorias no desempenho final encontrado, dada a complementariedade existente entre eles.

Para a modelagem computacional do mecanismo de pré-atenção visual, as imagens visíveis e térmicas são alinhadas e registradas como apresentado na Subseção 8.1. Em seguida, é feita a detecção da face. Para as imagens visíveis a detecção facial é obtida por meio do sistema de visão computacional Face Tracker (Saragih et al., 2011). Para as imagens térmicas, as faces são detectadas pela aplicação do algoritmo de segmentação proposto por Mekyska et al. (2010).

Resumidamente, este algoritmo detecta as coordenadas geométricas de um retângulo circunscrito na face, utilizando o método proposto por Otsu (1979) para, inicialmente, produzir uma versão binária da imagem original. A projeção vertical da imagem binária determina o limite superior $y_{1}$ da face, enquanto o restante da imagem é horizontalmente dividida em duas partes iguais. Para obter a projeção horizontal, a primeira das duas partes resultantes da imagem é utilizada. Deste modo, os limites esquerdo $x_{1}$ e direito $x_{2}$ são encontrados. Finalmente, como apresentado na Equação 6.1, a proporção áurea é utilizada para o cálculo do limite inferior $y_{2}$ da face.

$$
y_{2}=y_{1}+\left(x_{2}-x_{1}\right) * 1.618
$$

Na Figura 6.2 podem ser observados a imagem original, pertencente à base de dados USTC-NVIE, e o resultado da aplicação do algoritmo de segmentação de faces em imagens térmicas proposto por Mekyska et al. (2010). Neste trabalho, 
este algoritmo é implementado por uma função desenvolvida em Matlab (Matsumoto, 2013).

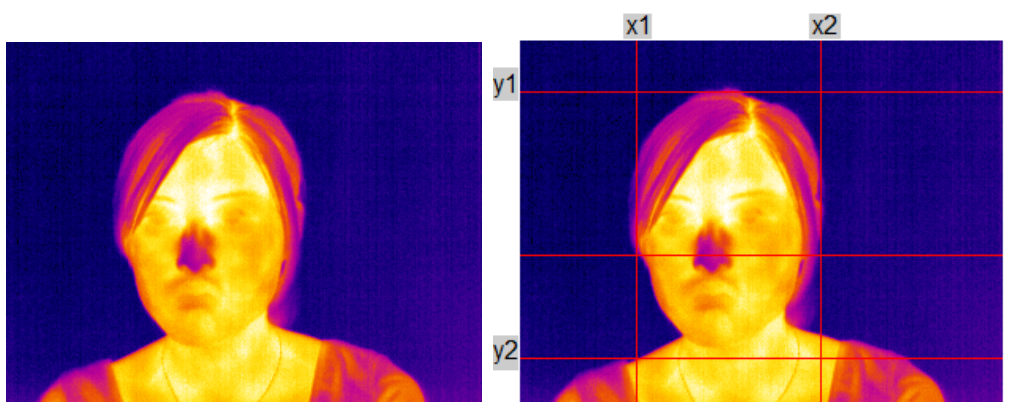

Figura 6.2: Aplicação do algoritmo de segmentação facial em imagens térmicas. À esquerda tem-se a imagem térmica original e, à direita, os limites faciais obtidos podem ser vistos.

Uma vez identificadas, as regiões faciais são recortadas. No entanto, como pode ser observado na Figura 6.3, a área ao redor da face também é obtida. Neste sentido, uma máscara elíptica é aplicada às imagens, como apresentado na Figura 6.4. Isto é feito para reduzir as influências do ambiente nos resultados obtidos pela aplicação dos métodos utilizados na modelagem.

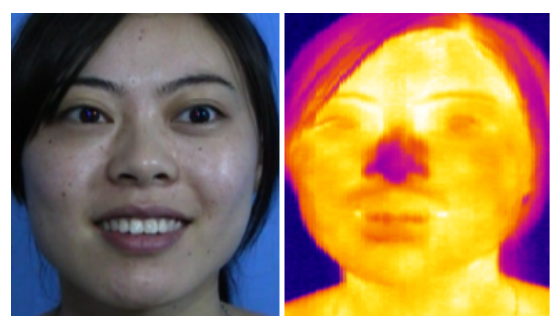

Figura 6.3: Recorte original aplicado às faces.

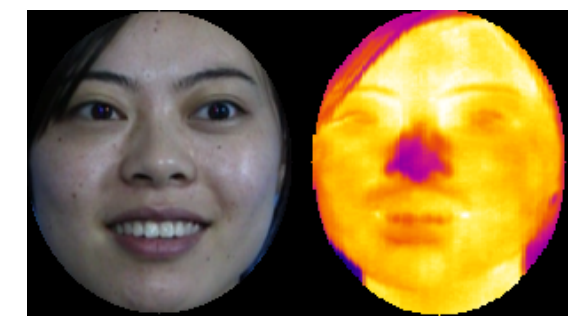

Figura 6.4: Aplicação da máscara elíptica, para minimizar as influências do ambiente.

A preocupação em minimizar as influências do ambiente advém do fato que, na abordagem desenvolvida, as faces são analisadas como um todo integrado, ou seja, de forma holística, sem a divisão em distintas "regiões de interesse". Esta escolha é feita com base em estudos comportamentais e psicológicos. Ainda, esta abordagem pode ser vantajosa, pois não existem garantias de que as regiões não selecionadas da face realmente não possuam informação relevante para o problema em análise. Porém, se ruídos do ambiente forem erroneamente considerados, os 
métodos aplicados podem ter seus resultados deteriorados.

Após o tratamento imposto às imagens para obter as regiões faciais, os mapas de saliência das imagens visíveis são calculados. Assim, as imagens térmicas e os mapas de saliência, utilizados para o reconhecimento emocional, estão prontos para análise. Deste modo, a entropia, variância, desvio-padrão, e o método HOG são aplicados a estas imagens para obtenção dos vetores de características que as representam.

Para a avaliação destes vetores, os algoritmos de agrupamento de dados k-médias e x-médias são utilizados. Eles seguem o paradigma de aprendizado não supervisionado para dividir os dados analisados em partições, de acordo com padrões de similaridade encontrados. O objetivo é identificar um conjunto de características que permita a estes algoritmos adequadamente separar as expressões faciais emocionais em partições distintas.

Deste modo, a pré-atenção visual atua como uma primeira triagem emocional, ou seja, é um mecanismo inicial de reconhecimento, que rapidamente identifica a provável expressão emocional do usuário, para direcionar quais características de diagnóstico devem ser analisadas. Este resultado será, posteriormente, validado por um mecanismo mais lento, que utiliza a análise geométrica da face para obter as características de diagnóstico e, assim, confirmar ou alterar o reconhecimento previamente realizado.

\subsubsection{Representações Faciais para o Reconhecimento de Emoções}

Os métodos baseados em características geométricas são utilizados na modelagem facial devido à existência de evidências psicológicas indicando que esta abordagem é mais semelhante à maneira como os seres humanos interpretam os elementos da face. Neste sentido, seis diferentes representações faciais são propostas para a identificação das emoções. Estas representações são capazes de codificar a configuração facial apresentada durante a expressão de uma emoção, assim como as diferenças entre esta configuração em relação a um modelo de face neutra, que não apresenta emoção. Deste modo, possibilitam a exploração de uma grande variedade de atributos e relações faciais, com o objetivo de disponibilizar um conjunto representativo de informações para ser utilizado na identificação das características de diagnóstico.

O sistema de visão computacional utilizado para a obtenção das informações faciais é o Face Tracker. Este sistema utiliza uma estratégia de otimização baseada em especialistas locais para o ajuste de um modelo deformável. Ajuste de modelo deformável é o problema de encontrar uma configuração ótima, ou seja, que melhor descreve o objeto de interesse, para um modelo de contorno parametrizado. Para isto, emprega uma aproximação linear na maneira como o formato de um objeto não rígido sofre deformações, ajustando os pontos de referência em localizações 
consistentes do objeto analisado a fim de registrar um modelo parametrizado para a imagem. Neste sentido, com base em um modelo de referência da face, composto por 66 pontos característicos, para cada nova imagem, o algoritmo do Face Tracker busca alinhar os elementos da face em análise com os pontos característicos do modelo de referência, para ajustar um modelo à esta nova face. A Figura 6.5 apresenta o exemplo de uma face mapeada pelo Face Tracker.

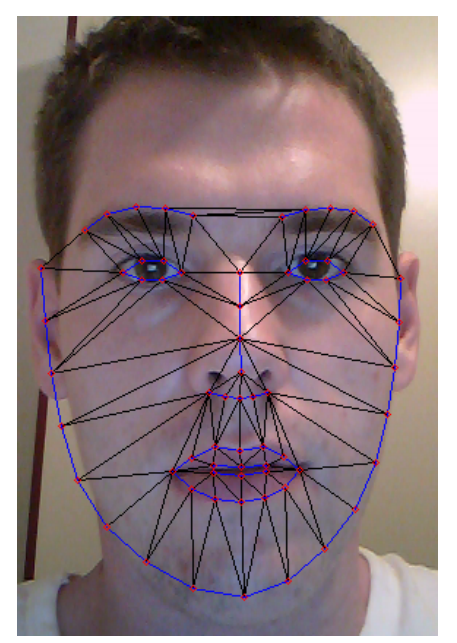

Figura 6.5: Mapeamento facial obtido pelo Face Tracker, baseado em 66 pontos característicos.

Os elementos considerados pelas representações propostas mapeiam as regiões faciais que estão essencialmente relacionadas a movimentos realizados quando da expressão de uma emoção, de acordo com estudos da psicologia (Ekman, 1999) (Ekman et al., 2002). Para obtê-los, o Face Tracker foi modificado para mapear apenas um subconjunto dos 66 pontos faciais inicialmente obtidos, composto por 33 pontos característicos. Experimentos apresentados na Subseção 7.2.1 do Capítulo 7 indicam que esta quantidade de pontos é suficiente para representar, de maneira satisfatória, a face humana.

A Figura 6.6 apresenta os elementos faciais considerados nas representações desenvolvidas. Nela é possivel notar que os 33 pontos selecionados estão distribuídos da seguinte maneira: oito mapeiam os lábios (boca), doze pontos mapeiam os olhos, seis para cada um deles. As narinas são representadas por dois pontos, assim como três pontos delimitam cada uma das sobrancelhas. O contorno facial é delimitado por cinco pontos característicos, sendo três para mapear o queixo, um para a extremidade direita, e o último para a extremidade esquerda da face. Estes pontos são apresentados em vermelho. Para representar o formato dos olhos, da boca, e de regiões faciais que ativam movimentos musculares emocionais, existem oito áreas, que podem ser observadas pelas regiões demarcadas em preto. Além disso, diferentes ângulos e distâncias entre os 33 pontos mapeados, não apresentados na figura para facilitar a visualização do modelo desenvolvido, completam as representações propostas. 


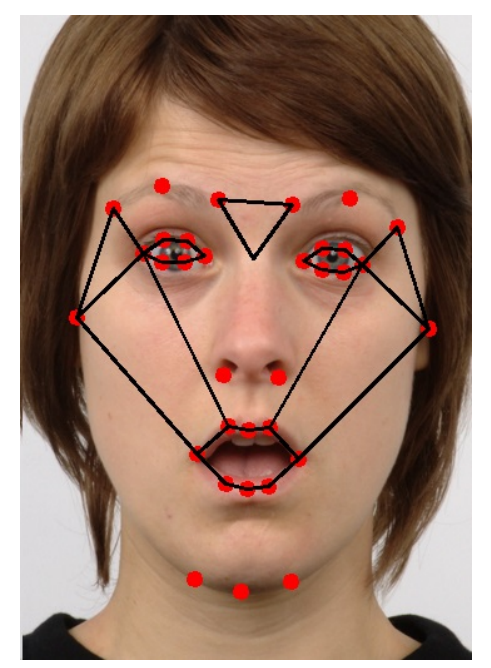

Figura 6.6: Apresentação gráfica das representações faciais desenvolvidas, ilustrada em uma imagem da base de dados RaFD.

Para facilitar as explicações, os diferentes vetores de características geométricas das representações faciais propostas são denominados, de agora em diante, como $F S_{1}, F S_{2}, F S_{3}, F S_{4}, F S_{1-3}$ e $F S_{2-4}$.

Para obter as representações $F S_{1}$ e $F S_{2}$, a diferença está nos ângulos e distâncias utilizados. Para a primeira, considerando todas as possíveis combinações de pontos, são calculados os ângulos que a linha conectando dois pontos distintos faz com a horizontal, assim como as respectivas distâncias. Isto resulta em 528 ângulos e distâncias diferentes. Desta forma, esta representação possui dimensionalidade $D_{1}=2 * 33+8+2 * 528=1130$ atributos.

Para a segunda, apenas um subconjunto das distâncias e ângulos da representação $F S_{1}$ são considerados. Neste sentido, são selecionados apenas as distâncias e ângulos existentes entre o lábio superior e as narinas, e entre o lábio inferior e o queixo. Assim como aqueles que mapeiam as regiões internas dos olhos e da boca, resultando em 107 ângulos e distâncias distintos. Deste modo, a dimensionalidade obtida é de apenas $D_{2}=2 * 33+8+2 * 107=288$ atributos.

É importante observar que esta representação é capaz de descrever alterações na boca e nos olhos, assim como movimentos da boca em relação às narinas ou ao queixo. Como as oito áreas continuam sendo consideradas, e supondo que estas são capazes de adequadamente representar os demais movimentos faciais emocionais que não são mapeados devido à remoção de alguns dos ângulos e distâncias iniciais, uma boa representatividade pode ser obtida, com a vantagem de apresentar reduzida dimensionalidade.

O principal objetivo desta representação é diminuir o custo computacional elevado imposto pelo cálculo de todos os ângulos e distâncias da representação $F S_{1}$, além da vantagem de eliminar possíveis redundâncias. A diminuição da quantidade de dados de entrada para os algoritmos de Aprendizado de Máquina (AM) melhora o processo de generalização, pois evita a produção de classificadores especializados e 
com elevada complexidade.

Estas duas representações possuem apenas características obtidas em um determinado instante na imagem analisada, ou seja, apenas no ápice das expressões emocionais. Não existem informações que comparem as alterações existentes entre o ápice de uma expressão e a expressão neutra, que representa a ausência de emoção. Sendo assim, as representações faciais $F S_{3}$ e $F S_{4}$ baseadas, respectivamente, nas representações $F S_{1}$ e $F S_{2}$, são propostas.

Elas apresentam informações sobre as diferenças existentes entre uma expressão emocional e uma expressão neutra, analisando alterações nas características faciais investigadas. Vale ressaltar que estas duas novas representações faciais contém informações apenas das diferenças observadas nas características faciais em análise, ou seja, diferenças nas coordenadas dos pontos característicos, distâncias, ângulos e áreas, e não possuem o valor real apresentado por estas características.

Por fim, as representações faciais $F S_{1-3}$ e $F S_{2-4}$ que correspondem, respectivamente, à combinação das representações $F S_{1} \operatorname{com} F S_{3}$, e das representações $F S_{2}$ com $\mathrm{FS}_{4}$, são propostas. O objetivo é investigar se as informações obtidas no ápice de uma expressão emocional, em conjunto com as informações das diferenças existentes entre uma expressão neutra e uma expressão emocional, possuem informações complementares que contribuam para uma melhor análise das emoções.

Para classificar as diferentes informações codificadas pelas representações faciais descritas em uma das seis emoções básicas investigadas ou na expressão neutra, os algoritmos de AM utilizados são as SVMs, algoritmo C4.5 e redes MLP, que seguem o paradigma de aprendizado supervisionado.

\section{Modelo de Face Neutra}

Algumas das representações faciais apresentadas utilizam informações das diferenças existentes entre uma expressão neutra e uma expressão emocional. Para isto precisam que, de algum modo, as informações faciais da expressão neutra de um usuário sejam obtidas, já que a falta destas informações implica na impossibilidade de análise de quatro das seis representações propostas.

Neste sentido, para garantir a aplicabilidade das representações faciais a sistemas reais, um modelo de face neutra, baseado em evidências psicológicas, é proposto. Tais evidências indicam que os seres humanos têm maior facilidade para identificar expressões faciais emocionais de pessoas da região em que vivem (Martinez and Du, 2012).

Uma vez que cada região é habitada por uma raça específica, a psicologia acredita que cada pessoa avalia as mudanças nas expressões faciais de acordo com um modelo de face existente em sua mente, que é adotado como padrão para aquela raça, e que provavelmente é resultado da observação ao longo dos anos. Deste modo, pessoas de diferentes regiões apresentam características faciais diversas por serem 
de raças distintas, e isto prejudica a identificação da expressão facial emocional, pois a face observada não segue o padrão esperado pelo cérebro. Como exemplo, é possivel citar a dificuldade de latino-americanos, que apresentam emoções mais exageradas, em identificar as emoções de povos asiáticos, que são mais contidas, e vice-versa.

De acordo com o apresentado, o modelo de face neutra é composto por diferentes modelos faciais criados separadamente para cada gênero, masculino ou feminino, e raça considerados. Deste modo, para cada modelo desenvolvido, considerando uma única raça e gênero, são obtidas medições dos 33 pontos mapeados pelo Face Tracker. Em seguida, é efetuado o cálculo das médias individuais de cada um dos 33 pontos mapeados, resultando em um vetor composto por 33 pontos médios.

Para incluir variabilidade às médias obtidas, o desvio-padrão médio observado durante as medições de cada um dos pontos considerados é também adicionado às médias individuais. Desta forma, cada um dos 33 pontos do vetor resultante representa a média das posições individuais de cada ponto e a variabilidade observada nas amostras utilizadas. As raças consideradas no modelo de face neutra proposto são as existentes nas bases de dados RaFD e CK+, a saber, caucasiana ou branca, negra e asiática.

Em seguida, para cada sexo, os vetores obtidos para as três raças consideradas são unidos pelo cálculo de uma combinação linear. A proporção de contribuição de cada raça ao modelo é definida por meio de um peso, que é aplicado ao vetor de características representante de cada raça. Isto permite alterar as proporções de influência das raças de acordo com a região que o sistema será utilizado, privilegiando as características de raças específicas.

Ao final deste processo, dois modelos de face neutra são obtidos, um para o sexo masculino e outro para o sexo feminino. Estes dois modelos são utilizados em conjunto. Vale destacar que o modelo de face neutra proposto é extensível, pois permite a adição de novas raças, desde que existam exemplos suficientes para a obtenção dos vetores de características necessários ao cálculo da combinação linear.

Para exemplificar, considere que uma face foi identificada pelo Face Tracker e padronizada pelas transformações afins já citadas. Seis pontos faciais característicos são utilizados como referência para aplicar o modelo de face neutra desenvolvido. Os pontos considerados são as extremidades direita e esquerda de cada olho e os pontos que representam as narinas, selecionados por não se movimentarem durante a expressão de diferentes emoções. Estes pontos são utilizados para comparar a face em análise com os modelos da expressão neutra existentes para os sexos masculino e feminino, com o objetivo de identificar qual apresenta maior similaridade com esta face para, assim, ser utilizado como referência na criação dos vetores de características das representações faciais. 
Duas maneiras distintas, que utilizam a distância Euclidiana, são avaliadas para o cálculo da similaridade. Na primeira, a quantidade de pontos mais próximos é considerada para a escolha do modelo de face neutra. Sendo assim, cada ponto da face em análise tem sua distância calculada ao correspondente ponto de referência dos modelos de face neutra masculino e feminino. O ponto que apresenta a menor distância euclidiana é atribuído ao modelo correspondente. Ao final deste processo, cada modelo tem um quantidade de pontos associada e ele. O modelo com a maior quantidade de pontos é selecionado para utilização, já que isto indica a obtenção de menores distâncias euclidianas e, portanto, maior similaridade. A quantidade de pontos utilizada possibilita a existência de empates durante a análise, se isto ocorrer, a segunda maneira é utilizada para escolha do modelo.

Na segunda maneira, a distância euclidiana média é considerada. Neste sentido, para cada um dos seis pontos de referência, são calculadas as distâncias individuais deles aos pontos correspondentes da face em análise. Todas as seis distâncias calculadas são somadas e a média é calculada. Desta forma, são obtidas duas distâncias médias, para os modelos de face neutra masculino e feminino. A menor distância média encontrada indica o modelo que será utilizado para obtenção das representações faciais.

\subsubsection{Abordagem para a Identificação das Características Faciais}

A identificação de características faciais utiliza nove diferentes algoritmos de seleção, que são aplicados às seis representações faciais, para obter as características de diagnóstico de cada uma das emoções investigadas, além da expressão neutra. Os algoritmos de seleção investigados, selecionados para garantir generalização aos resultados obtidos, são algoritmo genético (AG), forward selection, backward elimination, linear forward selection, algoritmo por enxame de partículas (PSO), busca scatter search, e ranqueamento de atributos utilizando os algoritmos reliefF, chi-squared e SVM.

A abordagem proposta tem como objetivo validar os estudos psicológicos que demonstram que os seres humanos direcionam o olhar para regiões específicas da face durante o processo de reconhecimento de emoções. Ainda, uma vez que estes estudos não revelam as características faciais de diagnóstico envolvidas neste processo, espera-se identificar tais características, com base na relevância computacional apresentada para a identificação da expressão emocional.

Além dos nove algoritmos de seleção utilizados, quatro diferentes funções de avaliação também são investigadas para cada algoritmo. Três destas funções de avaliação seguem a abordagem por wrappers, sendo utilizadas as SVMs, o algoritmo C4.5 e o algoritmo Naïve Bayes (Mitchell, 1997) para avaliar o processo de seleção de características. A quarta função de avaliação, ConcistencySubsetEval, é baseada na análise da consistência de uma classe. Os exemplares de treinamento são apresen- 
tados a cada uma das classes do problema, sendo obtidas as respectivas métricas de consistência. Sendo assim, um exemplar é atribuído à classe que apresentar a melhor métrica de consistência após a sua inclusão (Frank and Witten, 2005). Estas funções de avaliação são selecionadas pois apresentam bons resultados na análise de conjuntos de dados de elevada dimensionalidade, como os investigados neste trabalho.

Para garantir que as características faciais escolhidas pelos algoritmos de seleção estejam relacionadas apenas ao processo de reconhecimento de uma única emoção, cada uma das emoções estudadas é individualmente analisada, ou seja, um procedimento de seleção de características é realizado para cada emoção. A diversidade de paradigmas de aprendizado dos algoritmos de seleção avaliados propicia a criação de diferentes subconjuntos de características faciais. Neste sentido, considerando um único algoritmo de seleção e uma emoção, 24 diferentes subconjuntos de características são obtidos, sendo quatro para cada representação facial.

Para obter subconjuntos mais gerais, a fim de diminuir a relação entre as características obtidas e a função de avaliação utilizada pelo algoritmo de seleção, combinações dos subconjuntos obtidos pelos algoritmos de seleção são desenvolvidas, de acordo com três estratégias: votação por maioria ou por consenso, e união de todas as características existentes. Como consequência, são criados até três novos subconjuntos para cada representação facial. Ao final desta primeira etapa obtém-se, para cada algoritmo de seleção e emoção avaliados, um máximo de 42 subconjuntos de características distintos.

Estes subconjuntos são avaliados pelos algoritmos SVMs, redes MLP e algoritmo C4.5. Aqueles que apresentam os melhores desempenhos, calculados pela acurácia média obtida para os três classificadores são, então, combinados novamente segundo as três estratégias de combinação.

Esta segunda etapa permite obter combinações dos subconjuntos que apresentam os melhores desempenhos médios, com o objetivo de melhorar ainda mais a taxa de acerto final da classificação. É importante notar que esta segunda etapa produz novos subconjuntos apenas para as representações faciais que obtêm desempenho satisfatório. Para a definição dos melhores subconjuntos, o teste estatístico Student $t$ (Mason et al., 1989) é aplicado, e são escolhidos aqueles que apresentam desempenho estatístico igual ou superior ao obtido pela respectiva representação facial original que o subconjunto em análise simplifica.

$\mathrm{Na}$ terceira etapa de análise, os melhores subconjuntos encontrados, resultantes ou não das combinações desenvolvidas, são combinados de acordo com a representação facial que simplificam, mas considerando todos os algoritmos de seleção. Sendo assim, são obtidos novos subconjuntos de características para todas as representações faciais que apresentam bom desempenho, mas agora independentes do algoritmo de seleção empregado. Deste modo, pretende-se selecionar 
características faciais relacionadas intrinsecamente ao processo de reconhecimento emocional, que sejam independentes dos algoritmos utilizados. Por fim, estes novos subconjuntos têm seu desempenho avaliado de acordo com a taxa de acerto média obtida para os três classificadores.

Para concluir o processo de seleção de características, uma quarta etapa de combinações é realizada. Nela, as três estratégias são aplicadas a todos os melhores subconjuntos encontrados, que estão divididos por representação facial. Esta última etapa produz um máximo de até três novos subconjuntos de características que são independentes das representações faciais e dos algoritmos de seleção.

Dentre todos os subconjuntos resultantes, aqueles que apresentam a melhor taxa de acerto média obtida para os três classificadores são selecionados para representar a emoção em análise. Esta quarta etapa apenas pode ser realizada se os melhores subconjuntos encontrados pertencem a diferentes representações faciais. Vale salientar também que, após todo o processo realizado, podem ser obtidos subconjuntos de características diferentes que apresentam o mesmo desempenho e, portanto, igual importância computacional para a identificação de uma emoção específica.

Para facilitar a compreensão do procedimento de seleção de características explicado, a Figura 6.7 apresenta, considerando uma única emoção, o processo global para a seleção das características faciais. Como este procedimento é composto por diversas etapas intermediárias, pode ser observado, na Figura 6.8, o processo realizado com cada algoritmo de seleção para obter os melhores subconjuntos de características.

\subsection{Considerações Finais}

Este capítulo descreve as diferentes etapas propostas para modelar o sistema de reconhecimento emocional humano. Métodos baseados em características geométricas são utilizados para o desenvolvimento de seis representações que mapeiam a face de modo distinto, permitindo analisar as características importantes para a identificação das emoções. Esta análise é feita pelos algoritmos de seleção, que identificam as características faciais de diagnóstico, de acordo com o desempenho computacional obtido.

Imagens térmicas e mapas de saliência são utilizados para simular o mecanismo de pré-atenção visual encontrado nos seres humanos. Imagens térmicas complementam as informações obtidas a partir das imagens visíveis, pois permitem o reconhecimento facial mesmo em diferentes condições de iluminação, e mapas de saliência conferem fundamentação biológica.

Deste modo, nos próximos capítulos podem ser vistos os experimentos realizados para validar a modelagem proposta, discutindo as principais contribuições e resultados obtidos. 


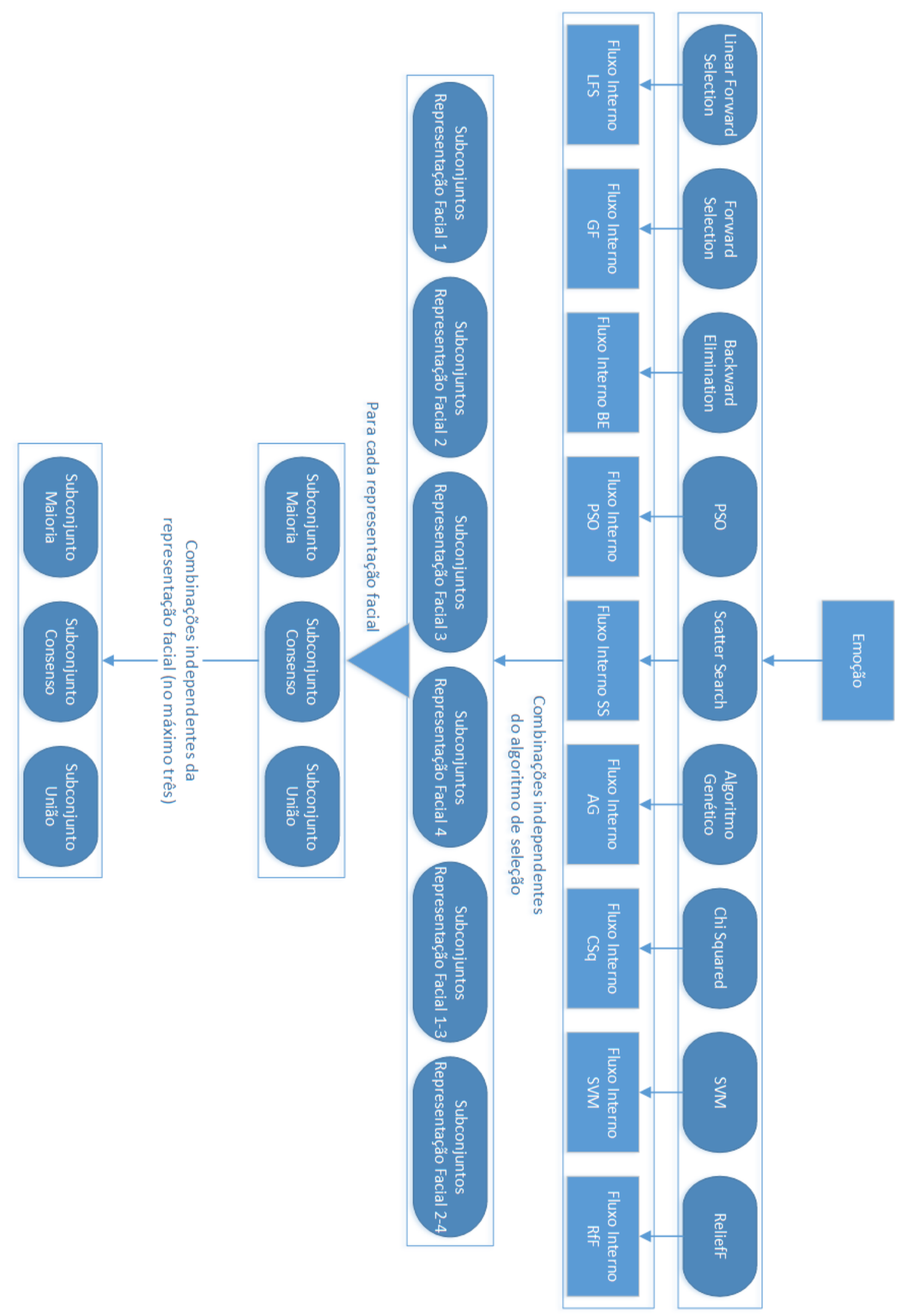

Figura 6.7: Representação gráfica do procedimento utilizado para a seleção de características faciais. 


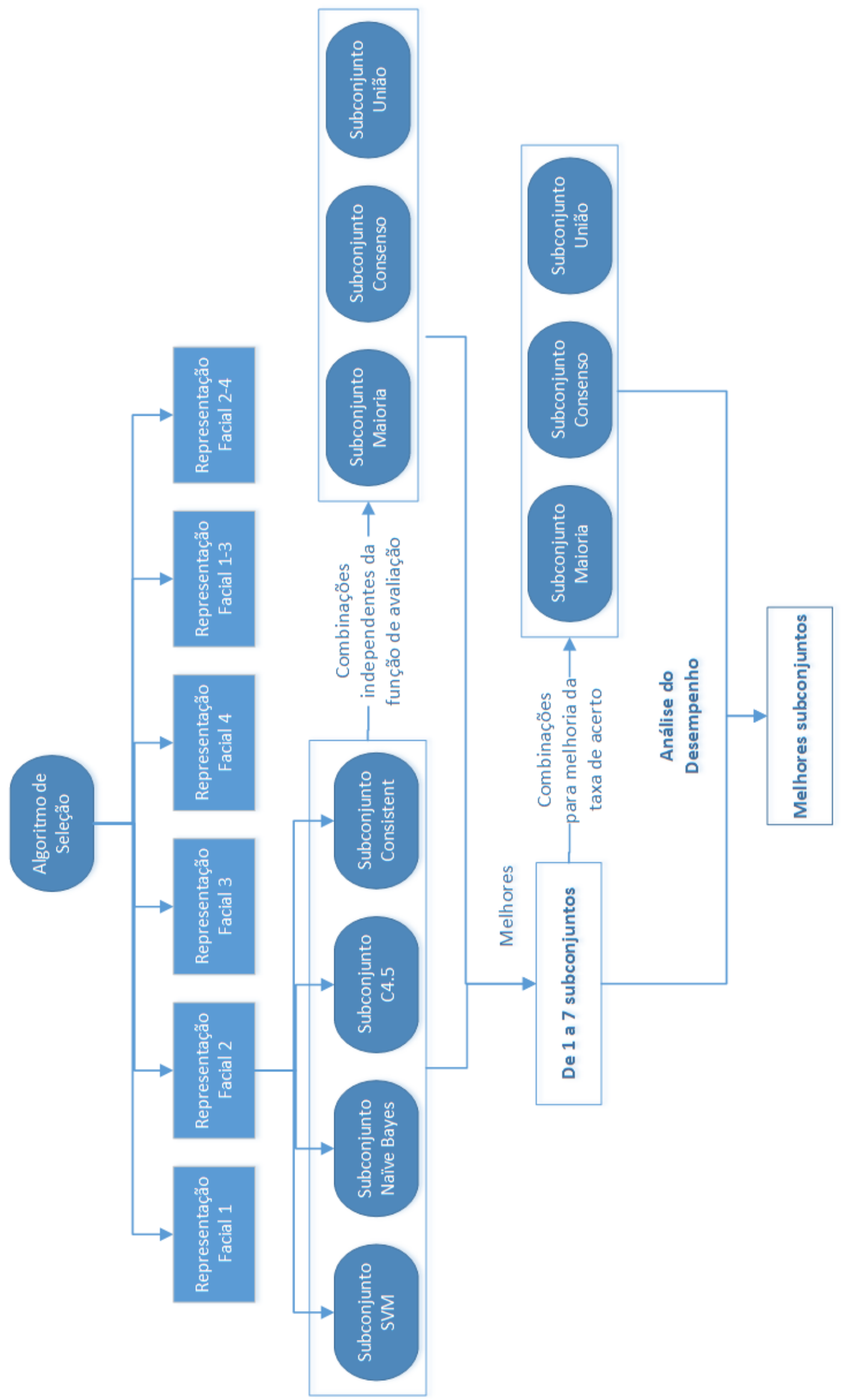

Figura 6.8: Fluxo interno da seleção de características, empregado para cada algoritmo de seleção utilizado. 


\section{CAPÍTULO 7 \\ Identificação das Características de Diagnóstico}

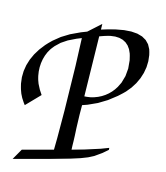

ara desenvolver uma modelagem computacional que simule o reconhecimento das emoções humanas, algoritmos de aprendizado supervisionado e não supervisionado são utilizados. Neste sentido, este capítulo apresenta os experimentos e resultados obtidos nas etapas supervisionadas desta modelagem, que compreendem o reconhecimento emocional pela análise geométrica da face humana valendo-se da identificação de características faciais de diagnóstico. As bases de dados utilizadas para realizar os experimentos estão descritas na Seção 7.1. Já os experimentos encontram-se na Seção 7.2, dividida em duas subseções: a Subseção 7.2.1, que abrange os experimentos realizados com a modelagem geométrica da face humana, e a Subseção 7.2.2, na qual são detalhados os principais resultados obtidos pela seleção das características faciais de diagnóstico. Por fim, a Seção 7.3 apresenta as considerações finais.

\subsection{Bases de Dados Avaliadas}

Para validar os experimentos apresentados neste capítulo, as imagens de expressões faciais emocionais visiveis, provenientes de câmeras RGB, são utilizadas. Deste modo, as bases de dados avaliadas são a Radboud Faces (RaFD) (Langner et al., 2010) e a Extended Cohn-Kanade (CK+) (Lucey et al., 2010). A base de dados RaFD é de acesso livre. Ela apresenta exemplos de expressões faciais de 67 atores, adultos ou crianças, do sexo masculino e feminino, e das raças caucasiana e marroquina. Com a cabeça na posição frontal, as expressões faciais de oito distintas emoções foram reproduzidas pelos atores, em três direções de olhar 
diferentes: frontal, direita e esquerda. As oito expressões disponíveis são alegria, tristeza, raiva, aversão, surpresa, medo, desprezo e neutra, e foram validadas de acordo com o sistema FACS (Ekman et al., 2002). Todos os indivíduos estão vestidos com camisetas pretas, sem cabelo, óculos, maquiagem ou joias sobre a face.

A base de dados $\mathrm{CK}+$ também é de acesso livre. Ela apresenta expressões faciais de atores adultos, em que 69\% são mulheres e $31 \%$ homens. Ainda, $81 \%$ são europeus ou americanos (caucasianos), 13\% afro-americanos e 6\% pertencentes a outros grupos étnicos. Esta base possui 593 expressões faciais, de 123 atores. Os atores foram orientados a realizar expressões faciais compostas por diferentes UAs, de acordo com o sistema FACS, e não apenas emoções, sempre com a cabeça na posição frontal. Com relação às expressões de emoção, diferentes quantidades das emoções de raiva, desprezo, aversão, medo, alegria, tristeza e surpresa podem ser encontradas, totalizando 327 exemplos. Ainda, todas as 593 expressões existentes têm início pela expressão neutra.

Para os experimentos apresentados, apenas subconjuntos das bases RaFD e CK+ são utilizados. Para a base RaFD, são selecionadas todas as imagens nas quais os atores estão com a direção do olhar voltada para a frente e expressando as seis emoções básicas propostas por Ekman (1999), assim como a expressão neutra. Desta forma, 67 exemplos de cada emoção são obtidos, incluindo adultos e crianças. O subconjunto selecionado para a base $\mathrm{CK}+$ inclui todas as expressões existentes, de diferentes atores, para cada uma das expressões faciais também avaliadas para a base RaFD. Exemplos de imagens encontradas nas bases de dados RaFD e CK+ podem ser vistas na Figura 7.1.

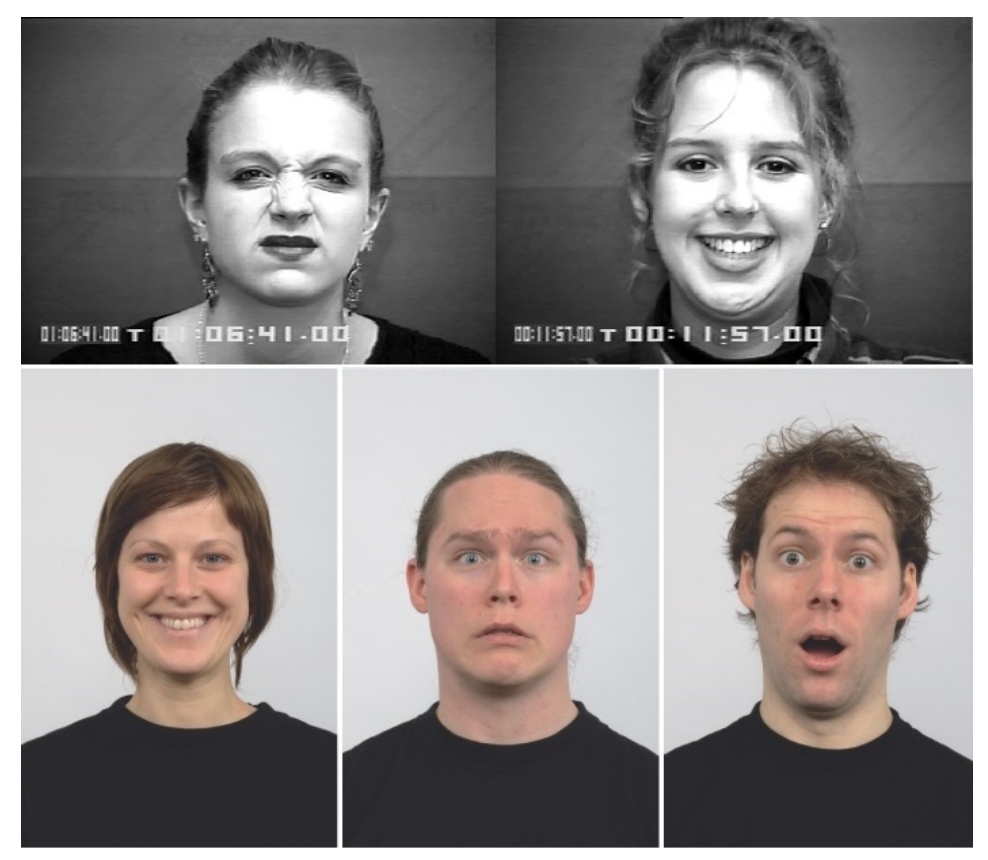

Figura 7.1: As duas imagens acima são exemplos existentes na base de dados $\mathrm{CK}^{+}$, e as três imagens abaixo podem ser encontradas na base de dados RaFD.

Uma vez que, nas bases de dados utilizadas, os atores podem apresentar 
diferentes inclinações de cabeça, as transformações afins de rotação e translação são aplicadas a cada imagem antes da análise das mesmas. A rotação alinha a face ao eixo horizontal e a translação padroniza as coordenadas para situá-la no primeiro quadrante de um plano cartesiano, definindo a origem do sistema. Ademais, para corrigir problemas de faces localizadas a diferentes distâncias da câmera ou de apresentarem formatos distintos, cada imagem é normalizada pela distância interna entre os olhos. Com essas padronizações é possível a comparação e análise das expressões emocionais.

\subsection{Experimentos e Resultados}

As bases de dados RaFD e CK+ são divididas, em todos os experimentos apresentados, segundo o método 10-fold cross validation (Mitchell, 1997). A maneira como os dados são particionados durante os experimentos tem grande influência nos resultados obtidos. De acordo com Cohen et al. (2002), ao realizar experimentos com expressões faciais, sistemas em que os dados de um mesmo indivíduo estão presentes nos conjuntos de treinamento e testes apresentam melhores resultados que aqueles em que isto não ocorre. Porém, a capacidade de generalização de tais sistemas é baixa, quando confrontados com dados de indivíduos desconhecidos.

Para que um sistema baseado na modelagem proposta apresente boa capacidade de generalização e possa reconhecer expressões faciais de diferentes indivíduos, presentes ou não nas bases de dados utilizadas, os dados são particionados de modo que os exemplos de um mesmo indivíduo não estejam presentes em ambos os conjuntos, de treinamento e de testes. Isto é feito pois o objetivo da abordagem proposta é reconhecer expressões faciais emocionais de quaisquer indivíduos, a fim de obter um sistema generalista. Neste sentido, para todos os experimentos apresentados, os dados são particionados de modo que $80 \%$ dos exemplos sejam utilizados para o treinamento e $20 \%$ para os testes. Ainda, para avaliar a capacidade de generalização obtida, o desempenho com base no conjunto de testes é utilizado.

Detalhes dos experimentos realizados, assim como dos resultados obtidos, são descritos nas próximas subseções.

\subsubsection{Resultados do Reconhecimento Emocional}

Nesta subseção são apresentados os experimentos realizados com as seis representações faciais propostas para identificar as expressões neutra, de alegria, tristeza, medo, raiva, aversão e surpresa, por meio da análise geométrica da face. Estes experimentos são necessários pois avaliam se as diferentes representações desenvolvidas são adequadas para o reconhecimento emocional e, consequentemente, disponibilizam características de diagnóstico representativas.

Os algoritmos utilizados para os experimentos são as SVMs, as redes MLP 
e o algoritmo C4.5, existentes no simulador Weka (Frank and Witten, 2005). Estes algoritmos possuem diferentes parâmetros que devem ter os valores definidos durante a fase de treinamento. Para encontrar os melhores valores de cada parâmetro, com base no erro de classificação, é importante que todo o processo de otimização seja independente do conjunto de testes. Caso contrário, os resultados obtidos serão excessivamente otimistas (Wessels et al., 2005). Assim, para encontrar valores ótimos para os diferentes parâmetros, um laço separado, utilizando o método 3-fold cross validation (Mitchell, 1997), é executado cada vez que a otimização dos parâmetros é feita para um determinado algoritmo. O desempenho deste algoritmo é avaliado para os diferentes valores de cada parâmetro a ser otimizado. Este processo produz, em geral, valores levemente diferentes para um mesmo parâmetro, que conferem o desempenho máximo. O valor final atribuído ao parâmetro é a média dos valores encontrados no método 3-fold cross validation. Durante todo este processo, assume-se que os parâmetros são independentes e que não existe uma ordem específica para a otimização deles.

Para as SVMs, os núcleos ou kernels investigados são Linear, Polinomial e Gaussiano (ou $R B F$ ), e todos os respectivos parâmetros relacionados a cada um dos núcleos são otimizados. Para o algoritmo C4.5, a otimização é feita para o número mínimo de instâncias por nó e para o Fator de Confidência. A diminuição do Fator de Confidência reduz a quantidade de poda a posteriori realizada pelo método. Poda a posteriori consiste no processo de avaliar o erro de decisão (porcentagem estimada dos erros de classificação) em cada junção da árvore, e propagar este erro no sentido da raiz. Para as redes MLP, a taxa de aprendizado, o termo momentum e a quantidade de nós nas camadas intermediárias são otimizados. Durante os experimentos, as redes MLP possuem apenas uma ou duas camadas intermediárias.

Como o Face Tracker considera uma quantidade elevada de pontos faciais para a obtenção do modelo deformável, uma análise inicial é feita na tentativa de identificar um conjunto ótimo de pontos característicos, dentre os mapeados, que melhor represente a face humana.

Para isto, foram realizados experimentos em que a face é representada somente por diferentes quantidades de pontos característicos mapeados pelo Face Tracker, que representam os distintos elementos faciais tais como boca, olhos, sobrancelhas, narinas e contorno da face. Desta forma, para estes experimentos, foram definidas quatro configurações de pontos faciais compostas, respectivamente, pelos 66 pontos originalmente mapeados, assim como configurações simplificadas, que possuem 16, 26 ou 33 pontos característicos, distribuídos de maneira distinta entre os elementos faciais.

Os experimentos realizados para estes quatro conjuntos de pontos avaliados seguiram a mesma metodologia descrita neste capítulo. Porém, como os resultados observados foram insatisfatórios, a apresentação deles é omitida. A principal contri- 
buição destes experimentos é a indicação de que apenas o mapeamento de pontos faciais não é suficiente para representar a face durante a tarefa de identificação emocional. A taxa média de acerto observada, considerando os quatro conjuntos de pontos avaliados para as seis emoções básicas e a expressão neutra, foi de apenas 41,9\%. Mesmo assim, a representação da face composta por 33 pontos faciais apresentou taxas de acerto superiores obtendo, para algumas das expressões faciais analisadas, 58\% de reconhecimento. Ainda, o desempenho médio apresentado pelo conjunto com 33 pontos foi de $51,9 \%$, ao passo que os demais conjuntos com 16 , 26 ou 66 pontos apresentaram, respectivamente, desempenhos médios de 33,0\%, $38,1 \%$ e $44,5 \%$. Por este motivo, todas as representações faciais investigadas neste trabalho, e descritas no Capítulo 6, são baseadas nesta quantidade de pontos, utilizada em conjunto com informações adicionais dos elementos da face, para melhorar as taxas de identificação das expressões emocionais em análise.

\section{Análise Individual das Emoções}

As emoções são individualmente analisadas, ou seja, cada classificador decide pela existência ou não de uma determinada emoção na face avaliada. Dessa forma, seja a expressão neutra e cada emoção investigada, um classificador diferente é empregado na análise do exemplo de entrada, que deve pertencer ou não à classe da emoção que o classificador reconhece. Esta escolha é feita pois estudos psicológicos indicam que os seres humanos interpretam a face de modo diferente para reconhecer cada uma das seis emoções básicas. Por este motivo, de modo análogo, cada classificador deve ser responsável por identificar apenas uma única emoção.

Os melhores resultados obtidos com a base RaFD para as emoções positivas e a expressão neutra podem ser vistos nas tabelas 7.1, 7.3 e 7.5, respectivamente para os classificadores SVMs, algoritmo C4.5 e redes MLP. Já as tabelas 7.2, 7.4 e 7.6 apresentam os resultados obtidos para as emoções negativas.

Tabela 7.1: Taxas de acerto obtidas pelas SVMs para a base RaFD com as emoções positivas e a expressão neutra.

\begin{tabular}{|c|c|c|c|}
\hline $\begin{array}{c}\text { Representação } \\
\text { Facial }\end{array}$ & Neutra & Alegria & Surpresa \\
\cline { 2 - 4 } & Acerto (\%) & Acerto (\%) & Acerto (\%) \\
\hline$F S_{1}$ & $84,6_{-}^{+} 1,14$ & $100,0_{-}^{+} 1,11$ & $100,0_{-}^{+} 1,03$ \\
\hline$F S_{2}$ & $76,9_{-}^{+} 1,09$ & $100_{-}^{+} 1,03$ & $100,0_{-}^{+} 1,01$ \\
\hline$F S_{3}$ & $100,0_{-}^{+} 1,03$ & $100,0_{-}^{+1,07}$ & $100,0_{-}^{+} 1,03$ \\
\hline$F S_{4}$ & $100,0_{-}^{+} 1,06$ & $100,0_{-}^{+} 1,04$ & $100,0_{-}^{+} 1,07$ \\
\hline$F S_{1-3}$ & $100,0_{-}^{+} 1,09$ & $100,0_{-}^{+} 1,05$ & $100,0_{-}^{+} 1,08$ \\
\hline$F S_{2-4}$ & $96,1_{-}^{+} 1,12$ & $100,0_{-}^{+} 1,09$ & $96,1_{-}^{+} 1,05$ \\
\hline Média & $92,9_{-}^{+} 1,09$ & $100,0_{-}^{+} 1,06$ & $99,3_{-}^{+} 1,04$ \\
\hline
\end{tabular}

A análise dos resultados apresentados para a base RaFD permite notar que todos os classificadores obtém elevadas taxas de acerto. No entanto, pode-se obser- 
Tabela 7.2: Taxas de acerto obtidas pelas SVMs para a base RaFD com as emoções negativas.

\begin{tabular}{|c|c|c|c|c|}
\hline $\begin{array}{c}\text { Representação } \\
\text { Facial }\end{array}$ & Tristeza & Medo & Raiva & Aversão \\
\cline { 2 - 5 } & Acerto (\%) & Acerto (\%) & Acerto (\%) & Acerto (\%) \\
\hline$F S_{1}$ & $88,4_{-}^{+} 1,05$ & $96,1_{-}^{+} 1,13$ & $92,3_{-}^{+} 1,05$ & $100,0_{-}^{+1,01}$ \\
\hline$F S_{2}$ & $84,6_{-}^{+} 1,09$ & $96,1_{-}^{+} 1,09$ & $88,4_{-}^{+} 1,15$ & $100,0_{-}^{+} 1,02$ \\
\hline$F S_{3}$ & $92,3_{-}^{+1,08}$ & $96,1_{-}^{+1,02}$ & $100,0_{-}^{+} 1,13$ & $100,0_{-}^{+1,04}$ \\
\hline$F S_{4}$ & $88,4_{-}^{+} 1,03$ & $88,4_{-}^{+} 1,11$ & $92,3_{-}^{+} 1,08$ & $100,0_{-}^{+} 1,01$ \\
\hline$F S_{1-3}$ & $88,4_{-}^{+1,01}$ & $100,0_{-}^{+} 1,07$ & $100,0_{-}^{+} 1,04$ & $100,0_{-}^{+} 1,01$ \\
\hline$F S_{2-4}$ & $84,6_{-}^{+} 0,99$ & $96,1_{-}^{+} 1,06$ & $100,0_{-}^{+} 1,10$ & $100,0_{-}^{+} 1,00$ \\
\hline Média & $87,8_{-}^{+} 1,04$ & $95,5_{-}^{+} 1,08$ & $95,5_{-}^{+} 1,09$ & $100,0_{-}^{+} 1,01$ \\
\hline
\end{tabular}

Tabela 7.3: Taxas de acerto obtidas pelo algoritmo C4.5 para a base RaFD com as emoções positivas e a expressão neutra.

\begin{tabular}{|c|c|c|c|}
\hline $\begin{array}{c}\text { Representação } \\
\text { Facial }\end{array}$ & Neutra & Alegria & Surpresa \\
\cline { 2 - 4 } & Acerto (\%) & Acerto (\%) & Acerto (\%) \\
\hline$F S_{1}$ & $53,8_{-}^{+} 1,05$ & $96,1_{-}^{+} 1,07$ & $92,3_{-}^{+} 1,03$ \\
\hline$F S_{2}$ & $53,8_{-}^{+} 1,12$ & $96,1_{-}^{+} 1,04$ & $96,1_{-}^{+} 1,07$ \\
\hline$F S_{3}$ & $96,1_{-}^{+1,07}$ & $96,1_{-}^{+} 1,09$ & $92,3_{-}^{+} 1,02$ \\
\hline$F S_{4}$ & $100,0_{-}^{+} 1,03$ & $100,0_{-}^{+} 1,11$ & $92,3_{-}^{+} 1,06$ \\
\hline$F S_{1-3}$ & $96,1_{-}^{+1,08}$ & $100,0_{-}^{+} 1,09$ & $96,1_{-}^{+} 1,01$ \\
\hline$F S_{2-4}$ & $100,0_{-}^{+} 1,09$ & $100,0_{-}^{+} 1,03$ & $96,1_{-}^{+} 1,08$ \\
\hline Média & $83,3_{-}^{+} 1,07$ & $98,1_{-}^{+} 1,07$ & $94,2_{-}^{+} 1,04$ \\
\hline
\end{tabular}

Tabela 7.4: Taxas de acerto obtidas pelo algoritmo C4.5 para a base RaFD com as emoções negativas.

\begin{tabular}{|c|c|c|c|c|}
\hline $\begin{array}{c}\text { Representação } \\
\text { Facial }\end{array}$ & Tristeza & Medo & Raiva & Aversão \\
\cline { 2 - 5 } & Acerto (\%) & Acerto (\%) & Acerto (\%) & Acerto (\%) \\
\hline$F S_{1}$ & $80,8_{-}^{+} 1,15$ & $84,6_{-}^{+} 1,02$ & $76,9_{-}^{+} 1,06$ & $76,9_{-}^{+} 1,13$ \\
\hline$F S_{2}$ & $84,6_{-}^{+1,07}$ & $69,2_{-}^{+} 1,05$ & $80,8_{-}^{+} 1,07$ & $80,8_{-}^{+} 1,05$ \\
\hline$F S_{3}$ & $73,1_{-}^{+} 1,03$ & $84,6_{-}^{+} 1,09$ & $84,6_{-}^{+} 1,04$ & $88,4_{-}^{+} 1,03$ \\
\hline$F S_{4}$ & $92,3_{-}^{+} 1,09$ & $88,4_{-}^{+} 1,03$ & $80,8_{-}^{+} 1,11$ & $84,6_{-}^{+} 1,01$ \\
\hline$F S_{1-3}$ & $92,3_{-}^{+} 1,13$ & $96,1_{-}^{+} 1,08$ & $76,9_{-}^{+} 1,17$ & $92,3_{-}^{+} 1,04$ \\
\hline$F S_{2-4}$ & $84,6_{-}^{+} 1,08$ & $88,4_{-}^{+} 1,11$ & $76,9_{-}^{+} 1,13$ & $88,4_{-}^{+} 1,07$ \\
\hline Média & $87,8_{-}^{+1,04}$ & $84,6_{-}^{+1,06}$ & $79,5_{-}^{+} 1,09$ & $85,2_{-}^{+} 1,07$ \\
\hline
\end{tabular}

var que as SVMs apresentam melhor desempenho que as redes MLP e o algoritmo C4.5, sendo que este último também é levemente inferior às redes MLP. Para as SVMs, os melhores resultados são obtidos com o núcleo gaussiano. Para as redes MLP, a utilização de uma única camada intermediária resulta nos melhores desempenhos.

A taxa de acerto média obtida por emoção, independente do classificador e representação facial utilizados é de $88,2 \%$ para a expressão neutra, 98,9\% para a alegria, $85,7 \%$ para a tristeza, 90,5\% para medo, $86,5 \%$ para raiva, $97,0 \%$ para 
Tabela 7.5: Taxas de acerto obtidas pelas MLPs para a base RaFD com as emoções positivas e a expressão neutra.

\begin{tabular}{|c|c|c|c|}
\hline $\begin{array}{c}\text { Representação } \\
\text { Facial }\end{array}$ & Neutra & Alegria & Surpresa \\
\cline { 2 - 4 } & Acerto (\%) & Acerto (\%) & Acerto (\%) \\
\hline$F S_{1}$ & $73,1_{-}^{+} 1,13$ & $100,0_{-}^{+} 1,05$ & $96,1_{-}^{+1,10}$ \\
\hline$F S_{2}$ & $76,9_{-}^{+} 1,09$ & $100,0_{-}^{+} 1,12$ & $100,0_{-}^{+} 1,04$ \\
\hline$F S_{3}$ & $100,0_{-}^{+} 1,05$ & $100,0_{-}^{+} 1,07$ & $96,1_{-}^{+} 1,06$ \\
\hline$F S_{4}$ & $92,3_{-}^{+} 1,06$ & $100,0_{-}^{+} 1,03$ & $92,3_{-}^{+} 1,09$ \\
\hline$F S_{1-3}$ & $96,1_{-}^{+} 1,02$ & $96,1_{-}^{+} 1,08$ & $100,0_{-}^{+} 1,08$ \\
\hline$F S_{2-4}$ & $92,3_{-}^{+} 1,04$ & $96,1_{-}^{+} 1,09$ & $100,0_{-}^{+} 1,06$ \\
\hline Média & $88,5_{-}^{+} 1,06$ & $98,7_{-}^{+} 1,07$ & $97,4_{-}^{+} 1,07$ \\
\hline
\end{tabular}

Tabela 7.6: Taxas de acerto obtidas pelas MLPs para a base RaFD com as emoções negativas.

\begin{tabular}{|c|c|c|c|c|}
\hline $\begin{array}{c}\text { Representação } \\
\text { Facial }\end{array}$ & Tristeza & Medo & Raiva & Aversão \\
\cline { 2 - 5 } & Acerto (\%) & Acerto (\%) & Acerto (\%) & Acerto (\%) \\
\hline$F S_{1}$ & $73,1_{-}^{+1,14}$ & $92,3_{-}^{+} 1,05$ & $88,4_{-}^{+1,03}$ & $88,4_{-}^{+} 1,11$ \\
\hline$F S_{2}$ & $80,8_{-}^{+} 1,10$ & $88,4_{-}^{+} 1,09$ & $80,8_{-}^{+} 1,02$ & $92,3_{-}^{+} 1,04$ \\
\hline$F S_{3}$ & $84,6_{-}^{+1,09}$ & $92,3_{-}^{+} 1,07$ & $84,6_{-}^{+1,04}$ & $88,4_{-}^{+} 1,09$ \\
\hline$F S_{4}$ & $80,8_{-}^{+} 1,07$ & $88,4_{-}^{+} 1,06$ & $84,6_{-}^{+} 1,08$ & $96,1_{-}^{+} 1,05$ \\
\hline$F S_{1-3}$ & $88,4_{-}^{+} 1,11$ & $92,3_{-}^{+} 1,04$ & $84,6_{-}^{+1,02}$ & $96,1_{-}^{+} 1,07$ \\
\hline$F S_{2-4}$ & $80,8_{-}^{+} 1,12$ & $96,1_{-}^{+} 1,07$ & $84,6_{-}^{+} 1,03$ & $96,1_{-}^{+} 1,03$ \\
\hline Média & $81,4_{-}^{+} 1,10$ & $91,6_{-}^{+} 1,06$ & $84,6_{-}^{+} 1,03$ & $92,9_{-}^{+} 1,06$ \\
\hline
\end{tabular}

surpresa e 92,7\% para aversão. Ainda, os resultados observados permitem identificar que as emoções de alegria e aversão, seguidas pela surpresa, são as mais facilmente reconhecidas pelas SVMs, assim como as expressões neutra e de tristeza estão entre as mais difíceis de reconhecer. O algoritmo C4.5 apresenta resultados semelhantes, facilmente reconhecendo as emoções de alegria e surpresa, mas apresentando dificuldades no reconhecimento das expressões neutra e de raiva. Similar ao algoritmo C4.5, as redes MLP são melhores em reconhecer as expressões de alegria e surpresa, apresentando dificuldades com as emoções de tristeza e raiva. Desta forma, é possível afirmar que as emoções de alegria e surpresa são as mais facilmente reconhecidas pelas representações faciais propostas, ao passo que as emoções de raiva, tristeza e a expressão neutra estão entre as mais difíceis de interpretar.

Estas observações sobre o reconhecimento emocional são semelhantes às obtidas pela psicologia, que afirma que os seres humanos facilmente reconhecem as expressões de alegria e surpresa, mas não são muito bons em reconhecer a raiva e a tristeza, sendo ainda piores com as expressões de medo e aversão. Embora as emoções de medo e aversão não tenham figurado entre os piores resultados, as representações faciais propostas não as reconheceram com a mesma facilidade com que reconheceram a alegria ou a surpresa. 
Considerando o desempenho das representações faciais, as representações $F S_{1-3}$ e $F S_{2-4}$, seguidas pelas representações $F S_{3}$ e $F S_{4}$, apresentam os melhores desempenhos, o que indica que a análise das diferenças entre as características faciais do ápice de uma emoção com o estado facial neutro têm grande influência no processo de reconhecimento.

Contudo, a comparação dos dois algoritmos considerando apenas a taxa de acerto na classificação, sem a utilização de algum teste estatístico válido, não permite concluir se um algoritmo é, de fato, melhor que o outro. Neste sentido, o teste estatístico Student $t$ (Mason et al., 1989), que permite comprovar, com um elevado grau de confiança, se o desempenho de um algoritmo é realmente superior ao de outro, é utilizado.

Para decidir qual dos algoritmos apresenta melhor desempenho, com grau de confiança, por exemplo, de 95\%, basta assumir um caso geral para determinar se a diferença entre os algoritmos $A s$ e $A p$ é significativa ou não, assumindo uma distribuição normal do erro (Weiss and Indurkhya, 1998). Para isto, a média e o desvio padrão combinados do erro são calculados de acordo com as equações 7.1 e 7.2, respectivamente. A diferença absoluta em desvios padrões é calculada pela equação 7.3 (Monard and Baranauskas, 2003).

$$
\begin{gathered}
\operatorname{media}(A s-A p)=\operatorname{media}(A s)-\operatorname{media}(A p) \\
s d(A s-A p)=\sqrt{\frac{s d(A s)^{2}+s d(A p)^{2}}{2}} \\
t_{c a l c}=a d(A s-A p)=\frac{\operatorname{media}(A s-A p)}{s d(A s-A p)}
\end{gathered}
$$

Estabelecendo a hipótese inicial nula $H_{0}: A s=A p$ e a hipótese alternativa $H_{1}: A s \neq A p$. Se $a d(A s-A p)>0$ então $A p$ supera $A s$. Porém, se $a d(A s-A p) \geq 2,00$ (limite da região de aceitação) então $A p$ supera $A s$ com grau de confiança de 95\%. Por outro lado, se $a d(A s-A p) \leq 0$ então $A s$ é melhor que $A p$ e se $a d(A s-A p) \leq-2,00$ então $A s$ é melhor que $A p$ com grau de confiança de $95 \%$. Os limites da região de aceitação RA:(-2,00, 2,00) utilizada para os experimentos são baseados na tabela de distribuição de Student $t$ (Mason et al., 1989).

A análise estatística confirma que as SVMs apresentam o melhor desempenho, independente da emoção investigada, com grau de confiança de 95\%. Apenas a análise da emoção tristeza pelo algoritmo $\mathrm{C} 4.5$ obteve resultados iguais às SVMs. As redes MLP, com exceção da emoção alegria, que apresentou desempenho semelhante, e da emoção tristeza, que teve desempenho inferior, apresentam desempenho superior ao algoritmo C4.5, para todas as demais emoções, com grau de confiança de 95\%. Com relação às representações faciais, não é possível encontrar diferenças estatísticas no desempenho apresentado pelas representações $F S_{1-3}, F S_{2-4}, F S_{3} \mathrm{e}$ 
$F S_{4}$. Porém, estas representações apresentam resultados estatisticamente superiores às representações $F S_{1}$ e $F S_{2}$.

As tabelas 7.7, 7.9 e 7.11 apresentam os melhores resultados obtidos para a base $\mathrm{CK}+$, respectivamente, para os classificadores SVMs, algoritmo C4.5 e redes MLP com as emoções positivas e a expressão neutra. Ao passo que as tabelas 7.8 , 7.10 e 7.12 apresentam os melhores resultados obtidos para as emoções negativas.

Tabela 7.7: Taxas de acerto obtidas pelas SVMs para a base CK+ com as emoções positivas e a expressão neutra.

\begin{tabular}{|c|c|c|c|}
\hline $\begin{array}{c}\text { Representação } \\
\text { Facial }\end{array}$ & Neutra & Alegria & Surpresa \\
\cline { 2 - 4 } & Acerto (\%) & Acerto (\%) & Acerto (\%) \\
\hline$F S_{1}$ & $91,8_{-}^{+} 1,03$ & $98,2_{-}^{+} 1,06$ & $98,4_{-}^{+} 1,01$ \\
\hline$F S_{2}$ & $93,9_{-}^{+} 1,01$ & $100,0_{-}^{+} 1,01$ & $98,4_{-}^{+} 1,01$ \\
\hline$F S_{3}$ & $100,0_{-}^{+1,02}$ & $100,0_{-}^{+} 1,05$ & $100,0_{-}^{+} 1,05$ \\
\hline$F S_{4}$ & $100,0_{-}^{+} 1,04$ & $100,0_{-}^{+} 1,02$ & $100,0_{-}^{+} 1,03$ \\
\hline$F S_{1-3}$ & $100,0_{-}^{+} 1,06$ & $100,0_{-}^{+} 1,03$ & $100,0_{-}^{+} 1,02$ \\
\hline$F S_{2-4}$ & $97,9_{-}^{+} 1,02$ & $100,0_{-}^{+} 1,07$ & $98,4_{-}^{+} 1,04$ \\
\hline Média & $97,2_{-}^{+} 1,03$ & $99,7_{-}^{+} 1,04$ & $99,2_{-}^{+} 1,03$ \\
\hline
\end{tabular}

Tabela 7.8: Taxas de acerto obtidas pelas SVMs para a base CK+ com as emoções negativas.

\begin{tabular}{|c|c|c|c|c|}
\hline $\begin{array}{c}\text { Representação } \\
\text { Facial }\end{array}$ & Tristeza & Medo & Raiva & Aversão \\
\cline { 2 - 5 } & Acerto (\%) & Acerto (\%) & Acerto (\%) & Acerto (\%) \\
\hline$F S_{1}$ & $100,0_{-}^{+1,08}$ & $90,0_{-}^{+} 1,10$ & $94,3_{-}^{+1,09}$ & $97,8_{-}^{+} 1,03$ \\
\hline$F S_{2}$ & $95,6_{-}^{+} 1,06$ & $95,0_{-}^{+} 1,05$ & $94,3_{-}^{+} 1,11$ & $95,6_{-}^{+} 1,05$ \\
\hline$F S_{3}$ & $100,0_{-}^{+1,07}$ & $100,0_{-}^{+} 1,06$ & $97,1_{-}^{+1,10}$ & $100,0_{-}^{+1,02}$ \\
\hline$F S_{4}$ & $100,0_{-}^{+1,00}$ & $95,0_{-}^{+} 1,08$ & $97,1_{-}^{+} 1,09$ & $100,0_{-}^{+} 1,00$ \\
\hline$F S_{1-3}$ & $100,0_{-}^{+} 1,02$ & $95,0_{-}^{+} 1,09$ & $100,0_{-}^{+} 1,07$ & $100,0_{-}^{+} 1,03$ \\
\hline$F S_{2-4}$ & $100,0_{-}^{+1,01}$ & $90,0_{-}^{+} 1,08$ & $97,1_{-}^{+1,12}$ & $100,0_{-}^{+} 1,05$ \\
\hline Média & $99,2_{-}^{+} 1,04$ & $94,1_{-}^{+} 1,08$ & $96,6_{-}^{+} 1,10$ & $98,9_{-}^{+} 1,03$ \\
\hline
\end{tabular}

Tabela 7.9: Taxas de acerto obtidas pelo algoritmo $\mathrm{C} 4.5$ para a base $\mathrm{CK}+\mathrm{com}$ as emoções positivas e a expressão neutra.

\begin{tabular}{|c|c|c|c|}
\hline $\begin{array}{c}\text { Representação } \\
\text { Facial }\end{array}$ & Neutra & Alegria & Surpresa \\
\cline { 2 - 4 } & Acerto (\%) & Acerto (\%) & Acerto (\%) \\
\hline$F S_{1}$ & $85,7_{-}^{+} 1,09$ & $94,6_{-}^{+} 1,05$ & $95,4_{-}^{+} 1,01$ \\
\hline$F S_{2}$ & $69,3_{-}^{+} 1,06$ & $91,1_{-}^{+} 1,03$ & $95,4_{-}^{+} 1,03$ \\
\hline$F S_{3}$ & $100,0_{-}^{+1,02}$ & $98,2_{-}^{+1,07}$ & $95,4_{-}^{+1,02}$ \\
\hline$F S_{4}$ & $100,0_{-}^{+1,01}$ & $98,2_{-}^{+} 1,06$ & $95,4_{-}^{+} 1,05$ \\
\hline$F S_{1-3}$ & $100,0_{-}^{+1,05}$ & $98,2_{-}^{+} 1,05$ & $95,4_{-}^{+} 1,03$ \\
\hline$F S_{2-4}$ & $100,0_{-}^{+1,02}$ & $92,8_{-}^{+1,08}$ & $95,4_{-}^{+} 1,04$ \\
\hline Média & $92,5_{-}^{+} 1,04$ & $95,5_{-}^{+} 1,06$ & $95,4_{-}^{+} 1,03$ \\
\hline
\end{tabular}

Os resultados obtidos para a base $\mathrm{CK}+$ também apresentam elevada taxa 
Tabela 7.10: Taxas de acerto obtidas pelo algoritmo C4.5 para a base $\mathrm{CK}+$ com as emoções negativas.

\begin{tabular}{|c|c|c|c|c|}
\hline $\begin{array}{c}\text { Representação } \\
\text { Facial }\end{array}$ & Tristeza & Medo & Raiva & Aversão \\
\cline { 2 - 5 } & Acerto (\%) & Acerto (\%) & Acerto (\%) & Acerto (\%) \\
\hline$F S_{1}$ & $69,5_{-}^{+} 1,11$ & $85,0_{-}^{+} 1,05$ & $88,6_{-}^{+} 1,08$ & $86,9_{-}^{+} 1,09$ \\
\hline$F S_{2}$ & $73,9_{-}^{+} 1,08$ & $70,0_{-}^{+} 1,03$ & $74,3_{-}^{+} 1,05$ & $76,1_{-}^{+} 1,11$ \\
\hline$F S_{3}$ & $78,2_{-}^{+} 1,05$ & $85,0_{-}^{+} 1,07$ & $88,6_{-}^{+1,07}$ & $91,3_{-}^{+} 1,05$ \\
\hline$F S_{4}$ & $69,5_{-}^{+} 1,13$ & $85,0_{-}^{+} 1,04$ & $82,6_{-}^{+} 1,09$ & $100,0_{-}^{+} 1,00$ \\
\hline$F S_{1-3}$ & $91,3_{-}^{+} 1,07$ & $75,0_{-}^{+} 1,02$ & $88,6_{-}^{+} 1,10$ & $93,5_{-}^{+} 1,07$ \\
\hline$F S_{2-4}$ & $86,9_{-}^{+} 1,06$ & $90,0_{-}^{+} 1,09$ & $80,0_{-}^{+1} 1,15$ & $93,5_{-}^{+} 1,06$ \\
\hline Média & $78,3_{-}^{+} 1,08$ & $81,7_{-}^{+} 1,05$ & $83,8_{-}^{+} 1,09$ & $85,2_{-}^{+} 1,06$ \\
\hline
\end{tabular}

Tabela 7.11: Taxas de acerto obtidas pelas MLPs para a base CK+ com as emoções positivas e a expressão neutra.

\begin{tabular}{|c|c|c|c|}
\hline $\begin{array}{c}\text { Representação } \\
\text { Facial }\end{array}$ & Neutra & Alegria & Surpresa \\
\cline { 2 - 4 } & Acerto (\%) & Acerto (\%) & Acerto (\%) \\
\hline$F S_{1}$ & $89,8_{-}^{+} 1,04$ & $96,4_{-}^{+} 1,03$ & $96,9_{-}^{+1,08}$ \\
\hline$F S_{2}$ & $85,7_{-}^{+} 1,06$ & $98,2_{-}^{+} 1,02$ & $98,4_{-}^{+} 1,07$ \\
\hline$F S_{3}$ & $97,9_{-}^{+} 1,03$ & $98,2_{-}^{+} 1,09$ & $96,9_{-}^{+1,03}$ \\
\hline$F S_{4}$ & $68,8_{-}^{+} 1,16$ & $94,6_{-}^{+} 1,06$ & $95,4_{-}^{+} 1,06$ \\
\hline$F S_{1-3}$ & $100,0_{-}^{+} 1,05$ & $98,2_{-}^{+} 1,07$ & $96,9_{-}^{+} 1,05$ \\
\hline$F S_{2-4}$ & $97,9_{-}^{+} 1,03$ & $98,2_{-}^{+} 1,08$ & $96,9_{-}^{+} 1,06$ \\
\hline Média & $90,0_{-}^{+} 1,06$ & $97,3_{-}^{+} 1,06$ & $96,9_{-}^{+} 1,06$ \\
\hline
\end{tabular}

Tabela 7.12: Taxas de acerto obtidas pelas MLPs para a base CK+ com as emoções negativas.

\begin{tabular}{|c|c|c|c|c|}
\hline $\begin{array}{c}\text { Representação } \\
\text { Facial }\end{array}$ & Tristeza & Medo & Raiva & Aversão \\
\cline { 2 - 5 } & Acerto (\%) & Acerto (\%) & Acerto (\%) & Acerto (\%) \\
\hline$F S_{1}$ & $78,2_{-}^{+} 1,08$ & $85,0_{-}^{+} 1,03$ & $82,8_{-}^{+} 1,05$ & $95,6_{-}^{+} 1,07$ \\
\hline$F S_{2}$ & $78,2_{-}^{+} 1,06$ & $60,0_{-}^{+} 1,08$ & $88,5_{-}^{+} 1,05$ & $93,5_{-}^{+} 1,06$ \\
\hline$F S_{3}$ & $95,6_{-}^{+} 1,07$ & $95,0_{-}^{+} 1,05$ & $91,4_{-}^{+1,03}$ & $89,1_{-}^{+} 1,02$ \\
\hline$F S_{4}$ & $91,3_{-}^{+} 1,08$ & $80,0_{-}^{+} 1,04$ & $85,7_{-}^{+} 1,07$ & $95,6_{-}^{+} 1,07$ \\
\hline$F S_{1-3}$ & $95,6_{-}^{+} 1,05$ & $100_{-}^{+1,03}$ & $85,7_{-}^{+1,06}$ & $95,6_{-}^{+} 1,09$ \\
\hline$F S_{2-4}$ & $78,2_{-}^{+} 1,10$ & $65,0_{-}^{+} 1,11$ & $85,7_{-}^{+} 1,08$ & $93,5_{-}^{+} 1,04$ \\
\hline Média & $86,2_{-}^{+} 1,07$ & $80,8_{-}^{+} 1,06$ & $86,6_{-}^{+} 1,06$ & $93,8_{-}^{+} 1,06$ \\
\hline
\end{tabular}

de acerto e, assim como observado para a base RaFD, as SVMs apresentam melhor desempenho que as redes MLP e o algoritmo C4.5, sendo que este último também é levemente inferior às redes MLP. Para as SVMs, os melhores resultados são novamente obtidos utilizando o núcleo gaussiano, assim como as redes MLP apresentam os melhores desempenhos com uma única camada intermediária. A taxa de acerto média obtida por emoção, independente do classificador e representação facial utilizados é de 93,2\% para a expressão neutra, 97,5\% para a alegria, 87,9\% para a tristeza, $85,5 \%$ para medo, $89,0 \%$ para raiva, $97,1 \%$ para surpresa e $92,6 \%$ 
para aversão.

As emoções de alegria, tristeza, surpresa e aversão são facilmente reconhecidas pelas SVMs, já as expressões de medo e raiva apresentam uma maior quantidade de classificações incorretas, embora as taxas de acerto obtidas ainda sejam elevadas. O algoritmo C4.5 facilmente reconhece as emoções de alegria e surpresa, mas apresenta dificuldades com as emoções de tristeza e medo. Semelhante a ele, as redes MLP são melhores em reconhecer as expressões de alegria e surpresa, apresentando maior dificuldade na interpretação das emoções de medo, tristeza e raiva. Estes resultados indicam que as emoções de alegria e surpresa são mais as facilmente reconhecidas pelas representações faciais propostas, ao passo que as emoções de medo, raiva e tristeza são as de maior dificuldade para classificação.

Esta observação é semelhante à obtida para os experimentos realizados com a base RaFD. Estranhamente, como pode ser observado nos resultados obtidos pelos demais classificadores, inclusive pelas SVMs com a base RaFD, estas apresentaram comportamento atípico na análise da emoção de tristeza para a base $\mathrm{CK}+$, obtendo elevadas taxas de acerto. Neste sentido, as baixas taxas de acerto obtidas para esta emoção na maioria dos experimentos realizados, assim como o comportamento atípico apresentado pelas SVMs com a base CK+ quando da análise desta emoção, podem ser o resultado de problemas encontrados no mapeamento facial realizado pelo Face Tracker que, na grande maioria das vezes, não é capaz de mapear os cantos dos lábios voltados para baixo, uma característica intrínseca e importante relacionada à tristeza.

Considerando as diferenças no reconhecimento emocional obtidas para as bases CK+ e RaFD, o desempenho dos classificadores é superior para a base CK+, com significância estatística, ao analisar as emoções de tristeza, raiva e a expressão neutra. É inferior na identificação das emoções de alegria e medo, e estatisticamente equivalente para reconhecer as emoções de aversão e surpresa.

A análise estatística também confirma que as SVMs apresentam o melhor desempenho dentre todos os classificadores, independente da emoção investigada, com grau de confiança de 95\%. As redes MLP, com exceção das expressões neutra e de medo, que apresentam desempenho inferior, obtém desempenho superior ao algoritmo $\mathrm{C} 4.5$ para todas as demais emoções. Com relação às representações faciais, mais uma vez não é possível encontrar diferenças estatísticas no desempenho apresentado pelas representações $F S_{1-3}, F S_{2-4}, F S_{3}$ e $F S_{4}$. No entanto, em sua maioria, estas representações apresentaram resultados estatisticamente superiores às representações $F S_{1}$ e $F S_{2}$.

Na tentativa de prever o comportamento de um sistema que utilize as representações faciais propostas em dados reais, e de avaliar a capacidade de generalização dos resultados obtidos, são realizados experimentos entre as duas bases de dados investigadas, ou seja, nestes experimentos a fase de treinamento é realizada 
com a base RaFD, e o modelos induzidos são testados com a base $\mathrm{CK}^{+}$, ou vice-versa. Os resultados encontrados para a fase de treinamento realizada com a base RaFD podem ser observados, respectivamente, para os classificadores SVMs, C4.5 e redes MLP, nas tabelas $7.13,7.15$ e 7.17 para as emoções positivas e a expressão neutra e, nas tabelas 7.14, 7.16 e 7.18, para as emoções negativas.

Do mesmo modo, os resultados obtidos para a fase de treinamento realizada com a base $\mathrm{CK}^{+}$podem ser encontrados, respectivamente, para os classificadores SVMs, C4.5 e MLPs, nas tabelas 7.19, 7.21 e 7.23 para as emoções positivas e a expressão neutra e, nas tabelas 7.20, 7.22 e 7.24, para as emoções negativas.

Tabela 7.13: Taxas de acerto obtidas pelas SVMs para as emoções positivas e a expressão neutra, quando treinadas com a base RaFD e avaliadas com a base CK+.

\begin{tabular}{|c|c|c|c|}
\hline $\begin{array}{c}\text { Representação } \\
\text { Facial }\end{array}$ & Neutra & Alegria & Surpresa \\
\cline { 2 - 4 } & Acerto (\%) & Acerto (\%) & Acerto (\%) \\
\hline$F S_{1}$ & $63,2_{-}^{+} 1,12$ & $92,8_{-}^{+} 1,12$ & $92,3_{-}^{+1,13}$ \\
\hline$F S_{2}$ & $50,0_{-}^{+} 1,10$ & $80,3_{-}^{+} 1,08$ & $50,2_{-}^{+} 1,15$ \\
\hline$F S_{1-3}$ & $91,8_{-}^{+} 1,09$ & $91,1_{-}^{+} 1,05$ & $95,4_{-}^{+1,06}$ \\
\hline$F S_{2-4}$ & $50,0_{-}^{+} 1,17$ & $50,2_{-}^{+} 1,11$ & $50,2_{-}^{+} 1,17$ \\
\hline$F S_{3}$ & $100,0_{-}^{+} 1,15$ & $92,8_{-}^{+} 1,08$ & $95,4_{-}^{+} 1,11$ \\
\hline$F S_{4}$ & $100,0_{-}^{+} 1,08$ & $89,3_{-}^{+} 1,09$ & $50,2_{-}^{+} 1,16$ \\
\hline Média & $75,8_{-}^{+} 1,12$ & $82,7_{-}^{+} 1,09$ & $72,3_{-}^{+} 1,13$ \\
\hline
\end{tabular}

Tabela 7.14: Taxas de acerto obtidas pelas SVMs para as emoções negativas, quando treinadas com a base RaFD e avaliadas com a base CK+.

\begin{tabular}{|c|c|c|c|c|}
\hline $\begin{array}{c}\text { Representação } \\
\text { Facial }\end{array}$ & Tristeza & Medo & Raiva & Aversão \\
\cline { 2 - 5 } & Acerto (\%) & Acerto (\%) & Acerto (\%) & Acerto (\%) \\
\hline$F S_{1}$ & $73,9_{-}^{+1,08}$ & $75,0_{-}^{+1,06}$ & $80,0_{-}^{+} 1,10$ & $58,7_{-}^{+} 1,05$ \\
\hline$F S_{2}$ & $50,8_{-}^{+} 1,10$ & $70,0_{-}^{+} 1,04$ & $50,5_{-}^{+} 1,07$ & $50,0_{-}^{+} 1,17$ \\
\hline$F S_{1-3}$ & $56,5_{-}^{+1} 1,07$ & $75,0_{-}^{+1,07}$ & $80,0_{-}^{+} 1,12$ & $84,8_{-}^{+} 1,03$ \\
\hline$F S_{2-4}$ & $50,1_{-}^{+} 1,15^{+}$ & $75,0_{-}^{+} 1,08$ & $51,4_{-}^{+} 1,05$ & $50,0_{-}^{+} 1,12$ \\
\hline$F S_{3}$ & $78,2_{-}^{+1,05}$ & $70,0_{-}^{+1,03}$ & $82,8_{-}^{+1,10}$ & $89,1_{-}^{+} 1,03$ \\
\hline$F S_{4}$ & $50,8_{-}^{+} 1,11$ & $85,0_{-}^{+} 1,06$ & $65,7_{-}^{+} 1,11$ & $73,9_{-}^{+} 1,05$ \\
\hline Média & $60,0_{-}^{+} 1,09$ & $75,0_{-}^{+} 1,05$ & $68,4_{-}^{+} 1,09$ & $67,8_{-}^{+} 1,07$ \\
\hline
\end{tabular}

As tabelas demonstram que a capacidade de generalização dos resultados é variável de acordo com as representações faciais e emoções investigadas porém, de modo geral, a generalização obtida é elevada.

Nestes novos experimentos, o algoritmo C4.5 apresenta o melhor desempenho estatístico, com grau de confiança de 95\% para diversas das emoções analisadas. Em seguida vêm as redes MLP. As SVMs, com o melhor desempenho nos experimentos individuais com as bases, apresenta os piores desempenhos na análise da generalização no reconhecimento emocional, para todas as emoções. Ainda, com relação às representações faciais, as representações $F S_{2}, F S_{2-4}$ e $F S_{4}$ apresentam o pior desempenho estatístico. A representação $F S_{1}$ apresenta, em geral, resultados 
Tabela 7.15: Taxas de acerto obtidas pelo algoritmo C4.5 para as emoções positivas e a expressão neutra, quando treinado com a base RaFD e avaliado com a base CK+.

\begin{tabular}{|c|c|c|c|}
\hline $\begin{array}{c}\text { Representação } \\
\text { Facial }\end{array}$ & Neutra & Alegria & Surpresa \\
\cline { 2 - 4 } & Acerto (\%) & Acerto (\%) & Acerto (\%) \\
\hline$F S_{1}$ & $65,3_{-}^{+} 1,09$ & $85,7_{-}^{+1,05}$ & $84,6_{-}^{+} 1,07$ \\
\hline$F S_{2}$ & $61,2_{-}^{+} 1,07$ & $78,6_{-}^{+} 1,03$ & $89,2_{-}^{+} 1,03$ \\
\hline$F S_{1-3}$ & $95,9_{-}^{+} 1,01$ & $91,1_{-}^{+} 1,08$ & $89,2_{-}^{ \pm} 1,01$ \\
\hline$F S_{2-4}$ & $100,0_{-}^{+} 1,00$ & $91,1_{-}^{+} 1,04$ & $93,8_{-}^{+} 1,05$ \\
\hline$F S_{3}$ & $97,9_{-}^{+} 1,06$ & $89,3_{-}^{+} 1,09$ & $92,3_{-}^{+} 1,02$ \\
\hline$F S_{4}$ & $95,9_{-}^{+} 1,03$ & $91,1_{-}^{+1,05}$ & $93,8_{-}^{+} 1,04$ \\
\hline Média & $86,1_{-}^{+} 1,04$ & $87,8_{-}^{+} 1,06$ & $90,5_{-}^{+} 1,04$ \\
\hline
\end{tabular}

Tabela 7.16: Taxas de acerto obtidas pelo algoritmo C4.5 para as emoções negativas, quando treinado com a base RaFD e avaliado com a base CK+.

\begin{tabular}{|c|c|c|c|c|}
\hline $\begin{array}{c}\text { Representação } \\
\text { Facial }\end{array}$ & Tristeza & Medo & Raiva & Aversão \\
\cline { 2 - 5 } & Acerto (\%) & Acerto (\%) & Acerto (\%) & Acerto (\%) \\
\hline$F S_{1}$ & $52,2_{-}^{+1,13}$ & $65,0_{-}^{+} 1,09$ & $77,1_{-}^{+} 1,06$ & $73,9_{-}^{+} 1,09$ \\
\hline$F S_{2}$ & $60,9_{-}^{+} 1,09$ & $70,0_{-}^{+} 1,06$ & $80,0_{-}^{+} 1,05$ & $76,1_{-}^{+} 1,07$ \\
\hline$F S_{1-3}$ & $56,5_{-}^{+1,15}$ & $85,0_{-}^{ \pm} 1,07$ & $85,7_{-}^{+} 1,07$ & $82,6_{-}^{+1,05}$ \\
\hline$F S_{2-4}$ & $73,9_{-}^{+} 1,10$ & $90,0_{-}^{+} 1,04$ & $68,6_{-}^{+} 1,11$ & $56,5_{-}^{+} 1,13$ \\
\hline$F S_{3}$ & $73,9_{-}^{+} 1,07$ & $65,0_{-}^{ \pm} 1,05$ & $77,1_{-}^{ \pm} 1,08$ & $89,1_{-}^{+} 1,08$ \\
\hline$F S_{4}$ & $82,6_{-}^{+1,05}$ & $75,0_{-}^{+} 1,07$ & $80,0_{-}^{+} 1,10$ & $71,7_{-}^{+} 1,06$ \\
\hline Média & $66,7_{-}^{+1,10}$ & $75,0_{-}^{+} 1,06$ & $78,1_{-}^{+} 1,08$ & $75,0_{-}^{+} 1,08$ \\
\hline
\end{tabular}

Tabela 7.17: Taxas de acerto obtidas pelas MLPs para as emoções positivas e a expressão neutra, quando treinadas com a base RaFD e avaliadas com a base CK+.

\begin{tabular}{|c|c|c|c|}
\hline $\begin{array}{c}\text { Representação } \\
\text { Facial }\end{array}$ & Neutra & Alegria & Surpresa \\
\cline { 2 - 4 } & Acerto (\%) & Acerto (\%) & Acerto (\%) \\
\hline$F S_{1}$ & $77,6_{-}^{+} 1,18$ & $89,3_{-}^{+} 1,16$ & $92,3_{-}^{+} 1,10$ \\
\hline$F S_{2}$ & $50,9_{-}^{+} 1,11$ & $87,5_{-}^{+} 1,10$ & $89,3_{-}^{+} 1,08$ \\
\hline$F S_{1-3}$ & $93,9_{-}^{+} 1,20$ & $92,8_{-}^{+} 1,07$ & $92,3_{-}^{+} 1,15$ \\
\hline$F S_{2-4}$ & $69,4_{-}^{+} 1,13$ & $89,3_{-}^{+} 1,13$ & $50,8_{-}^{+} 1,11$ \\
\hline$F S_{3}$ & $98,0_{-}^{+} 1,08$ & $89,3_{-}^{+1,10}$ & $93,8_{-}^{+} 1,17$ \\
\hline$F S_{4}$ & $93,9_{-}^{+} 1,07$ & $89,3_{-}^{+} 1,07$ & $90,8_{-}^{+} 1,06$ \\
\hline Média & $80,6_{-}^{+} 1,13$ & $89,6_{-}^{+1,10}$ & $84,9_{-}^{+1,11}$ \\
\hline
\end{tabular}

superiores às três citadas, porém inferiores aos obtidos pelas representações $F S_{1-3}$ e $F S_{3}$, que são estatisticamente superiores. Estes resultados diferem dos resultados anteriormente obtidos, pois indicam que as representações que simplificam os elementos faciais mapeados, baseadas na representação $F S_{2}$, são menos eficientes que as representações baseadas na representação $F S_{1}$, com maior detalhamento dos elementos faciais. Contudo, como já observado, as representações que se valem da comparação entre o ápice da emoção e o respectivo estado neutro mantêm elevadas taxas de acerto. 
Tabela 7.18: Taxas de acerto obtidas pelas MLPs para as emoções negativas, quando treinadas com a base RaFD e avaliadas com a base $\mathrm{CK}+$.

\begin{tabular}{|c|c|c|c|c|}
\hline $\begin{array}{c}\text { Representação } \\
\text { Facial }\end{array}$ & Tristeza & Medo & Raiva & Aversão \\
\cline { 2 - 5 } & Acerto (\%) & Acerto (\%) & Acerto (\%) & Acerto (\%) \\
\hline$F S_{1}$ & $60,9_{-}^{+} 1,18$ & $70,0_{-}^{+} 1,09$ & $82,8_{-}^{+} 1,12$ & $65,2_{-}^{+1,13}$ \\
\hline$F S_{2}$ & $52,2_{-}^{+} 1,16$ & $65,0_{-}^{+} 1,18$ & $71,4_{-}^{+} 1,09$ & $50,0_{-}^{+} 1,09$ \\
\hline$F S_{1-3}$ & $60,9_{-}^{+1,22}$ & $65,0_{-}^{+} 1,11$ & $85,7_{-}^{+} 1,11$ & $86,9_{-}^{+1,10}$ \\
\hline$F S_{2-4}$ & $50,8_{-}^{+} 1,13$ & $80,0_{-}^{+} 1,13$ & $74,3_{-}^{+} 1,17$ & $50,0_{-}^{+} 1,15$ \\
\hline$F S_{3}$ & $65,2_{-}^{+} 1,17$ & $75,0_{-}^{+} 1,07$ & $74,3_{-}^{+} 1,13$ & $91,3_{-}^{+} 1,14$ \\
\hline$F S_{4}$ & $52,2_{-}^{+} 1,19$ & $75,0_{-}^{+} 1,10$ & $88,6_{-}^{+} 1,07$ & $86,9_{-}^{+} 1,08$ \\
\hline Média & $57,0_{-}^{+} 1,17$ & $71,7_{-}^{+} 1,11$ & $79,5_{-}^{+} 1,11$ & $71,7_{-}^{+} 1,11$ \\
\hline
\end{tabular}

Tabela 7.19: Taxas de acerto obtidas pelas SVMs para as emoções positivas e a expressão neutra, quando treinadas com a base CK+ e avaliadas com a base RaFD.

\begin{tabular}{|c|c|c|c|}
\hline $\begin{array}{c}\text { Representação } \\
\text { Facial }\end{array}$ & Neutra & Alegria & Surpresa \\
\cline { 2 - 4 } & Acerto (\%) & Acerto (\%) & Acerto (\%) \\
\hline$F S_{1}$ & $69,2_{-}^{+1,11}$ & $96,1_{-}^{+} 1,04$ & $92,3_{-}^{+1,04}$ \\
\hline$F S_{2}$ & $50,0_{-}^{+} 1,15$ & $50,0_{-}^{+} 1,08$ & $50,0_{-}^{+} 1,10$ \\
\hline$F S_{1-3}$ & $80,8_{-}^{+1,08}$ & $100,0_{-}^{+1,05}$ & $96,1_{-}^{+1,04}$ \\
\hline$F S_{2-4}$ & $50,0_{-}^{+1,12}$ & $50,0_{-}^{+} 1,11$ & $50,0_{-}^{+} 1,15$ \\
\hline$F S_{3}$ & $100,0_{-}^{+} 1,05$ & $96,1_{-}^{+} 1,02$ & $92,3_{-}^{+} 1,03$ \\
\hline$F S_{4}$ & $100,0_{-}^{+} 1,03$ & $50,0_{-}^{+} 1,10$ & $73,1_{-}^{+1,09}$ \\
\hline Média & $75,0_{-}^{+} 1,09$ & $73,7_{-}^{+} 1,07$ & $75,6_{-}^{+} 1,07$ \\
\hline
\end{tabular}

Tabela 7.20: Taxas de acerto obtidas pelas SVMs para as emoções negativas, quando treinadas com a base $\mathrm{CK}+\mathrm{e}$ avaliadas com a base RaFD.

\begin{tabular}{|c|c|c|c|c|}
\hline $\begin{array}{c}\text { Representação } \\
\text { Facial }\end{array}$ & Tristeza & Medo & Raiva & Aversão \\
\cline { 2 - 5 } & Acerto (\%) & Acerto (\%) & Acerto (\%) & Acerto (\%) \\
\hline$F S_{1}$ & $65,4_{-}^{+} 1,12$ & $69,2_{-}^{+} 1,11$ & $80,8_{-}^{+} 1,06$ & $92,3_{-}^{+} 1,05$ \\
\hline$F S_{2}$ & $61,5_{-}^{+} 1,11$ & $61,5_{-}^{+} 1,13$ & $50,0_{-}^{+} 1,11$ & $50,0_{-}^{+} 1,14$ \\
\hline$F S_{1-3}$ & $69,2_{-}^{+} 1,07$ & $88,4_{-}^{+} 1,07$ & $88,4_{-}^{+} 1,03$ & $92,3_{-}^{+1,02}$ \\
\hline$F S_{2-4}$ & $50,0_{-}^{+} 1,15$ & $80,8_{-}^{+} 1,05$ & $50,0_{-}^{+} 1,13$ & $61,5_{-}^{+} 1,11$ \\
\hline$F S_{3}$ & $88,4_{-}^{+1,04}$ & $80,8_{-}^{+} 1,03$ & $92,3_{-}^{+} 1,03$ & $92,3_{-}^{+} 1,03$ \\
\hline$F S_{4}$ & $65,4_{-}^{+} 1,11$ & $69,2_{-}^{+} 1,09$ & $84,6_{-}^{+} 1,05$ & $88,4_{-}^{+} 1,05$ \\
\hline Média & $66,7_{-}^{+} 1,10$ & $75,0_{-}^{+} 1,08$ & $74,3_{-}^{+} 1,07$ & $79,5_{-}^{+} 1,07$ \\
\hline
\end{tabular}

Considerando as diferenças no reconhecimento emocional obtidas quando o treinamento é realizado com a base $\mathrm{CK}+$ ou $\mathrm{RaFD}$, as emoções de alegria e surpresa sempre apresentam as melhores taxas de acerto. A alegria apenas não figura entre as melhores taxas de acerto para as SVMs quando treinadas com a base $\mathrm{CK}+$. $\mathrm{O}$ mesmo é válido para a surpresa e as SVMs quando treinadas com a base RaFD. Além destas emoções, a expressão neutra apresenta também elevadas taxas de acerto. Dentre as emoções com maiores problemas de reconhecimento estão a tristeza, que apresenta, em todos os experimentos, as piores taxas de acerto, além de medo e 
Tabela 7.21: Taxas de acerto obtidas pelo algoritmo C4.5 para as emoções positivas e a expressão neutra, quando treinado com a base CK+ e avaliado com a base RaFD.

\begin{tabular}{|c|c|c|c|}
\hline $\begin{array}{c}\text { Representação } \\
\text { Facial }\end{array}$ & Neutra & Alegria & Surpresa \\
\cline { 2 - 4 } & Acerto (\%) & Acerto (\%) & Acerto (\%) \\
\hline$F S_{1}$ & $69,2_{-}^{+1,11}$ & $88,4_{-}^{+} 1,09$ & $92,3_{-}^{+1,04}$ \\
\hline$F S_{2}$ & $73,1_{-}^{+} 1,13$ & $88,4_{-}^{+} 1,07$ & $96,1_{-}^{+} 1,03$ \\
\hline$F S_{1-3}$ & $100,0_{-}^{+} 1,01$ & $96,1_{-}^{ \pm} 1,05$ & $88,4_{-}^{+1,03}$ \\
\hline$F S_{2-4}$ & $100,0_{-}^{+} 1,00$ & $100,0_{-}^{+} 1,04$ & $96,1_{-}^{+} 1,05$ \\
\hline$F S_{3}$ & $100,0_{-}^{+} 1,04$ & $92,3_{-}^{+} 1,06$ & $76,9_{-}^{+} 1,08$ \\
\hline$F S_{4}$ & $96,1_{-}^{+1,03}$ & $100,0_{-}^{+1,02}$ & $84,6_{-}^{+} 1,04$ \\
\hline Média & $89,7_{-}^{+} 1,05$ & $94,2_{-}^{+} 1,05$ & $89,1_{-}^{+} 1,04$ \\
\hline
\end{tabular}

Tabela 7.22: Taxas de acerto obtidas pelo algoritmo $\mathrm{C} 4.5$ para as emoções negativas, quando treinado com a base $\mathrm{CK}+\mathrm{e}$ avaliado com a base RaFD.

\begin{tabular}{|c|c|c|c|c|}
\hline $\begin{array}{c}\text { Representação } \\
\text { Facial }\end{array}$ & Tristeza & Medo & Raiva & Aversão \\
\cline { 2 - 5 } & Acerto (\%) & Acerto (\%) & Acerto (\%) & Acerto (\%) \\
\hline$F S_{1}$ & $53,8_{-}^{+1,16}$ & $50,1_{-}^{+} 1,21$ & $84,6_{-}^{+} 1,06$ & $80,7_{-}^{+1,07}$ \\
\hline$F S_{2}$ & $50,0_{-}^{+} 1,11$ & $73,1_{-}^{+} 1,08$ & $61,5_{-}^{+} 1,10$ & $76,9_{-}^{+} 1,09$ \\
\hline$F S_{1-3}$ & $88,4_{-}^{+1,06}$ & $61,5_{-}^{ \pm} 1,13$ & $73,1_{-}^{+} 1,07$ & $92,3_{-}^{+1,05}$ \\
\hline$F S_{2-4}$ & $76,9_{-}^{+} 1,10$ & $73,1_{-}^{+} 1,09$ & $80,7_{-}^{+} 1,10$ & $84,6_{-}^{+} 1,07$ \\
\hline$F S_{3}$ & $73,1_{-}^{+} 1,07$ & $80,7_{-}^{ \pm} 1,07$ & $88,4_{-}^{+} 1,05$ & $88,4_{-}^{+} 1,05$ \\
\hline$F S_{4}$ & $69,2_{-}^{+} 1,15$ & $76,9_{-}^{+} 1,08$ & $69,2_{-}^{+} 1,10$ & $80,7_{-}^{+} 1,06$ \\
\hline Média & $68,6_{-}^{+1,11}$ & $69,2_{-}^{+} 1,11$ & $76,3_{-}^{+} 1,08$ & $84,0_{-}^{+} 1,06$ \\
\hline
\end{tabular}

Tabela 7.23: Taxas de acerto obtidas pelas MLPs para as emoções positivas e a expressão neutra, quando treinadas com a base CK+ e avaliadas com a base RaFD.

\begin{tabular}{|c|c|c|c|}
\hline $\begin{array}{c}\text { Representação } \\
\text { Facial }\end{array}$ & Neutra & Alegria & Surpresa \\
\cline { 2 - 4 } & Acerto (\%) & Acerto (\%) & Acerto (\%) \\
\hline$F S_{1}$ & $73,1_{-}^{+} 1,08$ & $84,6_{-}^{+} 1,07$ & $92,3_{-}^{+} 1,04$ \\
\hline$F S_{2}$ & $50,1_{-}^{+} 1,07$ & $57,7_{-}^{+} 1,08$ & $73,1_{-}^{+} 1,08$ \\
\hline$F S_{1-3}$ & $92,3_{-}^{+1,10}$ & $96,1_{-}^{+} 1,05$ & $92,3_{-}^{+} 1,06$ \\
\hline$F S_{2-4}$ & $80,8_{-}^{+} 1,04$ & $100_{-}^{+} 1,06$ & $92,3_{-}^{+} 1,05$ \\
\hline$F S_{3}$ & $100,0_{-}^{+} 1,06$ & $88,4_{-}^{+} 1,08$ & $88,4_{-}^{+1,09}$ \\
\hline$F S_{4}$ & $50,0_{-}^{+} 1,13$ & $96,1_{-}^{+} 1,05$ & $92,3_{-}^{+} 1,07$ \\
\hline Média & $74,4_{-}^{+} 1,08$ & $87,2_{-}^{+} 1,06$ & $88,4_{-}^{+} 1,06$ \\
\hline
\end{tabular}

aversão. Estes resultados são semelhantes aos obtidos para as bases CK+ e RaFD quando avaliadas em separado. A única exceção é a aversão, que é facilmente identificada nos experimentos realizados apenas com as base RaFD ou CK+, e tem seu reconhecimento muito prejudicado nos experimentos realizados entre estas duas bases de dados, indicando que a generalização obtida para esta emoção é uma das mais afetadas.

Para facilitar a interpretação dos resultados, as tabelas 7.25 e 7.26 apresentam as diferenças encontradas no reconhecimento emocional, independente do 
Tabela 7.24: Taxas de acerto obtidas pelas MLPs para as emoções negativas, quando treinadas com a base CK+ e avaliadas com a base RaFD.

\begin{tabular}{|c|c|c|c|c|}
\hline $\begin{array}{c}\text { Representação } \\
\text { Facial }\end{array}$ & Tristeza & Medo & Raiva & Aversão \\
\cline { 2 - 5 } & Acerto (\%) & Acerto (\%) & Acerto (\%) & Acerto (\%) \\
\hline$F S_{1}$ & $73,1_{-}^{+} 1,12$ & $92,3_{-}^{+} 1,05$ & $88,4_{-}^{+} 1,08$ & $80,8_{-}^{+1,05}$ \\
\hline$F S_{2}$ & $57,7_{-}^{+} 1,18$ & $57,7_{-}^{+} 1,14$ & $73,1_{-}^{+} 1,14$ & $50,0_{-}^{+} 1,19$ \\
\hline$F S_{1-3}$ & $69,2_{-}^{+1,20}$ & $96,1_{-}^{+} 1,06$ & $88,4_{-}^{+} 1,10$ & $92,3_{-}^{+1,03}$ \\
\hline$F S_{2-4}$ & $61,5_{-}^{+} 1,11$ & $65,4_{-}^{+} 1,16$ & $92,3_{-}^{+} 1,06$ & $65,4_{-}^{+} 1,13$ \\
\hline$F S_{3}$ & $88,4_{-}^{+} 1,07$ & $84,6_{-}^{+} 1,07$ & $92,3_{-}^{+} 1,04$ & $84,6_{-}^{+} 1,07$ \\
\hline$F S_{4}$ & $65,4_{-}^{+} 1,16$ & $80,8_{-}^{+} 1,08$ & $76,9_{-}^{+} 1,09$ & $80,8_{-}^{+} 1,08$ \\
\hline Média & $69,2_{-}^{+} 1,14$ & $79,5_{-}^{+} 1,09$ & $85,2_{-}^{+} 1,08$ & $75,7_{-}^{+} 1,09$ \\
\hline
\end{tabular}

algoritmo de AM e representação facial, para os experimentos realizados entre as duas bases de dados, respectivamente, para as emoções positivas e negativas.

Tabela 7.25: Taxa de acerto média obtida para as emoções positivas com os experimentos entre as bases de dados.

\begin{tabular}{|c|c|c|c|}
\hline Treino - Teste & Neutra & Alegria & Surpresa \\
\cline { 2 - 4 } & Acerto (\%) & Acerto (\%) & Acerto (\%) \\
\hline RaFD - CK+ & $80,9_{-}^{+} 1,06$ & $86,8_{-}^{+} 1,04$ & $82,5_{-}^{+} 1,04$ \\
\hline CK+ - RaFD & $79,7_{-}^{+} 1,09$ & $85,0_{-}^{+} 1,05$ & $84,4_{-}^{+} 1,06$ \\
\hline
\end{tabular}

Tabela 7.26: Taxa de acerto média obtida para as emoções negativas com os experimentos entre as bases de dados.

\begin{tabular}{|c|c|c|c|c|}
\hline \multirow{2}{*}{ Treino-Teste } & Tristeza & Medo & Raiva & Aversão \\
\cline { 2 - 5 } & Acerto (\%) & Acerto (\%) & Acerto (\%) & Acerto (\%) \\
\hline RaFD - CK+ & $61,3_{-}^{+} 1,10$ & $73,9_{-}^{+} 1,08$ & $75,4_{-}^{+} 1,06$ & $71,5_{-}^{+} 1,06$ \\
\hline CK+ - RaFD & $68,2_{-}^{+} 1,11$ & $74,6_{-}^{+} 1,09$ & $78,6_{-}^{+} 1,05$ & $79,8_{-}^{+} 1,04$ \\
\hline
\end{tabular}

De acordo com estas tabelas, é possível notar que as representações faciais interpretam mais facilmente as emoções positivas que as negativas. Estas características vêm sendo percebidas desde os experimentos realizados individualmente com as bases CK+ e RaFD, e são esperadas de acordo com estudos da psicologia. Ademais, em geral, uma melhor generalização é obtida quando o treinamento é realizado com a base $\mathrm{CK}^{+}$, visto a obtenção de melhores taxas de acerto para praticamente todas as emoções investigadas. Estatisticamente, o desempenho dos classificadores é superior para o treinamento realizado com a base $\mathrm{CK}+$, com significância estatística, ao analisar as emoções de medo e surpresa e, com grau de confiança de 95\%, para aversão, tristeza e raiva. Ao passo que o treinamento realizado com a base RaFD obtém resultados estatisticamente superiores apenas para a alegria e a expressão neutra.

Observando as taxas de acerto médias encontradas, independente do algo- 
ritmo de AM e representação facial empregados, e considerando os resultados obtidos para as bases de dados $\mathrm{CK}+\mathrm{e}$ RaFD, a facilidade de reconhecimento emocional, em ordem decrescente, apresenta a alegria com 98,2\%, a surpresa com 97\%, a aversão com 92,7\%, a expressão neutra com $90,7 \%$, o medo com $88 \%$, a raiva com $87,8 \%$, e a tristeza com $86,8 \%$. Embora o acerto médio obtido para os experimentos entre as duas bases de dados seja menor, a facilidade no reconhecimento das emoções, considerando a taxa de acerto média, pouco é alterada sendo, em ordem decrescente, de $85,9 \%$ para a alegria, $83,5 \%$ para a surpresa, $80,3 \%$ para a expressão neutra, $77 \%$ para a raiva, $75,7 \%$ para a aversão, $74,3 \%$ para o medo, e $64,8 \%$ para a tristeza. Neste sentido, apenas a aversão tem seu posicionamento bastante alterado, todas as demais emoções tem suas posições praticamente mantidas, o que indica robustez das representações faciais propostas. Sendo assim, os experimentos entre as duas bases indicam uma boa capacidade de generalização, apresentando resultados coerentes com os previamente obtidos. Neles, as representações que possuem informações da emoção com relação à expressão neutra também obtêm melhor desempenho, a principal diferença encontrada está no fato das representações mais complexas, baseadas na representação $F S_{1}$, apresentarem melhor capacidade de generalização.

A análise dos diferentes experimentos apresentados permite notar que as representações faciais propostas conferem aos algoritmos de AM a capacidade de reconhecer as seis emoções básicas e a expressão neutra, uma vez que elevadas taxas de acerto são obtidas. Ademais, nos experimentos em que apenas uma das bases de dados, RaFD ou $\mathrm{CK}+$, é utilizada, as representações baseadas nas diferenças faciais de acordo com a expressão neutra $\left(F S_{3}\right.$ e $\left.F S_{4}\right)$, assim como as representações que combinam estas informações com as características da emoção em seu ápice $\left(F S_{1-3}\right.$ e $F S_{2-4}$ ), apresentam os melhores desempenhos, independente do algoritmo de AM ou emoção investigada. Portanto, a obtenção de bons resultados confirma que a modelagem utilizada nas representações faciais propostas, baseada na psicologia, que se vale da representação geométrica da face e enfatiza as mudanças na configuração ou disposição dos elementos faciais, é adequada para o reconhecimento emocional.

\section{Análise Conjunta das Emoções}

Para comparar se a abordagem escolhida, que analisa individualmente as emoções, é realmente adequada, ou seja, permite a obtenção dos melhores desempenhos para o reconhecimento emocional, as representações faciais propostas são também utilizadas para analisar as emoções em conjunto. Sendo assim, um único classificador deve escolher entre as seis emoções básicas ou a expressão neutra quando da análise facial. Para esta nova abordagem, é utilizada a mesma metodologia de experimentos já apresentada, e os melhores resultados para cada representação facial e classificador são apresentados nas tabelas 7.27 e 7.28 respec- 
tivamente, para as bases RaFD e CK+.

Tabela 7.27: Taxas de acerto obtidas para a base RaFD e as emoções em conjunto.

\begin{tabular}{|c|c|c|c|c|}
\hline \multirow{2}{*}{$\begin{array}{c}\text { Representação } \\
\text { Facial }\end{array}$} & \multicolumn{2}{|c|}{ SVMs } & C4.5 & MLPs \\
\cline { 2 - 5 } & Núcleo & $\begin{array}{c}\text { Taxa de } \\
\text { Acerto (\%) }\end{array}$ & $\begin{array}{c}\text { Taxa de } \\
\text { Acerto (\%) }\end{array}$ & $\begin{array}{c}\text { Taxa de } \\
\text { Acerto (\%) }\end{array}$ \\
\hline$F S_{1}$ & Gaussiano & $80,2_{-}^{+} 1,11$ & $71,4_{-}^{+} 2,74$ & $82,4_{-}^{+} 3,00$ \\
\hline$F S_{2}$ & Gaussiano & $75,8_{-}^{+} 1,60$ & $72,2_{-}^{+} 2,11$ & $80,2_{-}^{+} 2,70$ \\
\hline$F S_{3}$ & Linear & $90,1_{-}^{+} 1,15$ & $86,8_{-}^{+} 3,01$ & $92,3_{-}^{+} 2,68$ \\
\hline$F S_{4}$ & Linear & $87,9_{-}^{+} 1,25$ & $79,1_{-}^{+} 2,17$ & $89,0_{-}^{+} 1,98$ \\
\hline$F S_{1-3}$ & Gaussiano & $94,5_{-}^{+} 0,96$ & $84,6_{-}^{+} 1,53$ & $93,4_{-}^{+} 2,00$ \\
\hline$F S_{2-4}$ & Gaussiano & $90,1_{-}^{+} 1,07$ & $84,6_{-}^{+} 1,83$ & $85,7_{-}^{+} 3,50$ \\
\hline Média & \multicolumn{2}{|c|}{$86,4_{-}^{+} 1,19^{-}$} & $79,8_{-}^{+} 2,23$ & $87,2_{-}^{+2} 2,64$ \\
\hline
\end{tabular}

Tabela 7.28: Taxas de acerto obtidas para a base CK+ e as emoções em conjunto.

\begin{tabular}{|c|c|c|c|c|}
\hline \multirow{2}{*}{$\begin{array}{c}\text { Representação } \\
\text { Facial }\end{array}$} & \multicolumn{2}{|c|}{ SVMs } & C4.5 & MLPs \\
\cline { 2 - 5 } & Núcleo & $\begin{array}{c}\text { Taxa de } \\
\text { Acerto (\%) }\end{array}$ & $\begin{array}{c}\text { Taxa de } \\
\text { Acerto (\%) }\end{array}$ & $\begin{array}{c}\text { Taxa de } \\
\text { Acerto (\%) }\end{array}$ \\
\hline$F S_{1}$ & Gaussiano & $69,2_{-}^{+} 3,00$ & $58,4_{-}^{+} 3,51$ & $65,4_{-}^{+} 3,82$ \\
\hline$F S_{2}$ & Gaussiano & $70,3_{-}^{+} 2,26$ & $64,9_{-}^{+} 3,02$ & $64,5_{-}^{+} 3,02$ \\
\hline$F S_{3}$ & Gaussiano & $79,5_{-}^{+} 1,34$ & $68,7_{-}^{+} 2,94$ & $75,6_{-}^{+} 2,64$ \\
\hline$F S_{4}$ & Gaussiano & $79,7_{-}^{+} 1,41$ & $75,7_{-}^{+} 2,94$ & $78,4_{-}^{+} 3,99$ \\
\hline$F S_{1-3}$ & Gaussiano & $75,8_{-}^{+} 1,89$ & $71,0_{-}^{+} 2,65$ & $64,9_{-}^{+} 3,32$ \\
\hline$F S_{2-4}$ & Gaussiano & $79,2_{-}^{+} 1,19$ & $79,2_{-}^{+} 2,96$ & $79,2_{-}^{+} 3,00$ \\
\hline Média & \multicolumn{2}{|c|}{$75,6_{-}^{+} 1,85_{-}$} & $69,7_{-}^{+} 3,00$ & $71,4_{-}^{+} 3,30$ \\
\hline
\end{tabular}

É possível observar que os melhores resultados do classificador SVM são obtidos com o núcleo gaussiano, assim como todas as MLPs que apresentam melhores desempenhos possuem uma única camada intermediária. As taxas de acerto obtidas são elevadas mas, para a base RaFD, as MLPs são superiores e, para a base CK+, as SVMs apresentam o melhor desempenho. Ainda, para as duas bases, o algoritmo C4.5 apresenta o pior desempenho. Neste sentido, com grau de confiança de 95\%, as SVMs apresentam melhor desempenho que o algoritmo C4.5 para as bases CK+ e RaFD, e melhor desempenho que as MLPs para a base CK+. Para a base RaFD, as MLPs são estatisticamente superiores às SVMs e ao algoritmo C4.5, porém com relação a este último com grau de confiança de 95\%. Vale destacar também que as taxas de acerto obtidas para esta abordagem são inferiores às obtidas para a abordagem proposta, assim como os desvios-padrão observados são superiores.

Analisando as SVMs, as taxas de acerto para a base RaFD são entre 5\% e $19 \%$ superiores às obtidas para a base $\mathrm{CK}+$, dependendo da representação facial utilizada. Para o algoritmo C4.5, para as diferentes representações faciais, as taxas de acerto obtidas para a base RaFD são de $4 \%$ a $18 \%$ melhores que as obtidas para a base $\mathrm{CK}+$. O mesmo ocorre para as redes MLP, em que os resultados obtidos para a base RaFD são entre $6 \%$ e $29 \%$ superiores. Dessa forma, com grau de confiança de 95\%, o desempenho na identificação das emoções se mostra superior utilizando a base de dados RaFD. Para os experimentos realizados com as emoções 
individualmente analisadas, como já discutido, não é possivel encontrar uma clara superioridade entre uma ou outra base de dados.

Como as imagens pertencentes à base RaFD apresentam menor variabilidade, já que condições ambientais como iluminação, fundo e roupas são mais rigidamente controlados, a análise dos resultados obtidos para as emoções em conjunto permite afirmar que, quando o classificador precisa decidir entre uma quantidade maior de emoções, o desempenho é superior se este não sofre influências relevantes do ambiente em que a face analisada se encontra. Já para a análise de uma única emoção, os resultados indicam que as influências do ambiente são minimizadas.

A análise estatística para a base RaFD indica, com grau de confiança de 95\%, que a representação facial $F S_{1-3}$ apresenta melhor desempenho que as representações $F S_{2-4}$ e $F S_{3}$ para o classificador SVM. No entanto, para o algoritmo C4.5, a representação $F S_{3}$ é superior às representações $F S_{2-4}$ e $F S_{1-3}$, com grau de confiança de 95\%. Já para as MLPs, as representações $F S_{1-3}$ e $F S_{3}$ são estatisticamente melhores que a $F S_{4}$, com grau de confiança de 95\%, e a representação $F S_{1-3}$ é também estatisticamente superior à representação $F S_{3}$. Para todos os algoritmos de $\mathrm{AM}$, as representações $F S_{1}$ e $F S_{2}$ são as que apresentam pior desempenho.

Para a base CK+ e as SVMs, o melhor desempenho é obtido para a representação $F S_{4}$, que se mostra superior às representações $F S_{3}$ e $F S_{2-4}$, ao passo que a representação $F S_{1-3}$ é estatisticamente inferior. A análise do algoritmo C4.5 permite notar que a representação $F S_{2-4}$ é superior às representações $F S_{4}$ e $F S_{1-3}$, com grau de confiança de 95\%. Para as redes MLP, $F S_{2-4}$ é superior às representações $F S_{4} \mathrm{e}$ $F S_{3}$ que são, por sua vez, melhores que a $F S_{1-3}$. Considerando todos os algoritmos de AM, as representações faciais $F S_{1}$ e $F S_{2}$ apresentam o pior desempenho.

De acordo com o exposto, para os experimentos realizados com as emoções analisadas em conjunto, o pior desempenho continua pertencendo às representações $F S_{1}$ e $F S_{2}$. Embora os melhores desempenhos apresentem alguma variação, sendo eles, para a base RaFD, atribuídos às representações $F S_{1-3}$ e $F S_{3}$, seguidos pela $F S_{2-4}$ e, para a base $\mathrm{CK}+$, atribuídos às representações $F S_{2-4}$ e $F S_{4}$, seguidos pela $F S_{3}$. De modo geral, os resultados são similares aos obtidos para a abordagem proposta, em que as emoções são analisadas separadamente, pois as representações que enfatizam as diferenças entre a expressão neutra e uma expressão emocional, ou aquelas que combinam esta informação com as características do ápice da emoção, continuam sendo as que obtêm melhores taxas de acerto.

Um fato importante a ser destacado para a abordagem em que as emoções são analisadas em conjunto por um mesmo classificador é que, mesmo para os melhores resultados presentes nas tabelas 7.27 e 7.28 , não são todas as emoções que apresentam elevadas taxas de acerto. Por exemplo, a representação $F S_{1-3}$ para as MLPs e a base RaFD obteve um dos melhores desempenhos porém, ao analisar as taxas de acerto individuais para cada emoção, ou seja, a matriz de confusão 
deste classificador, é possível notar a baixa taxa de acerto, de apenas 69,2\%, obtida para a emoção tristeza. Do mesmo modo, se for observada a representação $F S_{2-4}$ para este mesmo classificador, a mesma emoção de tristeza apresenta taxa de acerto ainda menor, de apenas 30,8\%. Estes exemplos demonstram uma desvantagem em analisar conjuntamente as emoções, já que elevadas taxas de acerto não garantem que o acerto obtido para cada emoção seja também elevado. Adicionalmente, esta abordagem resulta em maior complexidade do classificador induzido e maior tempo de processamento computacional.

Para comparação, nas tabelas 7.29 e 7.30 são apresentadas, respectivamente, para as emoções positivas e a expressão neutra, assim como para as emoções negativas, as taxas médias de acerto obtidas, independente do algoritmo de AM utilizado, com a base RaFD. Do mesmo modo, as tabelas 7.31 e 7.32 contêm a mesma informação, respectivamente, para as emoções positivas e a expressão neutra, além das emoções negativas, mas agora para a base $\mathrm{CK}+$.

Tabela 7.29: Taxa de acerto média obtida para as emoções positivas e a expressão neutra com a base RaFD, quando analisadas em conjunto.

\begin{tabular}{|c|c|c|c|}
\hline \multirow[b]{2}{*}{$\begin{array}{l}\text { Representação } \\
\text { Facial }\end{array}$} & Neutra & Alegria & Surpresa \\
\hline & $\begin{array}{c}\text { Taxa de } \\
\text { Acerto (\%) }\end{array}$ & $\begin{array}{c}\text { Taxa de } \\
\text { Acerto (\%) }\end{array}$ & $\begin{array}{c}\text { Taxa de } \\
\text { Acerto (\%) }\end{array}$ \\
\hline$F S_{1}$ & $63,3_{-}^{+} 1,09$ & $97,5_{-}^{+} 1,03$ & $86,8_{-}^{+1,06}$ \\
\hline$F S_{2}$ & $58,9 \pm 1,11$ & $94,8_{-}^{+} 1,04$ & $89,7 \pm 1,04$ \\
\hline$F S_{3}$ & $100,0_{-}^{+} 1,00$ & $100,0_{-}^{+} 1,00$ & $74,3+1,06$ \\
\hline$F S_{4}$ & $100,0_{-}^{+} 0,92$ & $100,0_{-}^{+} 0,97$ & $84,6_{-}^{+} 1,07$ \\
\hline$F S_{1-3}$ & $100,0_{-}^{+} 0,86$ & $100,0+0,84$ & $89,7+1,08$ \\
\hline$F S_{2-4}$ & $97,4_{-}^{+} 1,02$ & $97,4_{-}^{+} 1,01$ & $95,5_{-}^{+} 1,02$ \\
\hline Média & $86,6+1,00$ & $98,3+0,98$ & $86,8+1,05$ \\
\hline
\end{tabular}

Tabela 7.30: Taxa de acerto média obtida para as emoções negativas com a base RaFD, quando analisadas em conjunto.

\begin{tabular}{|c|c|c|c|c|}
\hline \multirow[b]{2}{*}{$\begin{array}{c}\text { Representação } \\
\text { Facial }\end{array}$} & Tristeza & Medo & Raiva & Aversão \\
\hline & $\begin{array}{c}\text { Taxa de } \\
\text { Acerto (\%) }\end{array}$ & $\begin{array}{c}\text { Taxa de } \\
\text { Acerto (\%) }\end{array}$ & $\begin{array}{c}\text { Taxa de } \\
\text { Acerto (\%) }\end{array}$ & $\begin{array}{c}\text { Taxa de } \\
\text { Acerto (\%) }\end{array}$ \\
\hline$F S_{1}$ & $56,4_{-}^{+} 1,11$ & $77,9+1,04$ & $70,8_{-}^{+} 1,09$ & $95,1+1,02$ \\
\hline$F S_{2}$ & $53,8_{-}^{+} 1,09$ & $71,8_{-}^{+1,06}$ & $64,1_{-}^{+} 1,12$ & $97,4_{-}^{+} 1,00$ \\
\hline$F S_{3}$ & $79,5_{-}^{+} 1,03$ & $84,6_{-}^{+1,05}$ & $94,9+1,05$ & $94,9+1,05$ \\
\hline$F S_{4}$ & $71,7_{-}^{+} 1,06$ & $87,2_{-}^{+} 1,03$ & $71,8_{-}^{+} 1,04$ & $87,2_{-}^{+} 1,07$ \\
\hline$F S_{1-3}$ & $76,9_{-}^{+} 1,04$ & $92,3_{-}^{+1,02}$ & $76,9_{-}^{+} 1,07$ & $100,0_{-}^{+} 1,02$ \\
\hline$F S_{2-}$ & $53,8_{-1}^{+1,10}$ & $87,2+1,05$ & $79,5 \pm 1,06$ & $97,4_{-}^{+} 1,01$ \\
\hline Média & $65,3_{-1}^{+1,07}$ & $83,5_{-}^{+} 1,04$ & $76,3_{-}^{+} 1,073$ & $95,3_{-}^{+} 1,03$ \\
\hline
\end{tabular}

De acordo com estas tabelas, é possível observar que, na análise conjunta, todas as emoções, com exceção de surpresa, são melhor reconhecidas quando os classificadores são treinados com a base RaFD. Mais importante é o fato das taxas 
Tabela 7.31: Taxa de acerto média obtida para as emoções positivas com a base $\mathrm{CK}^{+}$, quando analisadas em conjunto.

\begin{tabular}{|c|c|c|c|}
\hline \multirow{3}{*}{$\begin{array}{c}\text { Representação } \\
\text { Facial }\end{array}$} & Neutra & Alegria & Surpresa \\
\hline & Taxa de & Taxa de & Taxa de \\
\hline & Acerto (\%) & Acerto (\%) & Acerto (\%) \\
\hline$F S_{1}$ & $50,0_{-}^{+} 1,15$ & $100,0_{-}^{+} 1,01$ & $89,9+1,06$ \\
\hline$F S_{2}$ & $47,1_{-}^{+} 1,22$ & $84,1+1,05$ & $97,9_{-}^{+1,03}$ \\
\hline$F S_{3}$ & $100,0_{-}^{+} 1,00$ & $93,9_{-}^{+} 1,03$ & $91,9+1,05$ \\
\hline$F S_{4}$ & $100,0 \pm 0,94$ & $86,0+1,07$ & $93,8+1,05$ \\
\hline$F S_{1-3}$ & $84,4_{-}^{+} 1,16$ & $84,1_{-}^{+} 1,11$ & $84,0_{-}^{+} 1,09$ \\
\hline & $97,2 \pm 1,03$ & $76,0_{-}^{+} 1,17$ & $100,0_{-}^{+} 1,01$ \\
\hline Média & $79,8_{-}^{+} 1,08$ & $89,0_{-}^{+} 1,07$ & $92,9_{-}^{+} 1,05$ \\
\hline
\end{tabular}

Tabela 7.32: Taxa de acerto média obtida para as emoções negativas com a base $\mathrm{CK}^{+}$, quando analisadas em conjunto.

\begin{tabular}{|c|c|c|c|c|}
\hline \multirow{3}{*}{$\begin{array}{c}\text { Representação } \\
\text { Facial }\end{array}$} & Tristeza & Medo & Raiva & Aversão \\
\hline & Taxa de & Taxa de & Taxa de & Taxa de \\
\hline & Acerto (\%) & Acerto (\%) & Acerto (\%) & Acerto (\%) \\
\hline$F S_{1}$ & $16,8_{-}^{+} 1,83$ & $63,8_{-}^{+} 1,14$ & $45,9_{-}^{+} 1,29$ & $55,1+1,23$ \\
\hline$F S_{2}$ & $34,0_{-}^{+} 1,59$ & $91,9+1,04$ & $32,8_{-}^{+} 1,42$ & $70,1_{-}^{+1,07}$ \\
\hline$F S_{3}$ & $19,9_{-}^{+} 1,93$ & $54,0_{-}^{+} 1,22$ & $72,0_{-}^{+} 1,11$ & $77,9_{-}^{+} 1,07$ \\
\hline$F S_{4}$ & $36,8_{-}^{+1,66}$ & $68,8_{-1,13}^{+1,13}$ & $69,8_{-}^{+1,14}$ & $90,0_{-}^{+1,03}$ \\
\hline$F S_{1}$ & $66,9+1,24$ & $54,3+1,19$ & $70,1+1,07$ & $45,8_{-}^{+} 1,32$ \\
\hline & $46,2_{-}^{+} 1,40$ & $97,1_{-}^{+1,00}$ & $56,0_{-}^{+} 1,12$ & $77,2_{-}^{+1,08}$ \\
\hline Média & $36,8_{-}^{+} 1,61$ & $71,6_{-}^{+} 1,12$ & $57,8_{-}^{+} 1,19$ & $69,3+1,14$ \\
\hline
\end{tabular}

de reconhecimento obtidas por esta abordagem serem muito inferiores às obtidas pela abordagem proposta, de análise individual das emoções. Apenas as emoções de alegria e aversão, com os classificadores treinados com a base RaFD, apresentam resultados estatisticamente equivalentes.

Ainda, os classificadores treinados com a base RaFD mais facilmente reconhecem, nesta ordem, as emoções de alegria, aversão, surpresa, expressão neutra, medo, raiva e tristeza. Com relação aos erros de classificação, a alegria é, muitas vezes, classificada como aversão. A aversão é confundida principalmente com as expressões neutra e surpresa. A expressão neutra é incorretamente classificada como tristeza, o que pode ser resultado do problema de mapeamento apresentado pelo Face Tracker. A surpresa é confundida com o medo e, em menor frequência, com a tristeza. Já a emoção de medo é confundida muitas vezes com as emoções de tristeza ou surpresa. A raiva é classificada incorretamente como tristeza ou expressão neutra sendo, em alguns casos, confundida também com a aversão. Já a tristeza, que obteve baixa taxa de reconhecimento, é confundida principalmente com a raiva, o medo e a expressão neutra.

Os classificadores treinados com a base $\mathrm{CK}+$ apresentam resultados semelhantes, ou seja, as melhores taxas de reconhecimento são obtidas, nesta ordem, 
para as expressões de surpresa, alegria, neutra, medo, aversão, raiva e tristeza. Adicionalmente, a alegria é confundida principalmente com as expressões de medo ou aversão. A aversão é incorretamente classificada como alegria, raiva ou expressão neutra. A expressão neutra é confundida com as emoções de tristeza, medo ou raiva. A surpresa é, muitas vezes, classificada incorretamente como tristeza ou medo. A emoção de medo é incorretamente classificada também como neutra, tristeza ou surpresa. A raiva é confundida principalmente com as expressões de tristeza, aversão ou neutra. Por fim, a tristeza é confundida principalmente com a raiva, o medo ou a expressão neutra.

Como pode ser notado, a classificação incorreta das emoções é semelhante para os treinamentos realizados com as bases CK+ ou RaFD, apenas uma maior confusão ocorre na classificação realizada com a base $\mathrm{CK}^{+}$, motivo pelo qual as taxas de acerto obtidas para esta base são inferiores. Ademais, mesmo com as desvantagens da abordagem de análise das emoções em conjunto, a facilidade em reconhecer as expressões de emoção é muito semelhante à apresentada pela abordagem de reconhecimento proposta. Neste sentido, apenas existem diferenças entre o desempenho obtido por estas duas abordagens.

Para avaliar a capacidade de generalização, são também realizados testes entre as bases de dados, cujos resultados podem ser observados nas tabelas $7.33 \mathrm{e}$ 7.34, respectivamente, para o treinamento com a base CK+ e testes com a base RaFD e vice-versa. De acordo com estas tabelas, embora seja obtida alguma generalização, as taxas de acerto médias encontradas são baixas, em sua maioria não muito superiores a 50\%. Adicionalmente, se analisada cada representação facial separadamente, é possivel encontrar diversos exemplos em que a taxa de acerto é inferior a 50\%, indicando que a generalização dos classificadores não é adequada para diversas das representações faciais. Esta afirmação é particularmente verdadeira para as representações $F S_{1}$ e $F S_{2}$, ao serem treinadas com a base RaFD, que confere, de maneira geral, uma pior capacidade de generalização aos classificadores induzidos. É possível que a maior variabilidade existente nos exemplos da base de dados CK+ tornaram os classificadores mais robustos.

Tabela 7.33: Taxas de acerto obtidas para as emoções em conjunto, quando treinadas com a base CK+ e avaliadas com a base RaFD.

\begin{tabular}{|c|c|c|c|c|}
\hline \multirow[b]{2}{*}{$\begin{array}{c}\text { Representação } \\
\text { Facial }\end{array}$} & \multicolumn{2}{|c|}{ SVMs } & $\mathrm{C} 4.5$ & MLPs \\
\hline & Núcleo & $\begin{array}{c}\text { Taxa de } \\
\text { Acerto (\%) }\end{array}$ & $\begin{array}{c}\text { Taxa de } \\
\text { Acerto (\%) }\end{array}$ & $\begin{array}{c}\text { Taxa de } \\
\text { Acerto (\%) }\end{array}$ \\
\hline$F S_{1}$ & Gaussiano & $63,7_{-}^{+2,01}$ & $46,1+2,84$ & $61,5_{-}^{+} 3,09$ \\
\hline$F S_{2}$ & Linear & $67,0_{-}^{+} 1,16$ & $39,5_{-}^{+} 3,16$ & $63,7_{-}^{+} 3,11$ \\
\hline$F S_{3}$ & Linear & $70,3_{-1,25}^{+}$ & $61,5_{-}^{+} 2,33$ & $80,2_{-}^{+} 2,41$ \\
\hline$F S_{4}$ & Gaussiano & $70,3_{-}^{+} 1,51$ & $67,0_{-}^{+} 2,19$ & $68,1_{-}^{+} 2,96$ \\
\hline$F S_{1-3}$ & Gaussiano & $71,4_{-}^{+} 1,42$ & $61,5_{-}^{+} 2,35$ & $71,4_{-}^{+} 2,77$ \\
\hline$F S_{2-4}$ & Linear & $73,6_{-}^{+} 1,09$ & $72,5_{-}^{+} 1,92$ & $81,3_{-}^{+} 2,01$ \\
\hline Média & 69,4 & 1,41 & $58,0_{-}^{+} 2,46$ & $71,0+2,72$ \\
\hline
\end{tabular}


Tabela 7.34: Taxas de acerto obtidas para as emoções em conjunto, quando treinadas com a base RaFD e avaliadas com a base $\mathrm{CK}+$.

\begin{tabular}{|c|c|c|c|c|}
\hline \multirow{2}{*}{$\begin{array}{c}\text { Representação } \\
\text { Facial }\end{array}$} & \multicolumn{2}{|c|}{ SVMs } & C4.5 & MLPs \\
\cline { 2 - 5 } & Núcleo & $\begin{array}{c}\text { Taxa de } \\
\text { Acerto (\%) }\end{array}$ & $\begin{array}{c}\text { Taxa de } \\
\text { Acerto (\%) }\end{array}$ & $\begin{array}{c}\text { Taxa de } \\
\text { Acerto (\%) }\end{array}$ \\
\hline$F S_{1}$ & Linear & $52,5_{-}^{+} 2,13$ & $47,4_{-}^{+} 2,50$ & $52,5_{-}^{+} 3,02$ \\
\hline$F S_{2}$ & Gaussiano & $44,6_{-}^{+} 1,44$ & $51,3_{-}^{+} 2,11$ & $52,7_{-}^{+} 3,10$ \\
\hline$F S_{3}$ & Gaussiano & $76,9_{-}^{+} 1,30$ & $69,2_{-}^{+} 1,95$ & $67,9_{-}^{+} 2,12$ \\
\hline$F S_{4}$ & Gaussiano & $71,6_{-}^{+} 1,25$ & $62,1_{-}^{+} 2,07$ & $70,3_{-}^{+} 1,84$ \\
\hline$F S_{1-3}$ & Linear & $74,2_{-}^{+1,33}$ & $67,7_{-}^{+2,03}$ & $64,5_{-}^{+2,35}$ \\
\hline$F S_{2-4}$ & Gaussiano & $73,6_{-}^{+} 1,17$ & $63,9_{-}^{+} 1,99$ & $63,9_{-}^{+} 2,17$ \\
\hline Média & \multicolumn{2}{|c|}{$65,5_{-}^{+} 1,44_{-}$} & $60,3_{-}^{+} 2,11$ & $62,0_{-}^{+} 2,44$ \\
\hline
\end{tabular}

Independente de qual base de dados é utilizada para o treinamento, nestes novos experimentos, o algoritmo C4.5 também apresenta o pior desempenho. Porém, diferente do que pode ser observado para os experimentos iniciais com as emoções em conjunto, para o treinamento realizado com a base de dados RaFD, as SVMs são estatisticamente superiores às MLPs, ao passo que, para o treinamento realizado com a base de dados $\mathrm{CK}^{+}$, as MLPs são estatisticamente superiores às SVMs.

A análise das representações faciais permite notar que, como pode ser observado nos experimentos iniciais, as representações $F S_{3}, F S_{4}, F S_{1-3}$ e $F S_{2-4}$ se alternam na obtenção dos melhores desempenhos encontrados. Dessa forma, embora a generalização tenha sido comprometida, os resultados observados são semelhantes aos obtidos para os experimentos em que as emoções são individualmente analisadas, ou seja, as representações faciais com melhor desempenho na abordagem de análise das emoções em conjunto são as mesmas obtidas nos experimentos com a abordagem de análise individual das emoções.

As tabelas 7.35 e 7.36 apresentam as diferenças encontradas no reconhecimento emocional, independente do algoritmo de AM e representação facial, para os experimentos realizados entre as duas bases de dados, respectivamente, para as emoções positivas e negativas.

Tabela 7.35: Taxa de acerto média obtida para as emoções positivas, quando analisadas em conjunto, para os experimentos entre as bases de dados.

\begin{tabular}{|c|c|c|c|}
\hline \multirow{2}{*}{ Treino - Teste } & Neutra & Alegria & Surpresa \\
\cline { 2 - 4 } & Acerto (\%) & Acerto (\%) & Acerto (\%) \\
\hline RaFD - CK+ & $67,8_{-}^{+} 1,60$ & $92,5_{-}^{+} 1,02$ & $71,2_{-}^{+} 1,17$ \\
\hline CK+ - RaFD $^{+}$ & $82,9_{-}^{+} 1,11$ & $93,1_{-}^{+} 1,08$ & $89,7_{-}^{+} 1,10$ \\
\hline
\end{tabular}

Estas tabelas demonstram que as representações faciais interpretam mais facilmente as emoções positivas que as negativas. Estas características vêm sendo percebidas desde os experimentos realizados individualmente com as bases $\mathrm{CK}+\mathrm{e}$ RaFD, e são esperadas de acordo com estudos psicológicos. Vale mencionar que pouca ou nenhuma generalização é obtida para as emoções negativas, já que as 
Tabela 7.36: Taxa de acerto média obtida para as emoções negativas, quando analisadas em conjunto, para os experimentos entre as bases de dados.

\begin{tabular}{|c|c|c|c|c|}
\hline \multirow{2}{*}{ Treino-Teste } & Tristeza & Medo & Raiva & Aversão \\
\cline { 2 - 5 } & Acerto (\%) & Acerto (\%) & Acerto (\%) & Acerto (\%) \\
\hline RaFD - CK+ & $50,4_{-}^{+} 1,71$ & $39,3_{-}^{+} 2,10$ & $55,8_{-}^{+} 1,67$ & $55,6_{-}^{+} 1,80$ \\
\hline CK+ - RaFD & $38,5_{-}^{+} 1,57$ & $44,0_{-}^{+} 1,35$ & $49,6_{-}^{+} 1,29$ & $65,4_{-}^{+} 1,44$ \\
\hline
\end{tabular}

taxas de acerto encontradas são, em geral, próximas ou inferiores a 50\%. Ademais, a generalização observada com a base $\mathrm{CK}+$ é superior, visto a obtenção de melhores taxas de acerto para praticamente todas as emoções investigadas quando esta base é utilizada na fase de treinamento do classificador. Estatisticamente, o desempenho dos classificadores é superior para o treinamento realizado com a base $\mathrm{CK}+$, com significância estatística, ao analisar as emoções de medo, aversão, alegria, surpresa e a expressão neutra. Para o treinamento realizado com a base RaFD, apenas as emoções de tristeza e raiva são estatisticamente superiores.

A Figura 7.2 apresenta um gráfico para facilitar a comparação entre o desempenho obtido pela abordagem proposta e pela abordagem de análise conjunta das emoções, independente do algoritmo de AM, representação facial e bases de dados investigadas. Nele, facilmente pode ser notada a superioridade, seja em desempenho e capacidade de generalização, obtida pela abordagem proposta.

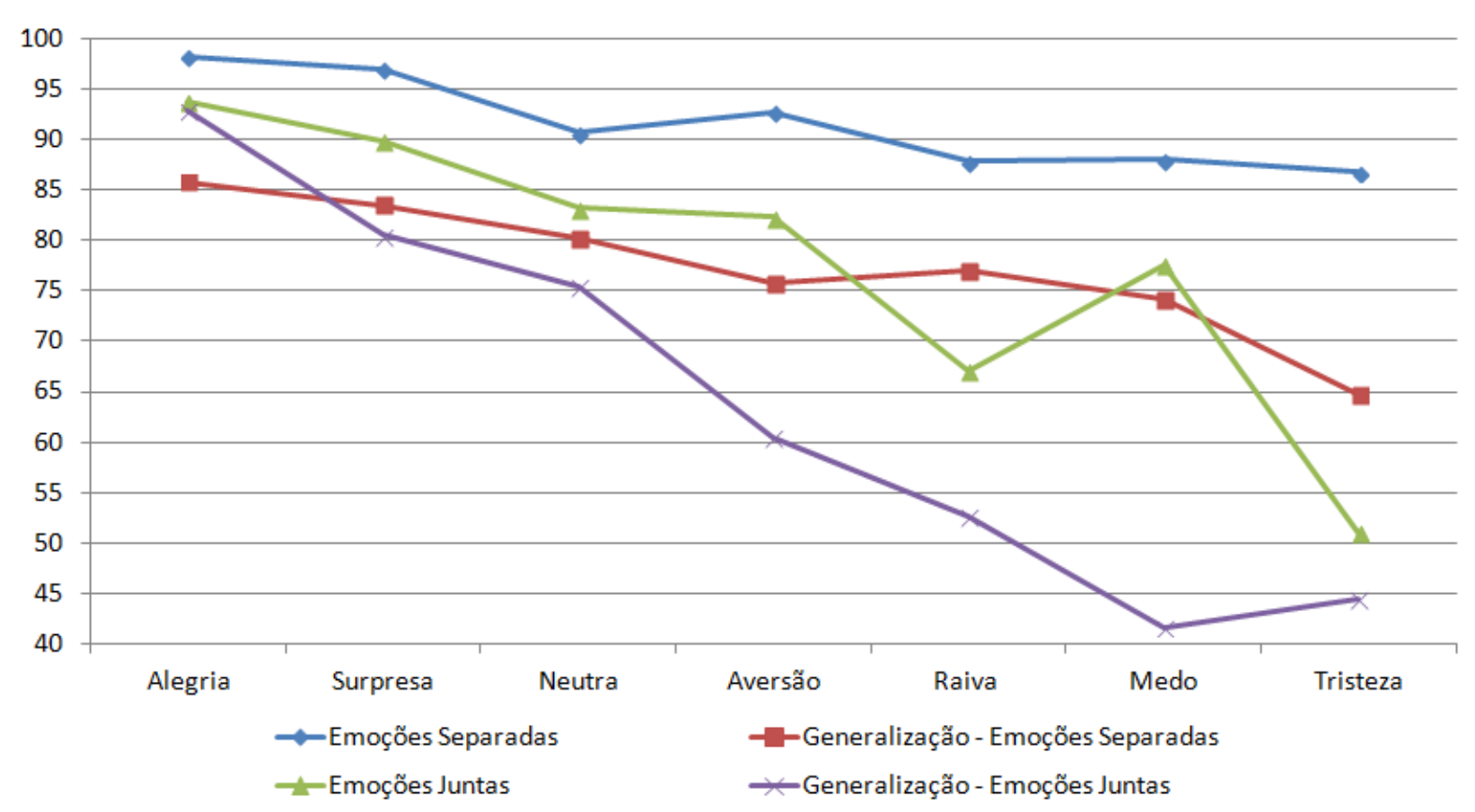

Figura 7.2: Gráfico comparativo entre a abordagem proposta e a abordagem de análise conjunta das emoções.

A realização de experimentos com esta abordagem visa demonstrar que a escolha da análise individual das emoções é mais vantajosa, seja pela diminuição do tempo computacional e da complexidade dos classificadores induzidos, por conferir 
uma melhor generalização para exemplos desconhecidos, ou pelo fato de efetivamente garantir que as emoções em análise são corretamente classificadas.

Como já apresentado, na análise conjunta das emoções, mesmo elevadas taxas de acerto não garantem que todas as emoções sejam satisfatoriamente aprendidas pelos classificadores de AM. Neste sentido, embora os resultados obtidos com esta abordagem tenham sido inferiores aos obtidos pela abordagem proposta, vale ressaltar que, ainda assim, as seis representações faciais permitiram o reconhecimento emocional, apresentando resultados satisfatórios.

Isto indica que a utilização de uma modelagem baseada em princípios psicológicos, que modela as características geométricas da face, é uma opção interessante para o reconhecimento das emoções humanas. Deste modo, estas representações estão aptas a serem utilizadas por algoritmos de seleção de características para obter as diferentes características faciais de diagnóstico relacionadas às emoções investigadas.

A seguir, são descritos os experimentos realizados para a validação do modelo de face neutra desenvolvido.

\section{Experimentos com o Modelo de Face Neutra}

O modelo de face neutra, apresentado no Capítulo 6, é proposto para que as representação faciais possam ser utilizadas em sistemas reais nos quais, diferentemente das bases de dados utilizadas, não se dispõe da expressão neutra dos usuários. Desta forma, esta subseção apresenta os experimentos em que o modelo de face neutra proposto é utilizado para obter uma aproximação da expressão neutra que possa ser utilizada na construção das representações faciais $F S_{3}, F S_{4}, F S_{1-3}$ e $F S_{2-4}$, em substituição às expressões neutras originais existentes nas bases de dados utilizadas.

Para todos os experimentos, a mesma metodologia empregada para a realização dos demais experimentos já apresentados é utilizada, e as emoções são individualmente analisadas. Vale enfatizar que apenas são realizados novos experimentos com as representações faciais $F S_{3}, F S_{4}, F S_{1-3}$ e $F S_{2-4}$, já que somente estas são afetadas pela utilização do modelo de face neutra.

A principal característica do modelo proposto é permitir a alteração das proporções de contribuição de cada raça, pela modificação dos pesos associados aos vetores de características correspondentes, assim como a adição de novas raças. Neste sentido, os pesos associados às três raças consideradas pelo modelo utilizado são $75 \%$ para caucasiana ou branca, 20\% para negra e 5\% para asiática. Estes pesos são definidos de modo empírico, ou seja, diversas tentativas foram realizadas e, com as proporções citadas, obtêm-se os melhores resultados para os experimentos.

As tabelas 7.37, 7.39 e 7.41 apresentam os melhores resultados obtidos com a base RaFD para as emoções positivas e expressão neutra, respectivamente para os 
classificadores SVMs, algoritmo C4.5 e redes MLP. Já as tabelas 7.38, 7.40 e 7.42 apresentam os melhores resultados obtidos para as emoções negativas. Para todas estas tabelas, o modelo de face neutra utilizado se baseia na distância euclidiana média. Do mesmo modo, mas utilizando o modelo de face neutra que considera a quantidade de pontos mais próximos, as tabelas 7.43, 7.45 e 7.47 apresentam os melhores resultados obtidos com a base RaFD para as emoções positivas e a expressão neutra, respectivamente para os classificadores SVMs, algoritmo C4.5 e redes MLP. E, nas tabelas 7.44, 7.46 e 7.48, podem ser vistos os melhores resultados obtidos para as emoções negativas.

Tabela 7.37: Taxas de acerto obtidas pelas SVMs para a base RaFD com as emoções positivas e a expressão neutra, utilizando o modelo de face neutra que tem a distância euclidiana média como métrica.

\begin{tabular}{|c|c|c|c|}
\hline $\begin{array}{c}\text { Representação } \\
\text { Facial }\end{array}$ & Neutra & Alegria & Surpresa \\
\cline { 2 - 4 } & Acerto (\%) & Acerto (\%) & Acerto (\%) \\
\hline$F S_{3}$ & $92,3_{-}^{+} 1,05$ & $96,1_{-}^{+} 1,06$ & $100,0_{-}^{+} 1,01$ \\
\hline$F S_{4}$ & $92,3_{-}^{+} 1,03$ & $96,1_{-}^{+1,05}$ & $92,3_{-}^{+} 1,09$ \\
\hline$F S_{1-3}$ & $96,1_{-}^{+} 1,07$ & $100,0_{-}^{+} 1,07$ & $96,1_{-}^{+} 1,11$ \\
\hline$F S_{2-4}$ & $96,1_{-}^{+} 1,10$ & $92,3_{-}^{+1,08}$ & $96,1_{-}^{ \pm} 1,08$ \\
\hline Média & $94,2_{-}^{+} 1,06$ & $96,1_{-}^{+} 1,06$ & $96,1_{-}^{+} 1,07$ \\
\hline
\end{tabular}

Tabela 7.38: Taxas de acerto obtidas pelas SVMs para a base RaFD com as emoções negativas, utilizando o modelo de face neutra que tem a distância euclidiana média como métrica.

\begin{tabular}{|c|c|c|c|c|}
\hline Representação & Tristeza & Medo & Raiva & Aversão \\
\cline { 2 - 5 } Facial & Acerto (\%) & Acerto (\%) & Acerto (\%) & Acerto (\%) \\
\hline$F S_{3}$ & $88,4_{-}^{+} 1,05$ & $92,3_{-}^{+} 1,04$ & $100,0_{-}^{+} 1,07$ & $100,0_{-}^{+} 1,04$ \\
\hline$F S_{4}$ & $88,4_{-}^{+} 1,06$ & $92,3_{-}^{+} 1,06$ & $92,3_{-}^{+1,10}$ & $100,0_{-}^{+} 1,02$ \\
\hline$F S_{1-3}$ & $88,4_{-}^{+} 1,04$ & $100,0_{-}^{+} 1,03$ & $100,0_{-}^{+} 1,05$ & $100,0_{-}^{+} 1,00$ \\
\hline$F S_{2-4}$ & $84,6_{-}^{+} 1,06$ & $92,3_{-}^{+} 1,05$ & $96,1_{-}^{+} 1,07$ & $100,0_{-}^{+} 1,01$ \\
\hline Média & $87,4_{-}^{+} 1,05$ & $94,2_{-}^{+} 1,04$ & $97,1_{-}^{+} 1,07$ & $100,0_{-}^{+} 1,02$ \\
\hline
\end{tabular}

Tabela 7.39: Taxas de acerto obtidas pelo algoritmo C4.5 para a base RaFD com as emoções positivas e a expressão neutra, utilizando o modelo de face neutra que tem a distância euclidiana média como métrica.

\begin{tabular}{|c|c|c|c|}
\hline $\begin{array}{c}\text { Representação } \\
\text { Facial }\end{array}$ & Neutra & Alegria & Surpresa \\
\cline { 2 - 4 } & Acerto (\%) & Acerto (\%) & Acerto (\%) \\
\hline$F S_{3}$ & $96,1_{-}^{+} 1,06$ & $96,1_{-}^{+} 1,07$ & $92,3_{-}^{+} 1,07$ \\
\hline$F S_{4}$ & $100,0_{-}^{+} 1,02$ & $100,0_{-}^{+} 1,04$ & $88,4_{-}^{+1,09}$ \\
\hline$F S_{1-3}$ & $96,1_{-}^{+} 1,05$ & $96,1_{-}^{+} 1,07$ & $96,1_{-}^{+} 1,02$ \\
\hline$F S_{2-4}$ & $96,1_{-}^{+} 1,08$ & $100,0_{-}^{+} 1,03$ & $92,3_{-}^{+} 1,05$ \\
\hline Média & $97,1_{-}^{+} 1,05$ & $98,1_{-}^{+} 1,05$ & $92,3_{-}^{+} 1,06$ \\
\hline
\end{tabular}


Tabela 7.40: Taxas de acerto obtidas pelo algoritmo C4.5 para a base RaFD com as emoções negativas, utilizando o modelo de face neutra que tem a distância euclidiana média como métrica.

\begin{tabular}{|c|c|c|c|c|}
\hline $\begin{array}{c}\text { Representação } \\
\text { Facial }\end{array}$ & Tristeza & Medo & Raiva & Aversão \\
\cline { 2 - 5 } & Acerto (\%) & Acerto (\%) & Acerto (\%) & Acerto (\%) \\
\hline$F S_{3}$ & $76,9_{-}^{+} 1,09$ & $80,8_{-}^{+} 1,07$ & $80,8_{-}^{+} 1,06$ & $84,6_{-}^{+} 1,04$ \\
\hline$F S_{4}$ & $88,4_{-}^{+} 1,04$ & $88,4_{-}^{+} 1,04$ & $76,9_{-}^{+} 1,08$ & $80,8_{-}^{+} 1,08$ \\
\hline$F S_{1-3}$ & $92,3_{-}^{+} 1,05$ & $96,1_{-}^{+} 1,04$ & $76,9_{-}^{+} 1,10$ & $92,3_{-}^{+} 1,05$ \\
\hline$F S_{2-4}$ & $88,4_{-}^{+} 1,06$ & $84,6_{-}^{+} 1,08$ & $76,9_{-}^{+} 1,09$ & $88,4_{-}^{+} 1,06$ \\
\hline Média & $86,5_{-}^{+1,06}$ & $87,5_{-}^{+} 1,06$ & $77,9_{-}^{+} 1,08$ & $86,5_{-}^{+} 1,06$ \\
\hline
\end{tabular}

Tabela 7.41: Taxas de acerto obtidas pelas MLPs para a base RaFD com as emoções positivas e a expressão neutra, utilizando o modelo de face neutra que tem a distância euclidiana média como métrica.

\begin{tabular}{|c|c|c|c|}
\hline $\begin{array}{c}\text { Representação } \\
\text { Facial }\end{array}$ & Neutra & Alegria & Surpresa \\
\cline { 2 - 4 } & Acerto (\%) & Acerto (\%) & Acerto (\%) \\
\hline$F S_{3}$ & $96,1_{-}^{+} 1,03$ & $100,0_{-}^{+} 1,05$ & $92,3_{-}^{+} 1,07$ \\
\hline$F S_{4}$ & $92,3_{-}^{+} 1,05$ & $96,1_{-}^{+} 1,03$ & $92,3_{-}^{+} 1,05$ \\
\hline$F S_{1-3}$ & $96,1_{-}^{+} 1,04$ & $96,1_{-}^{+} 1,07$ & $100,0_{-}^{+} 1,03$ \\
\hline$F S_{2-4}$ & $92,3_{-}^{+} 1,05$ & $96,1_{-}^{+} 1,09$ & $96,1_{-}^{+} 1,04$ \\
\hline Média & $94,2_{-}^{+} 1,04$ & $97,1_{-}^{+} 1,06$ & $95,2_{-}^{+} 1,05$ \\
\hline
\end{tabular}

Tabela 7.42: Taxas de acerto obtidas pelas MLPs para a base RaFD com as emoções negativas, utilizando o modelo de face neutra que tem a distância euclidiana média como métrica.

\begin{tabular}{|c|c|c|c|c|}
\hline $\begin{array}{c}\text { Representação } \\
\text { Facial }\end{array}$ & Tristeza & Medo & Raiva & Aversão \\
\cline { 2 - 5 } & Acerto (\%) & Acerto (\%) & Acerto (\%) & Acerto (\%) \\
\hline$F S_{3}$ & $80,8_{-}^{+} 1,08$ & $88,4_{-}^{+} 1,09$ & $84,6_{-}^{+} 1,05$ & $88,4_{-}^{+} 1,08$ \\
\hline$F S_{4}$ & $80,8_{-}^{+1,09}$ & $88,4_{-}^{+1,07}$ & $80,8_{-}^{+} 1,09$ & $92,3_{-}^{+1,08}$ \\
\hline$F S_{1-3}$ & $84,6_{-}^{+} 1,12$ & $92,3_{-}^{+} 1,05$ & $84,6_{-}^{+} 1,04$ & $96,1_{-}^{+} 1,05$ \\
\hline$F S_{2-4}$ & $80,8_{-}^{+} 1,10$ & $92,3_{-}^{+} 1,04$ & $84,6_{-}^{+} 1,02$ & $96,1_{-}^{+} 1,04$ \\
\hline Média & $81,8_{-}^{+} 1,10$ & $90,4_{-}^{+} 1,06$ & $83,7_{-}^{+} 1,05$ & $93,2_{-}^{+} 1,06$ \\
\hline
\end{tabular}

A observação das tabelas permite notar que o modelo de face neutra com a distância euclidiana média como métrica tem pouca influência nos resultados apresentados pelos classificadores, ou seja, os resultados obtidos, para todas as emoções, são semelhantes aos observados com a análise individual das emoções para a base RaFD.

Para facilitar o entendimento, considerando apenas as representações faciais $F S_{3}, F S_{4}, F S_{1-3}$ e $F S_{2-4}$, o desempenho obtido para a base de dados RaFD, independente do classificador e representação facial utilizada, e sem a utilização do modelo de face neutra proposto, é de 97,5\% para a expressão neutra, 99\% para a alegria, $96,8 \%$ para a surpresa, $85,9 \%$ para a tristeza, $92,3 \%$ para o medo, $87,5 \%$ para a 
raiva e $94,2 \%$ para a aversão.

Com a utilização do modelo da face neutra e a distância euclidiana média como métrica, o desempenho obtido é de 95,2\% para a expressão neutra, 97,1\% para a alegria, 94,5\% para a surpresa, $85,2 \%$ para a tristeza, 90,7\% para o medo, $86,2 \%$ para a raiva e $93,2 \%$ para a aversão. Muito embora diversos dos resultados sejam estatisticamente inferiores, a pequena diferença no desempenho não interfere significativamente no reconhecimento emocional.

Ainda, o modelo de face neutra que considera a quantidade de pontos mais próximos como métrica também pouco modifica o desempenho já apresentado com a distância euclidiana média. Neste sentido, o reconhecimento apresentado é de 95,2\% para a expressão neutra, 96,4\% para a alegria, 94,8\% para a surpresa, 84,6\% para a tristeza, 90,3\% para o medo, $86,2 \%$ para a raiva e $92,3 \%$ para a aversão. Estes resultados são, em geral, estatisticamente iguais ou levemente inferiores aos obtidos com a distância euclidiana média, porém ainda indicam boa capacidade de reconhecimento das emoções.

Tabela 7.43: Taxas de acerto obtidas pelas SVMs para a base RaFD com as emoções positivas e a expressão neutra, utilizando o modelo de face neutra que tem a quantidade de pontos próximos como métrica.

\begin{tabular}{|c|c|c|c|}
\hline $\begin{array}{c}\text { Representação } \\
\text { Facial }\end{array}$ & Neutra & Alegria & Surpresa \\
\cline { 2 - 4 } & Acerto (\%) & Acerto (\%) & Acerto (\%) \\
\hline$F S_{3}$ & $96,1_{-}^{+} 1,03$ & $96,1_{-}^{+} 1,05$ & $96,1_{-}^{+} 1,03$ \\
\hline$F S_{4}$ & $92,3_{-}^{+1,04}$ & $92,3_{-}^{+1,07}$ & $96,1_{-}^{ \pm} 1,07$ \\
\hline$F S_{1-3}$ & $96,1_{-}^{+} 1,08$ & $100,0_{-}^{+} 1,03$ & $96,1_{-}^{+} 1,08$ \\
\hline$F S_{2-4}$ & $96,1_{-}^{+} 1,09$ & $96,1_{-}^{+} 1,06$ & $96,1_{-}^{+} 1,05$ \\
\hline Média & $95,2_{-}^{+} 1,06$ & $96,1_{-}^{+1,05}$ & $96,1_{-}^{+} 1,06$ \\
\hline
\end{tabular}

Tabela 7.44: Taxas de acerto obtidas pelas SVMs para a base RaFD com as emoções negativas, utilizando o modelo de face neutra que tem a quantidade de pontos próximos como métrica.

\begin{tabular}{|c|c|c|c|c|}
\hline $\begin{array}{c}\text { Representação } \\
\text { Facial }\end{array}$ & Tristeza & Medo & Raiva & Aversão \\
\cline { 2 - 5 } & Acerto (\%) & Acerto (\%) & Acerto (\%) & Acerto (\%) \\
\hline$F S_{3}$ & $84,6_{-}^{+} 1,09$ & $92,3_{-}^{+} 1,03$ & $96,1_{-}^{+} 1,06$ & $100,0_{-}^{+} 1,02$ \\
\hline$F S_{4}$ & $88,4_{-}^{+} 1,04$ & $88,4_{-}^{+} 1,10$ & $96,1_{-}^{+} 1,04$ & $100,0_{-}^{+} 1,03$ \\
\hline$F S_{1-3}$ & $88,4_{-}^{+} 1,02$ & $96,1_{-}^{+} 1,05$ & $100,0_{-}^{+} 1,03$ & $100,0_{-}^{+} 1,01$ \\
\hline$F S_{2-4}$ & $84,6_{-}^{+} 1,08$ & $96,1_{-}^{+} 1,03$ & $96,1_{-}^{+} 1,05$ & $96,1_{-}^{+} 1,01$ \\
\hline Média & $86,5_{-}^{+} 1,06$ & $93,2_{-}^{+} 1,05$ & $97,1_{-}^{+} 1,04$ & $99,0_{-}^{+} 1,02$ \\
\hline
\end{tabular}

Assim como apresentado nas tabelas sobre a base de dados RaFD, as tabelas $7.49,7.50,7.51,7.52,7.53$ e 7.54 apresentam os melhores resultados obtidos pela base CK+ com o modelo de face neutra que se baseia na distância euclidiana média. Já as tabelas 7.55, 7.56, 7.57, 7.58, 7.59 e 7.60 apresentam os resultados obtidos pelo modelo de face neutra que utiliza como métrica a quantidade de pontos mais 
Tabela 7.45: Taxas de acerto obtidas pelo algoritmo C4.5 para a base RaFD com as emoções positivas e a expressão neutra, utilizando o modelo de face neutra que tem a quantidade de pontos próximos como métrica.

\begin{tabular}{|c|c|c|c|}
\hline $\begin{array}{c}\text { Representação } \\
\text { Facial }\end{array}$ & Neutra & Alegria & Surpresa \\
\cline { 2 - 4 } & Acerto (\%) & Acerto (\%) & Acerto (\%) \\
\hline$F S_{3}$ & $96,1_{-}^{+} 1,05$ & $96,1_{-}^{+} 1,07$ & $92,3_{-}^{+} 1,02$ \\
\hline$F S_{4}$ & $96,1_{-}^{+1,07}$ & $96,1_{-}^{ \pm} 1,06$ & $92,3_{-}^{+1,06}$ \\
\hline$F S_{1-3}$ & $96,1_{-}^{+} 1,04$ & $100,0_{-}^{+} 1,04$ & $96,1_{-}^{+} 1,01$ \\
\hline$F S_{2-4}$ & $100,0_{-}^{+} 1,03$ & $96,1_{-}^{+} 1,06$ & $92,3_{-}^{+} 1,08$ \\
\hline Média & $97,1_{-}^{+} 1,05$ & $97,1_{-}^{+} 1,06$ & $93,2_{-}^{+} 1,04$ \\
\hline
\end{tabular}

Tabela 7.46: Taxas de acerto obtidas pelo algoritmo C4.5 para a base RaFD com as emoções negativas, utilizando o modelo de face neutra que tem a quantidade de pontos próximos como métrica.

\begin{tabular}{|c|c|c|c|c|}
\hline \multirow{2}{*}{$\begin{array}{c}\text { Representação } \\
\text { Facial }\end{array}$} & Tristeza & Medo & Raiva & Aversão \\
\cline { 2 - 5 } & Acerto (\%) & Acerto (\%) & Acerto (\%) & Acerto (\%) \\
\hline$F S_{3}$ & $73,1_{-}^{+} 1,11$ & $80,8_{-}^{+} 1,09$ & $80,8_{-}^{+} 1,08$ & $84,6_{-}^{+} 1,03$ \\
\hline$F S_{4}$ & $92,3_{-}^{+1,04}$ & $84,6_{-}^{+} 1,05$ & $76,9_{-}^{+1,12}$ & $80,8_{-}^{+} 1,08$ \\
\hline$F S_{1-3}$ & $88,4_{-}^{+} 1,07$ & $96,1_{-}^{+} 1,02$ & $80,8_{-}^{+} 1,09$ & $92,3_{-}^{+} 1,04$ \\
\hline$F S_{2-4}$ & $84,6_{-}^{+1,07}$ & $88,4_{-}^{+1,07}$ & $76,9_{-}^{+1,11}$ & $84,6_{-}^{+} 1,05$ \\
\hline Média & $84,6_{-}^{+} 1,07$ & $87,5_{-}^{+} 1,06$ & $78,9_{-}^{+} 1,10$ & $85,6_{-}^{+} 1,05$ \\
\hline
\end{tabular}

Tabela 7.47: Taxas de acerto obtidas pelas MLPs para a base RaFD com as emoções positivas e a expressão neutra, utilizando o modelo de face neutra que tem a quantidade de pontos próximos como métrica.

\begin{tabular}{|c|c|c|c|}
\hline $\begin{array}{c}\text { Representação } \\
\text { Facial }\end{array}$ & Neutra & Alegria & Surpresa \\
\cline { 2 - 4 } & Acerto (\%) & Acerto (\%) & Acerto (\%) \\
\hline$F S_{3}$ & $96,1_{-}^{+} 1,03$ & $100,0_{-}^{+} 1,00$ & $92,3_{-}^{+} 1,06$ \\
\hline$F S_{4}$ & $88,4_{-}^{+} 1,07$ & $92,3_{-}^{+1,09}$ & $88,4_{-}^{+1,08}$ \\
\hline$F S_{1-3}$ & $96,1_{-}^{+} 1,02$ & $96,1_{-}^{+} 1,05$ & $100,0_{-}^{+} 1,02$ \\
\hline$F S_{2-4}$ & $92,3_{-}^{+} 1,05$ & $96,1_{-}^{+} 1,04$ & $100,0_{-}^{+} 1,02$ \\
\hline Média & $93,2_{-}^{+} 1,04$ & $96,1_{-}^{+1} 1,04$ & $95,2_{-}^{+} 1,04$ \\
\hline
\end{tabular}

Tabela 7.48: Taxas de acerto obtidas pelas MLPs para a base RaFD com as emoções negativas, utilizando o modelo de face neutra que tem a quantidade de pontos próximos como métrica.

\begin{tabular}{|c|c|c|c|c|}
\hline $\begin{array}{c}\text { Representação } \\
\text { Facial }\end{array}$ & Tristeza & Medo & Raiva & Aversão \\
\cline { 2 - 5 } & Acerto (\%) & Acerto (\%) & Acerto (\%) & Acerto (\%) \\
\hline$F S_{3}$ & $84,6_{-}^{+} 1,06$ & $88,4_{-}^{+} 1,07$ & $80,8_{-}^{+} 1,04$ & $88,4_{-}^{+} 1,09$ \\
\hline$F S_{4}$ & $80,8_{-}^{+1,09}$ & $88,4_{-}^{+} 1,06$ & $80,8_{-}^{+1} 1,08$ & $92,3_{-}^{+} 1,05$ \\
\hline$F S_{1-3}$ & $84,6_{-}^{+} 1,07$ & $88,4_{-}^{+} 1,04$ & $84,6_{-}^{+} 1,02$ & $92,3_{-}^{+} 1,07$ \\
\hline$F S_{2-4}$ & $80,8_{-}^{+1,07}$ & $96,1_{-}^{+} 1,07$ & $84,6_{-}^{+} 1,03$ & $96,1_{-}^{+} 1,03$ \\
\hline Média & $82,7_{-}^{+} 1,07$ & $90,3_{-}^{+} 1,06$ & $82,7_{-}^{+} 1,04$ & $92,3_{-}^{+} 1,06$ \\
\hline
\end{tabular}


próximos.

A comparação destas tabelas com os resultados da análise individual das emoções para a base de dados $\mathrm{CK}+$ apresenta o mesmo comportamento obtido para a base RaFD, ou seja, o desempenho observado é semelhante. Neste sentido, para a base de dados $\mathrm{CK}^{+}$, considerando apenas as representações faciais $F S_{3}, F S_{4}$, $F S_{1-3}$ e $F S_{2-4}$, o desempenho obtido sem a utilização do modelo de face neutra, e independente do classificador ou representação facial utilizada, é de 96,9\% para a expressão neutra, 98\% para a alegria, 97,2\% para a surpresa, 90,6\% para a tristeza, $87,9 \%$ para o medo, $90,0 \%$ para a raiva e $96,0 \%$ para a aversão. Com a utilização do modelo da face neutra e a distância euclidiana média como métrica, o desempenho obtido é de 96,1\% para a expressão neutra, 97,0\% para a alegria, 96,8\% para a surpresa, $89,8 \%$ para a tristeza, $85,4 \%$ para o medo, $88,9 \%$ para a raiva e $94,9 \%$ para a aversão.

Tabela 7.49: Taxas de acerto obtidas pelas SVMs para a base CK+ com as emoções positivas e a expressão neutra, utilizando o modelo de face neutra que tem a distância euclidiana média como métrica.

\begin{tabular}{|c|c|c|c|}
\hline $\begin{array}{c}\text { Representação } \\
\text { Facial }\end{array}$ & Neutra & Alegria & Surpresa \\
\cline { 2 - 4 } & Acerto (\%) & Acerto (\%) & Acerto (\%) \\
\hline$F S_{3}$ & $100,0_{-}^{+} 1,00$ & $100,0_{-}^{+} 1,05$ & $98,4_{-}^{+} 1,05$ \\
\hline$F S_{4}$ & $98,2_{-}^{+} 1,05$ & $98,2_{-}^{+} 1,04$ & $100,0_{-}^{+} 1,03$ \\
\hline$F S_{1-3}$ & $100,0_{-}^{+} 1,02$ & $100,0_{-}^{+} 1,02$ & $100,0_{-}^{+} 1,02$ \\
\hline$F S_{2-4}$ & $97,9_{-}^{+} 1,03$ & $100,0_{-}^{+} 1,04$ & $98,4_{-}^{+} 1,04$ \\
\hline Média & $99,0_{-}^{+} 1,02$ & $99,5_{-}^{+} 1,04$ & $99,2_{-}^{+} 1,03$ \\
\hline
\end{tabular}

Tabela 7.50: Taxas de acerto obtidas pelas SVMs para a base CK+ com as emoções negativas, utilizando o modelo de face neutra que tem a distância euclidiana média como métrica.

\begin{tabular}{|c|c|c|c|c|}
\hline $\begin{array}{c}\text { Representação } \\
\text { Facial }\end{array}$ & Tristeza & Medo & Raiva & Aversão \\
\cline { 2 - 5 } & Acerto (\%) & Acerto (\%) & Acerto (\%) & Acerto (\%) \\
\hline$F S_{3}$ & $100,0_{-}^{+} 1,03$ & $90,0_{-}^{+} 1,09$ & $94,3_{-}^{+} 1,13$ & $97,8_{-}^{+} 1,04$ \\
\hline$F S_{4}$ & $95,6_{-}^{+} 1,08$ & $95,0_{-}^{+} 1,05$ & $94,3_{-}^{+1,09}$ & $95,6_{-}^{+} 1,06$ \\
\hline$F S_{1-3}$ & $100,0_{-}^{+} 1,05$ & $95,0_{-}^{+} 1,04$ & $100,0_{-}^{+} 1,05$ & $100,0_{-}^{+} 1,03$ \\
\hline$F S_{2-4}$ & $100,0_{-}^{+} 1,02$ & $90,0_{-}^{+} 1,07$ & $97,1_{-}^{+} 1,05$ & $100,0_{-}^{+} 1,05$ \\
\hline Média & $98,9_{-}^{+} 1,04$ & $92,5_{-}^{+} 1,06$ & $96,4_{-}^{+} 1,08$ & $98,3_{-}^{+} 1,04$ \\
\hline
\end{tabular}

Já para o modelo de face neutra que utiliza a quantidade de pontos mais próximos, o reconhecimento apresentado é de 95,8\% para a expressão neutra, 97,3\% para a alegria, 96,9\% para a surpresa, 90,9\% para a tristeza, 85,0\% para o medo, $88,6 \%$ para a raiva e $94,9 \%$ para a aversão. Dentre estes resultados é possível observar que, de acordo com a emoção analisada, os desempenhos são estatisticamente iguais, levemente superiores ou levemente inferiores aos obtidos com a distância euclidiana média. Mesmo assim, o bom desempenho no reconhecimento emocional 
é mantido.

Tabela 7.51: Taxas de acerto obtidas pelo algoritmo $\mathrm{C} 4.5$ para a base $\mathrm{CK}+\mathrm{com}$ as emoções positivas e a expressão neutra, utilizando o modelo de face neutra que tem a distância euclidiana média como métrica.

\begin{tabular}{|c|c|c|c|}
\hline $\begin{array}{c}\text { Representação } \\
\text { Facial }\end{array}$ & Neutra & Alegria & Surpresa \\
\cline { 2 - 4 } & Acerto (\%) & Acerto (\%) & Acerto (\%) \\
\hline$F S_{3}$ & $93,9_{-}^{+} 1,09$ & $94,6_{-}^{+} 1,06$ & $95,4_{-}^{+} 1,05$ \\
\hline$F S_{4}$ & $97,9_{-}^{+} 1,05$ & $94,6_{-}^{+1,06}$ & $95,4_{-}^{+} 1,06$ \\
\hline$F S_{1-3}$ & $100,0_{-}^{+} 1,03$ & $98,2_{-}^{+} 1,02$ & $95,4_{-}^{+} 1,03$ \\
\hline$F S_{2-4}$ & $100,0_{-}^{+} 1,02$ & $92,8_{-}^{+} 1,07$ & $95,4_{-}^{+} 1,04$ \\
\hline Média & $97,9_{-}^{+} 1,05$ & $95,0_{-}^{+} 1,05$ & $95,4_{-}^{+} 1,04$ \\
\hline
\end{tabular}

Tabela 7.52: Taxas de acerto obtidas pelo algoritmo $\mathrm{C} 4.5$ para a base $\mathrm{CK}+\mathrm{com}$ as emoções negativas, utilizando o modelo de face neutra que tem a distância euclidiana média como métrica.

\begin{tabular}{|c|c|c|c|c|}
\hline \multirow{2}{*}{$\begin{array}{c}\text { Representação } \\
\text { Facial }\end{array}$} & Tristeza & Medo & Raiva & Aversão \\
\cline { 2 - 5 } & Acerto (\%) & Acerto (\%) & Acerto (\%) & Acerto (\%) \\
\hline$F S_{3}$ & $78,2_{-}^{+} 1,09$ & $80,0_{-}^{+} 1,06$ & $82,6_{-}^{+} 1,09$ & $91,3_{-}^{+} 1,03$ \\
\hline$F S_{4}$ & $73,9_{-}^{+} 1,10$ & $80,0_{-}^{+} 1,07$ & $82,6_{-}^{+} 1,08$ & $100,0_{-}^{+} 1,00$ \\
\hline$F S_{1-3}$ & $86,9_{-}^{+} 1,07$ & $75,0_{-}^{+} 1,09$ & $88,6_{-}^{+} 1,06$ & $91,3_{-}^{+} 1,05$ \\
\hline$F S_{2-4}$ & $86,9_{-}^{ \pm} 1,09$ & $85,0_{-}^{+} 1,07$ & $80,0_{-}^{+} 1,10$ & $91,3_{-}^{+} 1,07$ \\
\hline Média & $81,5_{-}^{+} 1,09$ & $80,0_{-}^{+} 1,07$ & $83,5_{-}^{+} 1,08$ & $93,5_{-}^{+} 1,04$ \\
\hline
\end{tabular}

Tabela 7.53: Taxas de acerto obtidas pelas MLPs para a base CK+ com as emoções positivas e a expressão neutra, utilizando o modelo de face neutra que tem a distância euclidiana média como métrica.

\begin{tabular}{|c|c|c|c|}
\hline $\begin{array}{c}\text { Representação } \\
\text { Facial }\end{array}$ & Neutra & Alegria & Surpresa \\
\cline { 2 - 4 } & Acerto (\%) & Acerto (\%) & Acerto (\%) \\
\hline$F S_{3}$ & $89,8_{-}^{+} 1,05$ & $96,4_{-}^{+} 1,09$ & $95,4_{-}^{+1,02}$ \\
\hline$F S_{4}$ & $85,7_{-}^{+} 1,08$ & $94,6_{-}^{+} 1,06$ & $95,4_{-}^{+} 1,05$ \\
\hline$F S_{1-3}$ & $97,9_{-}^{+} 1,03$ & $98,2_{-}^{+} 1,07$ & $96,9_{-}^{+} 1,03$ \\
\hline$F S_{2-4}$ & $91,8_{-}^{+} 1,05$ & $96,4_{-}^{+} 1,08$ & $95,4_{-}^{+} 1,02$ \\
\hline Média & $91,3_{-}^{+} 1,05$ & $96,4_{-}^{+} 1,07$ & $95,8_{-}^{+} 1,03$ \\
\hline
\end{tabular}

Embora muitos dos resultados obtidos com o modelo de face neutra sejam estatisticamente inferiores, independente da base de dados ou métrica avaliada, é importante notar que o reconhecimento emocional pouco é deteriorado, assim como a coerência dos resultados é mantida. Estas observações justificam a utilização do modelo em sistemas computacionais reais, em que não existem exemplos que permitam comparar a face em análise com um exemplar desta mesma face sem expressar qualquer emoção.

Como principal desvantagem do modelo proposto, tem-se a necessidade da existência de exemplos de expressões faciais emocionais de diferentes raças para 
Tabela 7.54: Taxas de acerto obtidas pelas MLPs para a base CK+ com as emoções negativas, utilizando o modelo de face neutra que tem a distância euclidiana média como métrica.

\begin{tabular}{|c|c|c|c|c|}
\hline $\begin{array}{c}\text { Representação } \\
\text { Facial }\end{array}$ & Tristeza & Medo & Raiva & Aversão \\
\cline { 2 - 5 } & Acerto (\%) & Acerto (\%) & Acerto (\%) & Acerto (\%) \\
\hline$F S_{3}$ & $95,6_{-}^{+} 1,04$ & $90,0_{-}^{+} 1,05$ & $88,5_{-}^{+} 1,02$ & $89,1_{-}^{+} 1,08$ \\
\hline$F S_{4}$ & $86,9_{-}^{+} 1,09$ & $75,0_{-}^{+1,04}$ & $85,7_{-}^{+1,05}$ & $93,5_{-}^{+} 1,06$ \\
\hline$F S_{1-3}$ & $95,6_{-}^{+} 1,03$ & $100,0_{-}^{+} 1,03$ & $85,7_{-}^{+} 1,06$ & $95,6_{-}^{+} 1,06$ \\
\hline$F S_{2-4}$ & $78,2_{-}^{+} 1,10$ & $70,0_{-}^{+1,09}$ & $85,7_{-}^{+} 1,05$ & $93,5_{-}^{+} 1,07$ \\
\hline Média & $89,1_{-}^{+} 1,06$ & $83,7_{-}^{+} 1,05$ & $86,4_{-}^{+} 1,04$ & $92,9_{-}^{+} 1,07$ \\
\hline
\end{tabular}

Tabela 7.55: Taxas de acerto obtidas pelas SVMs para a base CK+ com as emoções positivas e a expressão neutra, utilizando o modelo de face neutra que tem a quantidade de pontos próximos como métrica.

\begin{tabular}{|c|c|c|c|}
\hline \multirow{2}{*}{$\begin{array}{c}\text { Representação } \\
\text { Facial }\end{array}$} & Neutra & Alegria & Surpresa \\
\cline { 2 - 4 } & Acerto (\%) & Acerto (\%) & Acerto (\%) \\
\hline$F S_{3}$ & $100,0_{-}^{+} 1,01$ & $98,2_{-}^{+} 1,03$ & $98,4_{-}^{+} 1,07$ \\
\hline$F S_{4}$ & $97,9_{-}^{+} 1,06$ & $98,2_{-}^{+} 1,05$ & $98,4_{-}^{+1,04}$ \\
\hline$F S_{1-3}$ & $100,0_{-}^{+} 1,03$ & $100,0_{-}^{+} 1,03$ & $100,0_{-}^{+} 1,03$ \\
\hline$F S_{2-4}$ & $97,9_{-}^{+} 1,04$ & $100,0_{-}^{+} 1,01$ & $98,4_{-}^{+} 1,05$ \\
\hline Média & $98,9_{-}^{+} 1,03$ & $99,1_{-}^{+} 1,03$ & $98,8_{-}^{+} 1,05$ \\
\hline
\end{tabular}

Tabela 7.56: Taxas de acerto obtidas pelas SVMs para a base CK+ com as emoções negativas, utilizando o modelo de face neutra que tem a quantidade de pontos próximos como métrica.

\begin{tabular}{|c|c|c|c|c|}
\hline $\begin{array}{c}\text { Representação } \\
\text { Facial }\end{array}$ & Tristeza & Medo & Raiva & Aversão \\
\cline { 2 - 5 } & Acerto (\%) & Acerto (\%) & Acerto (\%) & Acerto (\%) \\
\hline$F S_{3}$ & $95,6_{-}^{+} 1,07$ & $95,0_{-}^{+} 1,06$ & $97,1_{-}^{+} 1,06$ & $97,8_{-}^{+} 1,02$ \\
\hline$F S_{4}$ & $95,6_{-}^{+} 1,04$ & $90,0_{-}^{+} 1,08$ & $94,3_{-}^{+} 1,09$ & $97,8_{-}^{+} 1,05$ \\
\hline$F S_{1-3}$ & $100,0_{-}^{+} 1,02$ & $95,0_{-}^{+} 1,09$ & $97,1_{-}^{+} 1,07$ & $100,0_{-}^{+} 1,03$ \\
\hline$F S_{2-4}$ & $100,0_{-}^{+1,01}$ & $90,0_{-}^{+} 1,08$ & $97,1_{-}^{+1,11}$ & $97,8_{-}^{+} 1,04$ \\
\hline Média & $97,8_{-}^{+} 1,03$ & $92,5_{-}^{+} 1,08$ & $96,4_{-}^{+} 1,08$ & $98,3_{-}^{+} 1,03$ \\
\hline
\end{tabular}

Tabela 7.57: Taxas de acerto obtidas pelo algoritmo C4.5 para a base CK+ com as emoções positivas e a expressão neutra, utilizando o modelo de face neutra que tem a quantidade de pontos próximos como métrica.

\begin{tabular}{|c|c|c|c|}
\hline $\begin{array}{c}\text { Representação } \\
\text { Facial }\end{array}$ & Neutra & Alegria & Surpresa \\
\cline { 2 - 4 } & Acerto (\%) & Acerto (\%) & Acerto (\%) \\
\hline$F S_{3}$ & $97,9_{-}^{+} 1,06$ & $98,2_{-}^{+} 1,03$ & $95,4_{-}^{+} 1,07$ \\
\hline$F S_{4}$ & $100,0_{-}^{+} 1,01$ & $94,6_{-}^{+} 1,05$ & $95,4_{-}^{+1,05}$ \\
\hline$F S_{1-3}$ & $100,0_{-}^{+} 1,05$ & $98,2_{-}^{+} 1,05$ & $96,9_{-}^{+} 1,05$ \\
\hline$F S_{2-4}$ & $97,9_{-}^{+} 1,04$ & $94,6_{-}^{+} 1,04$ & $95,4_{-}^{+} 1,06$ \\
\hline Média & $98,9_{-}^{+} 1,04$ & $96,4_{-}^{+} 1,04$ & $95,8_{-}^{+} 1,06$ \\
\hline
\end{tabular}


Tabela 7.58: Taxas de acerto obtidas pelo algoritmo $\mathrm{C} 4.5$ para a base $\mathrm{CK}+$ com as emoções negativas, utilizando o modelo de face neutra que tem a quantidade de pontos próximos como métrica.

\begin{tabular}{|c|c|c|c|c|}
\hline $\begin{array}{c}\text { Representação } \\
\text { Facial }\end{array}$ & Tristeza & Medo & Raiva & Aversão \\
\cline { 2 - 5 } & Acerto (\%) & Acerto (\%) & Acerto (\%) & Acerto (\%) \\
\hline$F S_{3}$ & $78,2_{-}^{+} 1,12$ & $80,0_{-}^{+} 1,06$ & $82,6_{-}^{+} 1,09$ & $91,3_{-}^{+} 1,07$ \\
\hline$F S_{4}$ & $78,2_{-}^{+1,10}$ & $75,0_{-}^{+} 1,07$ & $82,6_{-}^{+} 1,08$ & $93,5_{-}^{+} 1,04$ \\
\hline$F S_{1-3}$ & $91,3_{-}^{+} 1,05$ & $75,0_{-}^{+} 1,06$ & $88,6_{-}^{+} 1,07$ & $93,5_{-}^{+} 1,05$ \\
\hline$F S_{2-4}$ & $86,9_{-}^{+} 1,06$ & $90,0_{-}^{ \pm} 1,04$ & $80,0_{-}^{+} 1,10$ & $93,5_{-}^{+} 1,04$ \\
\hline Média & $83,7_{-}^{+} 1,08$ & $80,0_{-}^{+} 1,06$ & $83,5_{-}^{+} 1,08$ & $93,0_{-}^{+} 1,05$ \\
\hline
\end{tabular}

Tabela 7.59: Taxas de acerto obtidas pelas MLPs para a base CK+ com as emoções positivas e a expressão neutra, utilizando o modelo de face neutra que tem a quantidade de pontos próximos como métrica.

\begin{tabular}{|c|c|c|c|}
\hline $\begin{array}{c}\text { Representação } \\
\text { Facial }\end{array}$ & Neutra & Alegria & Surpresa \\
\cline { 2 - 4 } & Acerto (\%) & Acerto (\%) & Acerto (\%) \\
\hline$F S_{3}$ & $91,8_{-}^{+} 1,04$ & $96,4_{-}^{+} 1,08$ & $96,9_{-}^{+} 1,04$ \\
\hline$F S_{4}$ & $68,8_{-}^{+1,13}$ & $96,4_{-}^{+1,07}$ & $95,4_{-}^{+} 1,05$ \\
\hline$F S_{1-3}$ & $100,0_{-}^{+} 1,02$ & $96,4_{-}^{+} 1,05$ & $96,9_{-}^{+} 1,03$ \\
\hline$F S_{2-4}$ & $97,9_{-}^{+} 1,03$ & $96,4_{-}^{+} 1,06$ & $95,4_{-}^{+} 1,05$ \\
\hline Média & $89,6_{-}^{+} 1,05$ & $96,4_{-}^{+} 1,06$ & $96,1_{-}^{+} 1,04$ \\
\hline
\end{tabular}

Tabela 7.60: Taxas de acerto obtidas pelas MLPs para a base CK+ com as emoções negativas, utilizando o modelo de face neutra que tem a quantidade de pontos próximos como métrica.

\begin{tabular}{|c|c|c|c|c|}
\hline $\begin{array}{c}\text { Representação } \\
\text { Facial }\end{array}$ & Tristeza & Medo & Raiva & Aversão \\
\cline { 2 - 5 } & Acerto (\%) & Acerto (\%) & Acerto (\%) & Acerto (\%) \\
\hline$F S_{3}$ & $95,6_{-}^{+} 1,04$ & $90,0_{-}^{+} 1,02$ & $85,7_{-}^{+} 1,05$ & $89,1_{-}^{+} 1,08$ \\
\hline$F S_{4}$ & $86,9_{-}^{+1,09}$ & $80,0_{-}^{+1} 1,05$ & $85,7_{-}^{+} 1,07$ & $95,6_{-}^{+1,03}$ \\
\hline$F S_{1-3}$ & $95,6_{-}^{+} 1,02$ & $95,0_{-}^{+} 1,03$ & $85,7_{-}^{+} 1,05$ & $95,6_{-}^{+} 1,03$ \\
\hline$F S_{2-4}$ & $86,9_{-}^{+1,06}$ & $65,0_{-}^{ \pm} 1,13$ & $85,7_{-}^{ \pm 1,06}$ & $93,5_{-}^{+} 1,05$ \\
\hline Média & $91,2_{-}^{+} 1,05$ & $82,5_{-}^{+} 1,06$ & $85,7_{-}^{+} 1,06$ & $93,4_{-}^{+} 1,05$ \\
\hline
\end{tabular}

poder utilizá-lo em sistemas reais, de modo que estes possam adequadamente reconhecer as expressões emocionais das diversas culturas existentes. Como principal vantagem, pode-se citar a possibilidade de escolher quais raças farão parte do modelo, assim como a contribuição de cada uma delas ao mesmo, por meio do ajuste dos pesos correspondentes. Vale observar que, com o aumento da quantidade raças do modelo, o ajuste dos pesos pode se tornar uma tarefa exaustiva até a obtenção de valores que confiram desempenho adequado ao sistema.

A semelhança dos resultados obtidos pelas duas métricas utilizadas pode ser explicada pelo fato de ocorrer divergência na escolha do modelo a ser utilizado em menos de $5 \%$ dos experimentos. Ou seja, são poucas as situações em que uma das 
métricas opta pelo modelo masculino ao passo que a outra escolhe, para os mesmos dados, o modelo feminino. Deste modo, para as duas bases de dados investigadas, a escolha de uma ou outra métrica tem pouca influência no desempenho final dos classificadores utilizados.

Vale destacar que, embora sem significância estatística, os resultados observados para a distância euclidiana média são, em sua maioria, superiores, o que pode ser mais facilmente percebido pelas tabelas de resultados da base de dados RaFD. Ainda, em aproximadamente 1\% dos experimentos realizados com a métrica que se baseia na quantidade de pontos mais próximos, é obtido empate na seleção do modelo. Quando isto ocorre, a métrica da distância euclidiana média é adotada para escolha do modelo final a ser utilizado para a expressão neutra.

Um gráfico comparando o reconhecimento emocional obtido com e sem a utilização do modelo de face neutra é exposto na Figura 7.3. O desempenho apresentado é independente do algoritmo de AM, representação facial e bases de dados investigados. A observação deste gráfico evidencia que o desempenho obtido pelo modelo de face neutra é equivalente para as duas métricas utilizadas. Adicionalmente, como pode ser notado, as taxas de acerto são elevadas, mesmo que inferiores ao desempenho apresentado pela abordagem proposta, de análise individual das emoções.

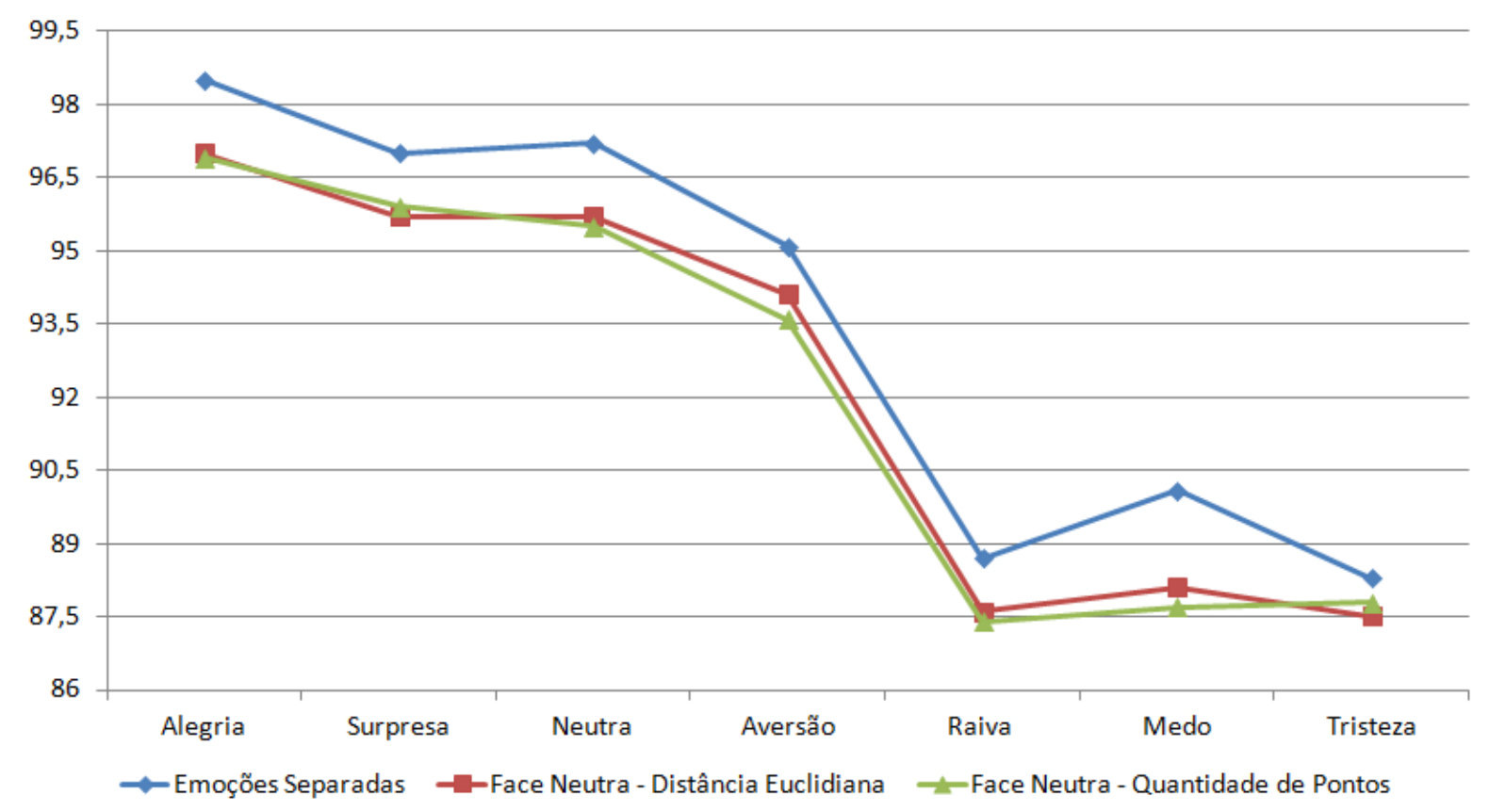

Figura 7.3: Gráfico comparativo entre os desempenhos apresentados pela abordagem proposta com e sem a utilização do modelo de face neutra.

Isto posto, a observação do desempenho encontrado para os experimentos realizados permite concluir que o modelo de face neutra se mostra robusto e adequado para utilização em sistemas reais, em substituição às imagens da expressão neutra dos usuários que, na grande maioria das vezes, não estarão disponíveis. 


\subsubsection{Resultados da Identificação de Características Faciais}

A identificação de características faciais utiliza nove diferentes algoritmos de seleção, que são aplicados às seis representações faciais, para obter as características de diagnóstico de cada uma das emoções investigadas, além da expressão neutra. Esta abordagem busca validar os estudos psicológicos que demonstram que os seres humanos direcionam o olhar para regiões específicas da face durante o processo de reconhecimento emocional, identificando possíveis características faciais de diagnóstico envolvidas neste processo.

Os algoritmos utilizados para avaliar as características selecionadas são as redes MLP, as SVMs e o algoritmo C4.5. A média do resultado obtido por estes três algoritmos é considerada para determinar o desempenho obtido pelo processo de seleção. Para estes experimentos, os classificadores são treinados com os valores-padrão do simulador Weka, sem a etapa de otimização de parâmetros, com o objetivo de obter resultados menos ajustados às especificidades de cada classificador. Adicionalmente, as emoções são individualmente analisadas.

Os algoritmos de seleção investigados são forward selection, backward elimination, linear forward selection, algoritmo por enxame de partículas (PSO), algoritmo genético (AG), busca scatter search, e ranqueamento de atributos utilizando os algoritmos reliefF, chi-squared e SVM, que podem ser encontrados no simulador Weka. É importante observar que a seleção realizada pode produzir subconjuntos de características diferentes que apresentam o mesmo desempenho final e, portanto, igual importância computacional para a identificação de uma emoção específica. Ainda, como todos os melhores subconjuntos obtidos no decorrer do processo de seleção são considerados, as melhores taxas de acerto, que indicam as características faciais mais relevantes para representar uma emoção, podem ser obtidas com subconjuntos de quaisquer da etapas da seleção.

Como resultado da seleção de características, não apenas os dados de entrada são simplificados, apresentando as possíveis características de diagnóstico para cada expressão facial emocional, mas também o tempo computacional e a complexidade final dos classificadores induzidos são diminuídos. O desempenho final obtido pelos classificadores também é superior. Ainda, a grande maioria dos subconjuntos produzidos pelas combinações realizadas durante o processo de seleção apresentam, em geral, desempenho igual ou superior aos subconjuntos encontrados nas etapas iniciais da seleção.

A Tabela 7.61 apresenta, para as emoções positivas e a expressão neutra, as melhores taxas de acerto obtidas com a base RaFD, a quantidade de melhores subconjuntos encontrada, assim como as quantidades mínima e máxima de atributos selecionados. Estas mesmas informações são apresentadas na Tabela 7.63, mas agora para a base de dados $\mathrm{CK}+$.

Ainda, na Tabela 7.62 podem ser encontradas as melhores taxas de acerto, 
quantidade de melhores subconjuntos obtidos e quantidades mínima e máxima de atributos selecionados, para as emoções negativas e a base RaFD. Já a Tabela 7.64 apresenta as mesmas informações para a base $\mathrm{CK}^{+}$. Vale destacar que os melhores desempenhos são obtidos com subconjuntos que apresentam independência do algoritmo de seleção investigado, ou independência da representação facial e do algoritmo de seleção, ou seja, com subconjuntos provenientes da terceira ou quarta etapas do processo de seleção.

Tabela 7.61: Melhores resultados obtidos pela seleção de características para as emoções positivas e a expressão neutra, com a base de dados RaFD.

\begin{tabular}{|c|c|c|c|c|}
\hline Emoções & $\begin{array}{c}\text { Melhor } \\
\text { Desempenho (\%) }\end{array}$ & $\begin{array}{c}\text { Quantidade } \\
\text { de Subconjuntos }\end{array}$ & $\begin{array}{c}\text { Máximo de } \\
\text { Atributos }\end{array}$ & $\begin{array}{c}\text { Mínimo de } \\
\text { Atributos }\end{array}$ \\
\hline Alegria & $100,0_{-}^{+1,03}$ & 3 & 136 & 1 \\
\hline Surpresa & $100,0_{-}^{+} 1,02$ & 4 & 44 & 2 \\
\hline Expressão Neutra & $98,7_{-}^{+} 1,04$ & 9 & 654 & 98 \\
\hline
\end{tabular}

Tabela 7.62: Melhores resultados obtidos pela seleção de características para as emoções negativas e a base de dados RaFD.

\begin{tabular}{|c|c|c|c|c|}
\hline $\begin{array}{c}\text { Melhor } \\
\text { Emoções }\end{array}$ & $\begin{array}{c}\text { Quantidade } \\
\text { Desempenho (\%) }\end{array}$ & $\begin{array}{c}\text { Máximo de } \\
\text { de Subconjuntos }\end{array}$ & $\begin{array}{c}\text { Mínimo de } \\
\text { Atributos }\end{array}$ \\
\hline Tristeza & $92,3_{-}^{+} 1,06$ & 1 & 5 & 5 \\
\hline Raiva & $96,1_{-}^{+} 1,04$ & 1 & 4 & 4 \\
\hline Medo & $97,4_{-}^{+} 1,05$ & 4 & 1823 & 62 \\
\hline Aversão & $100,0_{-}^{+} 1,03$ & 1 & 615 & 615 \\
\hline
\end{tabular}

Tabela 7.63: Melhores resultados obtidos pela seleção de características para as emoções positivas e a expressão neutra, com a base de dados $\mathrm{CK}^{+}$.

\begin{tabular}{|c|c|c|c|c|}
\hline Emoções & $\begin{array}{c}\text { Melhor } \\
\text { Desempenho (\%) }\end{array}$ & $\begin{array}{c}\text { Quantidade } \\
\text { de Subconjuntos }\end{array}$ & $\begin{array}{c}\text { Máximo de } \\
\text { Atributos }\end{array}$ & $\begin{array}{c}\text { Mínimo de } \\
\text { Atributos }\end{array}$ \\
\hline Alegria & $100,0_{-}^{+} 1,02$ & 3 & 112 & 2 \\
\hline Surpresa & $99,4_{-}^{+} 1,04$ & 3 & 50 & 2 \\
\hline Expressão Neutra & $99,4_{-}^{+1,03}$ & 8 & 573 & 85 \\
\hline
\end{tabular}

A comparação dos resultados apresentados, obtidos pela seleção de características para as duas bases de dados avaliadas, com os resultados destas mesmas bases na análise individual das emoções, permite afirmar, com grau de confiança de 95\%, que o desempenho encontrado para todas as emoções é estatisticamente superior.

Para a análise da alegria, as taxas de acerto obtidas por todos os subconjuntos produzidos pela seleção de características é de 100\%, independente da base de dados utilizada. Por este motivo, nas tabelas 7.61 e 7.63, são apresentados como melhores 
Tabela 7.64: Melhores resultados obtidos pela seleção de características para as emoções negativas e a base de dados CK+.

\begin{tabular}{|c|c|c|c|c|}
\hline Emoções & $\begin{array}{c}\text { Melhor } \\
\text { Desempenho (\%) }\end{array}$ & $\begin{array}{c}\text { Quantidade } \\
\text { de Subconjuntos }\end{array}$ & $\begin{array}{c}\text { Máximo de } \\
\text { Atributos }\end{array}$ & $\begin{array}{c}\text { Mínimo de } \\
\text { Atributos }\end{array}$ \\
\hline Tristeza & $93,8_{-}^{+1,05}$ & 3 & 9 & 5 \\
\hline Raiva & $98,2_{-}^{+1,03}$ & 3 & 11 & 3 \\
\hline Medo & $92,4_{-}^{+1,07}$ & 3 & 133 & 58 \\
\hline Aversão & $97,9_{-}^{+1,01}$ & 1 & 567 & 567 \\
\hline
\end{tabular}

apenas os três subconjuntos obtidos na etapa final da seleção, já que estes possuem independência do algoritmo de seleção ou representação facial utilizada, além de apresentarem maior simplificação, isto é, menor quantidade de atributos. Como todos os subconjuntos obtêm o mesmo desempenho, a quantidade de atributos dos demais subconjuntos varia entre 143 e 509 para a base RaFD e entre 119 e 507 para a base $\mathrm{CK}+$.

Para a aversão, um único subconjunto, independente da base de dados investigada, obtém o melhor desempenho. Estes subconjuntos são independentes do algoritmo de seleção e, para as duas bases, são baseados na representação facial $F S_{1-3}$. Para a base RaFD, o segundo melhor desempenho é de $98,7 \%$, obtido por seis distintos subconjuntos, que possuem entre 90 e 456 atributos. Para a base $\mathrm{CK}+$, o segundo melhor desempenho é obtido por três subconjuntos, com quantidade de atributos variável entre 87 e 405, e desempenho de 96,1\%.

A análise da emoção de tristeza também apresenta, para a base de dados RaFD, apenas um único melhor subconjunto, resultante da etapa final da seleção de atributos. O segundo melhor desempenho é de $89,7 \%$, obtido por cinco subconjuntos, que possuem entre 225 e 321 atributos. Para a base $\mathrm{CK}+$, os três subconjuntos que apresentam o melhor desempenho são também obtidos na etapa final da seleção e, portanto, independentes dos algoritmos de seleção e das representações faciais.

Para a emoção de medo, dentre os quatro melhores subconjuntos encontrados para a base RaFD, apenas um deles, com 62 atributos, é resultante da etapa final de seleção. Os demais são baseados na representação facial $F S_{1-3}$. Diferentemente, os três melhores subconjuntos obtidos para a base CK+ são resultado da última etapa da seleção de atributos realizada.

A surpresa obtém, para a base $\mathrm{CK}^{+}$, o melhor desempenho com três subconjuntos, produzidos na etapa final da seleção. Já para a base RaFD, dos quatro subconjuntos que apresentam o melhor desempenho, apenas um deles, com três atributos, é obtido na etapa final da seleção, os demais são baseados na representação facial $F S_{2}$.

A raiva, considerando a base $\mathrm{CK}^{+}$, apresenta três melhores subconjuntos, dois deles, com três e sete atributos, são obtidos na etapa final da seleção, já o terceiro é baseado na representação facial $F S_{3}$. Para a base RaFD, apenas um 
subconjunto, também baseado na representação $F S_{3}$, apresenta o melhor desempenho. O segundo melhor desempenho, de $94,9 \%$, é obtido por oito subconjuntos, que possuem entre 2 e 73 atributos, sendo que apenas um deles, com 2 atributos, é obtido na etapa final da seleção de características.

Por fim, a expressão neutra obtém o melhor desempenho com nove subconjuntos distintos para a base RaFD, sendo todos independentes dos algoritmos de seleção, porém baseados nas representações faciais $F S_{3}$ ou $F S_{1-3}$. Na análise da base de dados $\mathrm{CK}+$, oito subconjuntos apresentam os melhores desempenhos, sendo estes também independentes dos algoritmos de seleção, e baseados nas representações $F S_{3}, F S_{1-3}$ ou $F S_{4}$.

A melhoria no reconhecimento emocional, assim como a simplificação dos vetores de características utilizados pelos algoritmos de AM, são vantagens que podem ser destacadas com a utilização da seleção de características. No entanto, o principal objetivo é a identificação das possíveis características de diagnóstico que auxiliem um sistema computacional a mais facilmente reconhecer, pela análise da face, as emoções humanas.

Antes de apresentar as diferentes características de diagnóstico identificadas pelo processo de seleção, faz-se necessário definir os termos "diferença entre as distâncias" e "diferença entre os ângulos", que são utilizados para explicar algumas das características faciais selecionadas.

O termo "diferença entre as distâncias" indica que o atributo, ou característica, representa a diferença encontrada entre duas distâncias $x$ e $y$ calculadas para dois pontos $a$ e $b$, respectivamente, no momento do ápice de uma emoção, e a partir da expressão neutra da mesma face. Sendo assim, seja uma face $H$ e duas distâncias $x$ e $y$, a distância $x$ é obtida no ápice de uma emoção, por exemplo, raiva, e a distância $y$ é calculada a partir da expressão neutra. A "diferença entre as distâncias" consiste no cálculo do módulo de $|x-y|$. Do mesmo modo, considerando agora a mesma face $H$ e dois ângulos $k$ e $l$, obtidos da mesma maneira que as distâncias $x$ e $y$, a "diferença entre os ângulos" indica o cálculo do módulo de $|k-l|$.

A análise da base de dados RaFD identifica apenas distâncias como características de diagnóstico relacionadas à tristeza. Estas distâncias estão localizadas entre o queixo e a pálpebra inferior do olho esquerdo, o queixo e a extremidade direita da face, extremidade direita da face à sobrancelha esquerda, entre as duas extremidades da sobrancelha esquerda e entre sobrancelha esquerda e o canto esquerdo da boca.

Para a base de dados $\mathrm{CK}+$, a análise dos três subconjuntos permite encontrar, para a tristeza, algumas características diferentes das obtidas com a base RaFD. As cinco distâncias já destacadas são também observadas, além das distâncias entre a narina esquerda com o canto esquerdo da boca e com a pálpebra superior do olho esquerdo. Ademais, dois ângulos também são destacados, sendo eles entre os 
cantos direito e esquerdo da boca e entre o canto esquerdo do olho esquerdo e a sobrancelha esquerda. Desta forma, é possível notar que apenas as características da emoção em seu ápice recebem o foco de atenção da seleção de características, com maior preferência pelas distâncias.

Mesmo com novas características reveladas, as regiões e elementos faciais obtidos pela análise com a base RaFD são também observados pela análise com a base $\mathrm{CK}^{+}$, ou seja, a lateral esquerda da face se mostra mais importante no reconhecimento desta emoção, destacando o queixo, sobrancelha e olho esquerdos, além do canto esquerdo da boca. Porém, alguma relação entre o queixo e a sobrancelha esquerda com a extremidade direita da face também pode ser observada. Adicionalmente, por meio da análise das características faciais de diagnóstico identificadas, e utilizando os conceitos do sistema FACS (Ekman et al., 2002), é possível obter as prováveis UAs ativadas. Desta forma, são identificadas as UAs 1, 4, 15 e 17. As UAs 6 e 11, representativas desta emoção, não são claramente encontradas.

As principais regiões faciais identificadas pela seleção de características para o reconhecimento da emoção de tristeza podem ser vistas na Figura 7.4. Para esta emoção, assim como para as demais expressões emocionais apresentadas, a imagem da face utilizada é uma adaptação da original encontrada em Flores (2014).

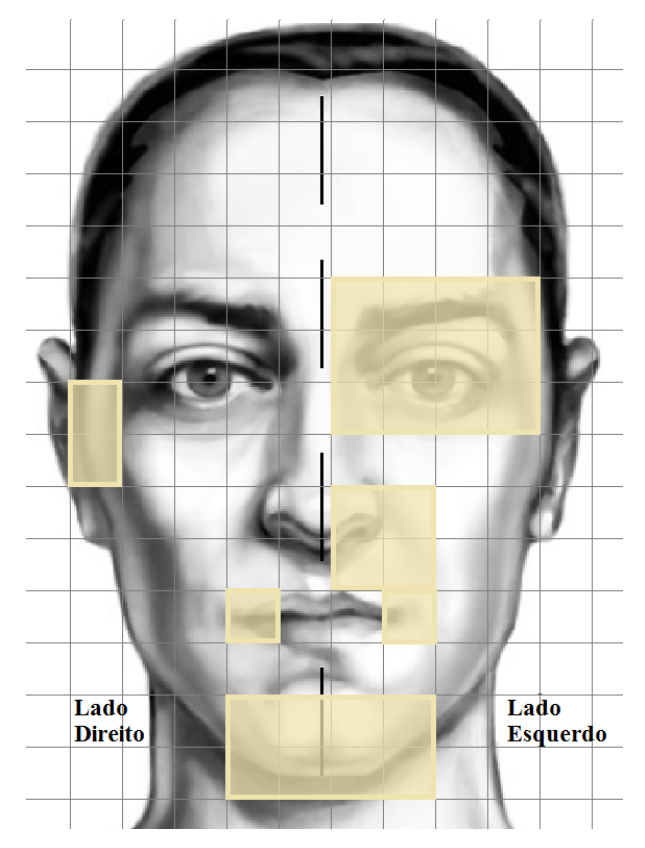

Figura 7.4: As regiões em destaque apresentam as características de diagnóstico identificadas para classificar a tristeza. Nota-se maior utilização do lado esquerdo da face.

As características faciais selecionadas para exemplificar a raiva, de acordo com a seleção obtida para a base RaFD, são apenas quatro: a diferença entre as distâncias da sobrancelha esquerda com a narina esquerda, a distância entre os lábios superior e inferior, a diferença entre os ângulos das extremidades internas das duas sobrancelhas e a diferença entre os ângulos da pálpebra superior do olho 
direito com a sobrancelha direita.

Para a base de dados $\mathrm{CK}^{+}$, a análise das características faciais dos três melhores subconjuntos mostra que o subconjunto com apenas três atributos possui, com exceção da distância acima descrita, os mesmos atributos selecionados para a base RaFD. Já o subconjunto com sete características apresenta a distância entre as extremidades internas das duas sobrancelhas, a diferença entre os ângulos do canto esquerdo do olho esquerdo com a extremidade esquerda da face, a diferença entre os ângulos da narina direita com a sobrancelha direita e a diferença entre as distâncias da pálpebra superior do olho esquerdo com a pálpebra inferior do olho direito, além das características também encontradas no subconjunto com três atributos.

O terceiro subconjunto, com 11 características selecionadas, possui a união das quatro características citadas acima, pertencentes ao subconjunto que possui sete atributos, com as quatro existentes no subconjunto obtido para a base RaFD. Ainda, são também encontrados a distância entre a pálpebra superior do olho direito com a sobrancelha esquerda, o ângulo entre a pálpebra superior do olho esquerdo e a narina direita e a diferença entre os ângulos das extremidades interna e externa da sobrancelha esquerda.

As características de diagnóstico obtidas indicam que a região de olhos e sobrancelhas é a mais relevante para identificar a raiva. Existem também relações entre estas regiões com as narinas além de que, em menor grau, a boca é considerada, pois apenas uma característica dos lábios é encontrada. Ainda, não é possível identificar clara preferência entre um ou outro lado da face, mas fica evidenciado que as características que comparam a expressão neutra com a emoção em seu ápice são as mais frequentemente selecionadas para representar a raiva, existindo um certo equilíbrio entre distâncias e ângulos.

A utilização das características de diagnóstico para encontrar as possíveis UAs ativadas indica que as UAs 4, 5, 7 e 10 são facilmente encontradas, já as UAs 23 ou 24, relacionadas a movimentos da boca, são observadas em alguns dos subconjuntos. As UAs 17, 22, 25 e 26, que também podem ser associadas a esta emoção, não são vistas nos subconjuntos de melhor desempenho. As principais regiões faciais selecionadas para o reconhecimento da emoção de raiva são apresentadas na Figura 7.5.

Para a emoção de aversão, apenas um único subconjunto apresenta o melhor desempenho, seja para a base RaFD ou CK+. Estes subconjuntos apresentam elevada quantidade de atributos, ou seja, muitas características faciais são consideradas para representar corretamente esta emoção. As características selecionadas para estes dois subconjuntos, independente da base de dados, não permitem determinar regiões faciais mais relevantes, uma vez que são encontradas relações entre todos os elementos faciais (boca, olhos, narinas e sobrancelhas), assim como relações destes com as extremidades direita e esquerda da face. Desta forma, a face 


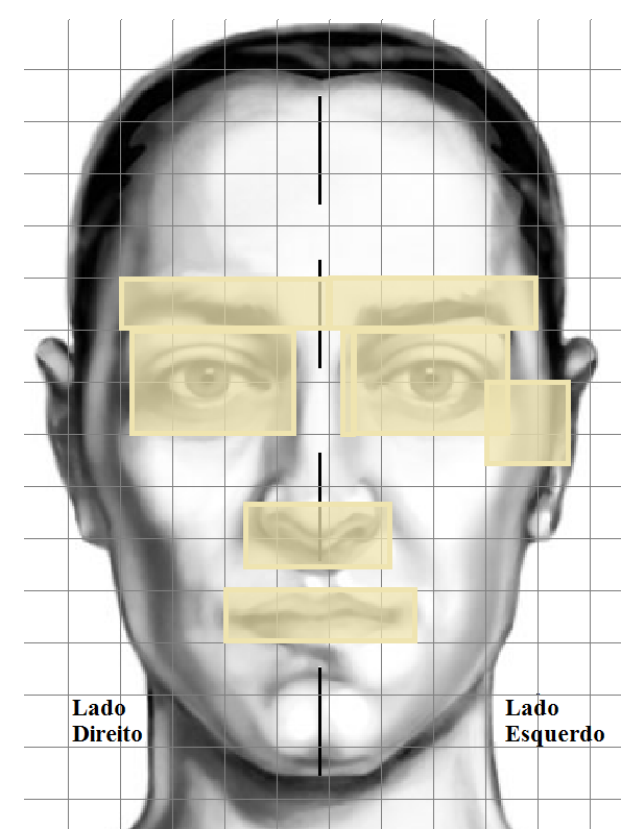

Figura 7.5: As regiões em destaque apresentam as características de diagnóstico identificadas para classificar a raiva.

como um todo se mostra importante para identificar a aversão, e não é possível dizer exatamente quais UAs são ativadas, pois tanto as UAs relacionadas a esta emoção quanto as demais UAs podem ser observadas com a análise das características de diagnóstico selecionadas.

Já que, para as duas bases de dados investigadas, existe pouca diferença entre o melhor subconjunto e os subconjuntos que apresentam o segundo melhor desempenho, e considerando o fato destes subconjuntos apresentarem menor quantidade de características, o resultado obtido por eles é analisado. Desta forma, é possivel observar que, embora os dois lados da face sejam importantes para o reconhecimento desta emoção, as extremidades não são utilizadas neste processo, as sobrancelhas são pouco utilizadas, e as características do lado direito são mais predominantes. Ademais, as regiões da boca e narinas são as com maior quantidade de características selecionadas, que se relacionam essencialmente entre si, mas também com os olhos, principalmente o direito e, em menor frequência, com o queixo. Avaliando as UAs ativadas, é possível encontrar as UAs 9, 10 e 16, assim como as UAs 25 e 26. A UA17, presente em algumas variações da aversão, não é identificada.

Vale destacar que, seja para os subconjuntos que apresentam o melhor desempenho, ou para os subconjuntos com menos atributos, que também apresentam desempenhos próximos aos melhores obtidos, dentre as características selecionadas, aquelas que mapeiam as diferenças entre o ápice da emoção e a expressão neutra estão mais presentes que as responsáveis por apenas mapear as características da emoção em seu ápice. Ainda, os ângulos, sejam propriamente ditos ou a diferença entre eles, são mais predominantes. 
Já que a face como um todo é considerada pelos melhores subconjuntos, as principais regiões faciais selecionadas para o reconhecimento da aversão, considerando os subconjuntos próximos dos ótimos, que também obtém bom desempenho, são apresentadas na Figura 7.6.

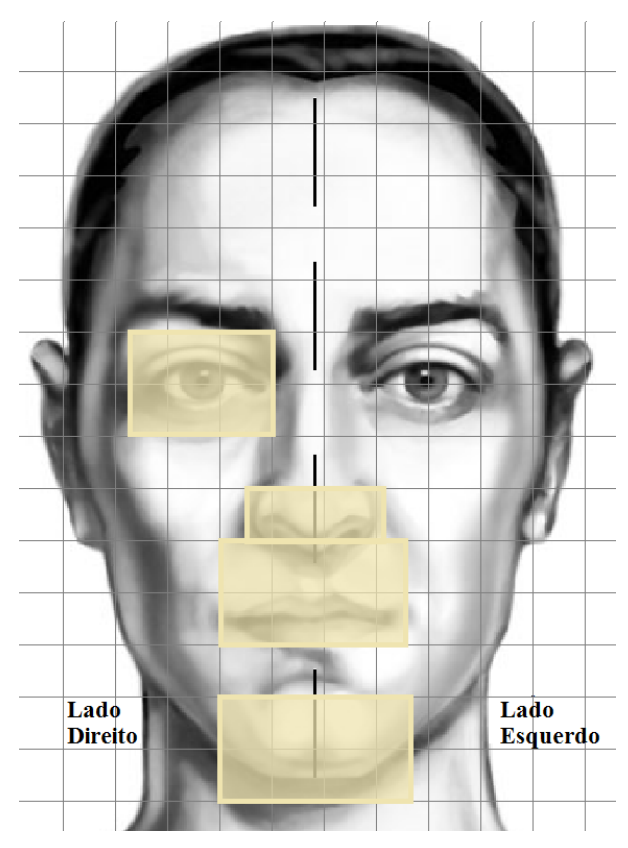

Figura 7.6: As regiões em destaque apresentam as características de diagnóstico identificadas para classificar a aversão. Maior predominância do lado direito da face.

Para a surpresa, e considerando a base de dados RaFD, dois dos quatro melhores subconjuntos apresentam, respectivamente, apenas duas e três características de diagnóstico. Elas são, para o subconjunto com dois atributos, o ângulo formado entre a pálpebra superior direita com a pálpebra inferior esquerda do olho direito, e o ângulo formado entre o lábio superior esquerdo e o lábio inferior direito. Para o subconjunto com três características, apenas o ângulo encontrado entre o canto esquerdo e a pálpebra inferior do olho esquerdo é adicionado. As características adicionais existentes nos outros dois subconjuntos estão relacionadas a diferentes ângulos e distâncias mapeados entre os lábios, além de distâncias entre as narinas esquerda e direita com os lábios.

Para a base $\mathrm{CK}^{+}$, o subconjunto com duas características apresenta o ângulo formado entre a pálpebra superior direita com a pálpebra inferior esquerda do olho direito, e a distância entre o canto esquerdo da boca com o lábio inferior. Os demais subconjuntos, que apresentam maior quantidade de atributos, destacam características semelhantes às obtidas para a base de dados RaFD, ou seja, distâncias e ângulos internos aos olhos e à boca, assim como distâncias entre as narinas e os lábios, são identificados.

Como observado, para identificar a surpresa, os olhos e a boca, assim como a região da face que engloba as narinas e a boca, possuem as características mais 
importantes. Na análise das UAs envolvidas, podem ser claramente identificadas as UAs 5, 26 ou 27. No entanto, as UAs 1 e 2, relacionadas ao movimento das sobrancelhas, não são encontradas entre os melhores subconjuntos. Adicionalmente, apenas as características faciais observadas no ápice da emoção se mostram mais relevantes para o reconhecimento, e não é possível observar preferência por ângulos ou distâncias. As principais regiões faciais selecionadas para o reconhecimento da emoção de surpresa são apresentadas na Figura 7.7.

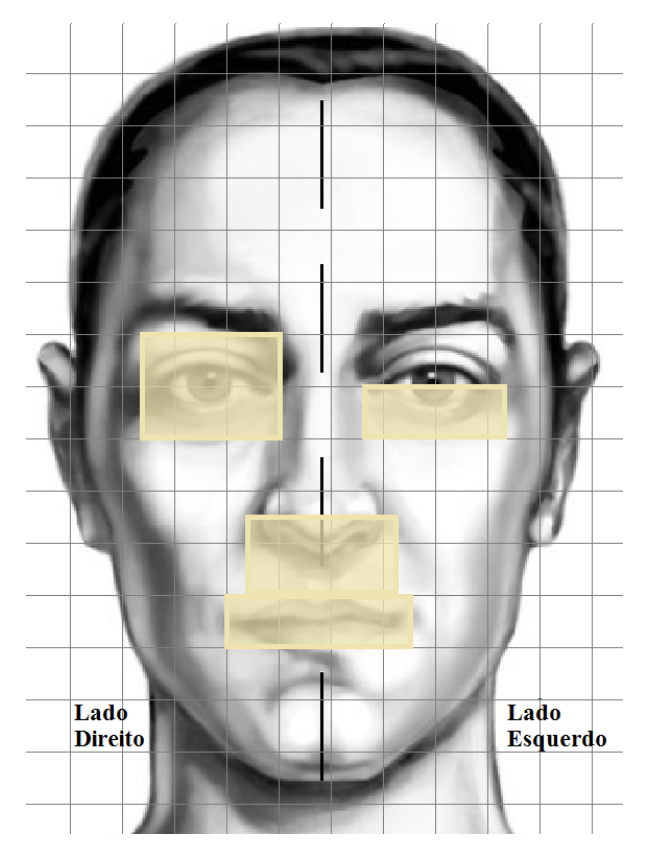

Figura 7.7: As regiões em destaque apresentam as características de diagnóstico identificadas para classificar a surpresa.

A identificação da expressão de alegria é a mais simples, pois todos os subconjuntos obtidos pela seleção, independente da base de dados, obtém 100\% de acerto. Neste sentido, pode-se afirmar que uma grande variedade de características faciais corretamente representam esta emoção. Dentre os subconjuntos existentes para a base de dados RaFD, 63,1\% possuem menos de 7 atributos, 25,7\% apresentam menos de 100 atributos, em 8,6\% deles são encontrados entre 100 e 199 atributos e, em apenas 2,6\%, pode-se observar 200 ou mais atributos. Neste sentido, no máximo 509 atributos são encontrados. Para a base $\mathrm{CK}^{+}$, dentre os subconjuntos produzidos, 60,5\% possuem menos de 9 características, em 29,2\% são encontradas menos de 100 características, 7,3\% apresentam entre 100 e 199 características, e apenas $3 \%$ possuem entre 200 e 507 características.

Para a base RaFD, dentre os três subconjuntos apresentados como os melhores por serem independentes do algoritmo de seleção e das representações faciais, além de possuírem as menores quantidades de características de diagnóstico identificadas, dois deles possuem, respectivamente, um e sete atributos. O subconjunto com apenas um atributo indica que a distância entre a narina direita e o canto direito da boca é suficiente para identificar a alegria. Ainda, o subconjunto com sete 
características seleciona a distância entre o lábio superior e o canto direito da boca, a área entre os olhos, a distância entre o lábio superior e o canto esquerdo da boca, a diferença entre os ângulos formados entre os cantos direito e esquerdo da boca, as diferenças entre as distâncias da narina direita aos cantos direito e esquerdo da boca, além da diferença entre as distâncias do queixo ao canto direito da boca.

O terceiro melhor subconjunto apresenta 136 características que evidenciam as regiões da boca, narinas e queixo como mais relevantes já que as relações encontradas são, em ordem decrescente de frequência, lábio inferior com superior, lábios com narinas, lábios com o queixo e lábios com os olhos.

Para a base $\mathrm{CK}^{+}$, os dois menores subconjuntos apresentam, respectivamente, duas e dez características. As duas características selecionadas são a distância entre a narina direita e o canto direito da boca, e o ângulo entre os lábios superior e inferior. Estas duas características são também encontradas no subconjunto com dez atributos, no qual também podem ser observadas a distância entre o lábio superior e o canto direito da boca, a distância entre o lábio inferior e o canto esquerdo da boca, a diferença entre os ângulos formados pelos cantos da boca, a diferença entre as distâncias do queixo com o canto direito da boca, a diferença entre as distâncias da narina direita com o canto esquerdo da boca, o ângulo entre o olho direito e o canto esquerdo da boca, a diferença entre os ângulos formados entre o canto esquerdo da boca com o olho esquerdo, e a distância entre a narina esquerda e o canto direito da boca. Para o subconjunto com 112 atributos, podem ser observadas características que relacionam os lábios entre si, com o queixo, narinas, ou olhos, assim como algumas relações entre as pálpebras do olho direito entre si e pálpebras do olho esquerdo entre si.

Se considerados todos os subconjuntos produzidos pela seleção, a quantidade de características obtida é muito grande. Neste sentido, as tabelas 7.65 e 7.66 apresentam, respectivamente, para as bases $\mathrm{RaFD}$ e $\mathrm{CK}^{+}$, todas as características escolhidas para reconhecer a alegria. Nestas tabelas, $C$ indica as coordenadas de um ponto que representa algum dos elementos faciais mapeados, $A$ indica um ângulo e $A D$ se refere à diferença entre os ângulos, $D$ indica uma distância, $D D$ representa a diferença entre as distâncias e $A r$ indica uma área. Para simplificar as tabelas, são apresentados apenas os elementos faciais importantes para esta emoção.

Como pode ser observado pelas tabelas, independente da base de dados utilizada, as características relacionadas principalmente aos lábios, e a relação destes com o queixo ou narinas são as mais importantes para identificar a alegria. Adicionalmente, algumas relações entre os lábios ou narinas com os olhos, assim como algumas características apenas dos olhos ou das sobrancelhas também podem ser encontradas, o que demonstra que estas regiões, embora menos relevantes, também auxiliam no reconhecimento.

Dentre as características selecionadas, existe balanceamento entre aquelas 
Tabela 7.65: Apresentação das características selecionadas para representar a alegria, com a base de dados RaFD.

\begin{tabular}{|c|c|c|c|c|c|c|c|c|c|}
\hline \multicolumn{2}{|c|}{$\begin{array}{c}\text { Elementos } \\
\text { Faciais }\end{array}$} & \multicolumn{2}{c|}{ Olhos } & Sobranc & Narina & \multicolumn{3}{|c|}{ Lábios } & Queixo \\
\cline { 2 - 11 } & Dir & Esq & Dir & Dir & Superior & Inferior & Cantos & \\
\hline Olhos & Dir & D & Ar & & & & A & AD;A & \\
\cline { 2 - 10 } & Esq & AD & AD & & & & & AD;A;D & \\
\hline Sobranc & Esq & & & A & & & & & \\
\hline Narina & Esq & & A & & & DD & & DD;A & \\
\hline Extr Face & Dir & & & & & & & D & \\
\hline \multirow{2}{*}{ Lábios } & Superior & & & & & AD;DD & AD & DD & \\
\cline { 2 - 10 } & Inferior & & & & & & DD & & \\
\cline { 2 - 10 } & Cantos & & & & DD;A & & & D & \\
\hline \multicolumn{2}{|l|}{ Queixo } & & & & & & DD & DD;D & DD;A \\
\hline
\end{tabular}

Tabela 7.66: Apresentação das características selecionadas para representar a alegria, com a base de dados $\mathrm{CK}+$.

\begin{tabular}{|c|c|c|c|c|c|c|c|c|c|}
\hline \multicolumn{2}{|c|}{$\begin{array}{c}\text { Elementos } \\
\text { Faciais }\end{array}$} & \multicolumn{2}{c|}{ Olhos } & Sobranc & Narina & \multicolumn{3}{|c|}{ Lábios } & Queixo \\
\cline { 2 - 10 } & Dir & Esq & Dir & Dir & Superior & Inferior & Cantos & \\
\hline & Dir & A & & & & & A & AD;A & \\
\hline & Esq & AD;D & DD & & & & DD & AD;A;D & \\
\hline Sobranc & Esq & & & A & & & & & \\
\hline Narina & Esq & & AD & & & DD & & D;A & \\
\hline \multirow{3}{*}{ Lábios } & Superior & & & & & AD;DD & AD;DD & DD & \\
\cline { 2 - 9 } & Inferior & & & & & & DD & A & \\
\cline { 2 - 10 } & Cantos & & & DD;A & & & A & \\
\hline \multicolumn{2}{|c|}{ Queixo } & & & & & DD & DD;D & A \\
\hline
\end{tabular}

que comparam a expressão neutra com o ápice da emoção e aquelas que apenas representam a emoção em seu ápice. Da mesma forma, não é possível observar diferenças significativas entre a escolha de ângulos ou distâncias. É importante notar que as UAs relacionadas a esta emoção, UA6 e UA12, são facilmente identificadas pelas características encontradas pela seleção. No entanto, percebe-se que a UA12 aparece com maior frequência nos subconjuntos obtidos.

As principais regiões faciais selecionadas para o reconhecimento da alegria são apresentadas na Figura 7.8. Nela, os olhos também são apresentados, embora sejam utilizados com menor frequência que narinas, boca e queixo.

Os resultados obtidos para a expressão de medo permitem notar que, assim como observado para a aversão, uma maior quantidade de características precisa ser utilizada para representá-la. A análise dos subconjuntos obtidos para as duas bases de dados demonstra que as características selecionadas representam as mesmas regiões faciais. Desta forma, nas tabelas 7.67 e 7.68 podem ser vistas, respectivamente, para as bases $\mathrm{RaFD}$ e $\mathrm{CK}+$, as características escolhidas para possibilitar o reconhecimento da expressão de medo. A mesma notação apresentada nas tabelas 7.65 e 7.66 é empregada para estas tabelas. Para simplificá-las, estão presentes apenas os elementos faciais importantes para esta emoção. 


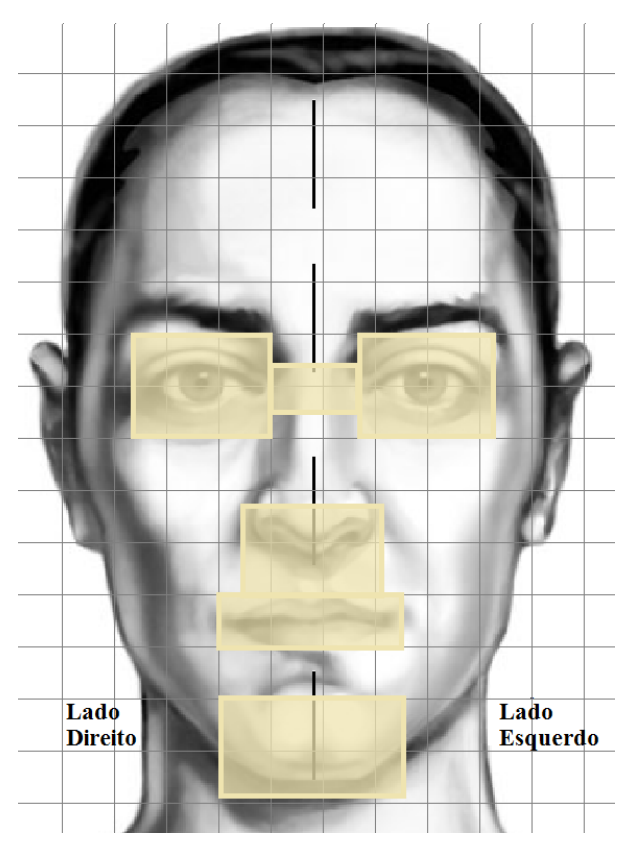

Figura 7.8: As regiões em destaque apresentam as características de diagnóstico identificadas para classificar a alegria.

Tabela 7.67: Apresentação das características selecionadas para representar a expressão de medo, com a base de dados RaFD.

\begin{tabular}{|c|c|c|c|c|c|c|c|c|c|}
\hline \multirow{2}{*}{\multicolumn{2}{|c|}{$\begin{array}{c}\text { Elementos } \\
\text { Faciais }\end{array}$}} & \multicolumn{2}{|c|}{ Olhos } & \multicolumn{2}{|c|}{ Sobranc } & \multirow{2}{*}{$\begin{array}{c}\text { Extr Face } \\
\text { Esq }\end{array}$} & \multicolumn{3}{|c|}{ Lábios } \\
\hline & & \multirow[t]{2}{*}{ Dir } & \multirow{2}{*}{$\begin{array}{c}\text { Esq } \\
\mathrm{DD} ; \mathrm{AD}\end{array}$} & \multirow[t]{2}{*}{ Dir } & \multirow[t]{2}{*}{ Esq } & & \multirow{2}{*}{$\begin{array}{c}\text { Superior } \\
\mathrm{D} ; \mathrm{A} ; \mathrm{DD}\end{array}$} & \multirow{2}{*}{$\begin{array}{c}\text { Inferior } \\
\mathrm{A} ; \mathrm{AD}\end{array}$} & \multirow{2}{*}{$\begin{array}{c}\text { Cantos } \\
\text { DD }\end{array}$} \\
\hline Olhos & Dir & & & & & & & & \\
\hline & Esq & $\mathrm{D} ; \mathrm{A}$ & & $\mathrm{A} ; \mathrm{AD}$ & $\mathrm{A}$ & & DD & & \\
\hline \multirow[t]{2}{*}{ Sobranc } & Dir & $\mathrm{D}$ & $\mathrm{D} ; \mathrm{DD}$ & & & & DD & & \\
\hline & Esq & $\mathrm{D}$ & $\mathrm{D} ; \mathrm{DD}$ & & & & $\mathrm{AD}$ & $\mathrm{DD}$ & $\mathrm{D} ; \mathrm{A}$ \\
\hline \multirow[t]{2}{*}{ Narinas } & Dir & A & & & & & & & \\
\hline & Esq & & $\mathrm{AD}$ & & & & $\mathrm{D}$ & & $\mathrm{D}$ \\
\hline \multirow[t]{2}{*}{ Extr Face } & Dir & & $\mathrm{A} ; \mathrm{DD} ; \mathrm{AD}$ & & $\mathrm{D}$ & & & $\mathrm{AD}$ & \\
\hline & Esq & & & & & & $\mathrm{AD}$ & & $\mathrm{AD}$ \\
\hline \multirow[t]{2}{*}{ Lábios } & Inferior & & & & & & & $\mathrm{D}$ & \\
\hline & Cantos & & & & & & A & $\mathrm{AD}$ & \\
\hline \multicolumn{2}{|c|}{ Queixo } & $\mathrm{AD}$ & $\mathrm{A} ; \mathrm{DD}$ & $\mathrm{D} ; \mathrm{AD}$ & $\mathrm{A} ; \mathrm{DD}$ & $\mathrm{A} ; \mathrm{DD} ; \mathrm{AD}$ & $\mathrm{A} ; \mathrm{AD}$ & $\mathrm{D} ; \mathrm{A}$ & \\
\hline
\end{tabular}

Pelas tabelas, é possivel notar que diferentes regiões faciais são selecionadas. Neste sentido, podem ser observadas relações entre as pálpebras, entre os olhos, e dos olhos com as sobrancelhas, as narinas, a boca e o queixo. Além dos olhos, as sobrancelhas se relacionam também com a boca e o queixo. As narinas também tem relação com a boca, e não apenas com os olhos. A extremidade direita da face se relaciona com a sobrancelha e olho esquerdos e com o lábio inferior. Já a extremidade esquerda da face se relaciona com a boca e o queixo. Por fim, a boca se relaciona, além de olhos, sobrancelhas e narinas, com suas diferentes partes, e com o queixo.

Portanto, pode-se observar que, de modo geral, todos os elementos da face auxiliam, em maior ou menor grau, com o reconhecimento da expressão de medo. Nesta tarefa, a boca e os olhos têm maior destaque, seguidos pelas sobrancelhas e 
Tabela 7.68: Apresentação das características selecionadas para representar a expressão de medo, com a base de dados $\mathrm{CK}+$.

\begin{tabular}{|c|c|c|c|c|c|c|c|c|c|}
\hline \multirow{2}{*}{\multicolumn{2}{|c|}{$\begin{array}{c}\text { Elementos } \\
\text { Faciais }\end{array}$}} & \multicolumn{2}{|c|}{ Olhos } & \multicolumn{2}{|c|}{ Sobranc } & \multirow{2}{*}{$\begin{array}{c}\text { Extr Face } \\
\text { Esq }\end{array}$} & \multicolumn{3}{|c|}{ Lábios } \\
\hline & & \multirow{2}{*}{ Dir } & \multirow{2}{*}{$\begin{array}{c}\text { Esq } \\
\mathrm{DD} ; \mathrm{AD}\end{array}$} & \multirow{2}{*}{ Dir } & \multirow[t]{2}{*}{ Esq } & & \multirow{2}{*}{$\begin{array}{c}\text { Superior } \\
\text { A;DD }\end{array}$} & \multirow{2}{*}{$\begin{array}{c}\text { Inferior } \\
\mathrm{A} ; \mathrm{AD}\end{array}$} & \multirow{2}{*}{$\begin{array}{c}\text { Cantos } \\
\text { DD }\end{array}$} \\
\hline Olhos & Dir & & & & & & & & \\
\hline & Esq & $\mathrm{D} ; \mathrm{A}$ & & $\mathrm{A} ; \mathrm{AD}$ & $\mathrm{A}$ & & $\mathrm{AD}$ & & DD \\
\hline \multirow[t]{2}{*}{ Sobranc } & Dir & $\mathrm{D}$ & $\mathrm{DD}$ & & & & DD & & \\
\hline & Esq & $\mathrm{D}$ & D;DD & & & & $\mathrm{AD}$ & DD & $\mathrm{D} ; \mathrm{A}$ \\
\hline \multirow[t]{2}{*}{ Narinas } & Dir & A & & & & & & & $\mathrm{A}$ \\
\hline & Esq & & $\mathrm{AD}$ & & & & $\mathrm{D}$ & & $\mathrm{D}$ \\
\hline \multirow[t]{2}{*}{ Extr Face } & Dir & & $\mathrm{DD} ; \mathrm{AD}$ & & $\mathrm{D}$ & & & $\mathrm{AD}$ & \\
\hline & Esq & DD & & & & & $\mathrm{AD}$ & & $\mathrm{AD}$ \\
\hline \multirow[t]{2}{*}{ Lábios } & Inferior & & & & & & DD & $\mathrm{D}$ & \\
\hline & Cantos & & & & & & $\mathrm{A}$ & $\mathrm{AD}$ & \\
\hline \multicolumn{2}{|c|}{ Queixo } & $\mathrm{AD}$ & A;DD & $\mathrm{D} ; \mathrm{AD}$ & A;DD & $\mathrm{A} ; \mathrm{AD}$ & $\mathrm{A} ; \mathrm{AD}$ & $\mathrm{D} ; \mathrm{A}$ & \\
\hline
\end{tabular}

pelo queixo. As características selecionadas indicam que são igualmente importantes aquelas que comparam a expressão neutra com o ápice da emoção, assim como aquelas que se referem somente ao ápice da emoção. Da mesma forma, não é possivel observar diferenças significativas entre a escolha de ângulos ou distâncias.

Pela análise das características identificadas, todas as UAs relacionadas a esta emoção, ou seja, as UAs 1, 2, 4, 5, 20, 25, 26 e 27 são observadas. Vale destacar que os subconjuntos menores, com 62 ou 58 atributos, não apresentam características que revelem as UAs 4 ou 5 presentes, de acordo com o sistema FACS, em todas as possiveis combinações que representam o medo. No entanto, esta expressão é corretamente classificada. Ainda, cada UA é descrita por diversas características faciais, o que pode indicar a necessidade de redundâncias para conferir uma correta classificação.

As principais regiões faciais selecionadas para o reconhecimento do medo são apresentadas na Figura 7.9. Todos os elementos faciais são observados, com destaque para as regiões da boca e olhos, assim como relações entre elas.

A expressão neutra representa a ausência de movimentos faciais. Desta forma, ela é definida, pelo sistema FACS, como a ausência de UAs. As principais características selecionadas para descrever esta expressão estão apresentadas nas tabelas 7.69 e 7.70, respectivamente, para as bases de dados RaFD e CK+. Nelas, a mesma nomenclatura utilizada para as tabelas 7.65 e 7.66 é empregada. Para efeito de simplificação, são apresentados apenas os elementos faciais importantes para esta expressão.

De acordo com as tabelas, diversas relações entre os elementos faciais são destacadas, tais como os contornos da face (queixo e extremidades), os olhos, as sobrancelhas, as narinas e a boca. O que indica que a face toda é importante para o reconhecimento desta expressão. Relações entre as pálpebras de cada um dos olhos, entre os olhos, e dos olhos com as sobrancelhas, os lábios, as narinas, o queixo, e a extremidade direita da face são obtidas. Além dos olhos, as sobrancelhas 


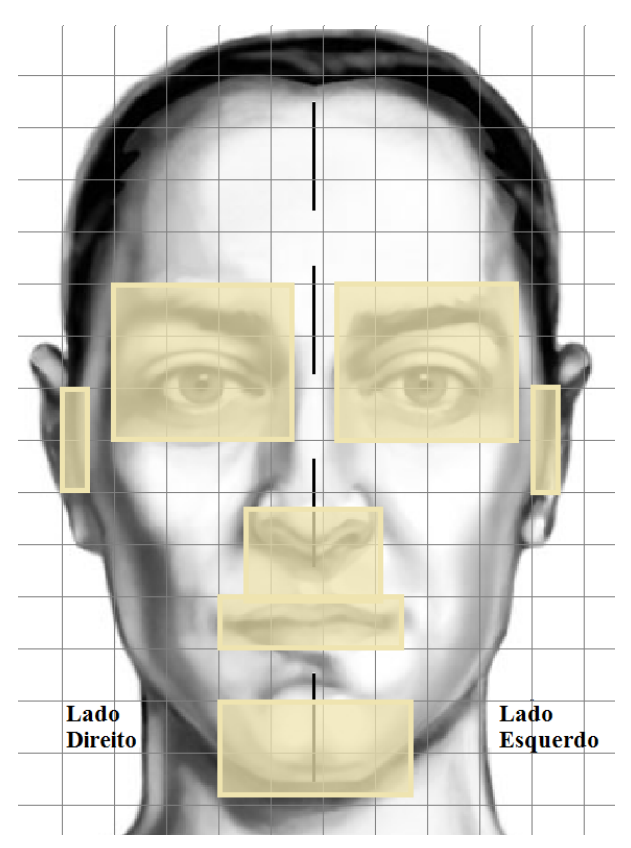

Figura 7.9: As regiões em destaque apresentam as características de diagnóstico identificadas para classificar o medo.

se relacionam entre si e com as narinas, os lábios, o queixo e a extremidade esquerda da face. A boca se relaciona com suas diferentes partes, e com o queixo, a narina esquerda e as extremidades da face. Por fim, o queixo e a narina esquerda também se relacionam com as duas extremidades da face.

As regiões faciais utilizadas para o reconhecimento da expressão neutra não são apresentadas em uma imagem ilustrativa pois, assim como pode ser notado para a emoção de medo (Figura 7.9), todos os elementos faciais mapeados são utilizados. Porém, diferente do que é observado para o medo, as distintas regiões apresentam igual importância para identificar esta expressão.

Um fato a se destacar é que apenas $21 \%$ dos atributos selecionados se referem a características da própria face neutra. Dentre estes atributos, os ângulos são encontrados em maior quantidade. Deste modo, para identificar a expressão neutra, as características que comparam a expressão neutra com o ápice de uma emoção, ou seja, as diferenças entre os ângulos ou distâncias, se mostram mais importantes.

É interessante notar que, especificamente para a expressão neutra, as "características que comparam a expressão neutra com o ápice de uma emoção" são constantes. Desta forma, acredita-se que a análise computacional tenha se baseado nesta informação, que é distinta da observada para as demais expressões faciais emocionais, como um padrão confiável para caracterizá-la.

A análise das características de diagnóstico identificadas nesta tese permite notar que, para a maioria das expressões avaliadas, as regiões faciais encontradas se assemelham às apresentadas na Figura 4.5, apresentada no Capítulo 6, Seção 4.3, obtidas por experimentos realizados pela psicologia. Vale destacar, ainda, que estas características não necessariamente representam os reais elementos obser- 
Tabela 7.69: Apresentação das características selecionadas para representar a expressão neutra, com a base de dados RaFD.

\begin{tabular}{|c|c|c|c|c|c|c|c|c|c|c|}
\hline \multirow{2}{*}{\multicolumn{2}{|c|}{$\begin{array}{c}\text { Elementos } \\
\text { Faciais }\end{array}$}} & \multicolumn{2}{|c|}{ Olhos } & \multicolumn{2}{|c|}{ Sobranc } & \multicolumn{2}{|c|}{ Extr Face } & \multicolumn{3}{|c|}{ Lábios } \\
\hline & & Dir & Esq & Dir & Esq & Dir & Esq & Sup & Inf & Cantos \\
\hline \multirow[t]{2}{*}{ Olhos } & Dir & $\begin{array}{l}\mathrm{C} ; \mathrm{DD} ; \\
\mathrm{AD}\end{array}$ & $\mathrm{AD}$ & & $\mathrm{DD} ; \mathrm{AD}$ & & & $\mathrm{DD} ; \mathrm{AD}$ & $\mathrm{DD} ; \mathrm{AD}$ & \\
\hline & Esq & $\mathrm{D} ; \mathrm{DD}$ & $\begin{array}{c}\mathrm{A} ; \mathrm{DD} ; \\
\mathrm{AD}\end{array}$ & & & & & $\mathrm{DD} ; \mathrm{AD}$ & $\overline{D D} ; \mathrm{AD}$ & \\
\hline \multirow[t]{2}{*}{ Sobranc } & Dir & DD;AD & $\mathrm{D}$ & & $\mathrm{D} ; \mathrm{AD}$ & & & $\mathrm{AD}$ & $\mathrm{DD} ; \mathrm{AD}$ & \\
\hline & Esq & A & $\mathrm{DD} ; \mathrm{AD}$ & A & & & & $\mathrm{AD}$ & A & \\
\hline \multirow[t]{2}{*}{ Narinas } & Dir & $\mathrm{DD}$ & $\mathrm{A} ; \mathrm{AD}$ & $\mathrm{AD}$ & & & & & & \\
\hline & Esq & $\mathrm{AD}$ & & & $\mathrm{AD}$ & & $\mathrm{AD}$ & $\mathrm{D}$ & & \\
\hline \multirow[t]{2}{*}{ Extr Face } & Dir & $\mathrm{AD} ; \mathrm{DD}$ & $\mathrm{AD}$ & & & & & & $\mathrm{AD}$ & \\
\hline & Esq & & & $\mathrm{D}$ & $\mathrm{AD}$ & & & $\mathrm{AD}$ & & \\
\hline \multirow[t]{2}{*}{ Lábios } & Sup & $\mathrm{D}$ & $\mathrm{D} ; \mathrm{A}$ & & & & & & $\mathrm{DD} ; \mathrm{AD}$ & DD \\
\hline & Cantos & & & & & & & & $\mathrm{AD}$ & $\mathrm{C} ; \mathrm{A}$ \\
\hline \multicolumn{2}{|c|}{ Queixo } & DD;AD & $\mathrm{A} ; \mathrm{AD}$ & $\mathrm{D} ; \mathrm{DD}$ & $\mathrm{D} ; \mathrm{AD}$ & $\mathrm{AD}$ & $\mathrm{AD}$ & DD;AD & $\mathrm{AD}$ & $\mathrm{AD}$ \\
\hline
\end{tabular}

Tabela 7.70: Apresentação das características selecionadas para representar a expressão neutra, com a base de dados $\mathrm{CK}+$.

\begin{tabular}{|c|c|c|c|c|c|c|c|c|c|c|}
\hline \multirow{2}{*}{\multicolumn{2}{|c|}{$\begin{array}{c}\text { Elementos } \\
\text { Faciais }\end{array}$}} & \multicolumn{2}{|c|}{ Olhos } & \multicolumn{2}{|c|}{ Sobranc } & \multicolumn{2}{|c|}{ Extr Face } & \multicolumn{3}{|c|}{ Lábios } \\
\hline & & Dir & Esq & Dir & Esq & Dir & Esq & Sup & Inf & Cantos \\
\hline \multirow[t]{2}{*}{ Olhos } & Dir & $\begin{array}{l}\text { C;DD; } \\
\text { A;AD }\end{array}$ & $\mathrm{AD}$ & & $\mathrm{DD} ; \mathrm{AD}$ & & & $\mathrm{DD} ; \mathrm{AD}$ & DD;AD & \\
\hline & Esq & D;DD & $\mathrm{A} ; \mathrm{AD}$ & & & & & DD;AD & DD;AD & \\
\hline \multirow[t]{2}{*}{ Sobranc } & Dir & $\mathrm{DD} ; \mathrm{AD}$ & $\mathrm{D} ; \mathrm{DD}$ & & $\mathrm{D} ; \mathrm{AD}$ & & & $\mathrm{DD} ; \mathrm{AD}$ & $\mathrm{DD} ; \mathrm{AD}$ & \\
\hline & Esq & $\mathrm{A}$ & $\mathrm{DD} ; \mathrm{AD}$ & $\mathrm{A}$ & & & & $\mathrm{AD}$ & $\mathrm{A}$ & \\
\hline \multirow[t]{2}{*}{ Narinas } & Dir & $\mathrm{DD}$ & $\mathrm{A} ; \mathrm{AD}$ & $\mathrm{AD}$ & & & & & & \\
\hline & Esq & A & & & $\mathrm{AD}$ & & $\mathrm{AD}$ & $\mathrm{D}$ & & \\
\hline \multirow[t]{2}{*}{ Extr Face } & Dir & $\mathrm{AD}$ & $\mathrm{AD}$ & & & & & & $\mathrm{AD}$ & \\
\hline & Esq & & & $\mathrm{D}$ & $\mathrm{AD}$ & & & $\mathrm{AD}$ & & \\
\hline \multirow[t]{2}{*}{ Lábios } & Sup & $\mathrm{D} ; \mathrm{A}$ & $\mathrm{D} ; \mathrm{A}$ & & & & & & $\mathrm{DD} ; \mathrm{AD}$ & DD \\
\hline & Cantos & & & & & & & & $\mathrm{AD}$ & $\mathrm{C} ; \mathrm{A}$ \\
\hline \multicolumn{2}{|c|}{ Queixo } & $\mathrm{DD} ; \mathrm{AD}$ & $\mathrm{A} ; \mathrm{AD}$ & $\mathrm{D} ; \mathrm{DD}$ & $\mathrm{D} ; \mathrm{A}$ & $\mathrm{AD}$ & $\mathrm{AD}$ & $\mathrm{DD} ; \mathrm{AD}$ & $\mathrm{AD}$ & $\mathrm{AD}$ \\
\hline
\end{tabular}

vados pelos seres humanos durante a tarefa de identificação emocional, uma vez que os estudos psicológicos não garantem que a face é modelada com base na geometria. No entanto, as características obtidas representam atributos importantes para computacionalmente analisar as emoções.

Assim, como os estudos psicológicos não conseguiram, até o momento, esclarecer quais elementos faciais são interpretados pelo cérebro durante o reconhecimento emocional, e considerando que os elementos utilizados pelos métodos computacionais para classificar uma emoção provavelmente são diferentes dos utilizados pelos seres humanos, cabe à psicologia analisar se os resultados apresentados por esta tese, relativos às possíveis características, regiões ou elementos faciais envolvidos na identificação de cada uma das seis emoções básicas, podem ser relevantes para o estudo das emoções humanas.

A obtenção de características que destaquem as regiões faciais mais rele- 
vantes tem aplicações não apenas para o reconhecimento emocional, mas também podem ser utilizadas, por exemplo, para a animação mais realística de faces virtuais ou robóticas, resultando em melhorias na interação-homem máquina. Nas áreas da psicologia e psiquiatria, para a compreensão dos processos de reconhecimento emocional humanos, ou para a identificação dos estados emocionais dos participantes de estudos realizados, que atualmente dependem de respostas em questionários, dentre outras possibilidades.

Ainda, a identificação computacional das diferentes características faciais de diagnóstico é promissora para a aplicação em ambientes reais, pois permite o direcionamento de recursos do sistema apenas para o processamento dos elementos fundamentais para realizar o reconhecimento emocional de uma pessoa, permitindo diminuir os custos com o processamento de itens desnecessários.

\subsection{Considerações Finais}

Detalhes sobre os experimentos realizados com os algoritmos de AM, que seguem o paradigma de aprendizado supervisionado, foram apresentados.

O fato da abordagem psicológica empregada, que analisa individualmente as emoções e enfatiza alterações na configuração dos elementos da face, obter bons resultados, é um indicativo que as representações faciais propostas são efetivas para o reconhecimento emocional. Ainda, a facilidade apresentada para o reconhecimento das distintas emoções é semelhante ao observado nos seres humanos, de acordo com estudos psicológicos. Vale destacar também que as representações que enfatizam as diferenças entre a expressão neutra e uma expressão emocional, assim como aquelas que combinam esta informação com as características do ápice da emoção obtêm os melhores desempenhos.

A análise individual das emoções facilita a identificação de características de diagnóstico distintas para cada expressão facial, obtidas pelo procedimento de seleção empregado, além de resultar em menor processamento computacional. Estas características permitem também encontrar os músculos faciais ou UAs relacionados à emoção investigada.

No próximo capítulo, podem ser vistos os demais experimentos realizados para desenvolver a modelagem proposta, assim como uma discussão mais detalhada sobre os resultados obtidos. 


\title{
- \\ Análise das Imagens Térmicas
}

\author{
Ceste capítulo, são descritos os experimentos que empregam imagens tér- \\ micas para o reconhecimento emocional, assim como aqueles realizados \\ com a modelagem completa. Assim, a Subseção 8.1 descreve a base de \\ dados de imagens térmicas avaliada, ao passo que os experimentos são detalha- \\ dos na Seção 8.2. Neste sentido, a Subseção 8.2.1 apresenta os experimentos e \\ resultados obtidos com a etapa não supervisionada, que se refere à modelagem do \\ mecanismo de pré-atenção visual humano e, na Subseção 8.2.2, são encontrados \\ os resultados obtidos com a modelagem completa, explicando as diferentes etapas \\ que atuam em conjunto para o reconhecimento emocional. Ainda, as considerações \\ finais podem ser vistas na Seção 8.3.
}

\subsection{Base de Dados Investigada}

Para a análise das imagens térmicas, a base de dados Natural Visible and Infrared Facial Expression (USTC-NVIE) (Wang et al., 2010) é utilizada. Esta base possui imagens de expressões faciais espontâneas e representadas, nas quais foi solicitado aos participantes reproduzir as expressões faciais de alegria, tristeza, raiva, medo, aversão ou surpresa, obtidas simultaneamente com as câmeras RGB (imagens visíveis) e térmica (imagens térmicas), em três condições diferentes de iluminação: luz frontal, proveniente da direita ou proveniente da esquerda. Ainda, foi solicitado aos participantes a utilização ou não de óculos, já que isto influencia na captação das imagens térmicas.

Originalmente, para a parte da base de dados USTC-NVIE composta apenas por expressões faciais representadas, as imagens foram obtidas de 215 estudantes, com idades entre 17 e 31 anos, totalizando 157 homens e 58 mulheres. Porém, parte 
das imagens foi perdida por problemas de aquisição, e alguns dos participantes não foram capazes de representar todas as expressões faciais solicitadas. Deste modo, expressões faciais de apenas 108 participantes foram obtidas.

Para utilização neste trabalho, são consideradas todas as imagens das expressões faciais representadas disponíveis, em que os participantes não utilizam óculos. Neste sentido, 582 imagens térmicas, e suas respectivas visíveis, são utilizadas. Dentre estas imagens, 81 representam a expressão facial de alegria, 81 a de tristeza, 76 indicam a aversão, 80 a raiva, 81 representam a surpresa, 82 o medo e 101 são relativas à expressão neutra. Exemplos de imagens disponíveis na base USTC-NVIE podem ser observadas na Figura 8.1.

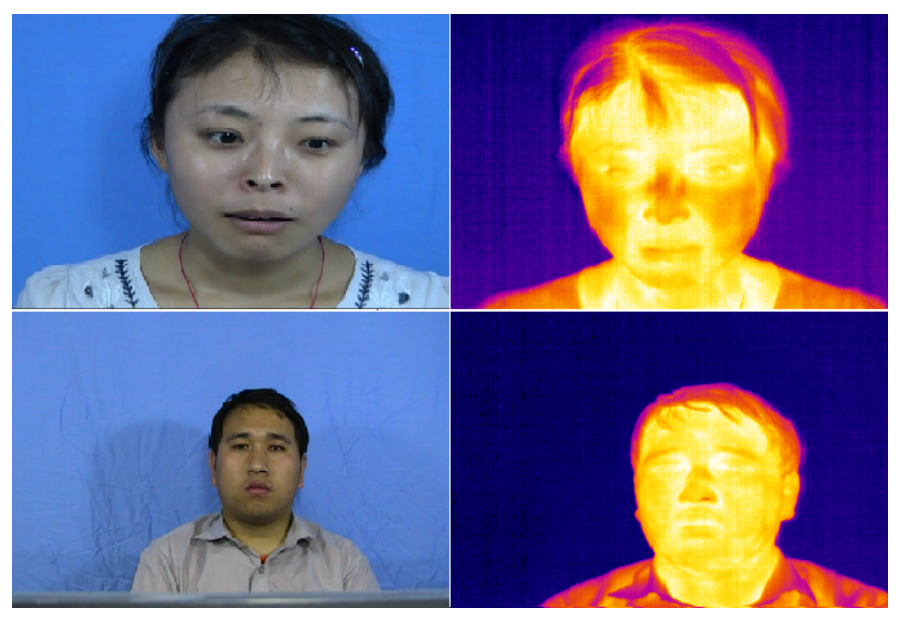

Figura 8.1: Exemplos de imagens existentes na base de dados USTC-NVIE. À esquerda encontram-se as imagens visíveis e, à direita, suas respectivas imagens térmicas.

No entanto, a observação desta figura permite notar que o posicionamento adotado para as câmeras durante a obtenção das imagens não garante o alinhamento entre imagens térmicas e visíveis equivalentes. Como neste trabalho estas imagens são utilizadas em conjunto, para cada imagem visível e térmica da base de dados USTC-NVIE, é realizado o alinhamento do centro dos olhos (íris) com a horizontal para, em seguida, fazer o registro das imagens. Somente após isto pode-se garantir a correspondência entre os dados analisados. É importante mencionar que este processo pode ser facilmente realizado para as imagens visíveis porém, para ser aplicado à imagens térmicas, implica na necessidade de identificação da íris.

Como pode ser visto na Figura 8.2, a base de dados USTC-NVIE possui um total de 13 pontos que foram manualmente anotados nas imagens térmicas durante sua construção. Assim, as coordenadas dos pontos existentes nos cantos de ambos os olhos são utilizadas para estimar os respectivos centros (íris). Em seguida, estas coordenadas são fornecidas a rotinas desenvolvidas em Matlab (Matsumoto, 2013), responsáveis por alinhar e fazer o registro destas imagens. O resultado final deste processo pode ser observado na Figura 8.3.

Além do processo de registro descrito, a translação é aplicada para padroni- 


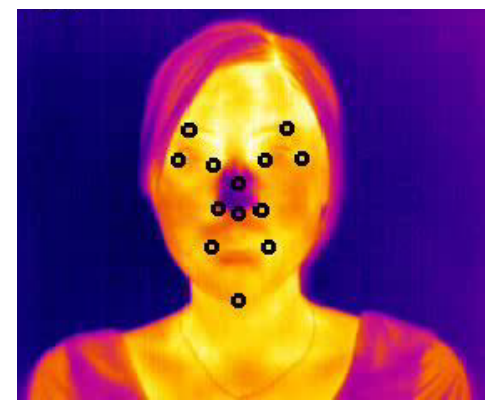

Figura 8.2: Pontos manualmente anotados nas imagens térmicas existentes na base de dados USTC-NVIE.
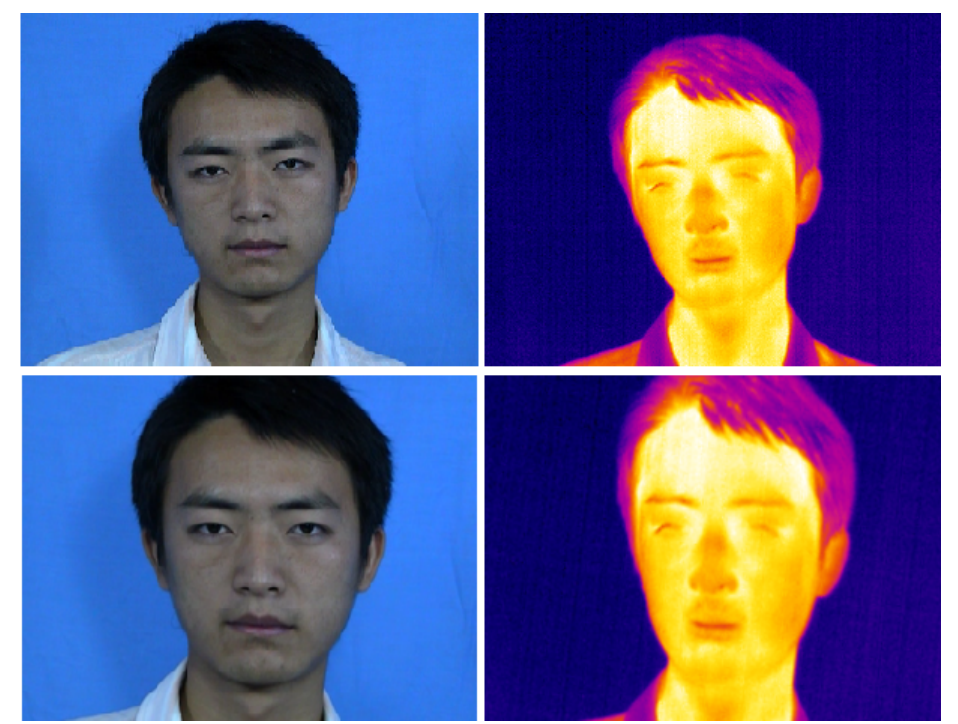

Figura 8.3: Processo executado para registrar as imagens visíveis e térmicas da base de dados USTC-NVIE. Acima encontram-se as imagens originais, abaixo são apresentadas as mesmas imagens após o processo de registro.

zação das coordenadas e posicionamento das faces no primeiro quadrante de um plano cartesiano, definindo a origem do sistema. Ainda, para corrigir problemas de faces localizadas a diferentes distâncias da câmera, ou que apresentam formatos distintos, cada imagem é normalizada pela distância interna entre os olhos. Somente após estas padronizações é possível a realização dos experimentos.

\subsection{Experimentos e Resultados}

A apresentação dos experimentos e resultados obtidos com a modelagem do mecanismo de pré-atenção visual, e com a modelagem proposta, que utiliza informações provenientes da pré-atenção visual para direcionar a utilização das características de diagnóstico e, assim, determinar a expressão facial emocional, é feita nas próximas subseções. 


\subsubsection{Resultados do Mecanismo de Pré-atenção Visual}

A modelagem do mecanismo de pré-atenção visual utiliza informações de mapas de saliência e de imagens térmicas para rapidamente reconhecer uma provável emoção. O objetivo é simular o comportamento dos seres humanos, que têm a habilidade de identificar a emoção expressa por uma pessoa mesmo quando a face em análise é apenas rapidamente observada, e não existe tempo hábil para analisá-la em detalhes. Neste sentido, os experimentos buscam encontrar informações relevantes que melhor representem as expressões emocionais em distintas partições, por meio de um processo não supervisionado, responsável por analisar as semelhanças ou diferenças existentes em seus respectivos vetores de características.

Para os experimentos realizados nesta etapa, a base de dados USTC-NVIE é avaliada, por possuir imagens visíveis e térmicas de expressões faciais emocionais. Neste sentido, apenas $70 \%$ das imagens disponíveis são utilizadas, as demais são empregadas para validar a modelagem proposta, como descrito na Subseção 8.2.2. A análise da expressão emocional da face é feita por algoritmos de agrupamento de dados, que interpretam os vetores de características obtidos pela aplicação das medidas estatísticas de entropia, variância e desvio-padrão, além do método de histograma de gradientes orientados (HOG).

Para obter os mapas de saliência e de entropia, assim como para os cálculos da variância, desvio-padrão e do método HOG, o software Matlab é utilizado (Matsumoto, 2013). Os mapas de saliência seguem o modelo proposto por Itti and Koch (2001). A variância e a entropia são calculadas, respectivamente, a partir da média de todos os valores locais de variância e entropia da imagem. Para isso, uma vizinhança de 5x5 pixels é utilizada. O desvio-padrão é auferido a partir da raiz quadrada da variância.

O método HOG define um grid quadrado sobre a imagem analisada para o cálculo dos gradientes orientados. Para aplicação neste trabalho, cada célula do grid ocupa uma região de 8x8 pixels, que é o valor-padrão definido pelo Matlab. Ainda, nove orientações, uniformemente espaçadas entre $0^{\circ}$ e $180^{\circ}$ (gradiente sem sinal), são utilizadas.

Os algoritmos de agrupamento avaliados são o k-médias e o x-médias, encontrados no simulador Weka (Frank and Witten, 2005). Ambos são utilizados com a distância euclidiana como métrica. Para execução, o algoritmo k-médias exige que o número $k$ de partições seja definido. Neste sentido, como o número de partições do problema é conhecido, ou seja, os dados de entrada representam seis emoções, além da expressão neutra, os valores escolhidos para o parâmetro $k$ são [7, 9, 11, 13], estabelecendo o mínimo de partições como a quantidade de expressões faciais analisadas, e o máximo como o valor do dobro da quantidade inicial, menos um. Todos os demais parâmetros têm mantidos os valores-padrão definidos pelo simulador. 
Para a execução do algoritmo x-médias, o número $k$ de partições não precisa ser informado, o algoritmo automaticamente identifica a quantidade de partições que melhor representa o problema, sendo necessário apenas determinar um intervalo para análise. Assim, o número de partições $k$ a ser explorado compreende o intervalo entre 7 e 14 partições, de modo a assemelhar-se às partições avaliadas pelo algoritmo k-médias.

$\mathrm{O}$ algoritmo x-médias internamente utiliza o k-médias durante sua execução. Deste modo, o número máximo de iterações locais e globais do algoritmo k-médias é definido como 200 pois, de acordo com Pelleg and Moore (2000), este é um valor que confere desempenho adequado ao x-médias. Ainda, o número de iterações adotado para o x-médias é 500, escolhido por ser igual ao valor-padrão utilizado pelo simulador Weka para o algoritmo k-médias. Os demais parâmetros existentes são mantidos em seus valores-padrão.

Inicialmente, os dados avaliados pelos algoritmos de agrupamento para os mapas de saliência e as imagens térmicas, convertidas para tons de cinza, são o resultado de todas as possíveis combinações dos cinco vetores de características originais: entropia (entr), variância (var), desvio-padrão (std), HOG da imagem em análise (HOG), e HOG do mapa de entropia da imagem $\left(\mathrm{HOG}_{\text {entr }}\right)$. Deste modo, são obtidos 31 possíveis conjuntos de dados, apresentados na Tabela 8.1.

Tabela 8.1: Conjuntos de dados avaliados.

\begin{tabular}{|c|c|c|c|c|c|}
\hline \# & Características & \# & Características & \# & Características \\
\hline 1 & entr & 12 & $\mathrm{HOG}_{e n t r}+\mathrm{HOG}$ & 23 & $\mathrm{HOG}_{e n t r}+\mathrm{std}+\mathrm{var}$ \\
\hline 2 & std & 13 & entr+std+var & 24 & $\mathrm{HOG}_{\text {entr }}+\mathrm{HOG}+\mathrm{entr}$ \\
\hline 3 & var & 14 & HOG+entr+std & 25 & $\mathrm{HOG}_{e n t r}+\mathrm{HOG}+\mathrm{std}$ \\
\hline 4 & HOG & 15 & HOG+entr+var & 26 & $\mathrm{HOG}_{\text {entr }}+\mathrm{HOG}+\mathrm{var}$ \\
\hline 5 & $\mathrm{HOG}_{\text {entr }}$ & 16 & HOG+std+var & 27 & $\mathrm{HOG}_{\text {entr }}+\mathrm{entr}+\mathrm{std}+\mathrm{var}$ \\
\hline 6 & entr+std & 17 & $\mathrm{HOG}_{e n t r}+\mathrm{entr}$ & 28 & $\mathrm{HOG}_{e n t r}+\mathrm{HOG}+\mathrm{entr}+\mathrm{std}$ \\
\hline 7 & entr+var & 18 & $\mathrm{HOG}_{\text {entr }}+\mathrm{std}$ & 29 & $\mathrm{HOG}_{\text {entr }}+\mathrm{HOG}+\mathrm{entr}+\mathrm{var}$ \\
\hline 8 & std+var & 19 & $\mathrm{HOG}_{\text {entr }}+\mathrm{var}$ & 30 & $\mathrm{HOG}_{\text {entr }}+\mathrm{HOG}+\mathrm{std}+\mathrm{var}$ \\
\hline 9 & HOG+entr & 20 & HOG+entr+std+var & 31 & $\mathrm{HOG}_{e n t r}+\mathrm{HOG}+\mathrm{entr}+$ \\
\hline 10 & HOG+std & 21 & $\mathrm{HOG}_{e n t r}+\mathrm{entr}+\mathrm{std}$ & & std+var \\
\hline 11 & HOG+var & 22 & $\mathrm{HOG}_{e n t r}+\mathrm{entr}+\mathrm{var}$ & & \\
\hline
\end{tabular}

Os algoritmos de agrupamento são executados 30 vezes para cada conjunto de dados, considerando diferentes inicializações dos protótipos iniciais. Índices de validação são aplicados na análise dos resultados. O índice interno silhueta é utilizado para medir a qualidade das partições, ou seja, como os exemplos estão distribuídos entre as diferentes partições geradas. Do mesmo modo, o índice externo Jaccard é empregado para analisar os agrupamentos encontrados, ou seja, mensurar o quanto estes se aproximam da estrutura ou classificação real dos dados.

As médias dos valores encontrados para os índices silhueta e Jaccard, com os conjuntos de dados obtidos a partir da análise dos mapas de saliência, são 
apresentadas, respectivamente, nas tabelas 8.2 e 8.3. Estas tabelas apresentam resultados bem diferenciados para os 31 conjuntos de dados avaliados. Ainda, em todos os experimentos realizados com o algoritmo x-médias e os mapas de saliência, o número de partições escolhido pelo algoritmo como melhor para representar o problema é sete, ou seja, a mesma quantidade das classes das expressões emocionais analisadas.

Tabela 8.2: Valores das médias obtidas para o índice silhueta com os mapas de saliência, para os diferentes conjuntos de dados avaliados.

\begin{tabular}{|c|c|c|c|c|c|}
\hline \multirow{2}{*}{$\begin{array}{c}\text { Conjuntos } \\
\text { de } \\
\text { Dados }\end{array}$} & \multicolumn{5}{|c|}{ Algoritmos } \\
\hline & x-médias & $\begin{array}{c}\text { k-médias } \\
k=7\end{array}$ & $\begin{array}{c}\text { k-médias } \\
k=9\end{array}$ & $\begin{array}{c}\text { k-médias } \\
k=11\end{array}$ & $\begin{array}{c}\text { k-médias } \\
k=13\end{array}$ \\
\hline 1 & $0,96_{-}^{+} 0,03$ & $0,95_{-}^{+} 0,05$ & $0,89_{-}^{+} 0,05$ & $0,82_{-}^{+} 0,04$ & $0,80_{-}^{+} 0,05$ \\
\hline 2 & $, 73_{-}^{+} 0,03$ & $, 69_{-}^{+} 0,04$ & $0,65_{-}^{+} 0,04$ & $0,61_{-}^{+} 0,05$ & $0,60_{-}^{+} 0,05$ \\
\hline 3 & $67_{-0,04}^{+}$ & $0,60_{-}^{+} 0,03$ & $0,60_{-}^{+} 0,03$ & $0,56_{-}^{+} 0,05$ & $0,52_{-}^{+} 0,07$ \\
\hline 4 & $, 74_{-}^{+} 0,02$ & $0,71_{-}^{+} 0,04$ & $0,67_{-}^{+} 0,04$ & $0,61_{-}^{+} 0,05$ & $0,59_{-}^{+} 0,05$ \\
\hline 5 & $0,67_{-}^{+} 0,04$ & $0,67_{-}^{+} 0,03$ & $0,63_{-}^{+} 0,05$ & $0,60_{-}^{+} 0,05$ & $0,54_{-}^{+} 0,06$ \\
\hline 6 & $0,95_{-}^{+} 0,02$ & $0,93_{-}^{+} 0,03$ & $0,87_{-}^{+} 0,04$ & $0,80_{-}^{+} 0,04$ & $0,76_{-}^{+} 0,06$ \\
\hline 7 & $0,66_{-}^{+} 0,03$ & $0,64_{-}^{+} 0,04$ & $0,60_{-}^{+} 0,04$ & $0,57_{-}^{+} 0,04$ & $0,50_{-}^{+} 0,06$ \\
\hline 8 & $0,50_{-}^{+} 0,04$ & $0,50_{-}^{+} 0,04$ & $0,45_{-}^{+} 0,06$ & $0,37_{-}^{+} 0,09$ & $0,31_{-}^{+} 0,08$ \\
\hline 9 & $65_{-}^{+} 0,03$ & $0,63_{-}^{+} 0,05$ & $0,57_{-}^{+} 0,04$ & $0,51_{-}^{+} 0,05$ & $0,50_{-}^{+} 0,09$ \\
\hline 10 & $70_{-}^{+} 0,01$ & $0,69_{-}^{+} 0,03$ & $0,62_{-}^{+} 0,04$ & $0,62_{-}^{+} 0,08$ & $0,54_{-}^{+} 0,07$ \\
\hline 11 & $0,60_{-}^{+} 0,02$ & $0,57_{-}^{+} 0,04$ & $0,55_{-}^{+} 0,04$ & $0,49_{-}^{+} 0,05$ & $0,47_{-}^{+} 0,04$ \\
\hline 12 & $, 35_{-}^{+} 0,05$ & $0,30_{-}^{+} 0,03$ & $0,24_{-}^{+} 0,04$ & $0,22_{-}^{+} 0,04$ & $0,18_{-}^{+} 0,06$ \\
\hline 13 & $0,71_{-}^{+} 0,01$ & $0,70_{-}^{+} 0,01$ & $0,68_{-}^{+} 0,02$ & $0,60_{-}^{+} 0,06$ & $0,59_{-}^{+} 0,05$ \\
\hline 14 & $0,49_{-}^{+} 0,05$ & $0,52_{-}^{+} 0,03$ & $0,46_{-}^{+} 0,05$ & $0,45_{-}^{+} 0,05$ & $0,40_{-}^{+} 0,05$ \\
\hline 15 & $0,51_{-}^{+} 0,03$ & $0,48_{-}^{+} 0,04$ & $0,44_{-}^{+} 0,06$ & $0,36_{-}^{+} 0,05$ & $0,29_{-}^{+} 0,04$ \\
\hline 16 & $0,67_{-}^{+} 0,01$ & $0,67_{-}^{+} 0,01$ & $0,62_{-}^{+} 0,03$ & $0,52_{-}^{+} 0,04$ & $0,50_{-}^{+} 0,04$ \\
\hline 17 & $45_{-}^{+} 0,05$ & $0,49_{-}^{+} 0,04$ & $0,45_{-}^{+} 0,04$ & $0,33_{-}^{+} 0,05$ & $0,29_{-}^{+} 0,07$ \\
\hline 18 & $0,71_{-}^{+} 0,01$ & $0,71_{-}^{+} 0,03$ & $0,66_{-}^{+} 0,04$ & $0,61_{-0,04}^{+}$ & $0,55_{-}^{+} 0,04$ \\
\hline 19 & $0,64_{-}^{+} 0,02$ & $0,62_{-}^{+} 0,02$ & $0,54_{-}^{+} 0,03$ & $0,54_{-}^{+} 0,03$ & $0,47_{-}^{+} 0,05$ \\
\hline 20 & $, 64_{-}^{+} 0,02$ & $0,64_{-}^{+} 0,04$ & $0,51_{-}^{+} 0,05$ & $0,51_{-}^{+} 0,05$ & $0,43_{-0,09}^{+}$ \\
\hline 21 & $0,71_{-}^{+} 0,01$ & $0,68_{-}^{+} 0,01$ & $0,60_{-}^{+} 0,05$ & $0,59_{-}^{+} 0,04$ & $0,45_{-}^{+} 0,03$ \\
\hline 22 & $0,59_{-}^{+} 0,03$ & $0,58_{-}^{+} 0,03$ & $0,50_{-}^{+} 0,02$ & $0,44_{-}^{+} 0,05$ & $0,40_{-}^{+} 0,04$ \\
\hline 23 & $0,70_{-}^{+} 0,02$ & $0,70_{-}^{+} 0,01$ & $0,66_{-}^{+} 0,03$ & $0,62_{-}^{+} 0,02$ & $0,59_{-}^{+} 0,04$ \\
\hline 24 & $0,70_{-}^{+} 0,01$ & $0,65_{-}^{+} 0,03$ & $0,52_{-}^{+} 0,07$ & $0,50_{-}^{+} 0,06$ & $0,41_{-}^{+} 0,05$ \\
\hline 25 & $0,50_{-}^{+} 0,02$ & $0,46_{-}^{+} 0,03$ & $0,44_{-}^{+} 0,02$ & $0,35_{-}^{+} 0,05$ & $0,29_{-}^{+} 0,04$ \\
\hline 26 & $0,46_{-}^{+} 0,02$ & $0,43_{-}^{+} 0,02$ & $0,34_{-}^{+} 0,03$ & $0,24_{-}^{+} 0,04$ & $0,16_{-}^{+} 0,06$ \\
\hline 27 & $0,72_{-}^{+} 0,01$ & $0,72_{-}^{+} 0,01$ & $0,65_{-}^{+} 0,04$ & $0,63_{-}^{+} 0,02$ & $0,49_{-}^{+} 0,04$ \\
\hline 28 & $0,67_{-}^{+} 0,03$ & $0,60_{-}^{+} 0,02$ & $0,62_{-}^{+} 0,02$ & $0,47_{-}^{+} 0,04$ & $0,46_{-}^{+} 0,03$ \\
\hline 29 & $0,61_{-}^{+} 0,03$ & $0,62_{-}^{+} 0,01$ & $0,53_{-}^{+} 0,01$ & $0,49_{-}^{+} 0,04$ & $0,44_{-}^{+} 0,04$ \\
\hline 30 & $0,49_{-}^{+} 0,04$ & $0,47_{-}^{+} 0,03$ & $0,32_{-}^{+} 0,06$ & $0,31_{-}^{+} 0,04$ & $0,26_{-}^{+} 0,04$ \\
\hline 31 & $0,35_{-}^{+} 0,04$ & $0,29_{-}^{+} 0,04$ & $0,29_{-}^{+} 0,03$ & $0,22_{-}^{+} 0,05$ & $0,14_{-}^{+} 0,07$ \\
\hline
\end{tabular}

Para facilitar a visualização dos resultados, nos gráficos descritos pelas figuras 8.4, 8.5 e 8.6, assim divididos devido à quantidade elevada de conjuntos de dados investigados, são apresentadas as médias dos valores obtidos para o índice silhueta. De modo análogo, os gráficos descritos pelas figuras 8.7, 8.8 e 8.9, apresentam as médias dos valores obtidos para o índice Jaccard. Neles, é possível observar as execuções do algoritmo k-médias, com os quatro distintos valores de $k$ avaliados, e 
Tabela 8.3: Valores das médias obtidas para o índice Jaccard com os mapas de saliência, para os diferentes conjuntos de dados avaliados.

\begin{tabular}{|c|c|c|c|c|c|}
\hline \multirow{2}{*}{$\begin{array}{c}\text { Conjuntos } \\
\text { de } \\
\text { Dados }\end{array}$} & \multicolumn{5}{|c|}{ Algoritmos } \\
\hline & $\mathrm{x}$-médias & $\begin{array}{c}\text { k-médias } \\
k=7\end{array}$ & $\begin{array}{c}\text { k-médias } \\
k=9\end{array}$ & $\begin{array}{c}\mathrm{k}-\mathrm{médias} \\
k=11\end{array}$ & $\begin{array}{c}\text { k-médias } \\
k=13\end{array}$ \\
\hline 1 & $0,93_{-}^{+} 0,02$ & $0,90_{-}^{+} 0,04$ & $0,84_{-}^{+} 0,05$ & $0,78_{-}^{+} 0,05$ & $0,72_{-}^{+} 0,04$ \\
\hline 2 & $0,79_{-}^{+} 0,03$ & $0,76_{-}^{+} 0,05$ & $0,72_{-}^{+} 0,03$ & $0,66_{-}^{+} 0,04$ & $0,64_{-}^{+} 0,02$ \\
\hline 3 & $0,70_{-}^{+} 0,03$ & $0,64_{-}^{+} 0,03$ & $0,61_{-}^{+} 0,02$ & $0,58_{-}^{+} 0,03$ & $0,50_{-}^{+} 0,05$ \\
\hline 4 & $0,77_{-}^{+} 0,02$ & $0,75_{-}^{+} 0,04$ & $0,69_{-}^{+} 0,02$ & $0,61_{-}^{+} 0,02$ & $0,57_{-}^{+} 0,03$ \\
\hline 5 & $0,74_{-}^{+} 0,04$ & $0,71_{-}^{+} 0,03$ & $0,69_{-}^{+} 0,04$ & $0,65_{-}^{+} 0,03$ & $0,60_{-}^{+} 0,02$ \\
\hline 6 & $0,85_{-}^{+} 0,03$ & $0,81_{-}^{+} 0,04$ & $0,77_{-}^{+} 0,05$ & $0,74_{-}^{+} 0,03$ & $0,66_{-}^{+} 0,04$ \\
\hline 7 & $0,76_{-}^{+} 0,02$ & $0,73_{-}^{+} 0,02$ & $0,68_{-}^{+} 0,03$ & $0,63_{-}^{+} 0,04$ & $0,51_{-}^{+} 0,04$ \\
\hline 8 & $0,62_{-}^{+} 0,03$ & $0,59_{-}^{+} 0,02$ & $0,50_{-}^{+} 0,06$ & $0,44_{-}^{+} 0,08$ & $0,41_{-}^{+} 0,06$ \\
\hline 9 & $0,70_{-}^{+} 0,04$ & $0,67_{-}^{+} 0,05$ & $0,62_{-}^{+} 0,05$ & $0,57_{-}^{+} 0,06$ & $0,50_{-}^{+} 0,07$ \\
\hline 10 & $0,73_{-}^{+} 0,03$ & $0,70_{-}^{+} 0,04$ & $0,65_{-}^{+} 0,06$ & $0,61_{-}^{+} 0,06$ & $0,49_{-}^{+} 0,10$ \\
\hline 11 & $0,68_{-}^{+} 0,05$ & $0,60_{-}^{+} 0,06$ & $0,55_{-}^{+} 0,09$ & $0,51_{-}^{+} 0,07$ & $0,45_{-}^{+} 0,08$ \\
\hline 12 & $0,43_{-}^{+} 0,09$ & $0,39_{-}^{+} 0,10$ & $0,37_{-}^{+} 0,09$ & $0,32_{-}^{+} 0,10$ & $0,28_{-}^{+} 0,11$ \\
\hline 13 & $0,75_{-}^{+} 0,04$ & $0,70_{-}^{+} 0,03$ & $0,69_{-}^{+} 0,04$ & $0,65_{-}^{+} 0,07$ & $0,62_{-}^{+} 0,06$ \\
\hline 14 & $0,60_{-}^{+} 0,07$ & $0,63_{-}^{+} 0,06$ & $0,55_{-}^{+} 0,07$ & $0,48_{-}^{+} 0,08$ & $0,41_{-}^{+} 0,09$ \\
\hline 15 & $0,60_{-}^{+} 0,06$ & $0,55_{-}^{+} 0,06$ & $0,50_{-}^{+} 0,06$ & $0,41_{-}^{+} 0,07$ & $0,35_{-}^{+} 0,08$ \\
\hline 16 & $0,70_{-}^{+} 0,04$ & $0,65_{-}^{+} 0,03$ & $0,62_{-}^{+} 0,07$ & $0,57_{-}^{+} 0,05$ & $0,52_{-}^{+} 0,04$ \\
\hline 17 & $0,59_{-}^{+} 0,08$ & $0,62_{-}^{+} 0,06$ & $0,53_{-}^{+} 0,05$ & $0,43_{-}^{+} 0,07$ & $0,39_{-}^{+} 0,08$ \\
\hline 18 & $0,73_{-}^{+} 0,02$ & $0,72_{-}^{+} 0,03$ & $0,68_{-}^{+} 0,05$ & $0,65_{-}^{+} 0,07$ & $0,59_{-}^{+} 0,05$ \\
\hline 19 & $0,65_{-}^{+} 0,04$ & $0,64_{-}^{+} 0,04$ & $0,60_{-}^{+} 0,04$ & $0,58_{-}^{+} 0,06$ & $0,50_{-}^{+} 0,07$ \\
\hline 20 & $0,62_{-}^{+} 0,03$ & $0,60_{-}^{+} 0,03$ & $0,56_{-}^{+} 0,05$ & $0,51_{-}^{+} 0,04$ & $0,47_{-}^{+} 0,06$ \\
\hline 21 & $0,69_{-}^{+} 0,02$ & $0,65_{-}^{+} 0,04$ & $0,63_{-}^{+} 0,05$ & $0,54_{-}^{+} 0,06$ & $0,49_{-}^{+} 0,05$ \\
\hline 22 & $0,62_{-}^{+} 0,05$ & $0,58_{-}^{+} 0,05$ & $0,55_{-}^{+} 0,03$ & $0,51_{-}^{+} 0,07$ & $0,41_{-}^{+} 0,04$ \\
\hline 23 & $0,72_{-}^{+} 0,03$ & $0,70_{-}^{+} 0,03$ & $0,68_{-}^{+} 0,04$ & $0,63_{-}^{+} 0,06$ & $0,57_{-}^{+} 0,06$ \\
\hline 24 & $0,68_{-}^{+} 0,02$ & $0,62_{-}^{+} 0,04$ & $0,56_{-}^{+} 0,05$ & $0,44_{-}^{+} 0,05$ & $0,37_{-}^{+} 0,08$ \\
\hline 25 & $0,45_{-}^{+} 0,04$ & $0,37_{-}^{+} 0,05$ & $0,33_{-}^{+} 0,04$ & $0,27_{-}^{+} 0,06$ & $0,20_{-}^{+} 0,07$ \\
\hline 26 & $0,44_{-}^{+} 0,06$ & $0,40_{-}^{+} 0,06$ & $0,32_{-}^{+} 0,05$ & $0,22_{-}^{+} 0,09$ & $0,19_{-}^{+} 0,13$ \\
\hline 27 & $0,69_{-}^{+} 0,02$ & $0,70_{-}^{+} 0,02$ & $0,68_{-}^{+} 0,02$ & $0,61_{-}^{+} 0,04$ & $0,55_{-}^{+} 0,05$ \\
\hline 28 & $0,68_{-}^{+} 0,03$ & $0,64_{-}^{+} 0,04$ & $0,62_{-}^{+} 0,04$ & $0,53_{-}^{+} 0,05$ & $0,51_{-}^{+} 0,05$ \\
\hline 29 & $0,65_{-}^{+} 0,01$ & $0,65_{-}^{+} 0,05$ & $0,58_{-}^{+} 0,03$ & $0,44_{-}^{+} 0,05$ & $0,41_{-}^{+} 0,05$ \\
\hline 30 & $0,59_{-}^{+} 0,03$ & $0,56_{-}^{+} 0,04$ & $0,53_{-}^{+} 0,04$ & $0,41_{-}^{+} 0,06$ & $0,33_{-}^{+} 0,07$ \\
\hline 31 & $0,44_{-}^{+} 0,07$ & $0,39_{-}^{+} 0,06$ & $0,30_{-}^{+} 0,09$ & $0,28_{-}^{+} 0,09$ & $0,19_{-}^{+} 0,12$ \\
\hline
\end{tabular}

também a execução do algoritmo x-médias, que automaticamente define o número de partições para os dados de entrada.

A análise destes gráficos permite notar que os diferentes conjuntos de dados investigados conferem, de acordo com os índices utilizados, melhor ou pior qualidade aos agrupamentos obtidos. Percebe-se ainda que os índices silhueta e Jaccard apresentam valores inferiores conforme a quantidade de partições $k$ aumenta. $\mathrm{O}$ fato de não serem observados valores negativos de silhueta indica que as partições obtidas são capazes de representar as expressões emocionais investigadas, com diferentes níveis de qualidade. Podem também ser encontrados elevados valores para o índice Jaccard, demonstrando que os agrupamentos produzidos são, muitas vezes, semelhantes à classificação conhecida dos dados.

Com relação às partições geradas, de acordo com as características obtidas 


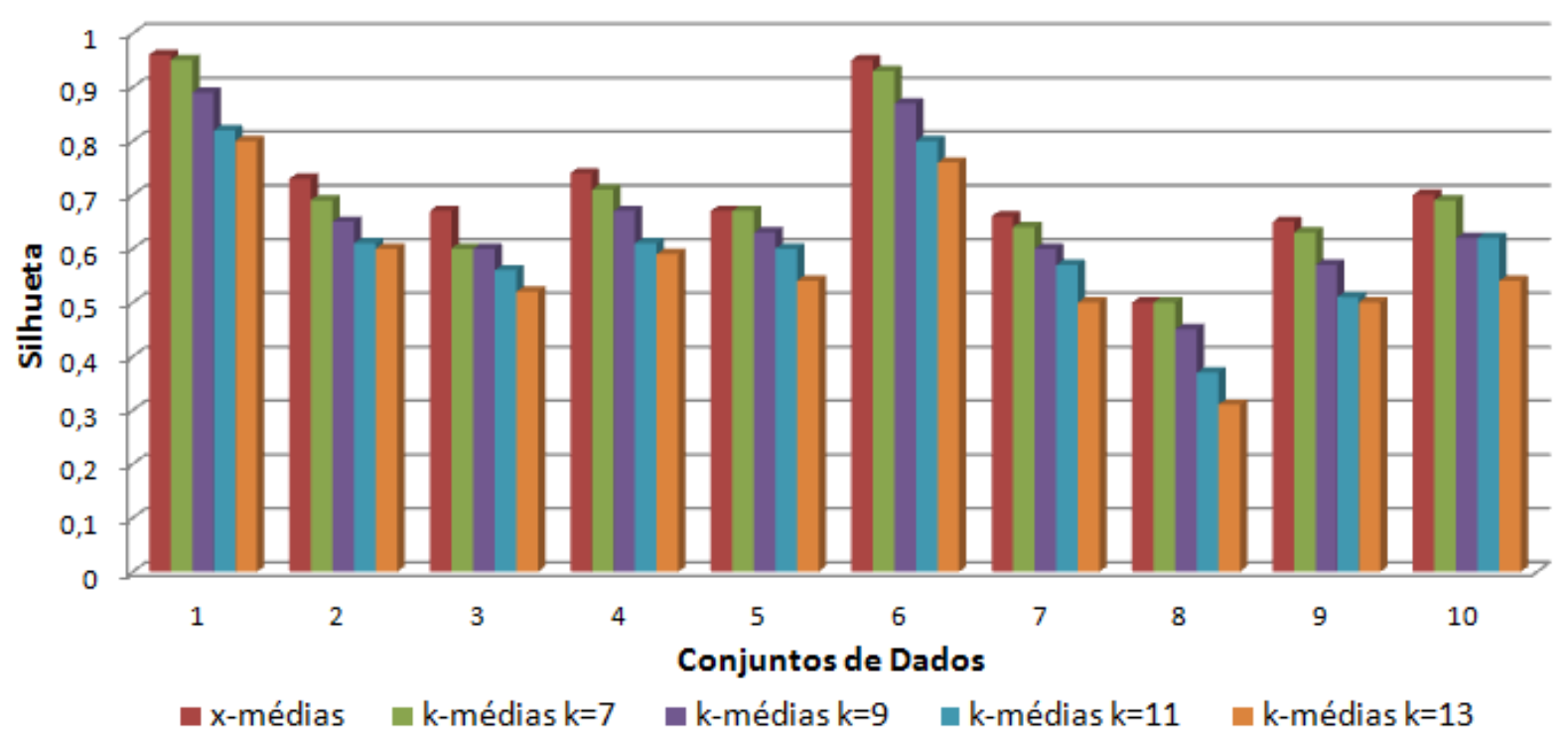

Figura 8.4: Gráfico com as médias do índice silhueta obtidas com os mapas de saliência, para os conjuntos de dados 1 a 10 .

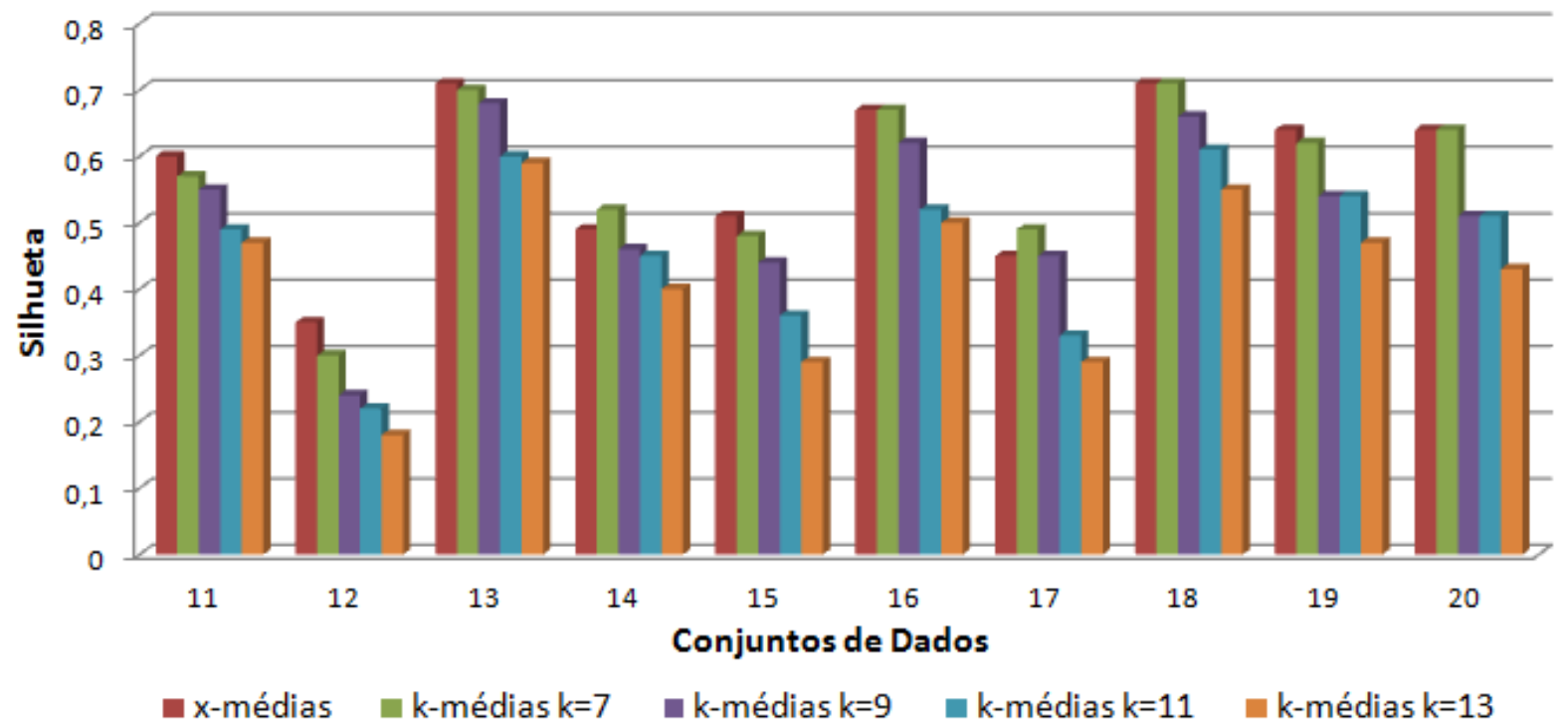

Figura 8.5: Gráfico com as médias do índice silhueta obtidas com os mapas de saliência, para os conjuntos de dados 11 a 20 .

dos mapas de saliência, tem-se que, em geral, os exemplos das expressões neutra, de aversão, e de raiva são distribuídos em duas partições distintas. Porém isto é mais frequentemente observado com as emoções de aversão e raiva. O medo parece ser a expressão de mais difícil reconhecimento, uma vez que, em grande parte das execuções, tem seus exemplos distribuídos entre todas as partições. Estes são também separados em duas ou até três partições, e dificilmente são agrupados em uma única partição, como é o comportamento esperado. As emoções de alegria, surpresa e tristeza parecem ser facilmente discerniveis, já que poucos conjuntos de dados produzem partições incorretas ao analisá-las.

É importante destacar que não é comum encontrar sobreposição entre os exemplos das diferentes expressões emocionais investigadas, indicando que os algo- 


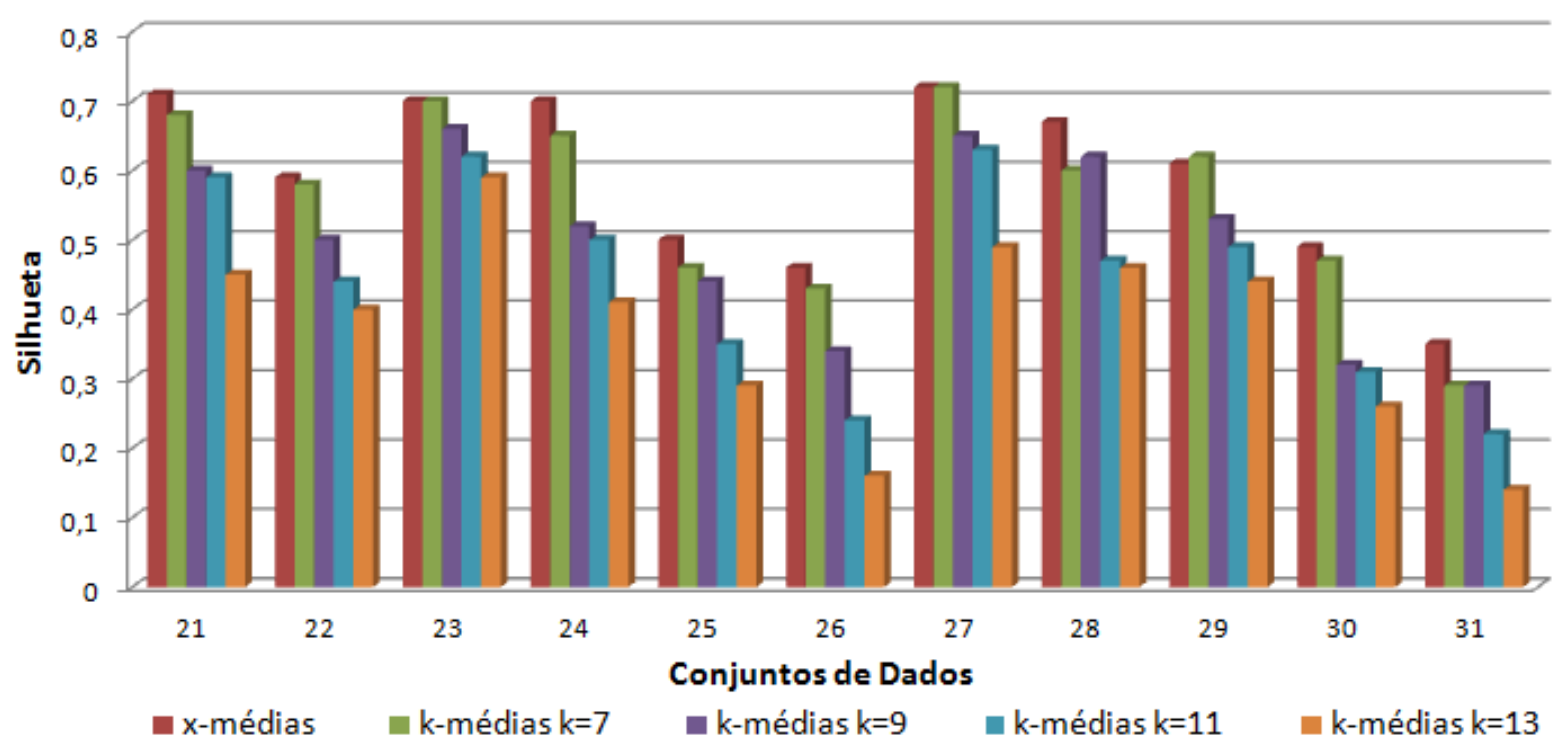

Figura 8.6: Gráfico com as médias do índice silhueta obtidas com os mapas de saliência, para os conjuntos de dados 21 a 31.

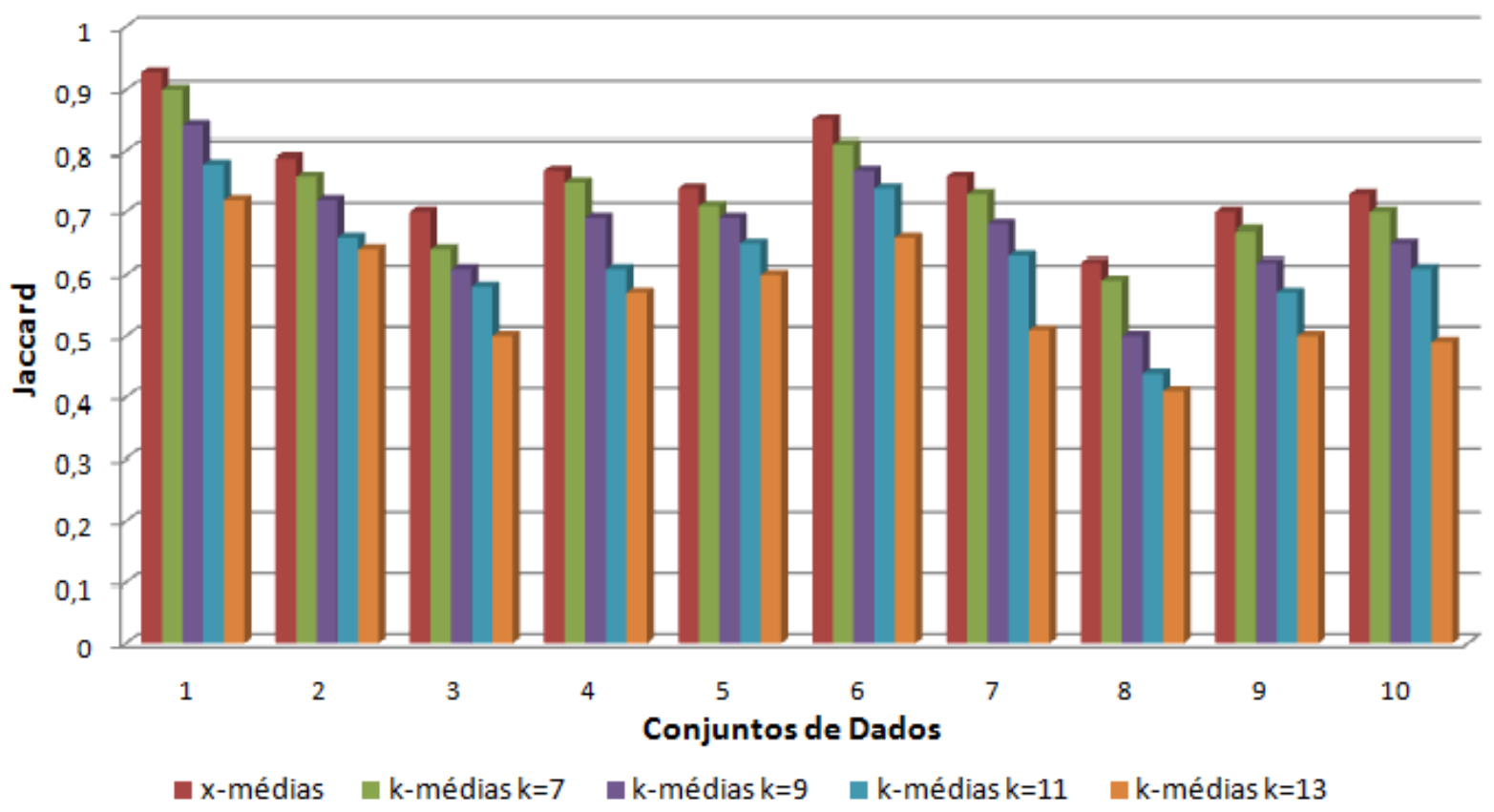

Figura 8.7: Gráfico com as médias do índice Jaccard obtidas com os mapas de saliência, para os conjuntos de dados 1 a 10.

ritmos de agrupamento consideram distintas as características destas expressões. Apenas é possivel observar sobreposição entre os exemplos de expressões que se distribuem entre mais de uma partição. No entanto, estes não interferem os demais exemplos que representam as emoções corretamente agrupadas. A Figura 8.10 apresenta a situação descrita. Ainda, com o aumento do número de partições, a separação ideal em sete não é encontrada, pois exemplos de uma mesma expressão muitas vezes são alocados em mais de uma partição.

Os resultados obtidos são comparados por meio dos testes estatísticos de Friedman e post-hoc de Nemenyi (Demsar, 2006). O teste de Friedman compara 


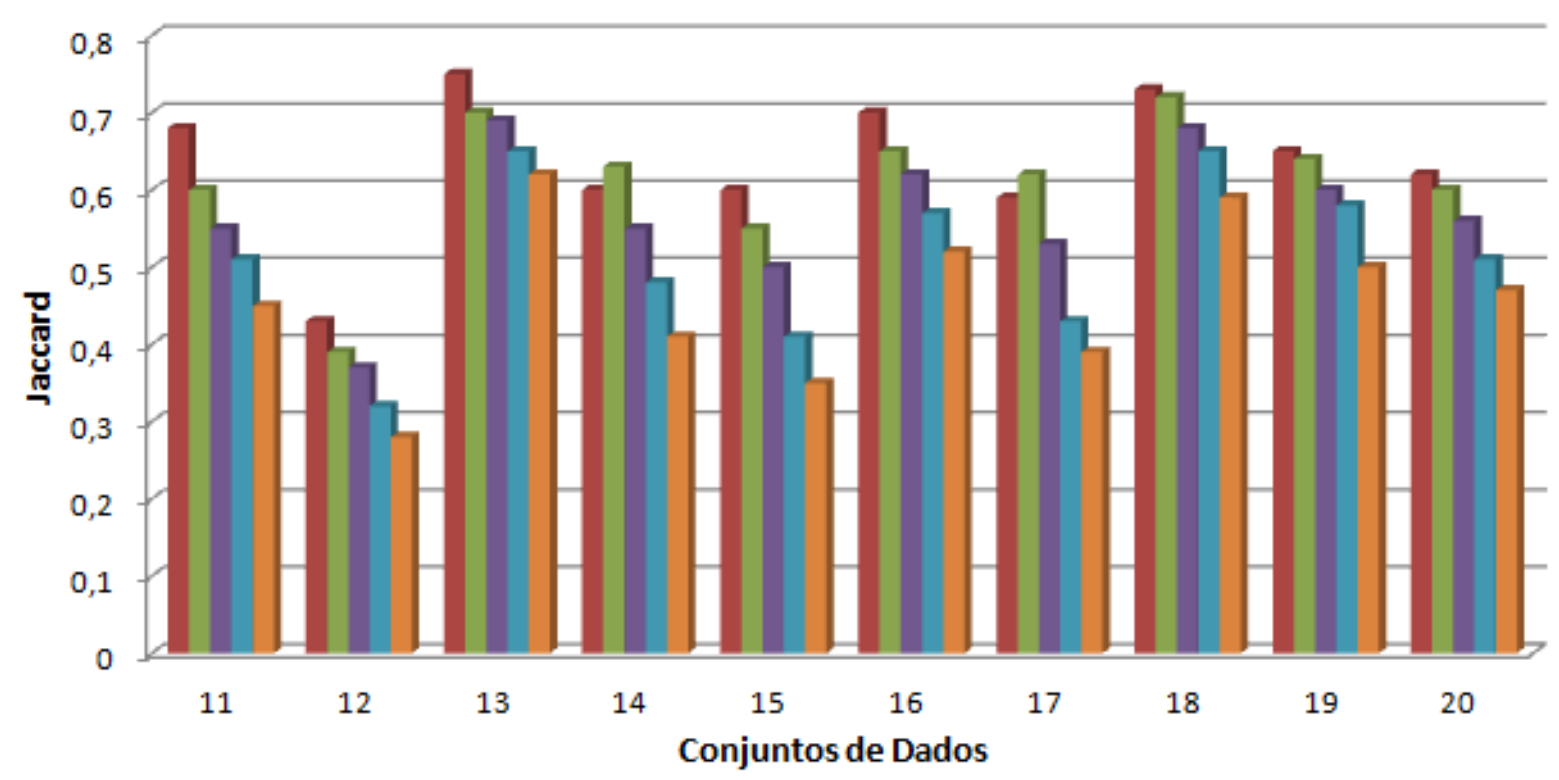

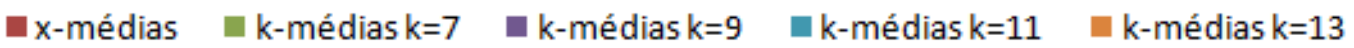

Figura 8.8: Gráfico com as médias do índice Jaccard obtidas com os mapas de saliência, para os conjuntos de dados 11 a 20.

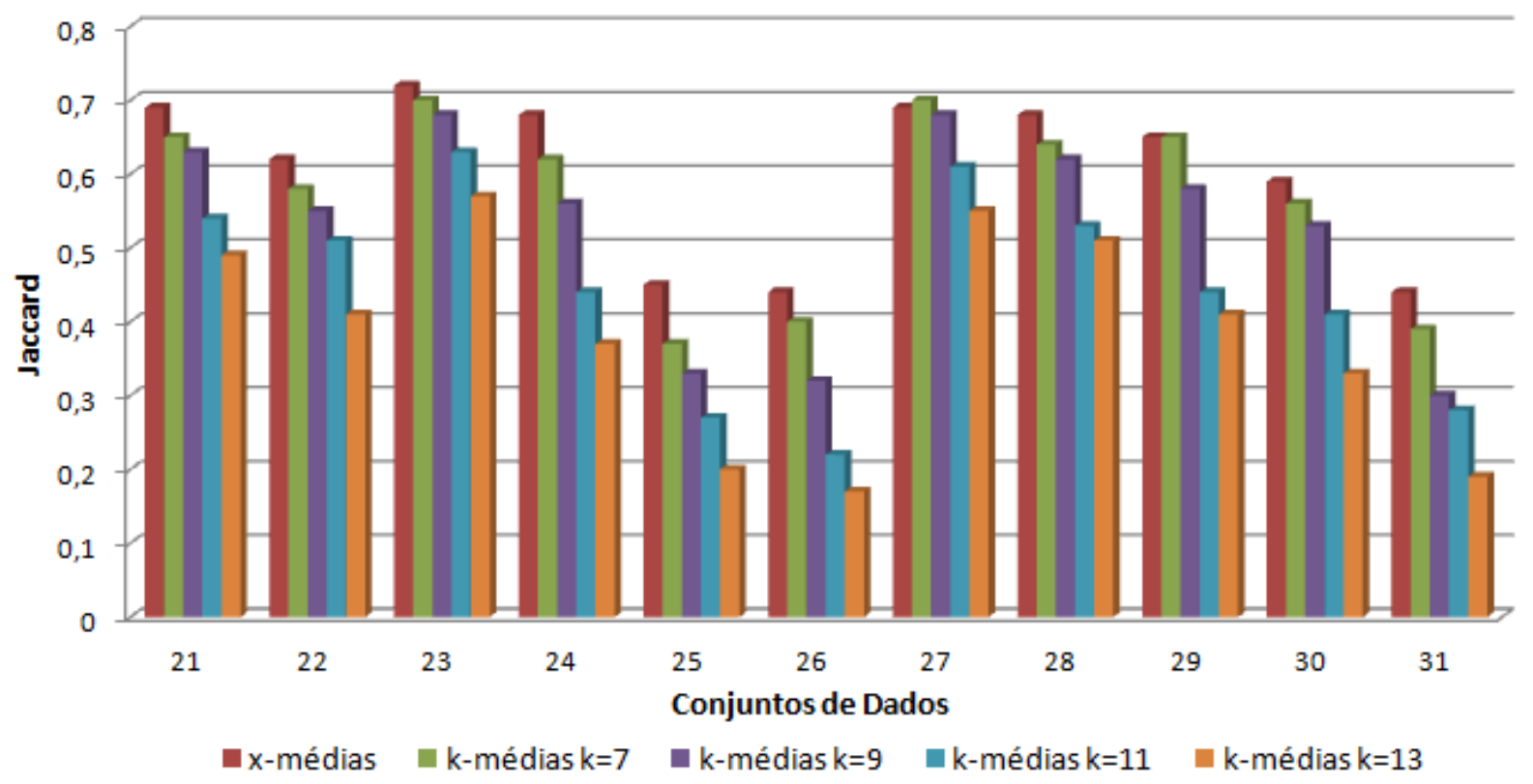

Figura 8.9: Gráfico com as médias do índice Jaccard obtidas com os mapas de saliência, para os conjuntos de dados 21 a 31 .

três ou mais grupos pareados de dados. Inicialmente, os algoritmos são ranqueados separadamente para cada conjunto de dados, sendo organizados do menor para o maior valor do ranqueamento obtido. No caso da existência de ranks com valores idênticos, ranks médios são associados a todos os algoritmos que apresentarem estes valores.

Seja $\mathrm{r}_{i}^{j}$ o valor do rank associado ao j-ésimo dos $k$ algoritmos no i-ésimo dos $N$ conjuntos de dados avaliados. O teste de Friedman compara os ranks médios de 


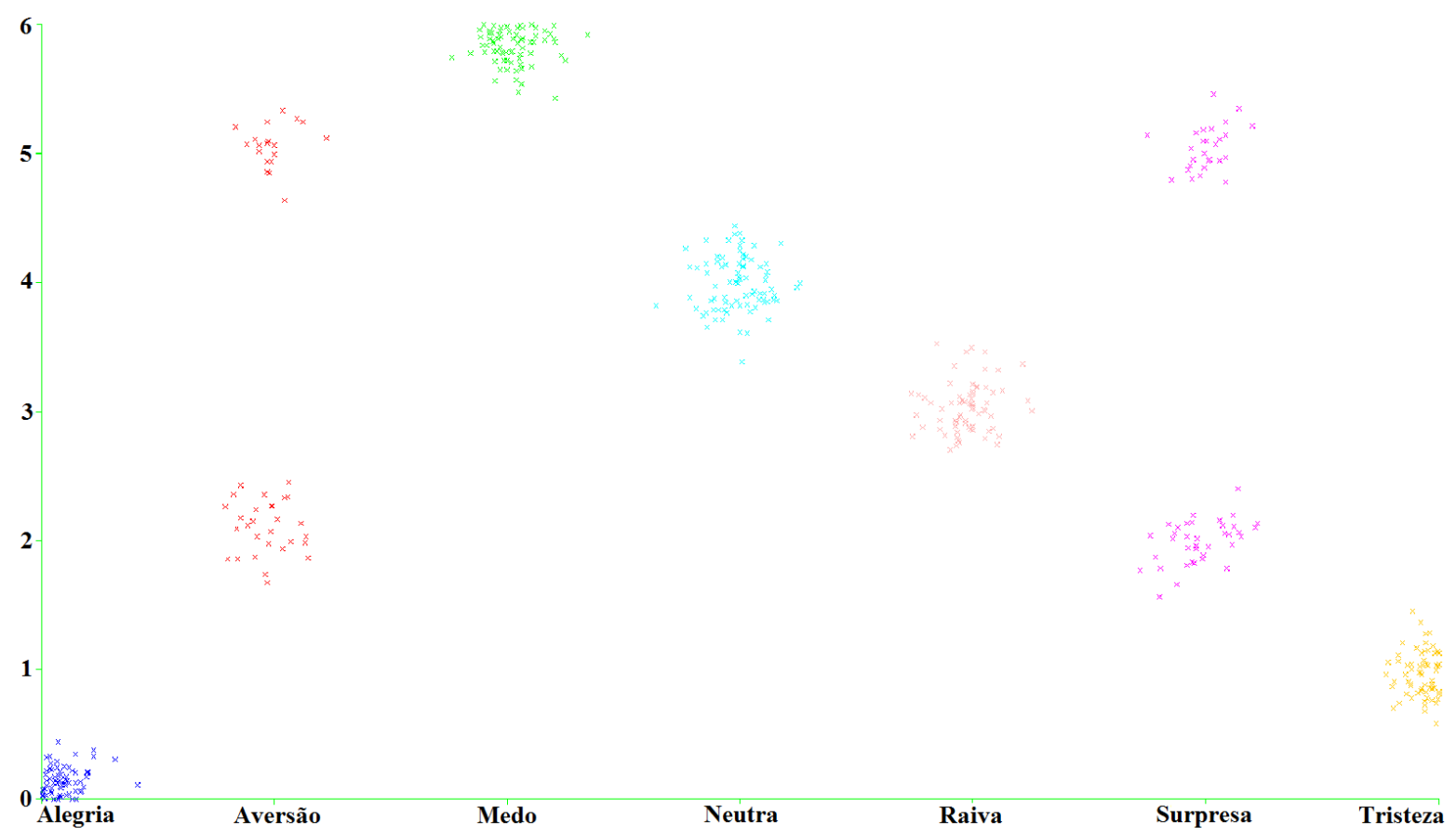

Figura 8.10: Exemplo típico dos agrupamentos obtidos, nota-se que apenas os exemplos incorretamente classificados ocupam partições iguais. No exemplo, a aversão é separada entre as partições de número 2 e 5, e seus exemplos apenas se sobrepõem aos exemplos que descrevem a surpresa, também incorretamente agrupada. A exceção é quando exemplos de uma mesma expressão estão distribuídos entre todas as partições existentes.

todos os algoritmos analisados, de acordo com a Equação 8.1.

$$
R_{j}=1 / N \sum_{i} r_{i}^{j}
$$

A hipótese nula afirma que, se todos os algoritmos analisados são equivalentes, então seus ranks médios $R_{j}$ devem ser iguais. Se a hipótese nula é rejeitada, ou seja, se os algoritmos analisados são estatisticamente diferentes, o teste post-hoc de Nemenyi é aplicado.

Inicialmente, com o objetivo de avaliar os algoritmos de agrupamento, o teste de Friedman, com grau de confiança de 95\%, é aplicado aos resultados apresentados nas tabelas 8.2 e 8.3. Nesta análise, a hipótese nula, que afirma que todos os algoritmos são equivalentes, é rejeitada, ou seja, de acordo com este teste, existem diferenças estatísticas entre os algoritmos investigados. Assim, é aplicado o teste post-hoc de Nemenyi, também com grau de confiança de 95\%, para analisar estas diferenças.

De acordo com os testes, para os índices silhueta e Jaccard, o algoritmo $\mathrm{x}$-médias é estatisticamente superior a todas as variações do algoritmo k-médias porém, para o valor de $k=7$, não é possível obter 95\% de confiança. Do mesmo modo, o k-médias com $k=7$ é estatisticamente superior às demais variações do k-médias, sem obter grau de confiança de 95\% apenas para a variação com $k=9$. 
A análise estatística é também aplicada aos resultados apresentados nas tabelas 8.2 e 8.3, mas agora com o objetivo de avaliar diferenças existentes entre os conjuntos de dados. Deste modo, as tabelas 8.4 e 8.5 apresentam, respectivamente, para os índices silhueta e Jaccard, as diferenças estatísticas encontradas. Nestas tabelas, e em todas as subsequentes que apresentam análises estatísticas, - indica que o teste é ignorado (representa posições da tabela que a aplicação do teste resultaria em comparar o algoritmo com ele mesmo), $\mathbf{\square}$ indica que nenhuma diferença estatística é encontrada, resultados inferiores são representados por $\mathbf{\nabla}$, e resultados superiores são representados por $\mathbf{\Lambda}$.

Tabela 8.4: Comparação estatística entre os conjuntos de dados utilizados, considerando o índice silhueta e os mapas de saliência.

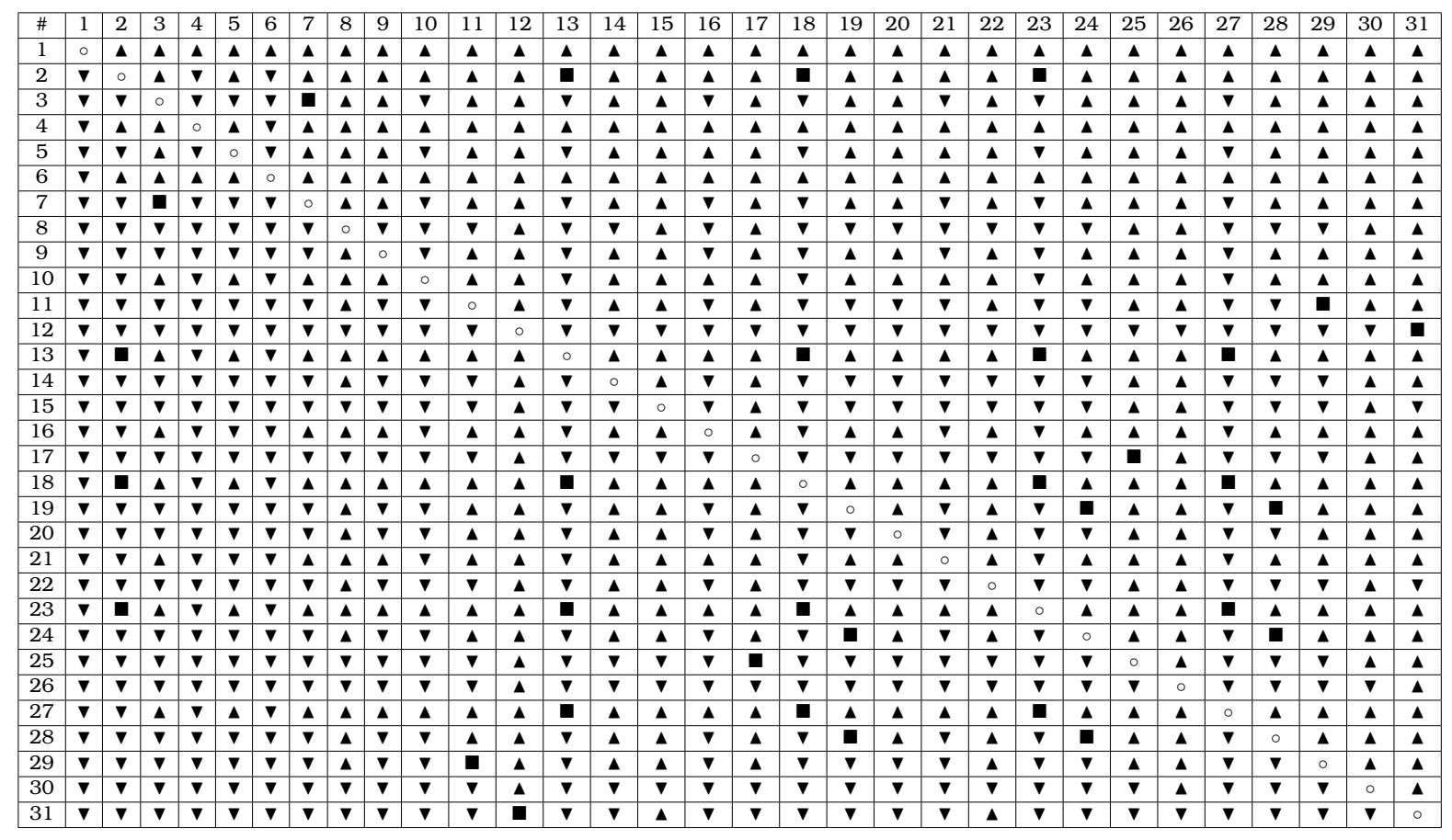

De acordo com estas tabelas, é possivel observar que o conjunto de dados 1, que representa o mapa de entropia obtido a partir das imagens de saliência, é estatisticamente superior a todos os demais. Do mesmo modo, o conjunto 6, que contém informações da entropia e do desvio-padrão, é também estatisticamente superior aos demais, com exceção do conjunto 1. Em seguida, é observada uma certa divergência entre os resultados apresentados pelas tabelas, ou seja, o conjunto 4, com os descritores do método HOG, é o terceiro melhor conjunto encontrado de acordo com o índice silhueta, que avalia a qualidade das partições. Em contrapartida, o índice Jaccard, que obtém a proximidade do agrupamento produzido com a classificação real dos dados, indica o conjunto 2, com informações sobre o desvio-padrão, como o terceiro melhor conjunto de dados obtido para representar as expressões faciais emocionais. 
Tabela 8.5: Comparação estatística entre os conjuntos de dados utilizados, considerando o índice Jaccard e os mapas de saliência.

\begin{tabular}{|c|c|c|c|c|c|c|c|c|c|c|c|c|c|c|c|c|c|c|c|c|c|c|c|c|c|c|c|c|c|c|c|}
\hline \# & 1 & 2 & 3 & 4 & 5 & 6 & 7 & 8 & 9 & 10 & 11 & 12 & 13 & 14 & 15 & 16 & 17 & 18 & 19 & 20 & 21 & 22 & 23 & 24 & 25 & 26 & 27 & 28 & 29 & 30 & 31 \\
\hline 1 & $\circ$ & $\Delta$ & $\Delta$ & $\Delta$ & $\Delta$ & $\Delta$ & $\Delta$ & $\Delta$ & $\Delta$ & $\Delta$ & $\Delta$ & $\Delta$ & $\Delta$ & $\Delta$ & $\Delta$ & $\boldsymbol{\Delta}$ & $\Delta$ & $\Delta$ & $\Delta$ & $\Delta$ & $\boldsymbol{\Delta}$ & $\Delta$ & $\boldsymbol{\Delta}$ & $\Delta$ & $\Delta$ & $\Delta$ & $\Delta$ & $\Delta$ & $\Delta$ & $\Delta$ & $\Delta$ \\
\hline 2 & $\nabla$ & $\circ$ & $\Delta$ & $\Delta$ & $\Delta$ & $\nabla$ & $\Delta$ & $\Delta$ & $\Delta$ & $\Delta$ & $\Delta$ & $\Delta$ & $\Delta$ & $\Delta$ & $\Delta$ & $\Delta$ & $\Delta$ & $\Delta$ & $\Delta$ & $\Delta$ & $\Delta$ & 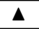 & $\Delta$ & $\Delta$ & $\Delta$ & $\Delta$ & $\Delta$ & $\Delta$ & $\Delta$ & $\Delta$ & 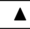 \\
\hline 3 & $\nabla$ & $\nabla$ & $\circ$ & $\nabla$ & $\nabla$ & $\nabla$ & $\nabla$ & $\Delta$ & $\nabla$ & $\nabla$ & $\Delta$ & $\Delta$ & $\nabla$ & $\Delta$ & $\Delta$ & $\nabla$ & $\Delta$ & $\nabla$ & 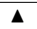 & $\Delta$ & $\square$ & $\Delta$ & $\boldsymbol{\nabla}$ & $\Delta$ & $\Delta$ & $\Delta$ & $\boldsymbol{\nabla}$ & $\Delta$ & $\Delta$ & $\Delta$ & $\Delta$ \\
\hline 4 & $\nabla$ & $\nabla$ & $\Delta$ & $\circ$ & $\square$ & $\nabla$ & 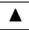 & $\Delta$ & $\Delta$ & $\Delta$ & $\Delta$ & $\Delta$ & $\square$ & $\Delta$ & $\Delta$ & 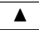 & $\Delta$ & $\Delta$ & 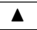 & $\Delta$ & $\Delta$ & $\Delta$ & $\boldsymbol{\Delta}$ & 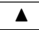 & 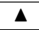 & $\Delta$ & $\Delta$ & $\Delta$ & $\Delta$ & $\Delta$ & 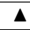 \\
\hline 5 & $\nabla$ & $\nabla$ & $\Delta$ & $\square$ & $\circ$ & $\nabla$ & 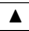 & $\Delta$ & $\Delta$ & $\Delta$ & $\Delta$ & $\Delta$ & $\square$ & $\Delta$ & $\Delta$ & 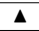 & $\Delta$ & 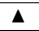 & $\Delta$ & $\Delta$ & $\Delta$ & $\Delta$ & $\Delta$ & $\Delta$ & $\Delta$ & $\Delta$ & $\Delta$ & 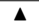 & $\Delta$ & $\Delta$ & $\Delta$ \\
\hline 6 & $\nabla$ & 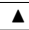 & $\Delta$ & $\Delta$ & $\Delta$ & $\circ$ & 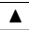 & $\Delta$ & $\Delta$ & $\Delta$ & $\Delta$ & $\Delta$ & $\Delta$ & $\Delta$ & $\Delta$ & $\Delta$ & $\Delta$ & $\Delta$ & $\overline{\Delta \Delta}$ & $\Delta$ & $\Delta$ & $\Delta$ & 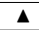 & $\Delta$ & $\Delta$ & $\Delta$ & 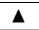 & $\Delta$ & $\Delta$ & $\Delta$ & $\Delta$ \\
\hline 7 & $\nabla$ & $\nabla$ & $\Delta$ & $\nabla$ & $\nabla$ & $\nabla$ & $\circ$ & $\Delta$ & $\Delta$ & $\Delta$ & $\Delta$ & $\Delta$ & $\nabla$ & $\Delta$ & $\Delta$ & $\Delta$ & $\Delta$ & $\nabla$ & $\Delta$ & $\Delta$ & $\Delta$ & $\Delta$ & $\Delta$ & $\Delta$ & $\Delta$ & $\Delta$ & $\Delta$ & $\Delta$ & $\Delta$ & $\Delta$ & 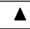 \\
\hline 8 & $\nabla$ & $\nabla$ & $\nabla$ & $\nabla$ & $\nabla$ & $\nabla$ & $\nabla$ & $\circ$ & $\nabla$ & $\nabla$ & $\nabla$ & $\Delta$ & $\nabla$ & $\nabla$ & $\Delta$ & $\nabla$ & $\Delta$ & $\nabla$ & $\nabla$ & $\nabla$ & $\nabla$ & $\nabla$ & $\nabla$ & $\nabla$ & $\Delta$ & $\Delta$ & $\nabla$ & $\nabla$ & $\nabla$ & $\Delta$ & $\Delta$ \\
\hline 9 & $\nabla$ & $\nabla$ & $\Delta$ & $\nabla$ & $\nabla$ & $\nabla$ & $\nabla$ & $\Delta$ & $\circ$ & $\nabla$ & $\Delta$ & $\Delta$ & $\nabla$ & $\Delta$ & $\Delta$ & $\nabla$ & $\Delta$ & $\nabla$ & $\Delta$ & $\Delta$ & $\Delta$ & $\Delta$ & $\nabla$ & $\Delta$ & $\Delta$ & $\Delta$ & $\nabla$ & $\Delta$ & $\Delta$ & $\Delta$ & $\Delta$ \\
\hline 10 & $\nabla$ & $\nabla$ & $\Delta$ & $\nabla$ & $\nabla$ & $\nabla$ & $\nabla$ & $\Delta$ & $\Delta$ & $\circ$ & $\Delta$ & $\Delta$ & $\nabla$ & $\Delta$ & $\Delta$ & $\Delta$ & $\Delta$ & $\nabla$ & $\Delta$ & $\Delta$ & $\Delta$ & $\Delta$ & $\nabla$ & $\Delta$ & $\Delta$ & $\Delta$ & $\nabla$ & $\Delta$ & $\Delta$ & $\Delta$ & $\Delta$ \\
\hline 11 & $\nabla$ & $\nabla$ & $\nabla$ & $\nabla$ & $\nabla$ & $\nabla$ & $\nabla$ & $\Delta$ & $\nabla$ & $\nabla$ & $\circ$ & $\Delta$ & $\nabla$ & $\Delta$ & $\Delta$ & $\nabla$ & $\Delta$ & $\nabla$ & $\nabla$ & [ & $\nabla$ & $\Delta$ & $\nabla$ & $\Delta$ & $\Delta$ & $\Delta$ & $\nabla$ & $\nabla$ & $\nabla$ & $\Delta$ & $\Delta$ \\
\hline 12 & $\nabla$ & $\nabla$ & $\nabla$ & $\nabla$ & $\nabla$ & $\nabla$ & $\nabla$ & $\nabla$ & $\nabla$ & $\nabla$ & $\nabla$ & $\circ$ & $\nabla$ & $\nabla$ & $\nabla$ & $\nabla$ & $\nabla$ & $\nabla$ & $\nabla$ & $\nabla$ & $\nabla$ & $\nabla$ & $\nabla$ & $\nabla$ & $\Delta$ & $\Delta$ & $\nabla$ & $\nabla$ & $\nabla$ & $\nabla$ & $\Delta$ \\
\hline 13 & $\nabla$ & $\nabla$ & 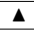 & 口 & E & $\nabla$ & 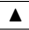 & $\Delta$ & $\Delta$ & $\Delta$ & $\Delta$ & $\Delta$ & $\circ$ & $\Delta$ & $\Delta$ & $\Delta$ & $\Delta$ & $\Delta$ & $\Delta$ & $\Delta$ & $\Delta$ & $\Delta$ & $\Delta$ & $\Delta$ & $\Delta$ & $\Delta$ & $\Delta$ & $\Delta$ & $\Delta$ & $\Delta$ & 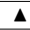 \\
\hline 14 & $\nabla$ & $\nabla$ & $\nabla$ & $\nabla$ & $\nabla$ & $\nabla$ & $\nabla$ & $\Delta$ & $\nabla$ & $\nabla$ & $\nabla$ & $\Delta$ & $\nabla$ & $\circ$ & $\Delta$ & $\nabla$ & $\Delta$ & $\nabla$ & $\nabla$ & $\nabla$ & $\nabla$ & $\square$ & $\nabla$ & $\nabla$ & $\Delta$ & $\Delta$ & $\nabla$ & $\nabla$ & $\nabla$ & $\Delta$ & $\Delta$ \\
\hline 15 & $\nabla$ & $\nabla$ & $\nabla$ & $\nabla$ & $\nabla$ & $\nabla$ & $\nabla$ & $\nabla$ & $\nabla$ & $\nabla$ & $\nabla$ & $\Delta$ & $\nabla$ & $\nabla$ & $\circ$ & $\nabla$ & $\nabla$ & $\nabla$ & $\nabla$ & $\nabla$ & $\nabla$ & $\nabla$ & $\boldsymbol{\nabla}$ & $\nabla$ & $\Delta$ & $\Delta$ & $\nabla$ & $\nabla$ & $\nabla$ & 口 & 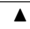 \\
\hline 16 & $\nabla$ & $\nabla$ & $\Delta$ & $\nabla$ & $\nabla$ & $\nabla$ & $\nabla$ & $\Delta$ & $\Delta$ & $\nabla$ & $\Delta$ & $\Delta$ & $\nabla$ & $\Delta$ & $\Delta$ & $\circ$ & $\Delta$ & $\nabla$ & $\Delta$ & $\Delta$ & $\Delta$ & $\Delta$ & $\nabla$ & $\Delta$ & $\Delta$ & $\Delta$ & $\nabla$ & $\Delta$ & $\Delta$ & $\Delta$ & 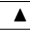 \\
\hline 17 & $\boldsymbol{\nabla}$ & $\boldsymbol{\nabla}$ & $\nabla$ & $\nabla$ & $\boldsymbol{\nabla}$ & $\nabla$ & $\nabla$ & $\nabla$ & $\nabla$ & $\boldsymbol{\nabla}$ & $\nabla$ & $\Delta$ & $\nabla$ & $\boldsymbol{\nabla}$ & $\Delta$ & $\nabla$ & $\circ$ & $\nabla$ & $\boldsymbol{\nabla}$ & $\boldsymbol{\nabla}$ & $\boldsymbol{\nabla}$ & $\nabla$ & $\boldsymbol{\nabla}$ & $\nabla$ & $\Delta$ & $\Delta$ & $\boldsymbol{\nabla}$ & $\nabla$ & $\nabla$ & $\Delta$ & 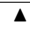 \\
\hline 18 & $\nabla$ & $\nabla$ & $\Delta$ & $\nabla$ & $\nabla$ & $\nabla$ & $\Delta$ & $\Delta$ & $\Delta$ & $\Delta$ & $\Delta$ & $\Delta$ & $\nabla$ & $\Delta$ & $\Delta$ & $\Delta$ & $\Delta$ & $\circ$ & $\Delta$ & $\Delta$ & $\Delta$ & $\Delta$ & 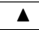 & $\Delta$ & $\Delta$ & $\Delta$ & $\Delta$ & $\Delta$ & $\Delta$ & $\Delta$ & 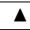 \\
\hline 19 & $\nabla$ & $\nabla$ & $\nabla$ & $\nabla$ & $\nabla$ & $\nabla$ & $\nabla$ & $\Delta$ & $\nabla$ & $\nabla$ & $\Delta$ & $\Delta$ & $\nabla$ & 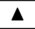 & $\Delta$ & $\nabla$ & $\Delta$ & $\nabla$ & $\circ$ & $\Delta$ & $\nabla$ & $\Delta$ & $\nabla$ & $\Delta$ & $\Delta$ & $\Delta$ & $\nabla$ & $\nabla$ & $\Delta$ & $\Delta$ & $\Delta$ \\
\hline 20 & $\nabla$ & $\nabla$ & $\nabla$ & $\nabla$ & $\nabla$ & $\nabla$ & $\nabla$ & $\Delta$ & $\nabla$ & $\nabla$ & $\square$ & $\Delta$ & $\nabla$ & $\Delta$ & $\Delta$ & $\nabla$ & $\Delta$ & $\nabla$ & $\nabla$ & $\circ$ & $\nabla$ & $\Delta$ & $\nabla$ & $\Delta$ & $\Delta$ & $\Delta$ & $\nabla$ & $\nabla$ & $\nabla$ & $\Delta$ & $\Delta$ \\
\hline 21 & $\nabla$ & $\nabla$ & $\square$ & $\nabla$ & $\nabla$ & $\nabla$ & $\nabla$ & $\Delta$ & $\nabla$ & $\nabla$ & $\Delta$ & $\Delta$ & $\nabla$ & $\Delta$ & $\Delta$ & $\nabla$ & $\Delta$ & $\nabla$ & $\Delta$ & $\Delta$ & $\circ$ & $\Delta$ & $\nabla$ & $\Delta$ & $\Delta$ & $\Delta$ & $\nabla$ & $\Delta$ & $\Delta$ & $\Delta$ & $\Delta$ \\
\hline 22 & $\nabla$ & $\nabla$ & $\nabla$ & $\nabla$ & $\nabla$ & $\nabla$ & $\nabla$ & $\Delta$ & $\nabla$ & $\nabla$ & $\nabla$ & $\Delta$ & $\nabla$ & $\square$ & $\Delta$ & $\nabla$ & $\Delta$ & $\nabla$ & $\nabla$ & $\nabla$ & $\nabla$ & $\circ$ & $\nabla$ & $\nabla$ & $\Delta$ & $\Delta$ & $\nabla$ & $\nabla$ & $\nabla$ & $\Delta$ & $\Delta$ \\
\hline 23 & $\nabla$ & $\nabla$ & $\boldsymbol{\Delta}$ & $\nabla$ & $\nabla$ & $\nabla$ & $\nabla$ & $\Delta$ & $\Delta$ & $\Delta$ & $\Delta$ & 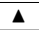 & $\nabla$ & $\Delta$ & $\Delta$ & 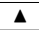 & $\Delta$ & $\nabla$ & 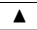 & $\Delta$ & 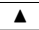 & $\Delta$ & $\circ$ & $\Delta$ & $\Delta$ & $\Delta$ & $\Delta$ & $\Delta$ & $\Delta$ & $\Delta$ & $\Delta$ \\
\hline 24 & $\nabla$ & $\nabla$ & $\nabla$ & $\nabla$ & $\nabla$ & $\nabla$ & $\nabla$ & $\Delta$ & $\nabla$ & $\nabla$ & $\nabla$ & $\Delta$ & $\nabla$ & $\Delta$ & $\Delta$ & $\nabla$ & $\Delta$ & $\nabla$ & $\nabla$ & $\nabla$ & $\nabla$ & $\Delta$ & $\nabla$ & $\circ$ & $\Delta$ & $\Delta$ & $\nabla$ & $\nabla$ & $\nabla$ & $\Delta$ & $\Delta$ \\
\hline 25 & $\nabla$ & $\nabla$ & $\nabla$ & $\nabla$ & $\nabla$ & $\nabla$ & $\nabla$ & $\nabla$ & $\nabla$ & $\nabla$ & $\nabla$ & $\nabla$ & $\nabla$ & $\nabla$ & $\nabla$ & $\nabla$ & $\nabla$ & $\nabla$ & $\nabla$ & $\nabla$ & $\nabla$ & $\nabla$ & $\nabla$ & $\nabla$ & $\circ$ & $\Delta$ & $\nabla$ & $\nabla$ & $\nabla$ & $\nabla$ & $\square$ \\
\hline 26 & $\nabla$ & $\nabla$ & $\nabla$ & $\nabla$ & $\nabla$ & $\nabla$ & $\nabla$ & $\nabla$ & $\nabla$ & $\nabla$ & $\nabla$ & $\mathbf{\nabla}$ & $\nabla$ & $\nabla$ & $\nabla$ & $\nabla$ & $\mathbf{\nabla}$ & $\nabla$ & $\nabla$ & $\nabla$ & $\nabla$ & $\nabla$ & $\nabla$ & $\nabla$ & $\nabla$ & $\circ$ & $\nabla$ & $\nabla$ & $\nabla$ & $\nabla$ & $\square$ \\
\hline 27 & $\nabla$ & $\nabla$ & $\Delta$ & $\nabla$ & $\nabla$ & $\nabla$ & $\nabla$ & $\Delta$ & $\Delta$ & $\Delta$ & $\Delta$ & $\Delta$ & $\nabla$ & $\Delta$ & $\Delta$ & $\Delta$ & $\Delta$ & $\nabla$ & $\Delta$ & $\Delta$ & $\Delta$ & $\Delta$ & $\nabla$ & $\Delta$ & $\Delta$ & $\Delta$ & $\circ$ & $\Delta$ & $\Delta$ & $\Delta$ & $\Delta$ \\
\hline 28 & $\nabla$ & $\nabla$ & $\nabla$ & $\nabla$ & $\nabla$ & $\nabla$ & $\nabla$ & $\Delta$ & $\nabla$ & $\nabla$ & $\Delta$ & $\Delta$ & $\nabla$ & $\Delta$ & $\Delta$ & $\nabla$ & $\Delta$ & $\nabla$ & $\Delta$ & $\Delta$ & $\nabla$ & $\Delta$ & $\boldsymbol{\nabla}$ & $\Delta$ & $\Delta$ & $\Delta$ & $\nabla$ & $\circ$ & $\Delta$ & $\Delta$ & $\Delta$ \\
\hline 29 & $\nabla$ & $\nabla$ & $\nabla$ & $\nabla$ & $\nabla$ & $\nabla$ & $\nabla$ & $\Delta$ & $\nabla$ & $\nabla$ & $\Delta$ & $\Delta$ & $\nabla$ & 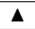 & $\Delta$ & $\nabla$ & $\Delta$ & $\nabla$ & $\nabla$ & $\Delta$ & $\nabla$ & $\Delta$ & $\nabla$ & $\Delta$ & $\Delta$ & $\Delta$ & $\nabla$ & $\nabla$ & $\circ$ & $\Delta$ & 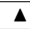 \\
\hline 30 & $\nabla$ & $\nabla$ & $\nabla$ & $\nabla$ & $\nabla$ & $\nabla$ & $\nabla$ & $\nabla$ & $\nabla$ & $\nabla$ & $\nabla$ & $\Delta$ & $\nabla$ & $\nabla$ & $\square$ & $\nabla$ & $\nabla$ & $\nabla$ & $\nabla$ & $\nabla$ & $\nabla$ & $\nabla$ & $\nabla$ & $\nabla$ & $\Delta$ & $\Delta$ & $\nabla$ & $\nabla$ & $\nabla$ & $\circ$ & $\Delta$ \\
\hline 31 & $\nabla$ & $\nabla$ & $\nabla$ & $\nabla$ & $\nabla$ & $\nabla$ & $\nabla$ & $\nabla$ & $\nabla$ & $\boldsymbol{\nabla}$ & $\nabla$ & $\boldsymbol{\nabla}$ & $\nabla$ & $\nabla$ & $\nabla$ & $\nabla$ & $\nabla$ & $\nabla$ & $\nabla$ & $\nabla$ & $\nabla$ & $\nabla$ & $\nabla$ & $\nabla$ & $\mathbf{\square}$ & $\mathbf{\square}$ & $\nabla$ & $\nabla$ & $\nabla$ & $\nabla$ & $\circ$ \\
\hline
\end{tabular}

Uma vez que os dois índices investigam características diferentes sobre os agrupamentos produzidos, é natural serem encontradas algumas divergências entre os resultados encontrados sem, no entanto, torná-los incoerentes.

Os resultados obtidos com as imagens térmicas podem ser vistos, respectivamente, para os índices silhueta e Jaccard, nas tabelas 8.6 e 8.7, em que são apresentadas as médias das 30 execuções dos algoritmos de agrupamento. Como observado na análise dos mapas de saliência, os resultados variam para cada conjunto de dados. Vale destacar que, nestes novos experimentos, o algoritmo x-médias também seleciona sete partições, a mesma quantidade de classes que descreve os dados reais, em todas as suas execuções.

Os gráficos $8.11,8.12$ e 8.13 , e os gráficos $8.14,8.15$ e 8.16, facilitam a análise dos resultados apresentados, respectivamente, nas tabelas 8.6 e 8.7. Neles é possível observar, para os diferentes conjuntos de dados, as execuções dos distintos algoritmos de agrupamento utilizados.

Os diversos conjuntos de dados analisados resultam em diferentes qualidades para os agrupamentos obtidos mas, como já observado, agrupamentos com sete partições conferem as melhores qualidades. Deste modo, os gráficos evidenciam que a divisão dos dados em uma maior quantidade de partições faz com que as médias dos índices silhueta e Jaccard sejam inferiores. Entretanto, as características utilizadas para representar as seis emoções básicas e a expressão neutra influenciam fortemente o reconhecimento emocional, ou seja, o simples fato de serem 
Tabela 8.6: Valores das médias obtidas para o índice silhueta com as imagens térmicas, para os diferentes conjuntos de dados avaliados.

\begin{tabular}{|c|c|c|c|c|c|}
\hline \multirow{2}{*}{$\begin{array}{c}\text { Conjuntos } \\
\text { de } \\
\text { Dados }\end{array}$} & \multicolumn{5}{|c|}{ Algoritmos } \\
\hline & x-médias & $\begin{array}{c}\text { k-médias } \\
k=7\end{array}$ & $\begin{array}{c}\text { k-médias } \\
k=9\end{array}$ & $\begin{array}{c}\text { k-médias } \\
k=11\end{array}$ & $\begin{array}{c}\text { k-médias } \\
k=13\end{array}$ \\
\hline 1 & $0,80_{-}^{+} 0,01$ & $0,79_{-}^{+} 0,02$ & $0,74_{-}^{+} 0,01$ & $0,69_{-}^{+} 0,04$ & $0,65_{-}^{+} 0,04$ \\
\hline 2 & $, 60_{-}^{+} 0,01$ & $0,62_{-}^{+} 0,01$ & $0,57_{-}^{+} 0,02$ & $0,48_{-}^{+} 0,03$ & $0,44_{-}^{+} 0,02$ \\
\hline 3 & $67_{-}^{+} 0,02$ & $0,64_{-}^{+} 0,02$ & $0,55_{-}^{+} 0,02$ & $0,50_{-}^{+} 0,03$ & $0,46_{-}^{+} 0,02$ \\
\hline 4 & $0,95_{-}^{+} 0,02$ & $0,93_{-}^{+} 0,01$ & $0,89_{-}^{+} 0,02$ & $0,84_{-}^{+} 0,02$ & $0,81_{-}^{+} 0,02$ \\
\hline 5 & $0,63_{-}^{+} 0,01$ & $0,59_{-}^{+} 0,03$ & $0,53_{-}^{+} 0,02$ & $0,46_{-}^{+} 0,03$ & $0,40_{-}^{+} 0,05$ \\
\hline 6 & $0,60_{-}^{+} 0,02$ & $0,59_{-}^{+} 0,01$ & $0,56_{-}^{+} 0,03$ & $0,46_{-}^{+} 0,03$ & $0,39_{-}^{+} 0,04$ \\
\hline 7 & $0,61_{-}^{+} 0,03$ & $0,55_{-}^{+} 0,02$ & $0,50_{-}^{+} 0,03$ & $0,43_{-}^{+} 0,04$ & $0,35_{-}^{+} 0,05$ \\
\hline 8 & $0,55_{-}^{+} 0,02$ & $0,53_{-}^{+} 0,02$ & $0,48_{-}^{+} 0,03$ & $0,42_{-}^{+} 0,05$ & $0,33_{-}^{+} 0,04$ \\
\hline 9 & $0,68_{-}^{+} 0,01$ & $0,70_{-}^{+} 0,01$ & $0,65_{-}^{+} 0,04$ & $0,58_{-}^{+} 0,03$ & $0,54_{-}^{+} 0,04$ \\
\hline 10 & $, 97_{-}^{+} 0,01$ & $0,95_{-}^{+} 0,02$ & $0,91_{-}^{+} 0,02$ & $0,84_{-}^{+} 0,03$ & $0,82_{-}^{+} 0,03$ \\
\hline 11 & $0,56_{-0,02}^{+}$ & $0,53_{-}^{+} 0,03$ & $0,45_{-}^{+} 0,02$ & $0,39_{-0,04}^{+}$ & $0,31_{-0,04}^{+}$ \\
\hline 12 &, $79_{-0,01}^{+}$ & $0,77_{-}^{+} 0,02$ & $0,74_{-}^{+} 0,03$ & $0,70_{-}^{+} 0,05$ & $0,69_{-0,07}^{+}$ \\
\hline 13 & $0,45_{-0,02}^{+}$ & $0,42_{-}^{+} 0,02$ & $0,35_{-}^{+} 0,04$ & $0,28_{-}^{+} 0,04$ & $0,22_{-}^{+} 0,06$ \\
\hline 14 & $0,74_{-}^{+} 0,02$ & $0,70_{-}^{+} 0,03$ & $0,67_{-}^{+} 0,03$ & $0,59_{-}^{+} 0,06$ & $0,55_{-}^{+} 0,05$ \\
\hline 15 & $0,71_{-}^{+} 0,01$ & $0,67_{-}^{+} 0,02$ & $0,62_{-}^{+} 0,03$ & $0,57_{-}^{+} 0,04$ & $0,56_{-}^{+} 0,04$ \\
\hline 16 & $0,66_{-}^{+} 0,02$ & $0,62_{-}^{+} 0,02$ & $0,59_{-}^{+} 0,03$ & $0,51_{-}^{+} 0,04$ & $0,49_{-}^{+} 0,03$ \\
\hline 17 & $0,75_{-}^{+} 0,01$ & $0,76_{-}^{+} 0,02$ & $0,69_{-}^{+} 0,04$ & $0,63_{-0,04}^{+}$ & $0,63_{-}^{+} 0,06$ \\
\hline 18 & $0,55_{-0,02}^{+}$ & $0,52_{-}^{+} 0,03$ & $0,50_{-}^{+} 0,03$ & $0,46_{-0,04}^{+}$ & $0,40_{-}^{+} 0,06$ \\
\hline 19 & $0,48_{-}^{+} 0,03$ & $0,48_{-}^{+} 0,02$ & $0,43_{-0,05}^{+}$ & $0,38_{-0,05}^{+}$ & $0,30_{-}^{+} 0,07$ \\
\hline 20 & $0,51_{-0,01}^{+}$ & $0,50_{-}^{+} 0,02$ & $0,45_{-}^{+} 0,02$ & $0,40_{-}^{+} 0,06$ & $0,36_{-}^{+} 0,05$ \\
\hline 21 & $0,63_{-0,02}^{+}$ & $0,63_{-0,01}^{+}$ & $0,59_{-}^{+} 0,03$ & $0,54_{-}^{+} 0,04$ & $0,50_{-0,05}^{+}$ \\
\hline 22 & $0,57_{-}^{+} 0,02$ & $0,54_{-}^{+} 0,02$ & $0,46_{-}^{+} 0,04$ & $0,42_{-}^{+} 0,05$ & $0,38_{-}^{+} 0,03$ \\
\hline 23 & $0,60_{-}^{+} 0,01$ & $0,60_{-}^{+} 0,02$ & $0,51_{-}^{+} 0,08$ & $0,46_{-}^{+} 0,06$ & $0,43_{-0,04}^{+}$ \\
\hline 24 & $0,75_{-}^{+} 0,02$ & $0,78_{-}^{+} 0,01$ & $0,73_{-}^{+} 0,05$ & $0,67_{-}^{+} 0,03$ & $0,66_{-}^{+} 0,04$ \\
\hline 25 & $0,85_{-}^{+} 0,02$ & $0,81_{-}^{+} 0,02$ & $0,77_{-}^{+} 0,04$ & $0,74_{-}^{+} 0,02$ & $0,69_{-0,05}^{+}$ \\
\hline 26 & $0,80_{-}^{+} 0,03$ & $0,80_{-}^{+} 0,01$ & $0,76_{-}^{+} 0,02$ & $0,70_{-}^{+} 0,05$ & $0,66_{-}^{+} 0,04$ \\
\hline 27 & $0,40_{-}^{+} 0,03$ & $0,44_{-}^{+} 0,02$ & $0,37_{-}^{+} 0,03$ & $0,31_{-}^{+} 0,05$ & $0,26_{-}^{+} 0,07$ \\
\hline 28 & $0,70_{-}^{+} 0,02$ & $0,68_{-}^{+} 0,01$ & $0,65_{-}^{+} 0,04$ & $0,60_{-}^{+} 0,04$ & $0,57_{-}^{+} 0,04$ \\
\hline 29 & $0,65_{-}^{+} 0,01$ & $0,68_{-}^{+} 0,02$ & $0,62_{-}^{+} 0,02$ & $0,57_{-}^{+} 0,05$ & $0,50_{-}^{+} 0,06$ \\
\hline 30 & $0,56_{-}^{+} 0,02$ & $0,53_{-}^{+} 0,03$ & $0,49_{-}^{+} 0,02$ & $0,40_{-}^{+} 0,06$ & $0,37_{-}^{+} 0,05$ \\
\hline 31 & $0,45_{-}^{+} 0,03$ & $0,41_{-}^{+} 0,03$ & $0,36_{-}^{+} 0,05$ & $0,30_{-}^{+} 0,05$ & $0,24_{-}^{+} 0,04$ \\
\hline
\end{tabular}

encontradas sete partições não é garantia de resultados adequados. Para este fim, faz-se necessário também um conjunto de dados adequado.

A inexistência de valores negativos de silhueta demonstra que as partições obtidas pela análise das imagens térmicas são adequadas para representar as expressões investigadas. Ademais, as médias observadas para o índice Jaccard indicam a obtenção de agrupamentos que se assemelham à classificação real dos dados.

De acordo com as partições produzidas, e diferente do que pode ser observado para os mapas de saliência, a maior facilidade está na separação das expressões de raiva, neutra, e alegria, pois apresentam maior número de partições corretas. Novamente, a expressão de medo é a de pior reconhecimento e, na maioria das execuções, seus exemplos são distribuídos entre todas as partições. Já as emoções de aversão, surpresa e tristeza têm seus exemplos, muitas vezes, distribuídos entre 
Tabela 8.7: Valores das médias obtidas para o índice Jaccard com as imagens térmicas, para os diferentes conjuntos de dados avaliados.

\begin{tabular}{|c|c|c|c|c|c|}
\hline \multirow{2}{*}{$\begin{array}{c}\text { Conjuntos } \\
\text { de } \\
\text { Dados }\end{array}$} & \multicolumn{5}{|c|}{ Algoritmos } \\
\hline & X-médias & $\begin{array}{c}\text { k-médias } \\
k=7\end{array}$ & $\begin{array}{c}\text { k-médias } \\
k=9\end{array}$ & $\begin{array}{c}\mathrm{k} \text {-médias } \\
k=11\end{array}$ & $\begin{array}{c}\text { k-médias } \\
k=13\end{array}$ \\
\hline 1 & $0,77_{-}^{+} 0,02$ & $0,76_{-}^{+} 0,02$ & $0,73_{-0,03}^{+}$ & $0,65_{-}^{+} 0,03$ & $0,60_{-0}^{+} 0,04$ \\
\hline 2 & $0,64_{-}^{+} 0,03$ & $0,67_{-}^{+} 0,03$ & $0,59_{-}^{+} 0,04$ & $0,52_{-0,05}^{+}$ & $0,49_{-0,04}^{+}$ \\
\hline 3 & $0,65_{-}^{+} 0,04$ & $0,65_{-}^{+} 0,04$ & $0,61_{-}^{+} 0,03$ & $0,55_{-}^{+} 0,04$ & $0,49_{-0,05}^{+}$ \\
\hline 4 & $0,91_{-}^{+} 0,02$ & $0,89_{-}^{+} 0,03$ & $0,85_{-}^{+} 0,04$ & $0,81_{-}^{+} 0,05$ & $0,78_{-}^{+} 0,06$ \\
\hline 5 & $0,61_{-}^{+} 0,03$ & $0,54_{-}^{+} 0,05$ & $0,49_{-}^{+} 0,07$ & $0,41_{-}^{+} 0,07$ & $0,33_{-}^{+} 0,09$ \\
\hline 6 & $0,63_{-}^{+} 0,02$ & $0,59_{-}^{+} 0,04$ & $0,51_{-}^{+} 0,06$ & $0,41_{-}^{+} 0,06$ & $0,35_{-}^{+} 0,07$ \\
\hline 7 & $0,63_{-}^{+} 0,04$ & $0,57_{-0,04}^{+}$ & $0,47_{-}^{+} 0,06$ & $0,40_{-}^{+} 0,08$ & $0,29_{-}^{+} 0,11$ \\
\hline 8 & $0,58_{-}^{+} 0,05$ & $0,58_{-}^{+} 0,05$ & $0,50_{-}^{+} 0,07$ & $0,41_{-}^{+} 0,07$ & $0,33_{-}^{+} 0,09$ \\
\hline 9 & $0,71_{-}^{+} 0,02$ & $0,70_{-}^{+} 0,03$ & $0,67_{-0,03}^{+}$ & $0,63_{-0,04}^{+}$ & $0,57_{-}^{+} 0,06$ \\
\hline 10 & $0,94_{-}^{+} 0,03$ & $0,90_{-}^{+} 0,02$ & $0,87_{-}^{+} 0,04$ & $0,85_{-}^{+} 0,04$ & $0,80_{-}^{+} 0,04$ \\
\hline 11 & $0,60_{-}^{+} 0,04$ & $0,55_{-}^{+} 0,05$ & $0,46_{-}^{+} 0,06$ & $0,41_{-}^{+} 0,06$ & $0,35_{-}^{+} 0,05$ \\
\hline 12 & $0,75_{-}^{+} 0,03$ & $0,74_{-}^{+} 0,03$ & $0,72_{-}^{+} 0,04$ & $0,70_{-}^{+} 0,03$ & $0,64_{-}^{+} 0,06$ \\
\hline 13 & $0,50_{-}^{+} 0,05$ & $0,46_{-}^{+} 0,05$ & $0,38_{-}^{+} 0,08$ & $0,30_{-}^{+} 0,09$ & $0,22_{-}^{+} 0,11$ \\
\hline 14 & $0,70_{-}^{+} 0,03$ & $0,70_{-}^{+} 0,04$ & $0,66_{-}^{+} 0,04$ & $0,61_{-}^{+} 0,05$ & $0,57_{-}^{+} 0,05$ \\
\hline 15 & $0,70^{+} 0,02$ & $0,68_{-}^{+} 0,03$ & $0,64_{-}^{+} 0,03$ & $0,59^{+} 0,03$ & $0,59_{-}^{+} 0,05$ \\
\hline 16 & $0,70^{+} 0,02$ & $0,65_{-0,03}^{+03}$ & $0,61_{-}^{+} 0,03$ & $0,55^{+} 0,03$ & $0,53_{-}^{+} 0,05$ \\
\hline 17 & $0,73_{-}^{+} 0,02$ & $0,75_{-}^{+} 0,02$ & $0,70_{-}^{+} 0,04$ & $0,69^{+} 0,04$ & $0,62_{-}^{+} 0,04$ \\
\hline 18 & $0,59_{-}^{+} 0,03$ & $0,55_{-}^{+} 0,04$ & $0,55_{-}^{+} 0,03$ & $0,48_{-}^{+} 0,05$ & $0,39_{-}^{+} 0,08$ \\
\hline 19 & $0,55_{-}^{+} 0,04$ & $0,54_{-}^{+} 0,04$ & $0,49_{-}^{+} 0,04$ & $0,40_{-}^{+} 0,06$ & $0,33_{-}^{+} 0,07$ \\
\hline 20 & $0,55_{-}^{+} 0,03$ & $0,57_{-}^{+} 0,02$ & $0,52_{-}^{+} 0,03$ & $0,44_{-}^{+} 0,05$ & $0,38_{-}^{+} 0,05$ \\
\hline 21 & $0,65_{-}^{+} 0,04$ & $0,66_{-}^{+} 0,04$ & $0,62_{-}^{+} 0,03$ & $0,57_{-}^{+} 0,05$ & $0,51_{-}^{+} 0,06$ \\
\hline 22 & $0,63_{-}^{+} 0,04$ & $0,63_{-}^{+} 0,03$ & $0,60_{-}^{+} 0,04$ & $0,52_{-}^{+} 0,04$ & $0,52_{-}^{+} 0,04$ \\
\hline 23 & $0,64_{-}^{+} 0,03$ & $0,62_{-}^{+} 0,02$ & $0,56_{-}^{+} 0,07$ & $0,53_{-}^{+} 0,05$ & $0,46_{-}^{+} 0,03$ \\
\hline 24 & $0,73_{-}^{+} 0,03$ & $0,77_{-0,05}^{+}$ & $0,70_{-}^{+} 0,04$ & $0,66_{-}^{+} 0,04$ & $0,64_{-}^{+} 0,03$ \\
\hline 25 & $0,82_{-}^{+} 0,04$ & $0,79_{-}^{+} 0,03$ & $0,79_{-0,05}^{+}$ & $0,73_{-0,04}^{+}$ & $0,70_{-}^{+} 0,06$ \\
\hline 26 & $0,78_{-}^{+} 0,03$ & $0,78_{-}^{+} 0,03$ & $0,74_{-}^{+} 0,04$ & $0,68_{-}^{+} 0,07$ & $0,69_{-}^{+} 0,05$ \\
\hline 27 & $0,44_{-}^{+} 0,06$ & $0,47_{-}^{+} 0,06$ & $0,35_{-}^{+} 0,05$ & $0,28_{-}^{+} 0,06$ & $0,25_{-}^{+} 0,09$ \\
\hline 28 & $0,73_{-}^{+} 0,04$ & $0,72_{-}^{+} 0,03$ & $0,70_{-}^{+} 0,04$ & $0,62_{-}^{+} 0,07$ & $0,62_{-}^{+} 0,05$ \\
\hline 29 & $0,69_{-}^{+} 0,04$ & $0,71_{-}^{+} 0,04$ & $0,67_{-}^{+} 0,03$ & $0,61_{-}^{+} 0,05$ & $0,54_{-}^{+} 0,05$ \\
\hline 30 & $0,62_{-}^{+} 0,03$ & $0,57_{-}^{+} 0,05$ & $0,55_{-}^{+} 0,05$ & $0,41_{-}^{+} 0,08$ & $0,33_{-}^{+} 0,10$ \\
\hline 31 & $0,52_{-}^{+} 0,05$ & $0,49_{-}^{+} 0,04$ & $0,44_{-}^{+} 0,07$ & $0,36_{-}^{+} 0,07$ & $0,28_{-}^{+} 0,06$ \\
\hline
\end{tabular}

duas partições.

É importante destacar que, embora a análise das imagens térmicas tenha apresentado diferenças no reconhecimento das expressões emocionais, a distribuição dos exemplos entre as partições apresenta as mesmas características destacadas na Figura 8.10. Deste modo, mesmo nas execuções em que o número de partições é maior, a separação ideal em sete não é encontrada.

O teste estatístico de Friedman é aplicado aos resultados existentes nas tabelas 8.6 e 8.7 para analisar diferenças entre os algoritmos e conjuntos de dados avaliados. Como a hipótese nula é rejeitada, o teste post-hoc de Nemenyi é também aplicado. Para ambos, o grau de confiança utilizado é de 95\%.

De acordo com estes testes estatísticos, o algoritmo x-médias apresenta desempenho superior a todas as variações do algoritmo k-médias porém, para o valor 


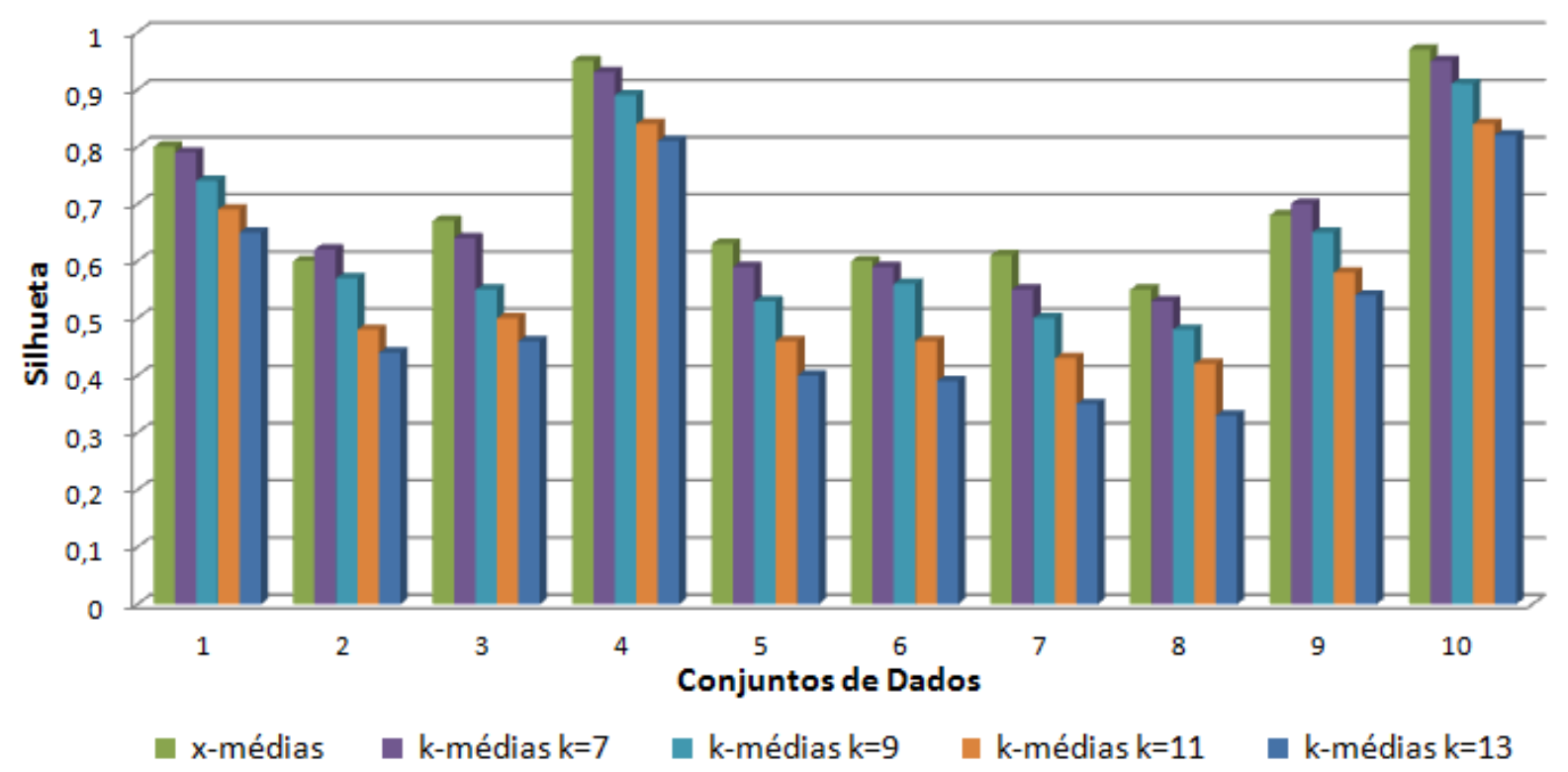

Figura 8.11: Gráfico com as médias do índice silhueta obtidas com as imagens térmicas, para os conjuntos de dados 1 a 10.

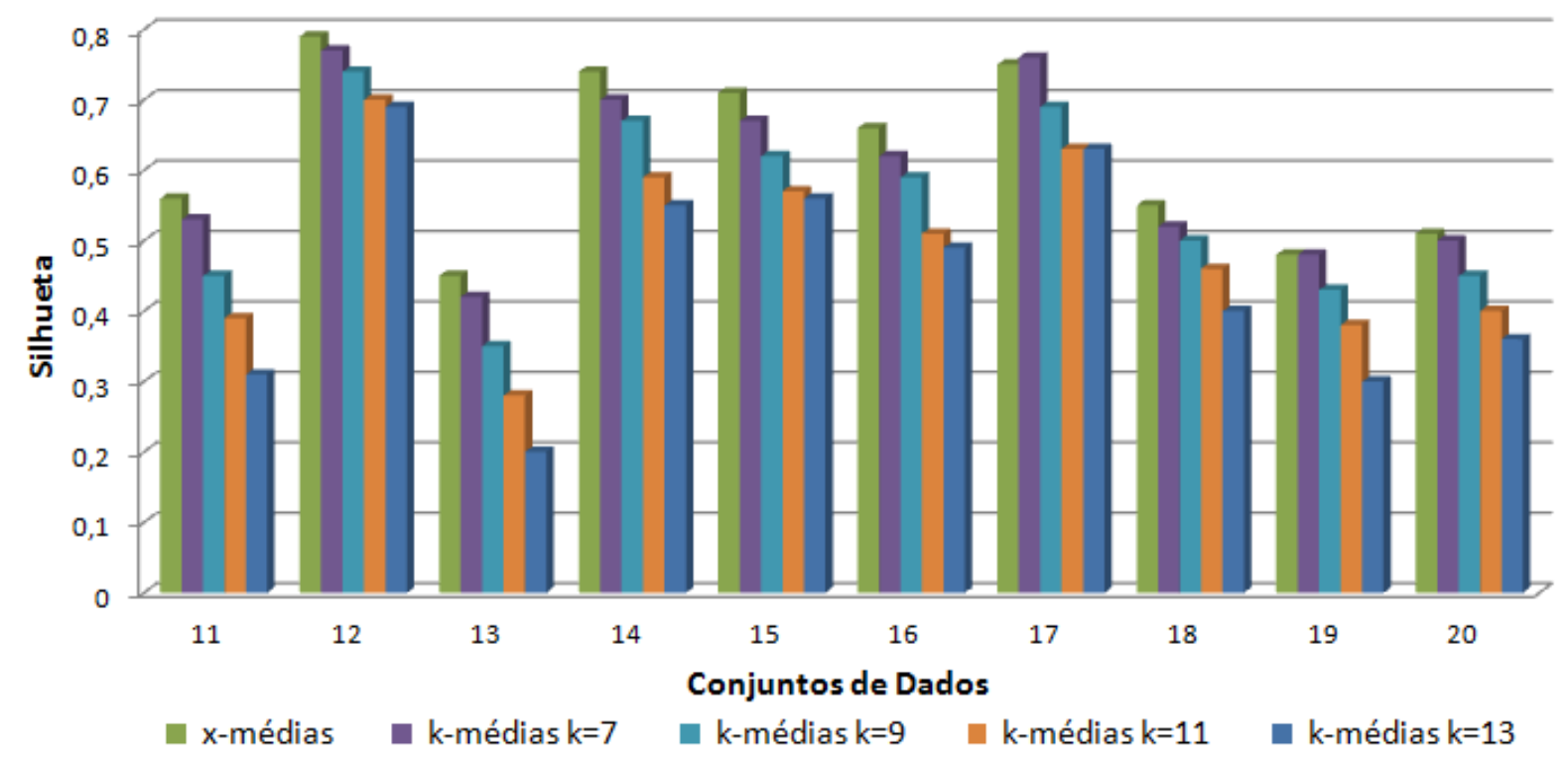

Figura 8.12: Gráfico com as médias do índice silhueta obtidas com as imagens térmicas, para os conjuntos de dados 11 a 20 .

de $k=7$, não é possível obter $95 \%$ de confiança. Do mesmo modo, o k-médias com $k=7$ é estatisticamente melhor que as demais variações do k-médias, mas agora com grau de confiança de 95\%.

$\mathrm{Na}$ análise dos conjuntos de dados, as tabelas 8.8 e 8.9 apresentam, respectivamente, para os índices silhueta e Jaccard, as diferenças estatísticas encontradas. Estas tabelas permitem notar, seja pela análise da silhueta ou do índice Jaccard, que o melhor conjunto de dados obtido é o de número 10, que apresenta o desvio-padrão e os descritores do método HOG. Em seguida, o conjunto 4 é encontrado. Este conjunto é estatisticamente inferior apenas ao conjunto 10, e possui os descritores do método HOG. Ainda, inferior aos dois conjuntos de dados citados, mas superior 


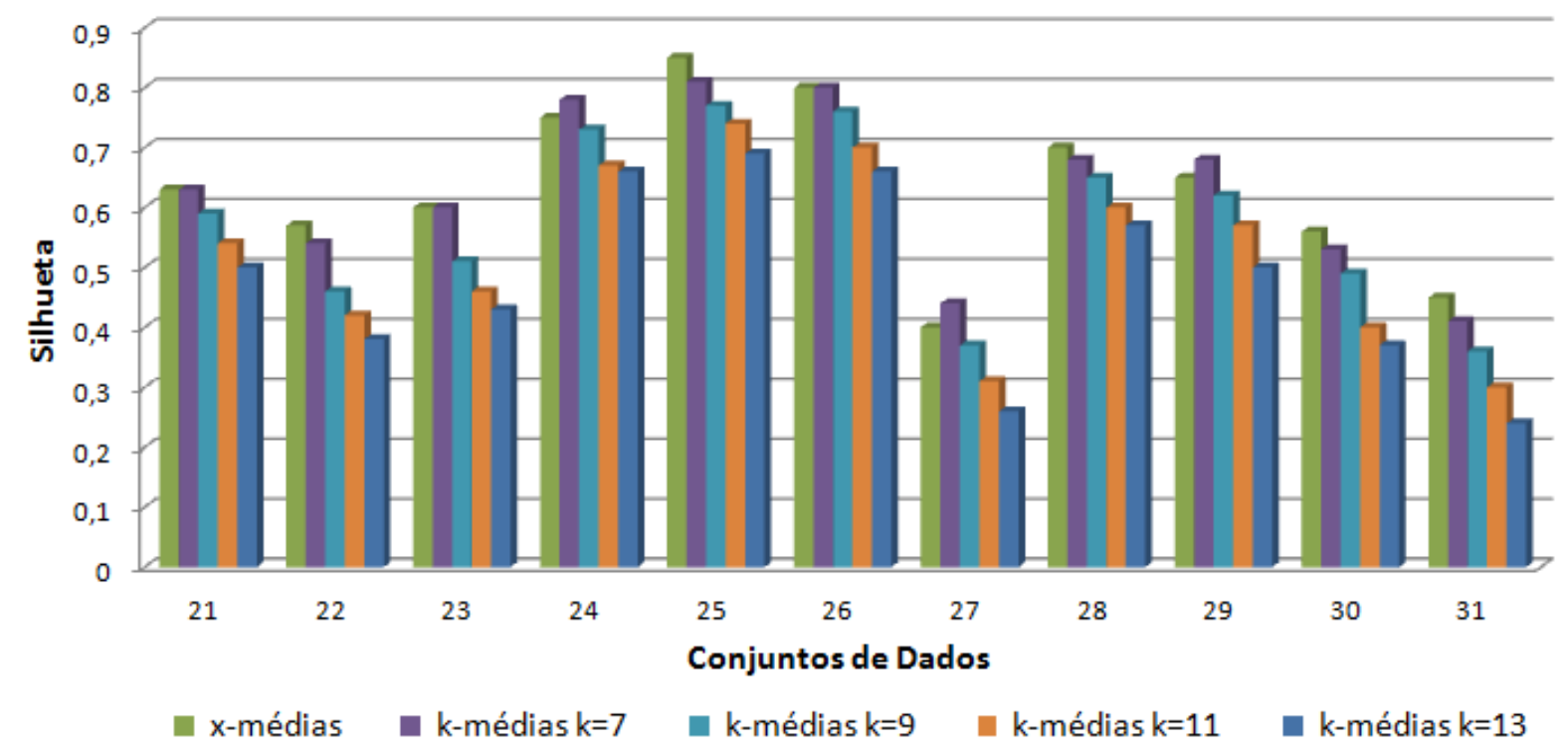

Figura 8.13: Gráfico com as médias do índice silhueta obtidas com as imagens térmicas, para os conjuntos de dados 21 a 31.

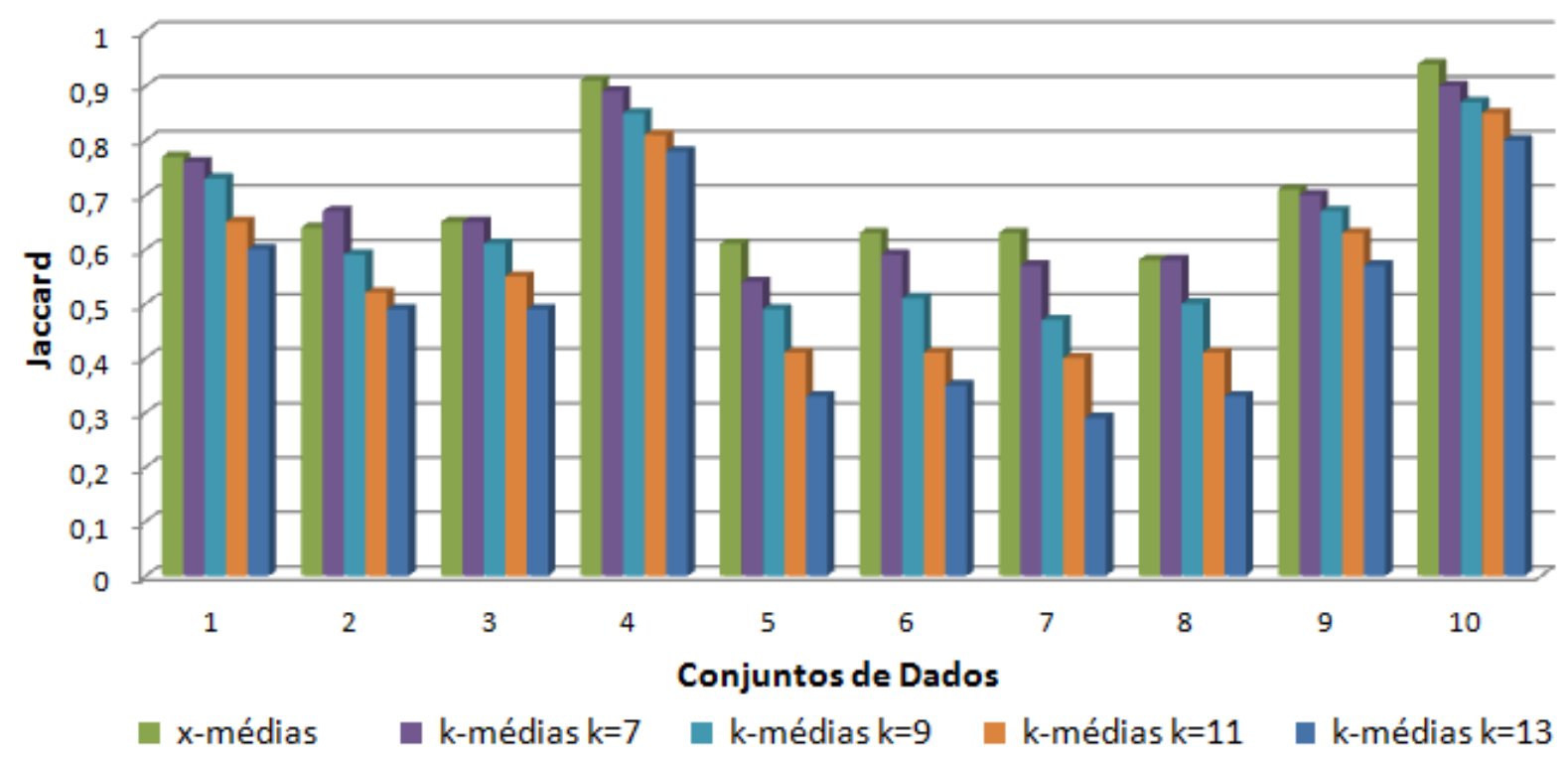

Figura 8.14: Gráfico com as médias do índice Jaccard obtidas com as imagens térmicas, para os conjuntos de dados 1 a 10 .

a todos os demais, pode-se observar o conjunto 25, composto pelos descritores do método HOG aplicados às imagens térmicas e aos mapas de entropia destas imagens, e pelo desvio-padrão.

Pelos resultados obtidos conclui-se que não apenas o reconhecimento das expressões emocionais é diferente, mas também os conjuntos de dados que apresentam melhor desempenho são distintos. Enquanto a entropia e o desvio-padrão conferem os melhores agrupamentos pela análise dos mapas de saliência, para as imagens térmicas destacam-se o método HOG e o desvio-padrão.

Assim, com o objetivo de produzir agrupamentos de melhor qualidade e mais próximos à classificação real dos dados, os quatro melhores conjuntos de dados 


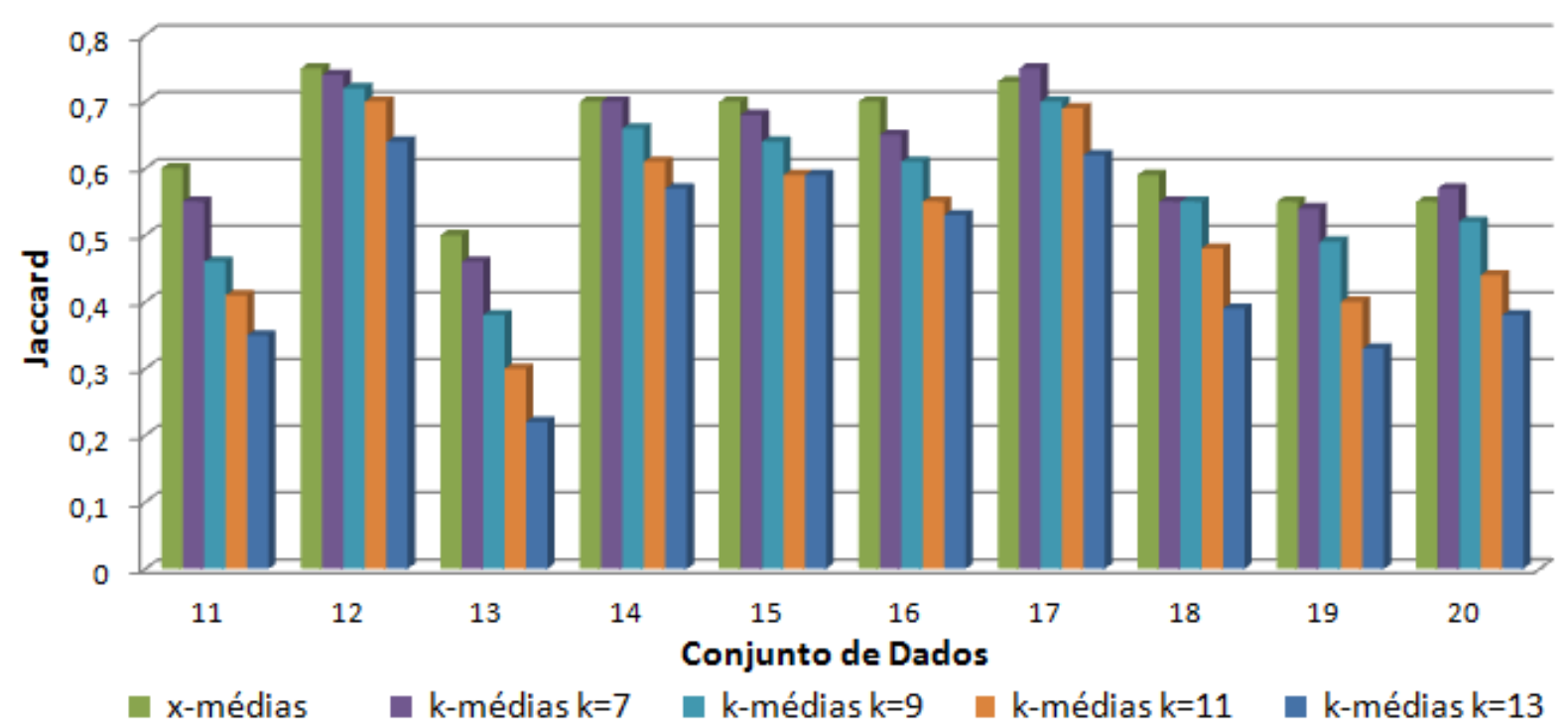

Figura 8.15: Gráfico com as médias do índice Jaccard obtidas com as imagens térmicas, para os conjuntos de dados 11 a 20.

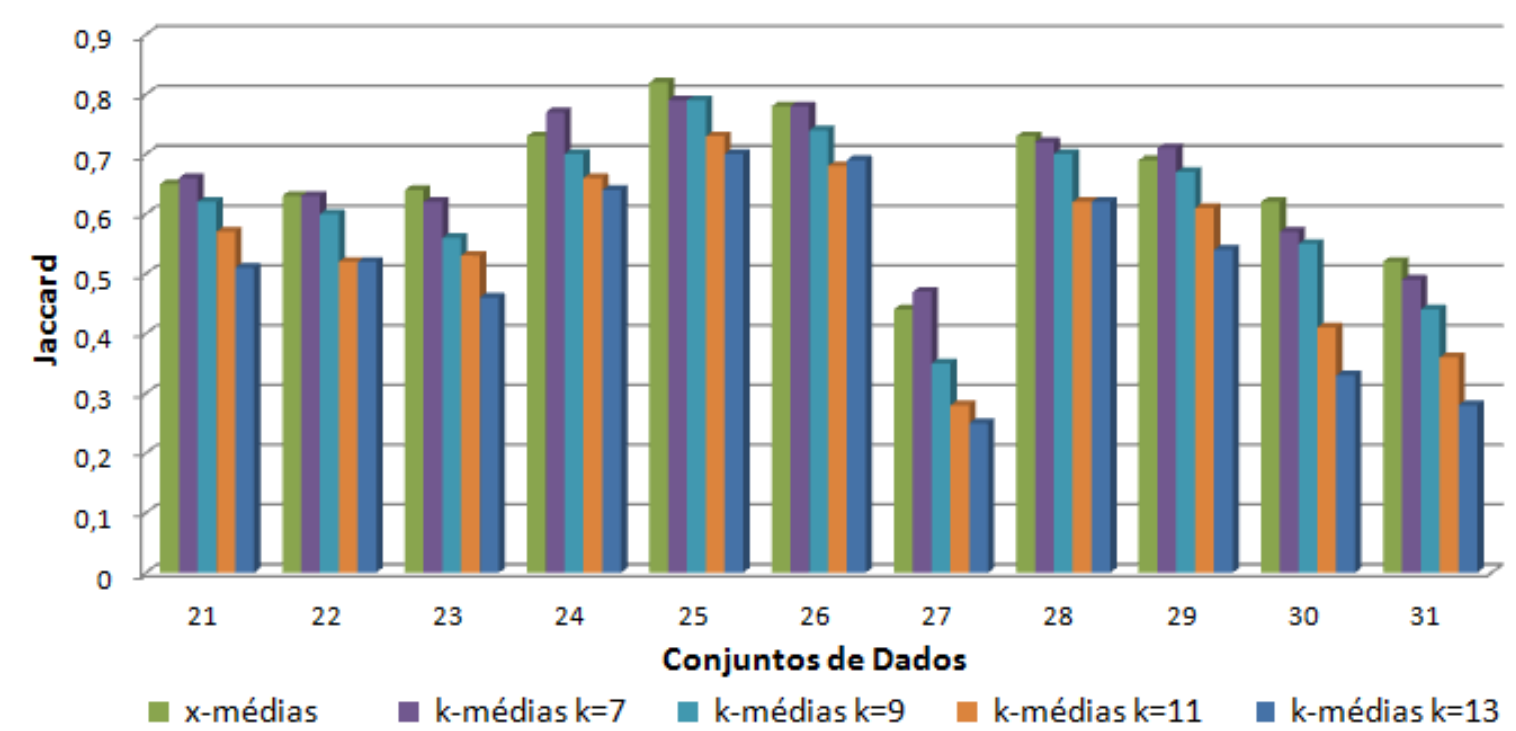

Figura 8.16: Gráfico com as médias do índice Jaccard obtidas com as imagens térmicas, para os conjuntos de dados 21 a 31 .

obtidos nos experimentos apresentados, ou seja, os dois melhores resultantes da análise dos mapas de saliência, e os dois melhores encontrados para as imagens térmicas, são combinados e avaliados.

Todas as possiveis combinações dos conjuntos selecionados produzem 15 novos conjuntos de dados. No entanto, alguns deles são iguais a conjuntos previamente apresentados na Tabela $8.1 \mathrm{e}$, portanto, não existem razões para avaliá-los novamente. Deste modo, nove são os conjuntos de dados realmente obtidos, que podem ser visualizados na Tabela 8.10. Nesta tabela, sal indica dados provenientes dos mapas de saliência, e term dados que representam as imagens térmicas.

O procedimento executado para estes novos experimentos é o mesmo descrito anteriormente, ou seja, os algoritmos de agrupamento são executados 30 vezes para 
Tabela 8.8: Comparação estatística entre os conjuntos de dados utilizados, considerando o índice silhueta e as imagens térmicas.

\begin{tabular}{|c|c|c|c|c|c|c|c|c|c|c|c|c|c|c|c|c|c|c|c|c|c|c|c|c|c|c|c|c|c|c|c|}
\hline$\#$ & 1 & 2 & 3 & 4 & 5 & 6 & 7 & 8 & 9 & 10 & 11 & 12 & 13 & 14 & 15 & 16 & 17 & 18 & 19 & 20 & 21 & 22 & 23 & 24 & 25 & 26 & 27 & 28 & 29 & 30 & 31 \\
\hline 1 & $\circ$ & $\Delta$ & $\Delta$ & $\nabla$ & $\Delta$ & $\Delta$ & $\Delta$ & $\Delta$ & $\Delta$ & $\nabla$ & $\Delta$ & - & $\Delta$ & $\Delta$ & $\Delta$ & $\Delta$ & $\Delta$ & $\Delta$ & $\Delta$ & $\Delta$ & $\Delta$ & $\Delta$ & $\Delta$ & & $\boldsymbol{\nabla}$ & $\boldsymbol{\nabla}$ & $\Delta$ & $\Delta$ & $\Delta$ & $\Delta$ & $\Delta$ \\
\hline 2 & $\nabla$ & $\circ$ & $\nabla$ & $\nabla$ & $\Delta$ & $\Delta$ & $\Delta$ & $\Delta$ & $\nabla$ & $\nabla$ & $\Delta$ & $\nabla$ & $\Delta$ & $\nabla$ & $\nabla$ & $\nabla$ & $\nabla$ & $\Delta$ & $\Delta$ & $\Delta$ & $\nabla$ & $\Delta$ & $\Delta$ & $\nabla$ & $\nabla$ & $\nabla$ & $\Delta$ & $\nabla$ & $\nabla$ & $\Delta$ & 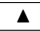 \\
\hline 3 & $\nabla$ & $\Delta$ & $\circ$ & $\nabla$ & $\Delta$ & $\Delta$ & $\Delta$ & $\Delta$ & $\nabla$ & $\nabla$ & $\Delta$ & $\nabla$ & $\Delta$ & $\nabla$ & $\nabla$ & $\square$ & $\nabla$ & $\Delta$ & $\Delta$ & $\Delta$ & $\nabla$ & $\Delta$ & $\Delta$ & $\nabla$ & $\nabla$ & $\nabla$ & $\Delta$ & $\nabla$ & $\nabla$ & $\Delta$ & $\Delta$ \\
\hline 4 & $\Delta$ & $\Delta$ & $\Delta$ & $\circ$ & $\Delta$ & $\Delta$ & $\Delta$ & $\Delta$ & $\Delta$ & $\nabla$ & $\Delta$ & $\Delta$ & $\Delta$ & $\Delta$ & $\Delta$ & $\Delta$ & $\Delta$ & $\Delta$ & $\Delta$ & $\Delta$ & $\Delta$ & $\Delta$ & $\Delta$ & $\Delta$ & $\Delta$ & $\Delta$ & $\Delta$ & $\Delta$ & $\Delta$ & $\Delta$ & $\Delta$ \\
\hline 5 & $\nabla$ & $\nabla$ & $\nabla$ & $\nabla$ & $\circ$ & $\Delta$ & $\Delta$ & $\Delta$ & $\nabla$ & $\nabla$ & $\Delta$ & $\nabla$ & $\Delta$ & $\nabla$ & $\nabla$ & $\nabla$ & $\nabla$ & $\Delta$ & $\Delta$ & $\Delta$ & $\nabla$ & $\Delta$ & E & $\nabla$ & $\nabla$ & $\nabla$ & $\Delta$ & $\nabla$ & $\nabla$ & $\Delta$ & $\Delta$ \\
\hline 6 & $\nabla$ & $\nabla$ & $\nabla$ & $\nabla$ & $\nabla$ & $\circ$ & $\Delta$ & $\Delta$ & $\nabla$ & $\nabla$ & $\Delta$ & $\nabla$ & $\Delta$ & $\nabla$ & $\nabla$ & $\nabla$ & $\nabla$ & $\Delta$ & $\Delta$ & $\Delta$ & $\nabla$ & $\Delta$ & $\square$ & $\nabla$ & $\nabla$ & $\nabla$ & $\Delta$ & $\nabla$ & $\nabla$ & $\Delta$ & $\Delta$ \\
\hline 7 & $\nabla$ & $\nabla$ & $\nabla$ & $\nabla$ & $\nabla$ & $\nabla$ & & $\Delta$ & $\nabla$ & $\nabla$ & $\Delta$ & $\nabla$ & $\Delta$ & $\nabla$ & $\nabla$ & $\nabla$ & $\nabla$ & $\Delta$ & $\Delta$ & $\Delta$ & $\nabla$ & $\Delta$ & $\nabla$ & $\nabla$ & $\nabla$ & $\nabla$ & $\Delta$ & $\nabla$ & $\nabla$ & $\Delta$ & $\Delta$ \\
\hline 8 & $\nabla$ & $\nabla$ & $\nabla$ & $\nabla$ & $\nabla$ & $\nabla$ & $\nabla$ & $\circ$ & $\nabla$ & $\nabla$ & $\Delta$ & $\nabla$ & $\Delta$ & $\nabla$ & $\nabla$ & $\nabla$ & $\nabla$ & $\nabla$ & $\Delta$ & $\Delta$ & $\nabla$ & $\nabla$ & $\nabla$ & $\nabla$ & $\nabla$ & $\nabla$ & $\Delta$ & $\nabla$ & $\nabla$ & $\nabla$ & $\Delta$ \\
\hline 9 & $\nabla$ & $\Delta$ & $\Delta$ & $\nabla$ & $\Delta$ & $\Delta$ & $\Delta$ & $\Delta$ & $\circ$ & $\nabla$ & $\Delta$ & $\nabla$ & $\Delta$ & $\nabla$ & $\Delta$ & $\Delta$ & $\nabla$ & $\Delta$ & $\Delta$ & $\Delta$ & $\Delta$ & $\Delta$ & $\Delta$ & $\nabla$ & $\nabla$ & $\nabla$ & $\Delta$ & $\nabla$ & $\Delta$ & $\Delta$ & $\Delta$ \\
\hline 10 & $\Delta$ & $\Delta$ & $\Delta$ & $\Delta$ & $\Delta$ & $\Delta$ & $\Delta$ & $\Delta$ & $\Delta$ & $\circ$ & $\Delta$ & $\Delta$ & $\Delta$ & $\Delta$ & $\Delta$ & $\Delta$ & $\Delta$ & $\Delta$ & $\Delta$ & $\Delta$ & $\Delta$ & $\Delta$ & 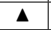 & $\Delta$ & $\Delta$ & $\Delta$ & $\Delta$ & $\Delta$ & $\Delta$ & $\Delta$ & $\Delta$ \\
\hline 11 & $\nabla$ & $\nabla$ & $\nabla$ & $\nabla$ & $\nabla$ & $\nabla$ & $\nabla$ & $\nabla$ & $\nabla$ & $\nabla$ & $\circ$ & $\nabla$ & $\Delta$ & $\nabla$ & $\nabla$ & $\nabla$ & $\nabla$ & $\nabla$ & $\Delta$ & $\square$ & $\nabla$ & $\nabla$ & $\nabla$ & $\nabla$ & $\nabla$ & $\nabla$ & $\Delta$ & $\nabla$ & $\nabla$ & $\nabla$ & $\Delta$ \\
\hline 12 & $\square$ & $\Delta$ & $\Delta$ & $\nabla$ & $\Delta$ & $\Delta$ & $\Delta$ & $\Delta$ & $\Delta$ & $\nabla$ & $\Delta$ & $\circ$ & $\Delta$ & $\Delta$ & $\Delta$ & $\Delta$ & $\Delta$ & $\Delta$ & $\Delta$ & $\Delta$ & $\Delta$ & $\Delta$ & $\Delta$ & $\Delta$ & $\nabla$ & $\nabla$ & & $\Delta$ & & & $\Delta$ \\
\hline 13 & $\nabla$ & $\nabla$ & $\nabla$ & $\nabla$ & $\nabla$ & $\nabla$ & $\nabla$ & $\nabla$ & $\nabla$ & $\nabla$ & $\nabla$ & $\nabla$ & $\circ$ & $\nabla$ & $\nabla$ & $\nabla$ & $\nabla$ & $\nabla$ & $\nabla$ & $\nabla$ & $\nabla$ & $\nabla$ & $\nabla$ & $\nabla$ & $\nabla$ & $\nabla$ & $\nabla$ & $\nabla$ & $\nabla$ & $\nabla$ & $\bar{\square}$ \\
\hline 14 & $\nabla$ & $\Delta$ & $\Delta$ & $\nabla$ & $\Delta$ & $\Delta$ & $\Delta$ & $\Delta$ & $\Delta$ & $\nabla$ & $\Delta$ & $\nabla$ & $\Delta$ & $\circ$ & $\Delta$ & $\Delta$ & $\nabla$ & $\Delta$ & $\Delta$ & $\Delta$ & 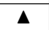 & $\Delta$ & $\Delta$ & $\nabla$ & $\nabla$ & $\nabla$ & $\Delta$ & $\Delta$ & $\Delta$ & $\Delta$ & $\Delta$ \\
\hline 15 & $\nabla$ & $\Delta$ & $\Delta$ & $\nabla$ & $\Delta$ & $\Delta$ & $\Delta$ & $\Delta$ & $\nabla$ & $\nabla$ & $\Delta$ & $\nabla$ & $\Delta$ & $\nabla$ & $\circ$ & $\Delta$ & $\nabla$ & $\Delta$ & $\Delta$ & $\Delta$ & $\Delta$ & $\Delta$ & $\Delta$ & $\nabla$ & $\nabla$ & $\nabla$ & $\Delta$ & $\nabla$ & $\Delta$ & $\Delta$ & $\Delta$ \\
\hline 16 & $\nabla$ & $\Delta$ & [ & $\nabla$ & $\Delta$ & $\Delta$ & $\Delta$ & $\Delta$ & $\nabla$ & $\nabla$ & $\Delta$ & $\nabla$ & $\Delta$ & $\nabla$ & $\nabla$ & 0 & $\nabla$ & $\Delta$ & $\Delta$ & $\Delta$ & $\square$ & $\Delta$ & $\Delta$ & $\nabla$ & $\nabla$ & $\nabla$ & $\Delta$ & $\nabla$ & $\nabla$ & $\Delta$ & \\
\hline 17 & $\nabla$ & $\Delta$ & $\Delta$ & $\nabla$ & $\Delta$ & $\Delta$ & $\Delta$ & $\Delta$ & $\Delta$ & $\nabla$ & $\Delta$ & $\nabla$ & $\Delta$ & $\Delta$ & $\Delta$ & $\Delta$ & $\circ$ & $\Delta$ & $\Delta$ & $\Delta$ & $\Delta$ & $\Delta$ & $\Delta$ & $\nabla$ & $\nabla$ & $\nabla$ & $\Delta$ & $\Delta$ & $\Delta$ & $\Delta$ & $\Delta$ \\
\hline 18 & $\nabla$ & $\nabla$ & $\nabla$ & $\nabla$ & $\nabla$ & $\nabla$ & $\nabla$ & $\Delta$ & $\nabla$ & $\nabla$ & $\Delta$ & $\nabla$ & $\Delta$ & $\nabla$ & $\nabla$ & $\nabla$ & $\nabla$ & $\circ$ & $\Delta$ & $\Delta$ & $\nabla$ & $\Delta$ & $\nabla$ & $\nabla$ & $\nabla$ & $\nabla$ & $\Delta$ & $\nabla$ & $\nabla$ & $\Delta$ & $\Delta$ \\
\hline 19 & $\nabla$ & $\nabla$ & $\nabla$ & $\nabla$ & $\nabla$ & $\nabla$ & $\nabla$ & $\nabla$ & $\nabla$ & $\nabla$ & $\nabla$ & $\nabla$ & $\Delta$ & $\nabla$ & $\nabla$ & $\nabla$ & $\nabla$ & $\nabla$ & $\circ$ & $\nabla$ & $\nabla$ & $\nabla$ & $\nabla$ & $\nabla$ & $\nabla$ & $\nabla$ & $\Delta$ & $\nabla$ & $\nabla$ & $\nabla$ & $\Delta$ \\
\hline 20 & $\nabla$ & $\nabla$ & $\nabla$ & $\nabla$ & $\nabla$ & $\nabla$ & $\nabla$ & $\nabla$ & $\nabla$ & $\nabla$ & प & $\nabla$ & $\Delta$ & $\nabla$ & $\nabla$ & $\nabla$ & $\nabla$ & $\nabla$ & $\Delta$ & $\circ$ & $\nabla$ & $\nabla$ & $\nabla$ & $\nabla$ & $\nabla$ & $\nabla$ & $\Delta$ & $\nabla$ & $\nabla$ & $\nabla$ & $\Delta$ \\
\hline 21 & $\nabla$ & $\Delta$ & $\Delta$ & $\nabla$ & $\Delta$ & $\Delta$ & $\Delta$ & $\Delta$ & $\nabla$ & $\nabla$ & $\Delta$ & $\nabla$ & $\Delta$ & $\nabla$ & $\nabla$ & $\square$ & $\nabla$ & $\Delta$ & $\Delta$ & $\Delta$ & $\circ$ & $\Delta$ & $\Delta$ & $\nabla$ & $\nabla$ & $\nabla$ & $\Delta$ & $\nabla$ & $\nabla$ & $\Delta$ & $\Delta$ \\
\hline 22 & $\nabla$ & $\nabla$ & $\nabla$ & $\nabla$ & $\nabla$ & $\nabla$ & $\nabla$ & $\Delta$ & $\nabla$ & $\nabla$ & $\Delta$ & $\nabla$ & $\Delta$ & $\nabla$ & $\nabla$ & $\nabla$ & $\nabla$ & $\nabla$ & $\Delta$ & $\Delta$ & $\nabla$ & $\circ$ & $\nabla$ & $\nabla$ & $\nabla$ & $\nabla$ & $\Delta$ & $\nabla$ & $\nabla$ & $\Delta$ & $\Delta$ \\
\hline 23 & $\nabla$ & $\nabla$ & $\nabla$ & $\nabla$ & E & E & $\Delta$ & $\Delta$ & $\nabla$ & $\nabla$ & $\Delta$ & $\nabla$ & $\Delta$ & $\nabla$ & $\nabla$ & $\nabla$ & $\nabla$ & $\Delta$ & $\Delta$ & $\Delta$ & $\nabla$ & $\Delta$ & $\circ$ & $\nabla$ & $\nabla$ & $\nabla$ & $\Delta$ & $\nabla$ & $\nabla$ & $\Delta$ & $\Delta$ \\
\hline 24 & $\nabla$ & $\Delta$ & $\Delta$ & $\nabla$ & $\Delta$ & $\Delta$ & $\Delta$ & $\Delta$ & $\Delta$ & $\nabla$ & $\Delta$ & $\nabla$ & $\Delta$ & $\Delta$ & $\Delta$ & $\Delta$ & $\Delta$ & $\Delta$ & $\Delta$ & $\Delta$ & $\Delta$ & $\Delta$ & $\Delta$ & $\circ$ & $\nabla$ & $\nabla$ & $\Delta$ & $\Delta$ & $\Delta$ & $\Delta$ & $\Delta$ \\
\hline 25 & $\Delta$ & $\Delta$ & $\Delta$ & $\nabla$ & $\Delta$ & $\Delta$ & $\Delta$ & $\Delta$ & $\Delta$ & $\nabla$ & $\Delta$ & $\Delta$ & $\Delta$ & $\Delta$ & $\Delta$ & $\Delta$ & $\Delta$ & $\Delta$ & $\Delta$ & $\Delta$ & $\Delta$ & $\Delta$ & $\Delta$ & $\Delta$ & $\circ$ & $\Delta$ & $\Delta$ & $\Delta$ & $\Delta$ & $\Delta$ & $\Delta$ \\
\hline 26 & $\Delta$ & $\Delta$ & $\Delta$ & $\nabla$ & $\Delta$ & $\Delta$ & $\Delta$ & $\Delta$ & $\Delta$ & $\nabla$ & $\Delta$ & $\Delta$ & $\Delta$ & $\Delta$ & $\Delta$ & $\Delta$ & $\Delta$ & $\Delta$ & $\Delta$ & $\Delta$ & $\Delta$ & $\Delta$ & $\Delta$ & $\Delta$ & $\nabla$ & & $\Delta$ & $\Delta$ & $\Delta$ & $\Delta$ & $\Delta$ \\
\hline 27 & $\nabla$ & $\nabla$ & $\nabla$ & $\nabla$ & $\nabla$ & $\nabla$ & $\nabla$ & $\nabla$ & $\nabla$ & $\nabla$ & $\nabla$ & $\nabla$ & $\Delta$ & $\nabla$ & $\nabla$ & $\nabla$ & $\nabla$ & $\nabla$ & $\nabla$ & $\nabla$ & $\nabla$ & $\nabla$ & $\nabla$ & $\nabla$ & $\nabla$ & $\nabla$ & $\circ$ & $\nabla$ & $\nabla$ & $\nabla$ & $\Delta$ \\
\hline 28 & $\nabla$ & $\Delta$ & $\Delta$ & $\nabla$ & $\Delta$ & $\Delta$ & $\Delta$ & $\Delta$ & $\Delta$ & $\nabla$ & $\Delta$ & $\nabla$ & $\Delta$ & $\nabla$ & $\Delta$ & $\Delta$ & $\nabla$ & $\Delta$ & $\Delta$ & $\Delta$ & $\Delta$ & $\Delta$ & $\Delta$ & $\nabla$ & $\nabla$ & $\nabla$ & $\Delta$ & $\circ$ & $\Delta$ & $\Delta$ & $\Delta$ \\
\hline 29 & $\nabla$ & $\Delta$ & $\Delta$ & $\nabla$ & $\Delta$ & $\Delta$ & $\Delta$ & $\Delta$ & $\nabla$ & $\nabla$ & $\Delta$ & $\nabla$ & $\Delta$ & $\nabla$ & $\nabla$ & $\Delta$ & $\nabla$ & & $\Delta$ & $\Delta$ & $\Delta$ & $\Delta$ & $\Delta$ & & & & $\Delta$ & & & $\Delta$ & $\Delta$ \\
\hline 30 & $\nabla$ & $\nabla$ & $\nabla$ & $\nabla$ & $\nabla$ & $\nabla$ & $\nabla$ & $\Delta$ & $\nabla$ & $\nabla$ & $\Delta$ & $\nabla$ & $\Delta$ & $\nabla$ & $\nabla$ & $\nabla$ & $\nabla$ & $\mathbf{v}$ & $\Delta$ & $\Delta$ & $\nabla$ & $\nabla$ & $\nabla$ & $\nabla$ & $\nabla$ & $\nabla$ & $\Delta$ & $\nabla$ & $\nabla$ & $\circ$ & $\Delta$ \\
\hline 31 & $\nabla$ & $\nabla$ & $\mathbf{\nabla}$ & $\nabla$ & $\nabla$ & $\nabla$ & $\nabla$ & $\nabla$ & $\nabla$ & $\nabla$ & $\nabla$ & $\nabla$ & 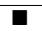 & $\nabla$ & $\nabla$ & $\nabla$ & $\nabla$ & $\nabla$ & $\nabla$ & $\nabla$ & $\nabla$ & $\nabla$ & $\nabla$ & $\nabla$ & $\nabla$ & $\nabla$ & $\nabla$ & $\nabla$ & $\nabla$ & $\nabla$ & $\circ$ \\
\hline
\end{tabular}

Tabela 8.9: Comparação estatística entre os conjuntos de dados utilizados, considerando o índice Jaccard e as imagens térmicas.

\begin{tabular}{|c|c|c|c|c|c|c|c|c|c|c|c|c|c|c|c|c|c|c|c|c|c|c|c|c|c|c|c|c|c|c|c|}
\hline \# & 1 & 2 & 3 & 4 & 5 & 6 & 7 & 8 & 9 & 10 & 11 & 12 & 13 & 14 & 15 & 16 & 17 & 18 & 19 & 20 & 21 & 22 & 23 & 24 & 25 & 26 & 27 & 28 & 29 & 30 & 31 \\
\hline 1 & $\circ$ & $\Delta$ & $\Delta$ & $\nabla$ & $\Delta$ & $\Delta$ & $\Delta$ & $\Delta$ & $\Delta$ & $\nabla$ & $\Delta$ & $\nabla$ & $\Delta$ & $\Delta$ & $\Delta$ & $\Delta$ & $\Delta$ & $\Delta$ & $\Delta$ & $\Delta$ & $\Delta$ & $\Delta$ & $\Delta$ & $\square$ & $\nabla$ & $\nabla$ & $\Delta$ & $\Delta$ & $\Delta$ & $\Delta$ & $\Delta$ \\
\hline 2 & $\nabla$ & $\circ$ & $\nabla$ & $\nabla$ & $\Delta$ & $\Delta$ & $\Delta$ & $\Delta$ & $\nabla$ & $\nabla$ & $\Delta$ & $\nabla$ & $\Delta$ & $\nabla$ & $\nabla$ & $\nabla$ & $\nabla$ & $\Delta$ & $\Delta$ & $\Delta$ & $\nabla$ & $\Delta$ & $\Delta$ & $\nabla$ & $\nabla$ & $\nabla$ & $\Delta$ & $\nabla$ & $\nabla$ & $\Delta$ & $\Delta$ \\
\hline 3 & $\nabla$ & $\Delta$ & $\circ$ & $\nabla$ & $\Delta$ & $\Delta$ & $\Delta$ & $\Delta$ & $\nabla$ & $\nabla$ & $\Delta$ & $\nabla$ & $\Delta$ & $\nabla$ & $\nabla$ & $\nabla$ & $\nabla$ & $\Delta$ & $\Delta$ & $\Delta$ & $\nabla$ & $\Delta$ & $\Delta$ & $\nabla$ & $\nabla$ & $\nabla$ & $\Delta$ & $\nabla$ & $\nabla$ & $\Delta$ & $\Delta$ \\
\hline 4 & $\Delta$ & $\Delta$ & $\Delta$ & $\circ$ & $\Delta$ & $\Delta$ & $\Delta$ & $\Delta$ & $\Delta$ & $\nabla$ & $\Delta$ & $\Delta$ & $\Delta$ & $\Delta$ & $\Delta$ & $\Delta$ & $\Delta$ & $\Delta$ & $\Delta$ & $\Delta$ & $\Delta$ & $\Delta$ & $\Delta$ & $\Delta$ & $\Delta$ & $\Delta$ & $\Delta$ & $\Delta$ & $\Delta$ & $\Delta$ & $\Delta$ \\
\hline 5 & $\nabla$ & $\nabla$ & $\nabla$ & $\nabla$ & $\circ$ & $\nabla$ & E & $\nabla$ & $\nabla$ & $\nabla$ & 口 & $\nabla$ & $\Delta$ & $\nabla$ & $\nabla$ & $\nabla$ & $\nabla$ & $\nabla$ & $\Delta$ & $\nabla$ & $\nabla$ & $\nabla$ & $\boldsymbol{\nabla}$ & $\nabla$ & $\boldsymbol{\nabla}$ & $\nabla$ & $\Delta$ & $\nabla$ & $\nabla$ & $\nabla$ & $\Delta$ \\
\hline 6 & $\nabla$ & $\nabla$ & $\nabla$ & $\nabla$ & $\Delta$ & $\circ$ & $\Delta$ & $\Delta$ & $\nabla$ & $\nabla$ & $\Delta$ & $\nabla$ & $\Delta$ & $\nabla$ & $\nabla$ & $\nabla$ & $\nabla$ & 口 & $\Delta$ & $\Delta$ & $\nabla$ & $\nabla$ & $\nabla$ & $\nabla$ & $\nabla$ & $\nabla$ & $\Delta$ & $\nabla$ & $\nabla$ & $\Delta$ & $\Delta$ \\
\hline 7 & $\nabla$ & $\nabla$ & $\nabla$ & $\nabla$ & 口 & $\nabla$ & $\circ$ & $\nabla$ & $\nabla$ & $\nabla$ & $\square$ & $\nabla$ & $\Delta$ & $\nabla$ & $\nabla$ & $\nabla$ & $\nabla$ & $\nabla$ & $\Delta$ & $\nabla$ & $\nabla$ & $\nabla$ & $\nabla$ & $\nabla$ & $\boldsymbol{\nabla}$ & $\nabla$ & $\Delta$ & $\nabla$ & $\nabla$ & $\nabla$ & $\Delta$ \\
\hline 8 & $\nabla$ & $\nabla$ & $\nabla$ & $\nabla$ & $\Delta$ & $\nabla$ & $\Delta$ & $\circ$ & $\nabla$ & $\nabla$ & $\Delta$ & $\nabla$ & $\Delta$ & $\nabla$ & $\nabla$ & $\nabla$ & $\nabla$ & $\nabla$ & $\Delta$ & $\nabla$ & $\nabla$ & $\nabla$ & $\nabla$ & $\nabla$ & $\nabla$ & $\nabla$ & $\Delta$ & $\nabla$ & $\nabla$ & $\nabla$ & $\Delta$ \\
\hline 9 & $\nabla$ & $\Delta$ & $\Delta$ & $\nabla$ & $\Delta$ & $\Delta$ & $\Delta$ & $\Delta$ & 0 & $\nabla$ & $\Delta$ & $\nabla$ & $\Delta$ & $\Delta$ & $\Delta$ & $\Delta$ & $\nabla$ & $\Delta$ & $\Delta$ & $\Delta$ & $\Delta$ & $\Delta$ & $\Delta$ & $\nabla$ & $\nabla$ & $\nabla$ & $\Delta$ & $\nabla$ & $\Delta$ & $\Delta$ & $\Delta$ \\
\hline 10 & $\Delta$ & $\Delta$ & $\Delta$ & $\Delta$ & $\Delta$ & $\Delta$ & $\Delta$ & $\Delta$ & $\Delta$ & $\circ$ & $\Delta$ & $\Delta$ & $\Delta$ & $\Delta$ & $\Delta$ & $\Delta$ & $\Delta$ & $\Delta$ & $\Delta$ & $\Delta$ & $\Delta$ & $\Delta$ & $\Delta$ & $\Delta$ & $\Delta$ & $\Delta$ & $\Delta$ & $\Delta$ & $\Delta$ & $\Delta$ & $\Delta$ \\
\hline 11 & $\nabla$ & $\nabla$ & $\nabla$ & $\nabla$ & $\bar{\square}$ & $\nabla$ & 口 & $\nabla$ & $\nabla$ & $\nabla$ & $\circ$ & $\nabla$ & $\Delta$ & $\nabla$ & $\nabla$ & $\nabla$ & $\nabla$ & $\nabla$ & $\Delta$ & $\nabla$ & $\nabla$ & $\nabla$ & $\nabla$ & $\nabla$ & $\nabla$ & $\nabla$ & $\Delta$ & $\nabla$ & $\nabla$ & $\nabla$ & $\Delta$ \\
\hline 12 & $\Delta$ & $\Delta$ & $\Delta$ & $\nabla$ & $\Delta$ & $\Delta$ & $\Delta$ & $\Delta$ & $\Delta$ & $\nabla$ & $\Delta$ & $\circ$ & $\Delta$ & $\Delta$ & $\Delta$ & $\Delta$ & $\Delta$ & $\Delta$ & $\Delta$ & $\Delta$ & $\Delta$ & $\Delta$ & $\Delta$ & $\Delta$ & $\nabla$ & $\nabla$ & $\Delta$ & $\Delta$ & $\Delta$ & $\Delta$ & $\Delta$ \\
\hline 13 & $\nabla$ & $\nabla$ & $\nabla$ & $\nabla$ & $\nabla$ & $\nabla$ & $\nabla$ & $\nabla$ & $\nabla$ & $\nabla$ & $\nabla$ & $\nabla$ & $\circ$ & $\nabla$ & $\nabla$ & $\nabla$ & $\nabla$ & $\nabla$ & $\nabla$ & $\nabla$ & $\nabla$ & $\nabla$ & $\nabla$ & $\nabla$ & $\nabla$ & $\nabla$ & $\bar{\square}$ & $\nabla$ & $\nabla$ & $\nabla$ & $\nabla$ \\
\hline 14 & $\nabla$ & $\Delta$ & $\Delta$ & $\nabla$ & $\Delta$ & $\Delta$ & $\Delta$ & $\Delta$ & $\nabla$ & $\nabla$ & $\Delta$ & $\nabla$ & $\Delta$ & $\circ$ & $\Delta$ & $\overline{\Delta \Delta}$ & $\nabla$ & $\Delta$ & $\Delta$ & $\Delta$ & $\Delta$ & $\Delta$ & $\Delta$ & $\nabla$ & $\nabla$ & $\nabla$ & $\Delta$ & $\nabla$ & $\square$ & $\Delta$ & $\Delta$ \\
\hline 15 & $\nabla$ & $\Delta$ & $\Delta$ & $\nabla$ & $\Delta$ & $\Delta$ & $\Delta$ & $\Delta$ & $\nabla$ & $\nabla$ & $\Delta$ & $\nabla$ & $\Delta$ & $\nabla$ & 0 & $\Delta$ & $\nabla$ & $\Delta$ & $\Delta$ & $\Delta$ & $\Delta$ & $\Delta$ & $\Delta$ & $\nabla$ & $\nabla$ & $\nabla$ & $\Delta$ & $\nabla$ & 口 & $\Delta$ & $\Delta$ \\
\hline 16 & $\nabla$ & 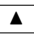 & 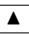 & $\boldsymbol{\nabla}$ & 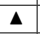 & $\Delta$ & $\Delta$ & $\Delta$ & $\nabla$ & $\nabla$ & $\Delta$ & $\nabla$ & $\Delta$ & $\nabla$ & $\nabla$ & $\circ$ & $\nabla$ & $\Delta$ & $\Delta$ & $\Delta$ & 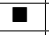 & $\Delta$ & $\Delta$ & 7 & $\nabla$ & $\nabla$ & $\Delta$ & $\nabla$ & $\nabla$ & $\Delta$ & $\Delta$ \\
\hline 17 & $\nabla$ & $\Delta$ & $\Delta$ & $\nabla$ & $\Delta$ & $\Delta$ & $\Delta$ & $\Delta$ & $\Delta$ & $\nabla$ & $\Delta$ & $\nabla$ & $\Delta$ & $\Delta$ & $\Delta$ & $\Delta$ & $\circ$ & $\Delta$ & $\Delta$ & $\Delta$ & $\Delta$ & $\Delta$ & $\Delta$ & $\bar{\square}$ & $\nabla$ & $\nabla$ & $\Delta$ & $\Delta$ & $\Delta$ & $\Delta$ & $\Delta$ \\
\hline 18 & $\nabla$ & $\nabla$ & $\nabla$ & $\nabla$ & $\Delta$ & $\square$ & $\Delta$ & $\Delta$ & $\nabla$ & $\nabla$ & $\Delta$ & $\nabla$ & $\Delta$ & $\nabla$ & $\nabla$ & $\nabla$ & $\nabla$ & $\circ$ & $\Delta$ & $\Delta$ & $\nabla$ & $\nabla$ & $\nabla$ & $\nabla$ & $\nabla$ & $\nabla$ & $\Delta$ & $\nabla$ & $\nabla$ & $\Delta$ & $\Delta$ \\
\hline 19 & $\nabla$ & $\nabla$ & $\nabla$ & $\nabla$ & $\nabla$ & $\nabla$ & $\nabla$ & $\nabla$ & $\nabla$ & $\nabla$ & $\nabla$ & $\nabla$ & $\Delta$ & $\nabla$ & $\nabla$ & $\nabla$ & $\nabla$ & $\nabla$ & $\circ$ & $\nabla$ & $\nabla$ & $\nabla$ & $\nabla$ & $\nabla$ & $\nabla$ & $\nabla$ & $\Delta$ & $\nabla$ & $\nabla$ & $\nabla$ & $\Delta$ \\
\hline 20 & $\nabla$ & $\nabla$ & $\nabla$ & $\nabla$ & $\Delta$ & $\nabla$ & $\Delta$ & $\Delta$ & $\nabla$ & $\nabla$ & $\Delta$ & $\nabla$ & $\Delta$ & $\nabla$ & $\nabla$ & $\nabla$ & $\nabla$ & $\nabla$ & $\Delta$ & $\circ$ & $\nabla$ & $\nabla$ & $\nabla$ & $\nabla$ & $\nabla$ & $\nabla$ & $\Delta$ & $\nabla$ & $\nabla$ & $\square$ & $\Delta$ \\
\hline 21 & $\nabla$ & $\Delta$ & $\Delta$ & $\nabla$ & $\Delta$ & $\Delta$ & $\Delta$ & $\Delta$ & $\nabla$ & $\nabla$ & $\Delta$ & $\nabla$ & $\Delta$ & $\nabla$ & $\nabla$ & 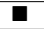 & $\nabla$ & $\Delta$ & $\Delta$ & $\Delta$ & $\circ$ & $\Delta$ & $\Delta$ & $\nabla$ & $\nabla$ & $\nabla$ & $\Delta$ & $\nabla$ & $\nabla$ & $\Delta$ & $\Delta$ \\
\hline 22 & $\nabla$ & $\nabla$ & $\nabla$ & $\nabla$ & $\Delta$ & $\Delta$ & $\Delta$ & $\Delta$ & $\nabla$ & $\nabla$ & $\Delta$ & $\nabla$ & $\Delta$ & $\nabla$ & $\nabla$ & $\nabla$ & $\nabla$ & $\Delta$ & $\Delta$ & $\Delta$ & $\nabla$ & $\circ$ & $\Delta$ & $\nabla$ & $\nabla$ & $\nabla$ & $\Delta$ & $\nabla$ & $\nabla$ & $\Delta$ & $\Delta$ \\
\hline 23 & $\nabla$ & $\nabla$ & $\nabla$ & $\nabla$ & $\Delta$ & $\Delta$ & $\Delta$ & $\Delta$ & $\nabla$ & $\nabla$ & $\Delta$ & $\nabla$ & $\Delta$ & $\nabla$ & $\nabla$ & $\nabla$ & $\nabla$ & $\Delta$ & $\Delta$ & $\Delta$ & $\nabla$ & $\nabla$ & $\circ$ & $\nabla$ & $\nabla$ & $\nabla$ & $\Delta$ & $\nabla$ & $\nabla$ & $\Delta$ & $\Delta$ \\
\hline 24 & 口 & $\Delta$ & $\Delta$ & $\nabla$ & $\Delta$ & $\Delta$ & $\Delta$ & $\Delta$ & $\Delta$ & $\nabla$ & $\Delta$ & $\nabla$ & $\Delta$ & $\Delta$ & $\Delta$ & $\Delta$ & 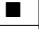 & $\Delta$ & $\Delta$ & $\Delta$ & $\Delta$ & $\Delta$ & $\Delta$ & $\circ$ & $\nabla$ & $\nabla$ & $\Delta$ & $\Delta$ & $\Delta$ & $\Delta$ & $\Delta$ \\
\hline 25 & $\Delta$ & $\Delta$ & $\Delta$ & $\nabla$ & $\Delta$ & $\Delta$ & $\Delta$ & $\Delta$ & $\Delta$ & $\nabla$ & $\Delta$ & $\Delta$ & $\Delta$ & $\Delta$ & $\Delta$ & $\Delta$ & $\Delta$ & $\Delta$ & $\Delta$ & $\Delta$ & $\Delta$ & $\Delta$ & $\Delta$ & $\Delta$ & $\circ$ & $\Delta$ & $\Delta$ & $\Delta$ & $\Delta$ & $\Delta$ & $\Delta$ \\
\hline 26 & $\Delta$ & $\Delta$ & $\Delta$ & $\nabla$ & $\Delta$ & $\Delta$ & $\Delta$ & $\Delta$ & $\Delta$ & $\nabla$ & $\Delta$ & $\Delta$ & $\Delta$ & $\Delta$ & $\Delta$ & $\Delta$ & $\Delta$ & $\Delta$ & $\Delta$ & $\Delta$ & $\Delta$ & $\Delta$ & $\Delta$ & $\Delta$ & $\nabla$ & $\circ$ & $\Delta$ & $\Delta$ & $\Delta$ & $\Delta$ & $\Delta$ \\
\hline 27 & $\nabla$ & $\nabla$ & $\nabla$ & $\nabla$ & $\nabla$ & $\nabla$ & $\nabla$ & $\nabla$ & $\nabla$ & 7 & $\nabla$ & $\nabla$ & $\square$ & $\nabla$ & $\nabla$ & $\nabla$ & $\nabla$ & $\nabla$ & $\nabla$ & $\nabla$ & $\nabla$ & $\nabla$ & $\nabla$ & $\nabla$ & $\nabla$ & 7 & $\circ$ & $\nabla$ & $\nabla$ & $\nabla$ & $\nabla$ \\
\hline 28 & $\nabla$ & $\Delta$ & $\Delta$ & $\nabla$ & $\Delta$ & $\Delta$ & $\Delta$ & $\Delta$ & $\Delta$ & $\nabla$ & $\Delta$ & $\nabla$ & $\Delta$ & $\Delta$ & $\Delta$ & $\Delta$ & $\nabla$ & $\Delta$ & $\Delta$ & $\Delta$ & $\Delta$ & $\Delta$ & $\Delta$ & $\nabla$ & $\nabla$ & $\nabla$ & $\Delta$ & $\circ$ & $\Delta$ & $\Delta$ & $\Delta$ \\
\hline 29 & $\nabla$ & $\Delta$ & $\Delta$ & $\nabla$ & $\Delta$ & $\Delta$ & $\Delta$ & $\Delta$ & $\nabla$ & $\nabla$ & $\Delta$ & $\nabla$ & $\Delta$ & $\square$ & 口 & $\Delta$ & $\nabla$ & $\Delta$ & $\Delta$ & $\Delta$ & $\Delta$ & $\Delta$ & $\Delta$ & $\nabla$ & $\nabla$ & $\nabla$ & $\Delta$ & $\nabla$ & $\circ$ & $\Delta$ & $\Delta$ \\
\hline 30 & $\nabla$ & $\nabla$ & $\nabla$ & $\nabla$ & $\Delta$ & $\nabla$ & $\Delta$ & $\Delta$ & $\nabla$ & $\nabla$ & $\Delta$ & $\nabla$ & $\Delta$ & $\boldsymbol{\nabla}$ & $\nabla$ & $\nabla$ & $\nabla$ & $\nabla$ & $\Delta$ & [ & $\nabla$ & $\nabla$ & $\nabla$ & $\nabla$ & $\nabla$ & $\nabla$ & $\Delta$ & $\nabla$ & $\nabla$ & $\circ$ & $\Delta$ \\
\hline 31 & $\nabla$ & $\nabla$ & $\nabla$ & $\nabla$ & $\nabla$ & $\nabla$ & $\nabla$ & $\nabla$ & $\nabla$ & $\nabla$ & $\nabla$ & $\nabla$ & $\Delta$ & $\nabla$ & $\nabla$ & $\nabla$ & $\nabla$ & $\nabla$ & $\nabla$ & $\nabla$ & $\nabla$ & $\nabla$ & $\nabla$ & $\nabla$ & $\nabla$ & $\nabla$ & $\Delta$ & $\nabla$ & $\nabla$ & $\nabla$ & $\circ$ \\
\hline
\end{tabular}

cada conjunto de dados, de modo a garantir diferentes inicializações dos protótipos iniciais. As médias dos valores obtidos para os índices silhueta e Jaccard são 
Tabela 8.10: Novos conjuntos de dados avaliados.

\begin{tabular}{|c|c|c|c|c|c|}
\hline \# & Características & \# & Características & \# & Características \\
\hline 32 & entr $_{\text {sal }}+\mathrm{HOG}_{\text {term }}$ & 35 & $\operatorname{std}_{\text {sal }}+$ std $_{\text {term }}$ & 38 & $\mathrm{entr}_{\text {sal }}+\mathrm{HOG}_{\text {term }}+\mathrm{std}_{\text {term }}$ \\
\hline 33 & entr $_{\text {sal }}+$ std $_{t e r m}$ & 36 & entr $_{\text {sal }}+\mathrm{std}_{\text {sal }}+\mathrm{HOG}_{\text {term }}$ & 39 & $\mathrm{HOG}_{\text {term }}+\mathrm{std}_{\text {term }}+\mathrm{std}_{\text {sal }}$ \\
\hline 34 & $\mathrm{std}_{\text {sal }}+\mathrm{HOG}_{\text {term }}$ & 37 & $\mathrm{entr}_{\text {sal }}+\mathrm{std}_{\text {sal }}+\mathrm{std}_{\text {term }}$ & 40 & entr $_{\text {sal }}+$ std $_{\text {sal }}++\mathrm{HOG}_{t e r m}+\mathrm{std}_{t e r m}$ \\
\hline
\end{tabular}

apresentadas, respectivamente, nas tabelas 8.11 e 8.12. Todas as execuções do algoritmo $\mathrm{x}$-médias resultaram novamente em sete partições.

Tabela 8.11: Valores das médias obtidas para o índice silhueta com mapas de saliência e imagens térmicas analisados em conjunto.

\begin{tabular}{|c|c|c|c|c|c|}
\hline $\begin{array}{c}\text { Conjuntos } \\
\text { de } \\
\text { Dados }\end{array}$ & \multicolumn{5}{|c|}{ Algoritmos } \\
\cline { 2 - 6 } & x-médias & $\begin{array}{c}\text { k-médias } \\
k=7\end{array}$ & $\begin{array}{c}\text { k-médias } \\
k=9\end{array}$ & $\begin{array}{c}\text { k-médias } \\
k=11\end{array}$ & $\begin{array}{c}\text { k-médias } \\
k=13\end{array}$ \\
\hline 32 & $0,97_{-}^{+} 0,01$ & $0,97_{-}^{+} 0,02$ & $0,92_{-}^{+} 0,04$ & $0,86_{-}^{+} 0,04$ & $0,83_{-}^{+} 0,03$ \\
\hline 33 & $0,95_{-}^{+} 0,02$ & $0,94_{-}^{+} 0,02$ & $0,91_{-}^{+} 0,02$ & $0,84_{-}^{+} 0,05$ & $0,81_{-}^{+} 0,03$ \\
\hline 34 & $0,82_{-}^{+} 0,02$ & $0,80_{-}^{+} 0,01$ & $0,76_{-}^{+} 0,03$ & $0,70_{-}^{+} 0,03$ & $0,67_{-}^{+} 0,03$ \\
\hline 35 & $0,71_{-}^{+} 0,03$ & $0,65_{-}^{+} 0,04$ & $0,63_{-}^{+} 0,03$ & $0,54_{-}^{+} 0,04$ & $0,51_{-}^{+} 0,04$ \\
\hline 36 & $0,77_{-}^{+} 0,01$ & $0,75_{-}^{+} 0,03$ & $0,72_{-}^{+} 0,02$ & $0,67_{-}^{+} 0,02$ & $0,63_{-}^{+} 0,03$ \\
\hline 37 & $0,65_{-}^{+} 0,03$ & $0,61_{-}^{+} 0,02$ & $0,58_{-}^{+} 0,03$ & $0,53_{-}^{+} 0,04$ & $0,49_{-}^{+} 0,05$ \\
\hline 38 & $0,99_{-}^{+} 0,01$ & $0,99_{-}^{+} 0,01$ & $0,95_{-}^{+} 0,04$ & $0,88_{-}^{+} 0,04$ & $0,83_{-}^{+} 0,04$ \\
\hline 39 & $0,60_{-}^{+} 0,04$ & $0,58_{-}^{+} 0,04$ & $0,53_{-}^{+} 0,03$ & $0,44_{-}^{+} 0,06$ & $0,39_{-}^{+} 0,05$ \\
\hline 40 & $0,63_{-}^{+} 0,03$ & $0,60_{-}^{+} 0,03$ & $0,54_{-}^{+} 0,05$ & $0,49_{-}^{+} 0,05$ & $0,42_{-}^{+} 0,06$ \\
\hline
\end{tabular}

Tabela 8.12: Valores das médias obtidas para o índice Jaccard com mapas de saliência e imagens térmicas analisados em conjunto.

\begin{tabular}{|c|c|c|c|c|c|}
\hline $\begin{array}{c}\text { Conjuntos } \\
\text { de } \\
\text { Dados }\end{array}$ & \multicolumn{5}{|c|}{ Algoritmos } \\
\cline { 2 - 6 } & X-médias & $\begin{array}{c}\text { k-médias } \\
k=7\end{array}$ & $\begin{array}{c}\text { k-médias } \\
k=9\end{array}$ & $\begin{array}{c}\text { k-médias } \\
k=11\end{array}$ & $\begin{array}{c}\text { k-médias } \\
k=13\end{array}$ \\
\hline 32 & $0,98_{-}^{+} 0,01$ & $0,97_{-}^{+} 0,01$ & $0,91_{-}^{+} 0,02$ & $0,87_{-}^{+} 0,02$ & $0,83_{-}^{+} 0,03$ \\
\hline 33 & $0,96_{-}^{+} 0,02$ & $0,96_{-}^{+} 0,01$ & $0,90_{-}^{+} 0,03$ & $0,84_{-}^{+} 0,03$ & $0,80_{-}^{+} 0,03$ \\
\hline 34 & $0,79_{-}^{+} 0,03$ & $0,76_{-}^{+} 0,02$ & $0,70_{-}^{+} 0,03$ & $0,69_{-}^{+} 0,02$ & $0,64_{-}^{+} 0,04$ \\
\hline 35 & $0,65_{-}^{+} 0,04$ & $0,61_{-}^{+} 0,03$ & $0,56_{-}^{+} 0,05$ & $0,50_{-}^{+} 0,05$ & $0,48_{-}^{+} 0,03$ \\
\hline 36 & $0,75_{-}^{+} 0,02$ & $0,72_{-}^{+} 0,01$ & $0,70_{-}^{+} 0,03$ & $0,64_{-}^{+} 0,05$ & $0,59_{-}^{+} 0,04$ \\
\hline 37 & $0,60_{-}^{+} 0,03$ & $0,59_{-}^{+} 0,03$ & $0,53_{-}^{+} 0,05$ & $0,49_{-}^{+} 0,05$ & $0,47_{-}^{+} 0,06$ \\
\hline 38 & $1,00_{-}^{+} 0,01$ & $1,00_{-}^{+} 0,01$ & $0,93_{-}^{+} 0,03$ & $0,89_{-}^{+} 0,03$ & $0,85_{-}^{+} 0,05$ \\
\hline 39 & $0,58_{-}^{+} 0,03$ & $0,55_{-}^{+} 0,03$ & $0,50_{-}^{+} 0,04$ & $0,40_{-}^{+} 0,03$ & $0,35_{-}^{+} 0,06$ \\
\hline 40 & $0,53_{-}^{+} 0,04$ & $0,55_{-}^{+} 0,02$ & $0,48_{-}^{+} 0,03$ & $0,41_{-}^{+} 0,06$ & $0,36_{-}^{+} 0,05$ \\
\hline
\end{tabular}

Embora seja possivel notar que alguns dos novos conjuntos de dados apresentam desempenhos superiores, pela observação destas tabelas percebe-se que não são obtidos apenas bons resultados. Para facilitar esta análise, os gráficos 8.17 e 8.18 ilustram, respectivamente, para os índices silhueta e Jaccard, os resultados encontrados nas tabelas 8.11 e 8.12 .

Pelos gráficos, é fácil identificar, mais uma vez, que os índices silhueta e Jac- 


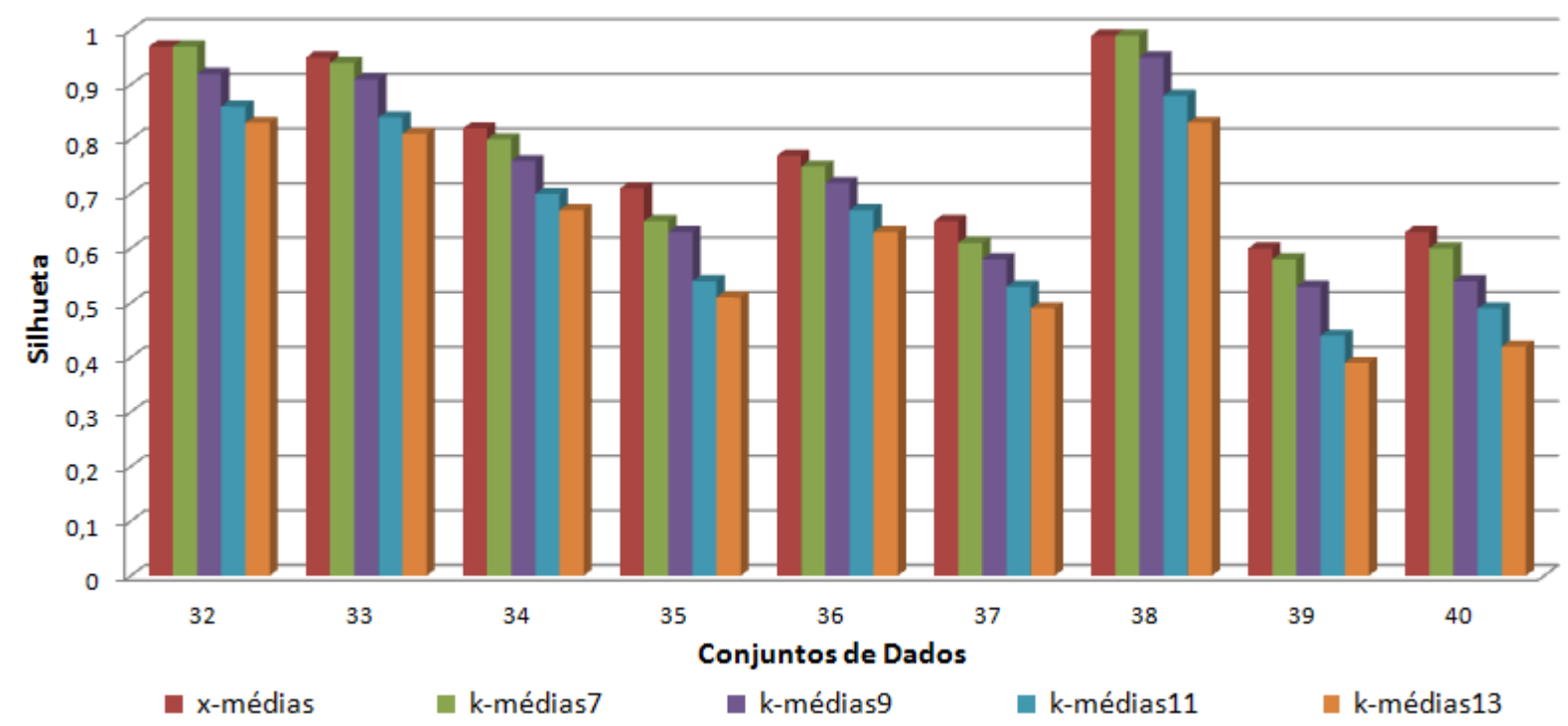

Figura 8.17: Gráfico com as médias do índice silhueta obtidas pela análise conjunta dos mapas de saliência e imagens térmicas.

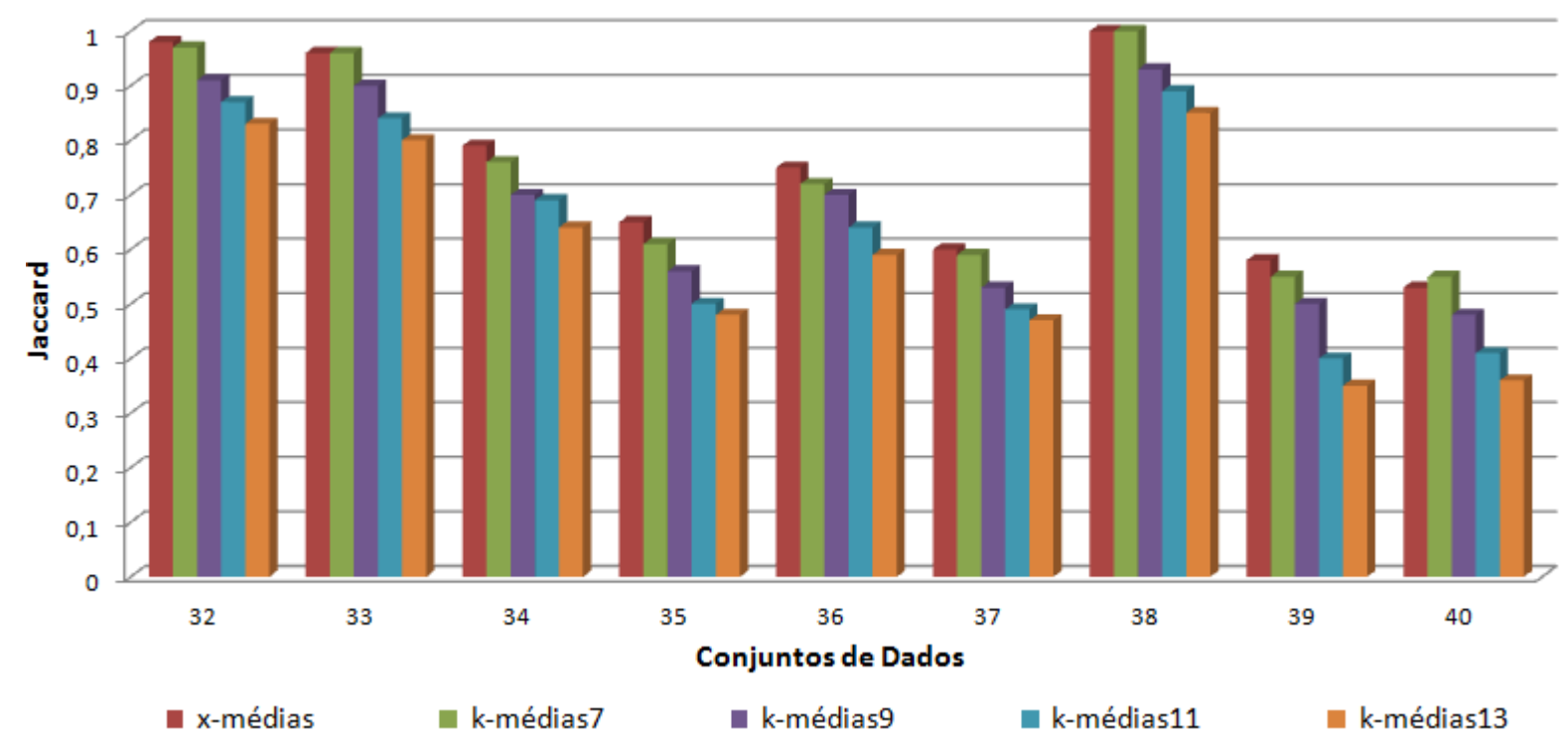

Figura 8.18: Gráfico com as médias do índice Jaccard obtidas pela análise conjunta dos mapas de saliência e imagens térmicas.

card apresentam valores inferiores conforme a quantidade de partições $k$ aumenta. É importante salientar também que, dentre os melhores resultados obtidos, não existem exemplos representativos de uma mesma expressão facial divididos entre todas as partições. Isto demonstra a capacidade destes novos conjuntos de melhor descrever as características relacionadas às seis emoções básicas e à expressão neutra.

Os exemplos das emoções de alegria e surpresa, assim como da expressão neutra, estão sempre corretamente agrupados. Em seguida, os exemplos das emoções de raiva e tristeza são mais facilmente reconhecidos. A aversão e a expressão de medo são, em geral, associadas a mais de uma partição. Mesmo assim, os exemplos de uma mesma expressão facial são distribuídos entre, no máximo, três partições 
distintas. O agrupamento ideal, que corretamente separa todos os exemplos em sete partições, é observado somente para o conjunto de número 38.

Para estatisticamente validar estes novos experimentos, os testes de Friedman e post-hoc de Nemenyi são também aplicados, com grau de confiança de 95\%. $\mathrm{Na}$ análise do desempenho obtido pelos algoritmos de agrupamento, o algoritmo $\mathrm{x}$-médias apresenta desempenho superior a todas as variações do algoritmo k-médias porém, para o valor de $k=7$, não é possível obter $95 \%$ de confiança. Adicionalmente, o algoritmo k-médias com $k=7$ é estatisticamente melhor que as demais variações do k-médias, com grau de confiança de 95\%, exceto para a versão com $k=9$, em que este grau de confiança não pode ser garantido.

Para comprovar a superioridade ou não dos novos conjuntos de dados avaliados, as tabelas 8.13 e 8.14 mostram, respectivamente, para os índices silhueta e Jaccard, as diferenças estatísticas encontradas. De modo a permitir a comparação destes conjuntos de dados com os melhores conjuntos encontrados na análise individual feita com os mapas de saliência e as imagens térmicas, os conjuntos 1 e 6 , relativos aos mapas de saliência, e os conjuntos 4 e 10, destacados para as imagens térmicas, são também apresentados.

Tabela 8.13: Comparação estatística obtida para os conjuntos de dados avaliados, considerando o índice silhueta e a análise conjunta dos mapas de saliência e imagens térmicas.

\begin{tabular}{|c|c|c|c|c|c|c|c|c|c|c|c|c|c|}
\hline \# & 32 & 33 & 34 & 35 & 36 & 37 & 38 & 39 & 40 & 1 & 6 & 4 & 10 \\
\hline 32 & $\circ$ & $\Delta$ & $\Delta$ & $\Delta$ & $\Delta$ & $\Delta$ & $\nabla$ & $\Delta$ & $\Delta$ & $\Delta$ & $\Delta$ & $\Delta$ & $\Delta$ \\
\hline 33 & $\nabla$ & 0 & $\bar{\Delta}$ & $\bar{\Delta}$ & $\Delta$ & $\bar{\Delta}$ & $\bar{\nabla}$ & $\bar{\Delta}$ & $\bar{\Delta}$ & $\square$ & $\bar{\Delta}$ & $\bar{\Delta}$ & $\mathbf{\square}$ \\
\hline 34 & $\nabla$ & $\nabla$ & 0 & $\Delta$ & $\Delta$ & $\Delta$ & $\nabla$ & $\Delta$ & $\Delta$ & $\nabla$ & $\nabla$ & $\nabla$ & $\nabla$ \\
\hline 35 & $\nabla$ & $\nabla$ & $\nabla$ & 0 & $\nabla$ & $\Delta$ & $\nabla$ & $\Delta$ & $\Delta$ & $\nabla$ & $\nabla$ & $\nabla$ & $\nabla$ \\
\hline 36 & $\nabla$ & $\nabla$ & $\nabla$ & $\Delta$ & $\circ$ & $\Delta$ & $\nabla$ & $\Delta$ & $\Delta$ & $\nabla$ & $\nabla$ & $\nabla$ & $\nabla$ \\
\hline 37 & $\nabla$ & $\nabla$ & $\nabla$ & $\nabla$ & $\nabla$ & 0 & $\nabla$ & $\Delta$ & $\Delta$ & $\nabla$ & $\nabla$ & $\nabla$ & $\nabla$ \\
\hline 38 & $\Delta$ & $\Delta$ & $\Delta$ & $\Delta$ & $\Delta$ & $\Delta$ & 0 & $\Delta$ & $\Delta$ & $\Delta$ & $\Delta$ & $\Delta$ & $\Delta$ \\
\hline 39 & $\nabla$ & $\nabla$ & $\nabla$ & $\nabla$ & $\nabla$ & $\nabla$ & $\nabla$ & 0 & $\nabla$ & $\nabla$ & $\nabla$ & $\nabla$ & $\nabla$ \\
\hline 40 & $\nabla$ & $\nabla$ & $\nabla$ & $\nabla$ & $\nabla$ & $\nabla$ & $\nabla$ & $\Delta$ & 0 & $\nabla$ & $\nabla$ & $\nabla$ & $\nabla$ \\
\hline 1 & $\nabla$ & $\square$ & $\Delta$ & $\Delta$ & $\bar{\Delta}$ & $\Delta$ & $\nabla$ & $\bar{\Delta}$ & $\bar{\Delta}$ & 0 & $\bar{\Delta}$ & $\square$ & $\boldsymbol{\nabla}$ \\
\hline 6 & $\nabla$ & $\nabla$ & $\Delta$ & $\Delta$ & $\Delta$ & $\Delta$ & $\nabla$ & $\Delta$ & $\Delta$ & $\nabla$ & 0 & $\nabla$ & $\nabla$ \\
\hline 4 & $\nabla$ & $\nabla$ & $\Delta$ & $\Delta$ & $\Delta$ & $\Delta$ & $\nabla$ & $\Delta$ & $\Delta$ & $\square$ & $\Delta$ & 0 & $\nabla$ \\
\hline 10 & $\nabla$ & $\square$ & $\Delta$ & $\Delta$ & $\Delta$ & $\Delta$ & $\nabla$ & $\Delta$ & $\Delta$ & $\Delta$ & $\Delta$ & $\Delta$ & 0 \\
\hline
\end{tabular}

Pelas tabelas, é possivel notar que o conjunto 38, composto pela entropia obtida dos mapas de saliência e pelos descritores HOG e desvio-padrão obtidos das imagens térmicas, é o de melhor desempenho. O conjunto 32 é estatisticamente inferior apenas ao conjunto 38. Nele, são encontradas características da saliência, provenientes dos mapas de entropia, e das imagens térmicas, advindas dos descritores HOG. Outro conjunto que se destaca é o de número 33, inferior apenas aos dois conjuntos acima citados. Este conjunto possui, além da entropia, obtida dos mapas de saliência, o desvio-padrão das imagens térmicas. Estas tabelas demonstram 
Tabela 8.14: Comparação estatística obtida para os conjuntos de dados avaliados, considerando o índice Jaccard e a análise conjunta dos mapas de saliência e imagens térmicas.

\begin{tabular}{|c|c|c|c|c|c|c|c|c|c|c|c|c|c|}
\hline$\#$ & 32 & 33 & 34 & 35 & 36 & 37 & 38 & 39 & 40 & 1 & 6 & 4 & 10 \\
\hline 32 & 0 & $\Delta$ & $\Delta$ & $\Delta$ & $\Delta$ & $\Delta$ & $\nabla$ & $\Delta$ & $\Delta$ & $\Delta$ & $\Delta$ & $\Delta$ & $\Delta$ \\
\hline 33 & $\boldsymbol{\nabla}$ & 0 & $\Delta$ & $\Delta$ & $\Delta$ & $\Delta$ & $\boldsymbol{\nabla}$ & $\Delta$ & $\Delta$ & $\Delta$ & $\Delta$ & $\Delta$ & $\Delta$ \\
\hline 34 & $\nabla$ & $\nabla$ & 0 & $\Delta$ & $\square$ & $\boldsymbol{\Delta}$ & $\nabla$ & $\Delta$ & $\Delta$ & $\nabla$ & $\nabla$ & $\nabla$ & $\nabla$ \\
\hline 35 & $\nabla$ & $\nabla$ & $\nabla$ & 0 & $\nabla$ & $\Delta$ & $\nabla$ & $\Delta$ & $\Delta$ & $\nabla$ & $\nabla$ & $\nabla$ & $\nabla$ \\
\hline 36 & $\nabla$ & $\nabla$ & $\square$ & $\Delta$ & 0 & $\Delta$ & $\nabla$ & $\Delta$ & $\Delta$ & $\nabla$ & $\nabla$ & $\nabla$ & $\nabla$ \\
\hline 37 & $\nabla$ & $\nabla$ & $\nabla$ & $\boldsymbol{\nabla}$ & $\nabla$ & 0 & $\nabla$ & $\Delta$ & $\Delta$ & $\nabla$ & $\nabla$ & $\nabla$ & $\nabla$ \\
\hline 38 & $\Delta$ & $\Delta$ & $\Delta$ & $\Delta$ & $\Delta$ & $\Delta$ & 0 & $\Delta$ & $\Delta$ & $\Delta$ & $\Delta$ & $\Delta$ & $\Delta$ \\
\hline 39 & $\nabla$ & $\nabla$ & $\nabla$ & $\nabla$ & $\nabla$ & $\nabla$ & $\nabla$ & 0 & $\square$ & $\nabla$ & $\nabla$ & $\nabla$ & $\nabla$ \\
\hline 40 & $\nabla$ & $\nabla$ & $\nabla$ & $\nabla$ & $\nabla$ & $\nabla$ & $\nabla$ & $\square$ & 0 & $\nabla$ & $\nabla$ & $\nabla$ & $\nabla$ \\
\hline 1 & $\nabla$ & $\nabla$ & $\Delta$ & $\Delta$ & $\Delta$ & $\Delta$ & $\nabla$ & $\Delta$ & $\Delta$ & 0 & $\Delta$ & $\square$ & $\nabla$ \\
\hline 6 & $\nabla$ & $\nabla$ & $\Delta$ & $\boldsymbol{\Delta}$ & $\Delta$ & $\Delta$ & $\nabla$ & $\Delta$ & $\Delta$ & $\nabla$ & 0 & $\nabla$ & $\nabla$ \\
\hline 4 & $\nabla$ & $\nabla$ & $\Delta$ & $\Delta$ & $\Delta$ & $\Delta$ & $\nabla$ & $\Delta$ & $\Delta$ & $\square$ & $\Delta$ & 0 & $\nabla$ \\
\hline 10 & $\nabla$ & $\nabla$ & $\Delta$ & $\Delta$ & $\Delta$ & $\Delta$ & $\nabla$ & $\Delta$ & $\Delta$ & $\Delta$ & $\Delta$ & $\Delta$ & 0 \\
\hline
\end{tabular}

também que, dentre os melhores resultados individuais, aqueles obtidos pela análise das imagens térmicas são superiores aos encontrados pela análise dos mapas de saliência.

A comparação estatística permite ainda identificar se os novos conjuntos de dados apresentam melhores desempenhos que os obtidos pela análise individual das imagens térmicas e dos mapas de saliência. Neste sentido, nota-se que os conjuntos de dados de número 32 e 38 têm desempenho superior aos melhores conjuntos individuais. O conjunto de número 33 apresenta resultados mistos, ou seja, considerando os quatro melhores conjuntos individuais, ele é melhor que alguns e semelhante a outros. Adicionalmente, os demais novos conjuntos de dados são estatisticamente inferiores.

Na Figura 8.19 são apresentadas as partições obtidas pelo conjunto de número 38, que possui o melhor desempenho estatístico dentre todos os 40 conjuntos de dados avaliados. Nesta figura, além da divisão das expressões faciais emocionais em sete partições distintas, o índice Jaccard encontrado é 1, ou seja, todos os exemplos estão corretamente agrupados de acordo com a classificação real dos dados em análise.

\subsubsection{Resultados obtidos com a Modelagem Proposta}

Uma vez validados os algoritmos e métodos que integram as diferentes partes da modelagem proposta, esta subseção apresenta os experimentos realizados para analisar o desempenho final obtido no reconhecimento da expressão neutra e das seis emoções básicas (Ekman, 1999).

A base de dados utilizada é a USTC-NVIE, pois contém imagens visíveis e térmicas obtidas simultaneamente de uma mesma expressão emocional, e neces- 


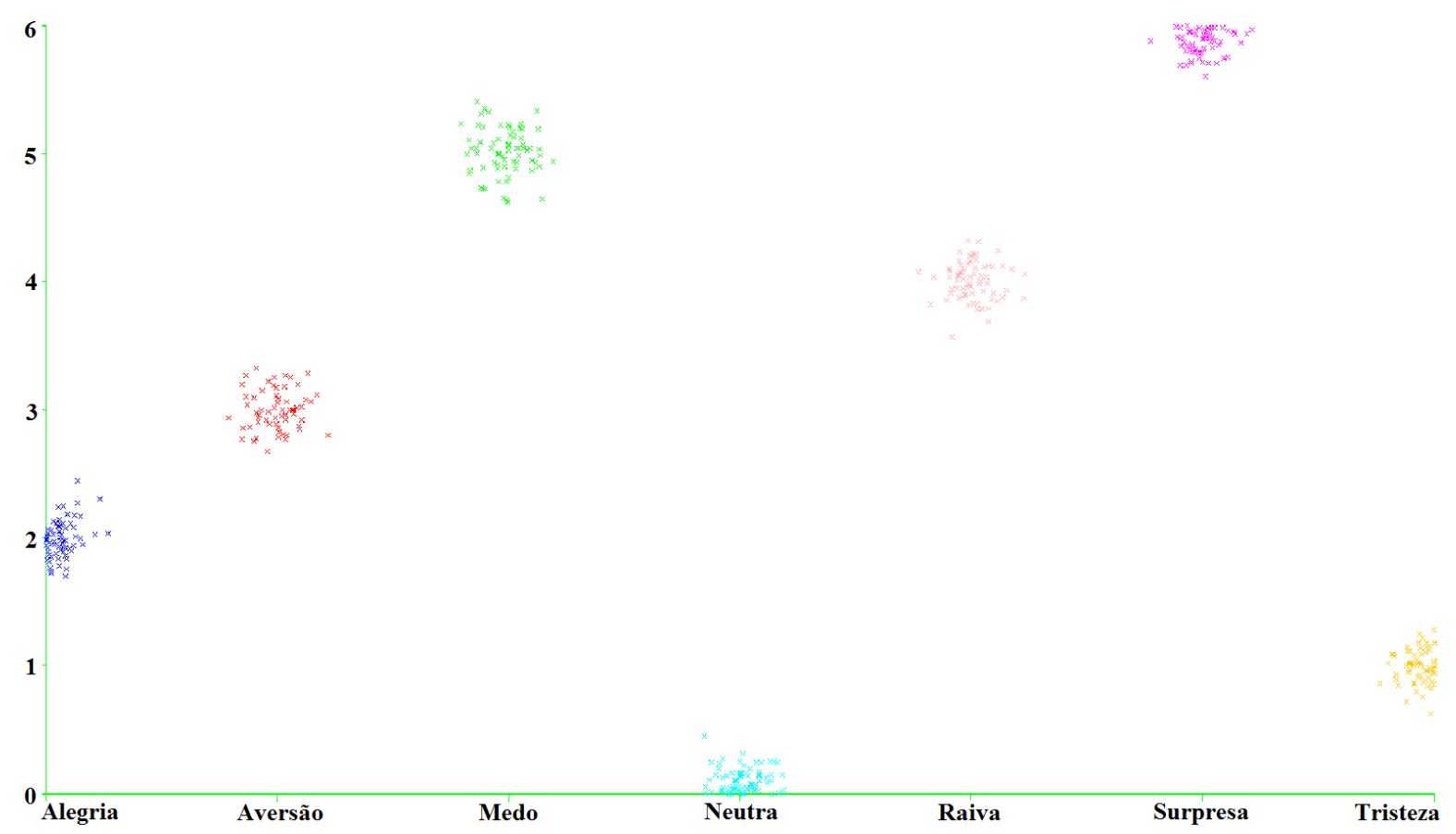

Figura 8.19: Melhor agrupamento encontrado, resultante da união de diferentes características dos mapas de saliência e das imagens térmicas.

sárias para o funcionamento do mecanismo de pré-atenção. Adicionalmente, uma vez que os classificadores utilizados são treinados com as bases CK+ e RaFD, esta base permite também avaliar a generalização da modelagem desenvolvida. Vale destacar que somente as imagens da base de dados USTC-NVIE não utilizadas nos experimentos realizados com os algoritmos de agrupamento são empregadas nestes experimentos, e representam 30\% do total de imagens encontradas nesta base.

Em todos os experimentos descritos, as emoções são individualmente analisadas, e o teste estatístico Student $t$ é aplicado para comparar os diferentes resultados obtidos. Ainda, o modelo de face neutra desenvolvido é também utilizado para simular condições reais de funcionamento da modelagem, nas quais a expressão neutra de um usuário não estará disponível.

Para facilitar o entendimento das diferentes etapas realizadas pela modelagem para a classificação de uma expressão emocional, a Figura 8.20 apresenta um exemplo de reconhecimento. Na figura, sete expressões faciais de alegria são analisadas. Assim, o mecanismo de pré-atenção avalia estas expressões, associando-as a partições do agrupamento. Nesta etapa, uma das expressões de alegria é incorretamente definida como raiva. Em seguida, o Face Tracker produz os vetores de características, que representam a geometria da face, e possuem apenas as características de diagnóstico correspondentes às expressões emocionais encontradas.

O vetor que representa a raiva é, pela análise das características faciais de diagnóstico, incorretamente classificado, ou seja, a modelagem identifica a emoção de raiva e não de alegria. Por outro lado, dentre as seis classificações corretas, as características de diagnóstico determinam que cinco representam a alegria. Neste 
sentido, uma delas não é reconhecida, sendo categorizada como indefinida. Nestas situações, novos vetores são produzidos pelo Face Tracker para as expressões indefinidas, e as características de diagnóstico das sete expressões emocionais consideradas neste trabalho são avaliadas para obter uma classificação final. No exemplo apresentado, a alegria é, nesta etapa, classificada como surpresa e, portanto, dentre as sete expressões de alegria, cinco são corretamente identificadas.

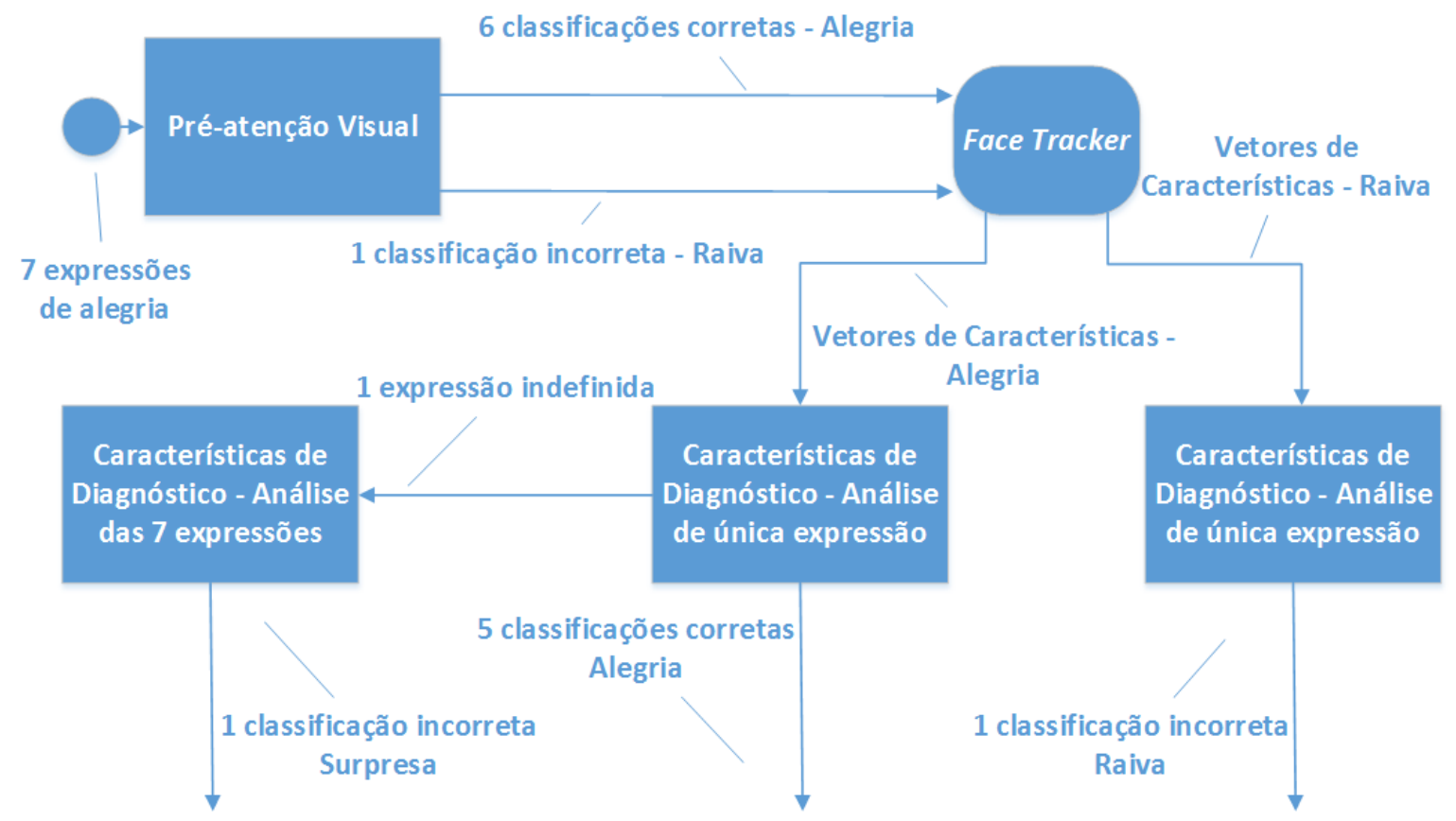

Figura 8.20: Exemplo de reconhecimento emocional realizado pela modelagem proposta.

Assim, na etapa inicial, a modelagem analisa as expressões emocionais com o mecanismo de pré-atenção visual. Este mecanismo é composto pelo algoritmo x-médias, que analisa as informações dos descritores HOG e do desvio-padrão, extraídas das imagens térmicas, e da entropia, obtida dos mapas de saliência. Estas informações representam o conjunto de dados 38, que obtém o melhor agrupamento encontrado, de acordo com a subseção 8.2.1. Do mesmo modo, o algoritmo x-médias é utilizado por apresentar o melhor desempenho dentre os algoritmos de agrupamento investigados.

Primeiramente, os mapas de saliência das imagens visíveis são obtidos. Estes, em conjunto com as imagens térmicas, são utilizados para produzir o vetor de características representativo da expressão emocional que, em seguida, é analisado pelo algoritmo x-médias. Como resultado, este vetor é associado a uma partição do agrupamento.

A classe da expressão em análise é obtida pela identificação da partição associada ao vetor de características que a representa. Deste modo, a comparação da classe encontrada com a classificação real da expressão emocional permite calcular as taxas de acerto e obter o desempenho desta etapa, apresentado na Tabela 
8.15. Nela, nota-se que uma taxa de reconhecimento de aproximadamente $80 \%$ é obtida pelo mecanismo de pré-atenção visual. Neste sentido, mesmo encontrando o agrupamento ideal durante os treinos, o algoritmo x-médias não confere resultados próximos a 100\% quando novos dados são apresentados.

Tabela 8.15: Desempenho obtido pelo mecanismo de pré-atenção visual.

\begin{tabular}{|c|c|}
\hline $\begin{array}{c}\text { Expressões } \\
\text { Faciais }\end{array}$ & $\begin{array}{c}\text { Taxa de } \\
\text { Acerto (\%) }\end{array}$ \\
\hline Raiva & 75,0 \\
\hline Medo & 64,0 \\
\hline Neutra & 80,6 \\
\hline Alegria & 92,0 \\
\hline Aversão & 73,9 \\
\hline Tristeza & 76,0 \\
\hline Surpresa & 84,0 \\
\hline Média & 77,9 \\
\hline
\end{tabular}

A generalização obtida pelas seis representações faciais na análise das expressões emocionais durante os experimentos realizados entre as bases RaFD e CK+, apresentados no Capítulo 7, é de 85,9\% para a alegria, 83,5\% para a surpresa, $80,3 \%$ para a expressão neutra, $77 \%$ para a raiva, $75,7 \%$ para a aversão, $74,3 \%$ para o medo, e $64,8 \%$ para a tristeza. Comparando estes resultados com os obtidos pelo mecanismo não supervisionado de pré-atenção visual tem-se que, para as expressões neutra e de surpresa, o desempenho é semelhante.

Ainda, a pré-atenção apresenta resultados estatisticamente inferiores para as emoções de raiva, medo e aversão, e superiores para as emoções de alegria e tristeza. De fato, o desempenho médio encontrado é similar, sendo 77,9\% para a pré-atenção visual e 77,3\% para a generalização entre as bases RaFD e CK+. A obtenção de desempenho semelhante ao encontrado para os experimentos supervisionados indica que a triagem inicial realizada pelo mecanismo de pré-atenção é satisfatória.

A provável expressão emocional identificada determina quais características faciais de diagnóstico devem ser analisadas para confirmar a validade do reconhecimento obtido. Deste modo, o Face Tracker é acionado para realizar o mapeamento da face e permitir a construção dos vetores de características necessários.

Os vetores de características utilizados na modelagem correspondem àqueles que conferem melhor desempenho aos algoritmos de seleção, independente se obtidos em experimentos com as bases CK+ ou RaFD, descritos no Capítulo 7, Subseção 7.2.2. Neste sentido, diferentes características de diagnóstico são responsáveis por representar cada expressão avaliada, assim como conjuntos distintos conferem igual desempenho aos classificadores na análise de uma mesma expressão emocional. A Tabela 8.16 apresenta a quantidade de vetores de características utilizada para representar cada expressão investigada. 
Tabela 8.16: Quantidade de vetores de características considerada para representar as diferentes expressões emocionais.

\begin{tabular}{|c|c|c|c|}
\hline $\begin{array}{c}\text { Expressões } \\
\text { Faciais }\end{array}$ & $\begin{array}{c}\text { \# de Vetores de } \\
\text { Características }\end{array}$ & $\begin{array}{c}\text { Máximo de } \\
\text { Atributos }\end{array}$ & $\begin{array}{c}\text { Mínimo de } \\
\text { Atributos }\end{array}$ \\
\hline Raiva & 4 & 11 & 3 \\
\hline Medo & 4 & 133 & 58 \\
\hline Neutra & 5 & 144 & 85 \\
\hline Alegria & 6 & 136 & 1 \\
\hline Aversão & 4 & 121 & 87 \\
\hline Tristeza & 4 & 9 & 5 \\
\hline Surpresa & 7 & 50 & 2 \\
\hline
\end{tabular}

Ainda, para que o reconhecimento emocional aconteça quase instantaneamente, permitindo a utilização da modelagem proposta em sistemas ou arquiteturas robóticas reais, apenas os vetores que possuem menos de 150 atributos são considerados. Devido à restrição imposta, é importante destacar que, para a aversão, os melhores vetores de características não são utilizados, pois apresentam mais de 150 atributos. Deste modo, os vetores selecionados são aqueles que garantem o segundo melhor desempenho aos algoritmos de seleção.

A análise das características de diagnóstico é feita pelos classificadores induzidos pelas SVMs, algoritmo C4.5 e redes MLP, obtidos a partir dos experimentos realizados com os algoritmos de seleção. Para a classificação final, os resultados individuais apresentados pelos diferentes classificadores são combinados utilizando a estratégia de votação por maioria. Neste processo, apenas as características que representam a expressão emocional anteriormente identificada pelo mecanismo de pré-atenção são avaliadas, reduzindo o esforço computacional da modelagem desenvolvida. Deste modo, o resultado obtido pode ou não ser igual ao apresentado pela pré-atenção.

O desempenho do procedimento descrito, no qual a pré-atenção direciona, de acordo com a expressão identificada, a análise de características faciais específicas, com o objetivo de encontrar uma correta classificação, pode ser visto na Tabela 8.17. Nesta tabela, a coluna "Expressão Indefinida" representa as situações em que os resultados obtidos pelo mecanismo de pré-atenção visual e pela análise das características faciais de diagnóstico são divergentes. Nestes casos, nenhuma classificação é atribuída à expressão emocional.

De acordo com os resultados apresentados, a análise das características de diagnóstico específicas da expressão emocional previamente reconhecida apresenta bom desempenho. Embora aproximadamente 25\% das expressões avaliadas sejam categorizadas como "indefinidas", é importante destacar que a pré-atenção classifica incorretamente $22,1 \%$ de todas as expressões analisadas. Neste sentido, o desempenho ideal desta etapa, supondo que não ocorram erros de análise, deve apresentar esta mesma taxa de expressões emocionais indefinidas, pois o objetivo é validar o 
Tabela 8.17: Análise das características de diagnóstico, direcionadas pelo mecanismo de pré-atenção visual, para identificar as expressões emocionais.

\begin{tabular}{|c|c|c|c|}
\hline $\begin{array}{c}\text { Expressões } \\
\text { Faciais }\end{array}$ & $\begin{array}{c}\text { Taxa de } \\
\text { Acerto (\%) }\end{array}$ & $\begin{array}{c}\text { Taxa de } \\
\text { Erro (\%) }\end{array}$ & $\begin{array}{c}\text { Expressão } \\
\text { Indefinida (\%) }\end{array}$ \\
\hline Raiva & 70,8 & 0,0 & 29,2 \\
\hline Medo & 52,0 & 4,0 & 44,0 \\
\hline Neutra & 74,2 & 3,2 & 22,6 \\
\hline Alegria & 92,0 & 0,0 & 8,0 \\
\hline Aversão & 69,6 & 0,0 & 30,4 \\
\hline Tristeza & 72,0 & 4,0 & 24,0 \\
\hline Surpresa & 84,0 & 0,0 & 16,0 \\
\hline Média & 73,5 & 1,6 & 24,9 \\
\hline
\end{tabular}

reconhecimento prévio. Deste modo, observando que a taxa de erro é inferior a $2 \%$, pode-se concluir que taxas de acerto elevadas são obtidas.

Nas situações de divergência entre a classificação obtida pela pré-atenção e a encontrada pela análise das características faciais de diagnóstico, a modelagem avalia todas as expressões emocionais conhecidas. Assim, os classificadores analisam as características de diagnóstico das sete possíveis expressões emocionais investigadas, resultando em maior tempo de processamento, mas permitindo a escolha de quaisquer delas, inclusive a existência de empates.

Para obter a predição final, os resultados encontrados pelos diferentes classificadores são combinados pela estratégia de votação por maioria. Se a confiança obtida para a expressão emocional em análise é superior a um determinado limiar, este resultado é aceito, e ocorre a classificação. Se este limiar não é atingido ou se valores iguais de confiança são obtidos para diferentes expressões emocionais, uma lista das classificações encontradas é disponibilizada. Para aceitação dos resultados, o limiar de confiança é fixado em 75\%. É importante notar que a falta de um valor de confiança mínimo permite que quaisquer expressões emocionais sejam listadas, por isso é feita a análise de todas as sete expressões.

Pelo apresentado, percebe-se que a modelagem proposta obtém, em alguns casos, mais de uma classificação para as expressões emocionais investigadas. A não identificação da expressão em análise pode ocorrer devido ao mapeamento de uma expressão facial desconhecida ou a erros de reconhecimento. Uma vez que a modelagem não é capaz de determinar a razão da falha, a lista de possíveis classificações é disponibilizada para permitir, a um sistema ou arquitetura que a utilize, avaliar os resultados encontrados.

A Tabela 8.18 mostra o desempenho obtido, em que a coluna "Acerto Parcial" representa situações de empate entre a classificação correta e classificações incorretas. Nesta tabela, somente as expressões que não obtém uma classificação final, ou seja, representadas pela coluna "Expressão Indefinida" da Tabela 8.17, são 
analisadas. Por isso, estes são apenas resultados intermediários da modelagem, a classificação final pode ser vista na Tabela 8.19.

Tabela 8.18: Reconhecimento, pela análise das características de diagnóstico, das expressões emocionais que apresentam resultados divergentes.

\begin{tabular}{|c|c|c|c|}
\hline $\begin{array}{c}\text { Expressões } \\
\text { Faciais }\end{array}$ & $\begin{array}{c}\text { Taxa de } \\
\text { Acerto (\%) }\end{array}$ & $\begin{array}{c}\text { Taxa de } \\
\text { Erro (\%) }\end{array}$ & $\begin{array}{c}\text { Acerto } \\
\text { Parcial (\%) }\end{array}$ \\
\hline Raiva & 57,1 & 28,6 & 14,3 \\
\hline Medo & 54,5 & 27,3 & 18,2 \\
\hline Neutra & 57,1 & 28,6 & 14,3 \\
\hline Alegria & 100,0 & 0,0 & 0,0 \\
\hline Aversão & 71,4 & 28,6 & 0,0 \\
\hline Tristeza & 50,0 & 16,7 & 33,3 \\
\hline Surpresa & 100,0 & 0,0 & 0,0 \\
\hline Média & 70,0 & 18,5 & 11,5 \\
\hline
\end{tabular}

Tabela 8.19: Classificação final das expressões emocionais investigadas, obtida pela modelagem proposta.

\begin{tabular}{|c|c|c|c|}
\hline $\begin{array}{c}\text { Expressões } \\
\text { Faciais }\end{array}$ & $\begin{array}{c}\text { Taxa de } \\
\text { Acerto (\%) }\end{array}$ & $\begin{array}{c}\text { Taxa de } \\
\text { Erro (\%) }\end{array}$ & $\begin{array}{c}\text { Acerto } \\
\text { Parcial (\%) }\end{array}$ \\
\hline Raiva & 87,5 & 8,3 & 4,2 \\
\hline Medo & 76,0 & 16,0 & 8,0 \\
\hline Neutra & 87,1 & 9,7 & 3,2 \\
\hline Alegria & 100,0 & 0,0 & 0,0 \\
\hline Aversão & 91,3 & 8,7 & 0,0 \\
\hline Tristeza & 84,0 & 8,0 & 8,0 \\
\hline Surpresa & 100,0 & 0,0 & 0,0 \\
\hline Média & 89,5 & 7,2 & 3,3 \\
\hline
\end{tabular}

Os resultados observados para a modelagem desenvolvida, que reconhece as expressões faciais emocionais de modo semelhante à maneira como os seres humanos possivelmente identificam as emoções, são comparados com o desempenho encontrado nos experimentos que medem a capacidade de generalização das seis representações faciais para as bases RaFD e $\mathrm{CK}^{+}$, detalhados no Capítulo 7, e apresentados também no início desta subseção.

Neste sentido, considerando todas as expressões avaliadas, os resultados obtidos pela modelagem são estatisticamente superiores. A diferença de desempenho supera 10\% para a maioria das emoções, com uma expressiva melhora de 19,2\% para a tristeza. As únicas exceções são a expressão neutra, que apresenta desempenho $6,8 \%$ superior, e a emoção de medo, que praticamente não vê seus resultados alterados. No entanto, mesmo com a melhoria no reconhecimento da tristeza, ela e o medo figuram entre as mais baixas taxas de acerto. Alegria e surpresa são 
perfeitamente identificadas seguidas, nesta ordem, pela aversão, raiva e expressão neutra.

Uma vez que a base de dados USTC-NVIE é composta por expressões faciais de asiáticos, e esta raça tem contribuição de apenas 5\% na combinação linear que determina as raças mais representativas do modelo de face neutra utilizado, isto pode ter prejudicado o desempenho observado para a expressão neutra.

Ainda, os resultados apresentados pela modelagem são também estatisticamente superiores aos obtidos apenas pelo mecanismo de pré-atenção, descritos na Tabela 8.15. Assim, é possível afirmar que as diferentes partes desenvolvidas, que envolvem a identificação das características faciais de diagnóstico e a utilização de métodos baseados em aparência em conjunto com métodos baseados em geometria, são responsáveis por melhorar o reconhecimento emocional.

Nas situações em que uma classificação única para a expressão em análise não é obtida, a disponibilização de uma lista com as prováveis expressões emocionais possibilita, a uma arquitetura ou sistema computacional que utilize a modelagem desenvolvida, empregar menos recursos para encontrar o resultado correto. Deste modo, é possível diminuir o tempo de resposta do sistema, importante para a obtenção de interações homem-máquina mais realísticas e duradouras.

Porém, com o objetivo de avaliar se as diferentes partes da modelagem são realmente necessárias para obter uma classificação emocional adequada, experimentos apenas com as características faciais de diagnóstico são realizados. A diferença fundamental deste experimento está no fato do mecanismo de pré-atenção não ser utilizado. Deste modo, o foco é avaliar se a pré-atenção visual, que direciona a análise para uma única expressão, contribui com o desempenho final observado. Os resultados obtidos podem ser vistos na tabela 8.20, em que a coluna "Acerto Parcial" indica situações de empate entre a classificação correta e classificações incorretas.

Tabela 8.20: Reconhecimento das expressões emocionais pela análise das características de diagnóstico, sem a utilização do mecanismo de pré-atenção.

\begin{tabular}{|c|c|c|c|}
\hline $\begin{array}{c}\text { Expressões } \\
\text { Faciais }\end{array}$ & $\begin{array}{c}\text { Taxa de } \\
\text { Acerto (\%) }\end{array}$ & $\begin{array}{c}\text { Taxa de } \\
\text { Erro (\%) }\end{array}$ & $\begin{array}{c}\text { Acerto } \\
\text { Parcial (\%) }\end{array}$ \\
\hline Raiva & 83,4 & 12,4 & 4,2 \\
\hline Medo & 76,0 & 16,0 & 8,0 \\
\hline Neutra & 80,6 & 12,9 & 6,5 \\
\hline Alegria & 96,0 & 4,0 & 0,0 \\
\hline Aversão & 86,9 & 13,1 & 0,0 \\
\hline Tristeza & 80,0 & 20,0 & 0,0 \\
\hline Surpresa & 92,0 & 8,0 & 0,0 \\
\hline Média & 85,0 & 12,3 & 2,7 \\
\hline
\end{tabular}

De acordo com esta tabela, tem-se que a utilização do mecanismo de pré-atenção para direcionar a análise de uma expressão emocional específica se mostra van- 
tajosa, pois a modelagem proposta apresenta desempenho estatisticamente superior ao obtido apenas pela avaliação das características de diagnóstico. Neste sentido, com exceção da expressão de medo, todas as demais têm seu reconhecimento aprimorado. Como resultado, um aumento de aproximadamente $5 \%$ na capacidade final de identificação das expressões emocionais avaliadas pode ser observado. Ainda, as taxas de acerto parciais da modelagem são superiores, assim como as taxas de erro são bastante reduzidas.

Portanto, os resultados encontrados demonstram a importância de utilizar a pré-atenção visual em conjunto com as características de diagnóstico para que a modelagem obtenha melhores desempenhos. No entanto, a contribuição apenas das características faciais de diagnóstico para o reconhecimento emocional ainda não é totalmente conhecida. Para isto, um novo experimento, em que as seis representações faciais desenvolvidas são avaliadas, é realizado.

Para obter a classificação de cada expressão emocional, são utilizados os classificadores induzidos pelas SVMs, algoritmo C4.5 e redes MLP, obtidos nos experimentos apresentados no Capítulo 7, Subseção 7.2.1. Deste modo, como existem dois classificadores para cada algoritmo de Aprendizado de Máquina (AM) investigado, obtidos pela análise das bases CK+ e RaFD, a classe da expressão avaliada, considerando cada representação facial, é dada pela combinação, utilizando votação por maioria, dos resultados individuais obtidos pelos diferentes classificadores.

O desempenho obtido, em porcentagem, para as emoções positivas e a expressão neutra pode ser visto na Tabela 8.21 e, na Tabela 8.22, são apresentados os resultados encontrados para as emoções negativas. Nestas tabelas, a coluna "Parcial" representa situações de empate entre a classificação correta e classificações incorretas.

Tabela 8.21: Resultados obtidos com as representações faciais desenvolvidas, para as emoções positivas e a expressão neutra.

\begin{tabular}{|c|c|c|c|c|c|c|}
\hline \multirow{2}{*}{$\begin{array}{c}\text { Representação } \\
\text { Facial }\end{array}$} & \multicolumn{2}{|c|}{ Neutra } & \multicolumn{2}{c|}{ Alegria } & \multicolumn{2}{c|}{ Surpresa } \\
\cline { 2 - 7 } & Acerto & Parcial & Acerto & Parcial & Acerto & Parcial \\
\hline$F S_{1}$ & 61,3 & 6,5 & 88,0 & 4,0 & 88,0 & 4,0 \\
\hline$F S_{2}$ & 48,4 & 3,2 & 80,0 & 0,0 & 76,0 & 8,0 \\
\hline$F S_{3}$ & 90,3 & 3,2 & 88,0 & 8,0 & 92,0 & 4,0 \\
\hline$F S_{4}$ & 87,1 & 0,0 & 88,0 & 0,0 & 76,0 & 0,0 \\
\hline$F S_{1-3}$ & 83,9 & 3,2 & 88,0 & 4,0 & 92,0 & 4,0 \\
\hline$F S_{2-4}$ & 67,7 & 6,5 & 76,0 & 0,0 & 64,0 & 0,0 \\
\hline Média & 73,1 & 3,8 & 84,7 & 2,7 & 81,3 & 3,4 \\
\hline
\end{tabular}

Os resultados obtidos indicam que a análise de todas as características existentes nas representações faciais aumenta a propensão a erros. Isto possivelmente ocorre pois a natureza do problema não é considerada, demonstrando que as características de diagnóstico têm grande influência no reconhecimento das diferentes expressões emocionais avaliadas. 
Tabela 8.22: Resultados obtidos com as representações faciais desenvolvidas, para as emoções negativas.

\begin{tabular}{|c|c|c|c|c|c|c|c|c|}
\hline Representação & \multicolumn{2}{|c|}{ Medo } & \multicolumn{2}{c|}{ Raiva } & \multicolumn{2}{c|}{ Tristeza } & \multicolumn{2}{c|}{ Aversão } \\
\cline { 2 - 9 } Facial & Acerto & Parcial & Acerto & Parcial & Acerto & Parcial & Acerto & Parcial \\
\hline$F S_{1}$ & 68,0 & 0,0 & 83,4 & 0,0 & 68,0 & 4,0 & 73,9 & 0,0 \\
\hline$F S_{2}$ & 68,0 & 4,0 & 70,8 & 8,3 & 60,0 & 8,0 & 60,8 & 8,7 \\
\hline$F S_{3}$ & 68,0 & 4,0 & 75,0 & 8,3 & 72,0 & 12,0 & 91,3 & 0,0 \\
\hline$F S_{4}$ & 76,0 & 12,0 & 79,2 & 0,0 & 68,0 & 4,0 & 78,2 & 4,3 \\
\hline$F S_{1-3}$ & 72,0 & 4,0 & 83,4 & 0,0 & 76,0 & 4,0 & 91,3 & 0,0 \\
\hline$F S_{2-4}$ & 80,0 & 0,0 & 62,5 & 4,2 & 76,0 & 4,0 & 56,5 & 0,0 \\
\hline Média & 72,0 & 4,0 & 75,7 & 3,5 & 70,0 & 6,0 & 75,3 & 2,2 \\
\hline
\end{tabular}

De fato, pelo observado na Tabela 8.20, a análise das características de diagnóstico melhora consideravelmente a capacidade de reconhecimento emocional, já que o desempenho encontrado é, para todas as expressões avaliadas, estatisticamente superior se comparado às médias obtidas para as mesmas expressões apresentadas nas tabelas 8.21 e 8.22. Para alegria, surpresa, aversão e tristeza, a análise de características de diagnóstico selecionadas resulta em melhorias acima de $10 \%$. Ainda, os resultados encontrados para a raiva e a expressão neutra facilitam, em mais de $7 \%$, a identificação. Por fim, uma melhoria de $4 \%$ é obtida para o medo. A taxa média de acerto, considerando todas as expressões emocionais, é de 85\%, com $2,7 \%$ de acertos parciais, ao passo que as representações faciais obtêm taxa de acerto média de $76 \%$, com $3,7 \%$ de acertos parciais, ou seja, um aumento de desempenho próximo a 10\% é alcançado.

A comparação dos resultados apresentados pelas tabelas 8.21 e 8.22 com os obtidos nos experimentos realizados no Capítulo 7, que avaliam, para as bases RaFD e CK+, a capacidade de generalização destas mesmas representações faciais, mostra que, para a análise da base de dados USTC-NVIE, o desempenho encontrado é similar. Como exceções, a emoção de tristeza tem sua taxa de reconhecimento melhorada, ao passo que a expressão neutra apresenta deterioração significativa dos resultados. Deste modo, se observado o acerto encontrado para a expressão neutra na Tabela 8.20, que avalia as características de diagnóstico, é possível notar que o desempenho é estatisticamente equivalente ao encontrado para os experimentos realizados no Capítulo 7 , portanto, apenas com o direcionamento para características específicas desta expressão, é possível obter taxas de acerto semelhantes às encontradas com as bases CK+ e RaFD.

Piores desempenhos podem ter sido encontrados para a expressão neutra devido à pequena contribuição da raça asiática na combinação linear utilizada pelo modelo de face neutra, como descrito anteriormente. Também, a melhor identificação da emoção de tristeza pode ser explicada pelas diferenças na maneira como orientais e ocidentais a expressam, exemplificada na Figura 8.21.

Esta figura mostra que, comparados aos ocidentais, os orientais são mais 

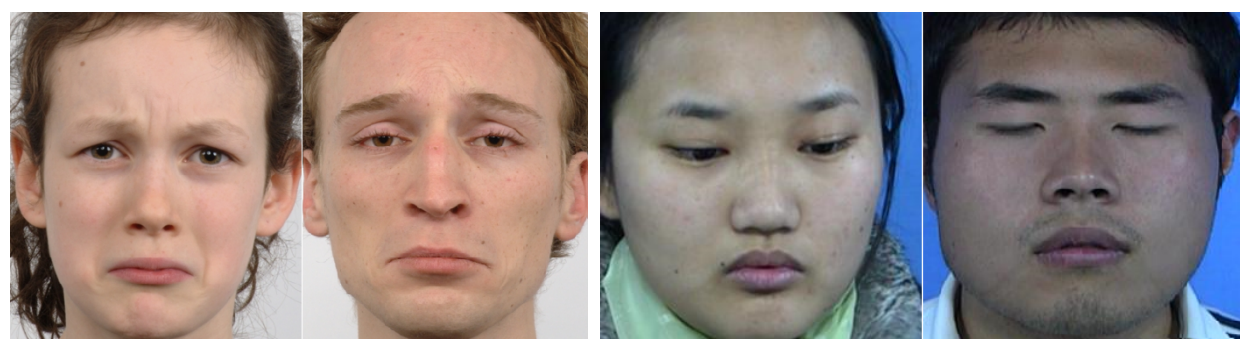

Figura 8.21: Diferenças na maneira de expressar a emoção de tristeza. À esquerda, pessoas ocidentais e, à direita, orientais.

contidos ao expressar emoções, por isso, os cantos dos lábios estão menos voltados para baixo. Devido a problemas de mapeamento encontrados no Face Tracker, que apresenta deficiências para representar corretamente os cantos dos lábios voltados para baixo, os exemplos previamente utilizados para treinar os classificadores podem ter se assemelhado ao mapeamento obtido pelo Face Tracker ao analisar as faces orientais que representam a tristeza. Como resultado, a identificação pode ter sido facilitada.

Uma vez que os experimentos realizados com a seis representações faciais desenvolvidas apresentam resultados semelhantes, independente se feitos com as bases RaFD e CK+, ou aplicados a exemplos da base de dados USTC-NVIE, pode-se assegurar a validade dos experimentos apresentados nesta subseção. Assim, o desempenho obtido pela análise das características faciais de diagnóstico, sem a utilização da pré-atenção, já indica, se comparado ao reconhecimento obtido pelas representações faciais, uma melhoria significativa nas taxas de identificação encontradas para as expressões emocionais avaliadas. Deste modo, nota-se que a utilização de vetores de características mais específicos para o domínio do problema investigado confere maior qualidade aos resultados finais.

Ainda, o fato da modelagem proposta obter desempenho estatisticamente superior, permite afirmar que conceitos psicológicos, assim como inspiração biológica, utilizados em conjunto, podem melhorar a tarefa de reconhecimento das expressões emocionais, além de conferir, a um sistema ou arquitetura que a utilize, a possibilidade de atuar de forma mais semelhante à maneira como os seres humanos, pela análise da face, interpretam as emoções.

O mecanismo de pré-atenção visual desenvolvido também apresenta benefícios, pois auxilia na identificação de quais características de diagnóstico devem ser primeiro avaliadas. Se esta análise obtém resultado divergente do encontrado pelo mecanismo de pré-atenção, a investigação de novas características é feita com o objetivo de corretamente classificar a expressão emocional. Dentre as emoções estudadas neste trabalho, a alegria e a surpresa são as de mais fácil reconhecimento. Neste sentido, já que a modelagem desenvolvida pouco melhora a classificação das expressões de medo, esta emoção pode apresentar relações faciais complexas que não puderam ser adequadamente mapeadas pelos algoritmos e métodos utilizados 
nesta tese.

Devido à utilização de diferentes representações faciais, metodologias, algoritmos de seleção, classificadores e bases de dados, é difícil comparar os resultados de trabalhos existentes na literatura com os apresentados pela modelagem proposta. Neste sentido, vale notar que é pequena a quantidade de trabalhos baseados em fundamentos psicológicos para o reconhecimento das emoções, e cada trabalho existente utiliza teorias distintas daquelas abordadas nesta tese (Khan et al., 2011; 2013). No entanto, é importante destacar que as taxas de acerto obtidas são elevadas e assemelham-se aos melhores desempenhos encontrados. Adicionalmente, tem-se a vantagem de que o reconhecimento emocional baseado em fundamentos psicológicos pode resultar em interações homem-máquina mais realísticas e naturais.

Como o objetivo é a utilização da modelagem para obter interações sociais reais, os tempos de execução, em segundos, da modelagem e de suas diferentes etapas são apresentados na Tabela 8.23. Para efeito de comparação, os tempos de execução obtidos pelas seis representações faciais são também apresentados, embora estas não sejam diretamente utilizadas pela modelagem.

O tempos apresentados foram obtidos pela média de 30 execuções distintas, utilizando um notebook com processador intel core i5 de segunda geração, com 2,27Ghz e 4Gb de memória RAM. Nesta tabela, "Inicialização da Modelagem" consiste em uma etapa inicial necessária, na qual os modelos induzidos pelos classificadores, assim como os modelos de face neutra, são carregados na memória para posterior utilização.

Tabela 8.23: Tempos de execução das diferentes etapas da modelagem.

\begin{tabular}{|c|c|c|c|}
\hline \multirow{2}{*}{ Etapas } & \multicolumn{3}{|c|}{ Tempos de Execução (segs) } \\
\cline { 2 - 4 } & Mínimo & Máximo & Médio \\
\hline $\begin{array}{c}\text { Representações } \\
\text { Faciais }\end{array}$ & 3,158 & 8,075 & 4,138 \\
\hline $\begin{array}{c}\text { Inicialização } \\
\text { da Modelagem }\end{array}$ & 7,102 & 11,103 & 7,849 \\
\hline Pré-atenção Visual & 0,096 & 0,247 & 0,138 \\
\hline $\begin{array}{c}\text { Características de } \\
\text { Diagnóstico }\end{array}$ & 2,511 & 3,504 & 2,721 \\
\hline Modelagem & 2,614 & 3,759 & 2,886 \\
\hline
\end{tabular}

Como pode ser observado, os tempos computacionais encontrados para a análise das características de diagnóstico, assim como os obtidos com a modelagem completa, não são demasiadamente elevados, indicando a possibilidade de utilizá-la em aplicações reais. Vale destacar que as representações faciais não são apenas mais lentas para a identificação das expressões faciais em análise, mas também apresentam desempenho inferior se comparadas com a modelagem ou com as características faciais de diagnóstico. Ainda, a pré-atenção visual modelada é um mecanismo instantâneo assemelhando-se, desta forma, aos estudos da psicologia. 


\subsection{Considerações Finais}

A modelagem desenvolvida se vale dos benefícios de métodos baseados em aparência e em geometria para reconhecer as seis emoções básicas, além da expressão neutra, utilizando conceitos biológicos e psicológicos. Deste modo, as medidas estatísticas e o método HOG conferem um desempenho apropriado ao mecanismo não supervisionado de pré-atenção visual, assim como a representação geométrica da face permite a análise supervisionada das características de diagnóstico.

Ademais, as imagens térmicas em conjunto com as imagens visiveis fornecem informações complementares para a identificação das emoções, tornando a modelagem menos suscetivel às condições de iluminação ou à qualidade das imagens analisadas. Vale também destacar que, quanto mais preciso o sistema de visão computacional utilizado para mapear os diferentes pontos, ângulos, distâncias e áreas faciais, melhor será o desempenho encontrado.

Neste sentido, além de obter taxas de acerto elevadas, semelhantes às melhores taxas de reconhecimento observadas na literatura, o emprego de teorias e conceitos psicológicos pode resultar no desenvolvimento de sistemas que demonstrem comportamento mais próximo ao apresentado pelos seres humanos durante o convivio em sociedade. 


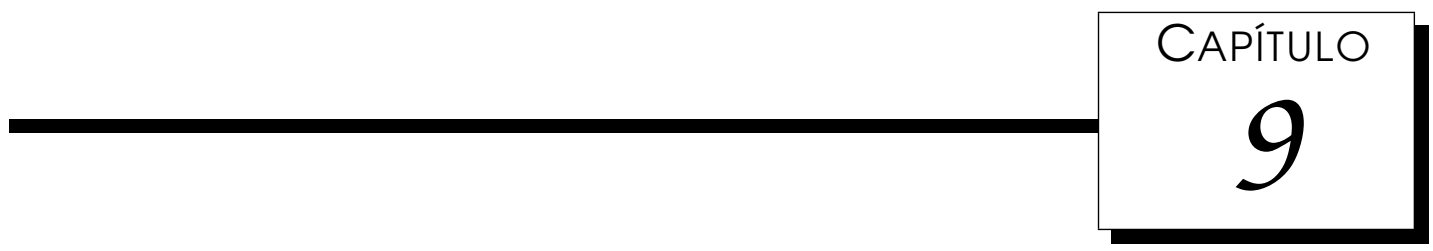

\section{Conclusões e Trabalhos Futuros}

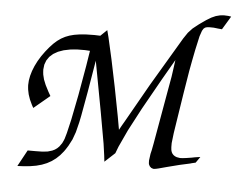
otivado pelos desafios encontrados pela Robótica Sociável que, dentre outros aspectos, desenvolve mecanismos para possibilitar a realização de interações mais realísticas e duradouras entre robôs e seres humanos, este trabalho investigou o reconhecimento das seis emoções básicas (Ekman, 1999) e da expressão neutra.

Acredita-se que, para um sistema exibir comportamento semelhante ao apresentado pelos seres humanos, os princípios utilizados em sua modelagem devem reproduzir os mecanismos que se pretende simular. Neste sentido, antes de desenvolver a modelagem computacional, os processos psicológicos e biológicos relacionados à identificação das emoções humanas foram estudados. No entanto, de acordo com a psicologia, não existe consenso sobre a natureza das emoções e seu reconhecimento. Deste modo, é necessário selecionar as teorias que serão utilizadas.

Dentre as modalidades responsáveis por expressar e reconhecer emoções, existem evidências da importância das expressões faciais no convivio e comunicação em sociedade, sendo consideradas a forma mais efetiva utilizada pelos seres humanos para a identificação emocional. Ainda, estudos psicológicos indicam que o sistema visual humano se baseia em alterações na configuração dos elementos faciais para categorizar uma emoção. Deste modo, métodos baseados em características geométricas são utilizados para representar as expressões emocionais analisadas pela modelagem computacional proposta.

Adicionalmente, as teorias psicológicas empregadas neste trabalho descrevem que, inicialmente, um mecanismo pré-atencional propicia uma rápida identificação das emoções. Em seguida, o direcionamento da atenção para locais específicos da face sofre influências de processos cognitivos top-down para encontrar as distintas características de diagnóstico, importantes para caracterizar as expressões emocio- 
nais. Uma vez que elementos faciais idênticos não são utilizados para reconhecer uma mesma expressão, distintas estruturas cerebrais podem ser responsáveis por esta tarefa. Por este motivo, as emoções são individualmente analisadas, o que permite aos métodos computacionais determinar as características responsáveis pelo melhor reconhecimento de cada uma das emoções estudadas.

A modelagem desenvolvida nesta tese confere ao mecanismo de pré-atenção visual a mesma função a ele atribuída pela psicologia, ou seja, rapidamente determinar o estado emocional de uma pessoa, para direcionar movimentos oculares subsequentes (Scheller et al., 2012). Vale destacar que este mecanismo é mais suscetível a falhas. A fixação do olhar para diferentes regiões faciais, de acordo com a expressão emocional identificada, é representada pelas características de diagnóstico, obtidas pelos algoritmos de seleção.

Taxas de acerto elevadas, próximas às melhores encontradas na literatura, são obtidas. A facilidade de reconhecimento apresentada pela modelagem, para as distintas emoções avaliadas, é semelhante ao descrito pela psicologia, com exceção da aversão. Neste sentido, os estudos psicológicos afirmam que as emoções de alegria e surpresa são as mais facilmente identificadas, seguidas por raiva e tristeza, e maior dificuldade existe na caracterização do medo e da aversão. Na modelagem, a classificação da aversão é apenas inferior aos desempenhos observados para as emoções de alegria e surpresa e, portanto, é possivel notar uma maior facilidade computacional para identificá-la.

Esta tese contribui com os trabalhos da literatura, em sua maioria recentes, que analisam as características extraídas de imagens térmicas e de imagens visíveis para aprimorar o reconhecimento emocional (Yoshitomi et al., 2000; Wang and He, 2013; Wang et al., 2014; Nguyen et al., 2014). As imagens térmicas em conjunto com as imagens visíveis fornecem informações complementares, fazendo com que a modelagem seja menos sensível às condições de iluminação ou à qualidade das imagens. É possível destacar também o modelo de face neutra desenvolvido que, ao mesmo tempo, possibilita a utilização da modelagem em aplicações reais, e confere flexibilidade a ela já que, ao permitir a alteração das contribuições das raças avaliadas, facilita o reconhecimento de diferenças sutis existentes na maneira como povos de distintas culturas interpretam as emoções.

Outra contribuição é o desenvolvimento das seis representações faciais que, ao apresentarem diferenças na complexidade e na maneira como os elementos geométricos estão distribuídos, permitem a exploração de uma grande variedade de atributos, e das relações entre eles, na tentativa de disponibilizar um conjunto de características de diagnóstico que possa ser efetivamente representativo para o reconhecimento das emoções.

Ainda, a avaliação destas características separadamente para cada expressão emocional, com a análise de diferentes algoritmos de seleção, que possuem para- 
digmas de aprendizado, funções de avaliação e métodos de busca distintos, além de duas bases de dados, permite encontrar uma lista diversificada de possibilidades. Isto, aliado à metodologia empregada para a escolha das características de diagnóstico, pode resultar na obtenção de elementos faciais que sejam mais eficientes para o reconhecimento das emoções, e apresentem menor dependência dos métodos computacionais utilizados.

Neste sentido, as diferentes características faciais identificadas são, por si só, uma contribuição, já que diversas áreas podem ser beneficiadas. Como exemplos, tem-se a validação computacional dos músculos ou unidades de ação (UAs) associados às seis emoções básicas, a modelagem em software de avatares capazes de movimentar a face de maneira mais natural, melhorando a qualidade das animações para jogos eletrônicos ou indústria de entretenimento. O desenvolvimento de faces robóticas com mecanismos que possibilitem corretamente sincronizar os movimentos envolvidos na expressão das emoções, a redução da complexidade dos dados de entrada para análise durante uma interação social, diminuindo o tempo de resposta do sistema ou robô. A utilização em estudos psicológicos, para aprimorar a compreensão das expressões relacionadas às seis emoções básicas, ou encontrar aspectos faciais comuns a distintos estados emocionais, permitindo o desenvolvimento de taxonomias para relacionar as emoções que apresentam características de diagnóstico semelhantes, dentre outros.

Por fim, a principal contribuição deste trabalho consiste na modelagem proposta, que pode ser incorporada a sistemas ou arquiteturas computacionais, para reconhecer as seis emoções básicas e a expressão neutra valendo-se de mecanismos semelhantes aos utilizados pelos seres humanos, com a possibilidade de aperfeiçoar as interações homem-máquina.

Neste sentido, até o momento, três artigos foram publicados em congressos internacionais (Libralon and Romero, 2013a;b; 2014b). Os dois primeiros estão relacionados especificamente ao reconhecimento emocional pela análise de expressões faciais, e o último trata da identificação das características faciais relevantes para reconhecer as diferentes emoções estudadas. Adicionalmente, um artigo descrevendo o procedimento de identificação das expressões emocionais investigadas, pela análise geométrica da face, juntamente com o reconhecimento das principais características de diagnóstico, foi submetido para avaliação por um periódico internacional (Libralon and Romero, 2014a).

\subsection{Trabalhos Futuros}

Embora a modelagem desenvolvida esteja apta para identificar as seis emoções básicas e a expressão neutra, existem melhorias que podem torná-la mais efetiva ao ser incorporada em sistemas ou arquiteturas computacionais. Assim, é possível destacar: 
- Validação em aplicações e robôs reais: Sistemas reais impõem a necessidade de tratar situações não controladas. Neste sentido, a modelagem proposta começa a ser aplicada para a identificação do estado emocional de pacientes em sessões de fisioterapia, assim como adaptações estão sendo feitas para o funcionamento em celulares com sistema Android. Outra possibilidade é a implementação em hardware para a realização de testes com robôs. Deste modo, será possível identificar possíveis limitações e desenvolver aprimoramentos;

- Análise de expressões emocionais em vídeos: Em aplicações reais, para classificar uma expressão, é necessário obter o frame que representa a face, pois a modelagem trabalha com imagens estáticas. Este processo pode gerar distorções nos resultados, uma vez que a expressão do usuário é constantemente alterada. Portanto, a eliminação deste procedimento, pela análise de vídeos, possibilita melhorar a qualidade das interações realizadas. Ainda, a utilização de vídeos permite que a modelagem avalie a dinâmica temporal das emoções;

- Aprendizado: Os classificadores atuais são estáticos, e precisam ser treinados para que novas expressões emocionais sejam identificadas. Neste sentido, a incorporação de mecanismos de aprendizagem como, por exemplo, imitação ou reforço, possibilita o aprendizado contínuo durante as interações com usuários. Assim, erros de reconhecimento ou o mapeamento de uma expressão facial desconhecida devem ser utilizados por estes mecanismos, para conferir autonomia à modelagem nas situações em que uma classificação única não é obtida, e a lista com as prováveis emoções é apresentada;

- Adição de características geométricas: O mapeamento de características relativas, ou seja, que modelam relações entre as diferentes partes da face, como o grau de abertura entre ângulos, ou as proporções entre diferentes elementos faciais, pode melhorar o desempenho obtido pela modelagem. Ainda, os atuais atributos utilizados permitem identificar as UAs associadas às diferentes regiões faciais, mas muitas delas como, por exemplo, as UAs 22, 23 e 24, relacionadas a movimentos dos lábios, não são precisamente determinadas pois representam diferentes movimentos de um mesmo músculo. Assim, a análise de novas características pode minimizar ou corrigir esta limitação;

- Reconhecimento de UAs: Uma vez que a modelagem é capaz de identificar as características de diagnóstico, a adaptação para automaticamente reconhecer as UAs faciais amplia sua aplicabilidade. 


\section{Referências Bibliográficas}

Anderson, K. and P. McOwan (2006). A real-time automated system for recognition of human facial expressions. IEEE Trans. Systems, Man and Cybernetics Part B 36(1), 96-105.

Baltrusaitis, T., D. McDuff, N. Banda, M. Mahmoud, R. Kaliouby, P. Robinson, and R. Picard (2011). Real-time inference of mental states from facial expressions and upper body gestures. In Proceedings of IEEE International Conference on Automatic Face and Gesture Recognition and Workshops (FG 2011), pp. 909-914. IEEE.

Bennewitz, M., F. Faber, D. Joho, and S. Behnke (2007). Fritz - a humanoid communication robot. In Proceedings of 16th IEEE International Symposium on Robot and Human Interactive Communication (RO-MAN), pp. 1072-1077. IEEE.

Berlin, M., C. Breazeal, and A. Thomaz (2005). Robot science meets social science: Embodied computational model of social referencing. In 20th Annual Meeting of the Cognitive Science Society, Toward social mechanisms of android science, Stresa, Itália, pp. 7-17.

Bethel, C. and R. Murphy (2008). Survey of non-facial/non-verbal affective expressions for appearance-constrained robots. IEEE Transactions on Systems, Man, and Cybernetics. Part C: Applications and Reviews 38(1), 83-92.

Bettadapura, V. (2012). Face expression recognition and analysis: The state of the art. In Technical Report, Cornell University Library, arXiv:1203.6722.

Boccignone, G. and M. Ferraro (2010). Gaze shifts as dynamical random sampling. In 2nd European Workshop on Visual Information Processing (EUVIP), pp. 29-34.

Breazeal, C. (2002). Designing Sociable Robots. MIT Press.

Breazeal, C. (2003a). Emotion and sociable humanoid robots. Human-Computer Studies 59(1), 119-155. 
Breazeal, C. (2003b). Toward sociable robots. Robotics and Autonomous Systems 42(3-4), 167-175.

Burt, P. and E. Adelson (1983). The laplacian pyramid as a compact image code. IEEE Transactions on Communications 31, 532-540.

Cañamero, L. (2003). Designing emotions for activity selection in autonomuos agents. Emotions in Humans and Artifacts. The MIT Press, Cambridge, Massachusetts, 115-148.

Calvo, M. and L. Nummenmaa (2008). Detection of emotional faces: Salient physical features guide effective visual search. Journal of Experimental Psychology: General 137(3), 471-494.

Caridakis, G., G. Castellano, L. Kessous, A. Raouzaiou, L. Malatesta, S. Asteriadis, and K. Karpouzis (2007). Multimodal emotion recognition from expressive faces, body gestures and speech. Artificial Intelligence and Innovations 2007: from Theory to Applications. IFIP The International Federation for Information Processing 247, 375-388.

Chen, S., T. Y., Q. Liu, and D. Metaxas (2013). Recognizing expressions from face and body gesture by temporal normalized motion and appearance features. Image and Vision Computing, Elsevier 31, 175-185.

Cohen, I., N. Sebe, A. Garg, L. Chen, and T. Huang (2003). Facial expression recognition from video sequences: temporal and static modeling. Computer Vision and Image Understanding 91, 160-187.

Cohen, I., N. Sebe, A. Garg, and T. Huang (2002). Facial expression recognition from video sequences. In Proc. International Conf. Multimedia and Expo, Volume 2, pp. 121-124.

Cohn, J. (2006). Foundations of human computing: Facial expression and emotion. In Proc. ACM Int. Conf. Multimodal Interfaces, Volume 1, pp. 610-616.

Cohn, J., Z. Ambadar, and P. Ekman (2007). Observer-based measurement of facial expression with the Facial Action Coding System. The Handbook of Emotion Elicitation and Assessment. Series in Affective Science (chapter 13). Oxford University Press.

Cowie, R., E. Douglas-Cowie, N. Tsapatsoulis, G. Votsis, S. Kollias, W. Fellenz, and J. Taylor (2001). Emotion recognition in human-computer interaction. IEEE Signal Processing Magazine 1, 32-80.

Dahmane, M. and J. Meunier (2011). Emotion recognition using dynamic grid-based hog features. In IEEE International Conference on Automatic Face and Gesture Recognition and Workshops (FG 2011), pp. 884-888. 
Dalal, N. and B. Triggs (2005). Histograms of oriented gradients for human detection. Computer Vision and Pattern Recognition (CVPR), 886-893.

Damasio, A. (1994). Descartes' Error: Emotion, Reason, and the Human Brain. Picador, Londres.

Darwin, C. (1872). The Expression of Emotions in Man and Animals. John Murray, reprinted by University of Chicago Press.

Deák, G. and J. Triesch (2005). Origins of shared attention in human infants. In K. Fuzita and S. Itakura (Eds.), Diversity of Cognition (In Press), pp. 67-74. Kyoto University Press.

Demsar, J. (2006). Statistical comparisons of classifiers over multiple data sets. Journal of Machine Learning Research 7, 1-30.

Du, S. and A. Martinez (2011). The resolution of facial expressions of emotion. Journal of Vision 11(13).

Ekman, P. (1973). Cross-cultural studies of facial expression. New York: Academic.

Ekman, P. (1999). Basic emotions. Wiley.

Ekman, P. and W. Friesen (2003). Unmasking the face. Cambridge, MA: Malor Books.

Ekman, P., W. Friesen, and J. Hager (2002). The Facial Action Coding System. Second edition. Salt Lake City: Research Nexus eBook. London: Weidenfeld and Nicolson.

El-Barkouky, A., H. Rara, A. Farag, and P. Womble (2012). Face detection at a distance using saliency maps. In Computer Vision and Pattern Recognition Workshops (CVPRW), IEEE Computer Society Conference on Biometrics Compendium, pp. 31-36.

Elazary, L. and L. Itti (2008). Interesting objects are visually salient. Journal of Vision 8(3), 1-15.

Faceli, K. (2001). Combinação de Métodos de Inteligência Artificial para Fusão de Sensores. Ph. D. thesis.

Faigan, G. (1990). The Artist's guide to Facial Expressions. Watson-Guphill Publications.

Flores, V. (2005/2014). Artnamoty/Artnatomia. http://www.artnatomia.net.

Fragopanagos, N. and J. Taylor (2005). Emotion recognition in human-computer interaction. Neural Networks 18, 389-405.

Frank, E. and I. Witten (2005). Data Mining: Practical Machine Learning Tools and Techniques. Morgan Kaufmann. 
Gazzaniga, M. and T. Heatherton (2005). Ciência Psicológica - Mente, Cérebro e Comportamento. Capítulo 10 - Emoções, estresse e coping. $1^{a}$ edição. Artmed.

Ghahari, A., Y. Fatmehsari, and R. Zoroofi (2009). A novel clustering-based feature extraction method for an automatic facial expression analysis system. In IEEE (Ed.), Proceedings of the 15th International Conference on Intelligent Information Hiding and Multimedia Signal Processing (IIH-MSP), pp. 1314-1317.

Gockley, R., R. Simmons, and J. Forlizzi (2006). Modeling affect in socially interactive robots. In 15th IEEE International Symposium on Robot and Human Interactive Communication, pp. 558-563.

Goldberg, D. E. (1989). Genetic algorithms in search, optimization and machine learning. Addison-Wesley Longman Publishing, Boston, MA.

Goswami, G., S. Bharadwaj, M. Vatsa, and R. Singh (2013). On rgb-d face recognition using kinect. In IEEE Sixth International Conference on Biometrics: Theory, Applications and Systems (BTAS), pp. 1-6.

Grizard, A. and C. Lisetti (2006). Generation of facial emotional expressions based on psychological theory. In 1rst Workshop on Emotion and Computing at KI 2006, 29th Annual Conference on Artificial Intelligence, Bremen, Alemanha, pp. 1482-1487.

Gualberto, L. and P. Filho (2007). Reconhecimento de ambientes costeiros a partir de análise textural de imagens. In Anais do Simpósio Brasileiro de Sensoriamento Remoto - SBSR'07, Volume 13, pp. 4889-4896.

Guyon, I. and A. Elisseeff (2003). An introduction to variable and feature selection. Journal of Machine Learning Research 3, 1157-1182.

Hanheide, M. and G. Sagerer (2008). Active memory-based interaction strategies for learning-enabling behaviors. In 17th International Symposium on Robot and Human Interactive Communication (RO-MAN).

Haykin, S. (1999). Neural networks - a compreensive foundation. Prentice-Hall, New Jersey, $2^{a}$ edição.

Hu, Y., Z. Zeng, L. Yin, X. Wei, X. Zhou, and T. Huang (2008). Multi-view facial expression recognition. In 8th IEEE International Conference on Automatic Face and Gesture Recognition, pp. 1-6.

Itoh, C., S. Kato, and H. Itoh (2009). Mood-transition-based emotion generation model for the robot's personality. In IEEE (Ed.), Proc. of the IEEE International Conference on Systems, Man and Cybernetics, pp. 2878-2883.

Itti, L. and C. Koch (2001). Computational modelling of visual attention. Nature Reviews Neuroscience 2, 194-203. 
Itti, L., C. Koch, and E. Niebur (1998). A model of saliency-based visual attention for rapid scene analysis. IEEE Transactions on Pattern Analysis and Machine Intelligence 2O(11), 1254-1259.

Jaccard, P. (1908). Nouvelles recherches sur la distribution florale. Bull. Soc. Vandoise des Sci. Nat. 44, 223-270.

Jain, A. and R. Dubes (1988). Algorithms for clustering data. Prentice Hall Inc.

Joyce, C., P. Schyns, F. Gosselin, G. Cottrell, and B. Rossion (2006). Early selection of diagnostic facial information in the human visual cortex. Journal of Vision Research, Elsevier 46, 800-813.

Kanade, T. (1973). Picture Processing System by Computer Complex and Recognition of Human Faces. Ph. D. thesis, Kyoto University.

Kasap, Z. and N. Magnenat-Thalmann (2010). Towards episodic memory-based long-term affective interaction with a human-like robot. In 19th IEEE International Symposium on Robot and Human Interactive Communication, pp. 479-484.

Khan, M., R. Ward, and M. Ingleby (2004). Automated classification and recognition of facial expressions using infrared thermal imaging. In IEEE Conference on Cybernetics and Intelligent Systems, Volume 1, pp. 202-206.

Khan, M., R. Ward, and M. Ingleby (2006). Infrared thermal sensing of positive and negative affective states. In IEEE Conference on Robotics, Automation and Mechatronics, pp. 1-6.

Khan, M., R. Ward, and M. Ingleby (2009). Classifying pretended and evoked facial expressions of positive and negative affective states using infrared measurement of skin temperature. ACM Transactions on Applied Perception 6(1), 1-22.

Khan, R., A. Meyer, H. Konik, and S. Bouakaz (2011). Facial expression recognition using entropy and brightness features. In 11th International Conference on Intelligent Systems Design and Applications (ISDA).

Khan, R., A. Meyer, H. Konik, and S. Bouakaz (2013). Framework for reliable, real-time facial expression recognition for low resolution images. Pattern Recognition Letters 34(10), 1159-1168.

Kim, H., S. Kwak, and M. Kim (2008). Personality design of sociable robots by control of gestures design factors. In IEEE (Ed.), Proc. of the 17th IEEE International Symposium on Robot and Human Interactive Communication, Munich, Alemanha, pp. 494-499.

Koch, C. and S. Ullman (1985). Shifts in selective visual attention: Towards the underlying neural circuitry. Human Neurobiology 4, 219-227. 
Kong, S., J. Heo, B. Abidi, J. Paik, and M. Abidi (2005). Recent advances in visual and infrared face recognition - a review. Computer Vision and Image Understanding 97(1), 103-135.

Kotsia, I. and I. Pitas (2007). Facial expression recognition in image sequences using geometric deformation features and support vector machines. In IEEE Transactions on Image Processing, Volume 16, pp. 172-187.

Langner, O., R. Dotsch, G. Bijlstra, D. Wigboldus, S. Hawk, and A. van Knippenberg (2010). Presentation and validation of the radboud faces database. Cognition and Emotion 24(8), 1377-1388.

Lee, H., J. Park, and M. Chung (2007). A linear affect-expression space model and control points for mascot-type facial robots. IEEE Transactions on Robotics 23(5), 863-873.

Li, H., J. Buenaposada, and L. Baumela (2008). Real-time facial expression recognition with illumination-corrected image sequences. In IEEE (Ed.), 8th IEEE International Conference on Automatic Face \& Gesture Recognition, pp. 1-6.

Libralon, G. and R. Romero (2013a). Geometrical facial modeling for emotion recognition. In Proceedings of the International Joint Conference on Neural Networks (IJCNN), pp. 2714-2721.

Libralon, G. and R. Romero (2013b). Investigating facial features for identification of emotions. In M. e. a. E. I. . Lee (Ed.), Proceedings of the 20th International Conference on Neural Information Processing (ICONIP), Part II, Lecture Notes in Computer Science, Springer-Verlag Berlin Heidelberg, Volume 8227, pp. 409-416.

Libralon, G. and R. Romero (2014a). Identification and mapping of emotional facial expressions. Artificial Intelligence Journal, Elsevier Submetido para análise.

Libralon, G. and R. Romero (2014b). Mapping of facial elements for emotion analysis. In Proceedings of the Brazilian Conference on Intelligent Systems (BRACIS).

Lohse, M., M. Hanheide, B. Wrede, M. L. Walters, K. L. Koay, D. S. Syrdal, A. Green, H. Hüttenrauch, K. Dautenhahn, G. Sagerer, and K. Severinson-Eklundh (2008). Evaluating extrovert and introvert behaviour of a domestic robot - a video study. In International Symposium on Robot and Human Interactive Communication (RO-MAN).

Lorena, A.C.; Souto, M. D. A. e. C. A. (2003). Técnicas de aprendizado de máquina para problemas de biologia molecular. Minicursos de Inteligência Artificial, Jornada de Atualização Científica em Inteligência Artificial, XXIII Congresso da Sociedade Brasileira de Computação, 103-152. 
Lucey, P., J. Cohn, T. Kanade, J. Saragih, Z. Ambadar, and I. Matthews (San Francisco, USA, 2010). The extended cohn-kanade dataset (ck+): A complete dataset for action unit and emotion-specified expression. In IEEE Workshop on CVPR for Human Communicative Behavior Analysis.

Lucey, P., S. Lucey, and J. Cohn (2010). Registration invariant representations for expression detection. In IEEE International Conference on Digital Image Computing: Techniques and Applications (DICTA), pp. 255-261.

Lucey, S., A. Ashraf, and J. Cohn (2007). Investigating Spontaneous Facial Action Recognition through AAM Representations of the Face. Face Recognition, Delac,K. and Grgic,M. eds., pp. 275-286, I-Tech Education and Publishing.

Ma, R. and J. Wang (2005). Automatic facial expression recognition using linear and nonlinear holistic spatial analysis. Affective Computing and Intelligent Interaction, Lecture Notes in Computer Science 3784, 144-151.

Malatesta, L., J. Murray, A. Raouzaiou, A. Hiolle, L. Canamero, and K. Karpouzis. Emotion Modelling and Facial Affect Recognition in Human-Computer and Human-Robot Interaction. State of the Art in Face Recognition, Book edited by: Dr. Mario I. Chacon M., I-Tech.

Marr, D. (1976). Early processing of visual information. Philosophical Transactions of the Royal Society of London 275(942), 483-519.

Martinez, A. and S. Du (2012). A model of the perception of facial expressions of emotion by humans: Research overview and perspectives. Journal of Machine Learning Research 13, 1589-1608.

Martinez, A. and D. Neth (2010). A computational shape-based model of anger and sadness justifies a configural representation of faces. Journal of Vision Research, Elsevier 50(17), 1693-1711.

Mason, R., R. Gunst, and J. Hess (1989). Statistical design and analysis of experiments. John Wiley and Sons.

Matsumoto, E. (2013). Matlab R2013a - Teoria e Programação - Guia Prático. Editora Érica, $1^{\mathrm{a}}$ edição.

Mekyska, J., V. Espinosa-Duró, and M. Faundez-Zanuy (2010). Face segmentation: A comparison between visible and thermal images. In IEEE International Carnahan Conference on Security Technology (ICCST), Volume 1, pp. 185-189.

Mitchell, T. (1997). Machine Learning. McGraw Hill.

Mitra, S., C. Saha, and A. Das (2011). Hierarchical clustering based facial expression analysis from video sequence. In IEEE (Ed.), International Conference on Communication and Industrial Application (ICCIA), pp. 1-5. 
Mohameda, Z. and G. Capi (2012). Development of a new mobile humanoid robot for assisting elderly people. In Elsevier (Ed.), International Symposium on Robotics and Intelligent Sensors (IRIS 2012), Procedia Engineering, Volume 41, pp. 345-351.

Monard, M. and J. Baranauskas (2003). Conceitos sobre Aprendizado de Máquina. Em Rezende,S.O. (ed.): Sistemas Inteligentes - Fundamentos e Aplicações. pp. 89-114, Editora Manole Ltda.

Navot, A. (2006). On the Role of Feature Selection in Machine Learning. Ph. D. thesis, Hebrew University.

Nguyen, H., F. Chen, K. Kotani, and B. Le (2014). Human emotion estimation using wavelet transform and t-rois for fusion of visible images and thermal image sequences. In Proceedings of the 14th International Conference Computational Science and Its Applications (ICCSA), Part VI, Lecture Notes in Computer Science, Volume 8584, pp. 224-235.

Nhan, B. and T. Chau (2010). Classifying affective states using thermal infrared imaging of the human face. IEEE Transactions on Biomedical Engineering 57(4), 979-987.

Orrite, C., A. Gañán, and G. Rogez (2009). Hog-based decision tree for facial expression classification. In Em H. Araujo et al. (Eds.): IbPRIA 2009, Pattern Recognition and Image Analysis, Lecture Notes in Computer Science, Springer-Verlag Berlin Heidelberg, Volume 5524, pp. 176-183.

Otsu, N. (1979). A threshold selection method from gray-level histograms. IEEE Transactions on Systems, Man and Cybernetics 9(1), 62-66.

Paleari, M., R. Chellali, and B. Huet (2010). Features for multimodal emotion recognition: An extensive study. In IEEE Conference on Cybernetics and Intelligent Systems, pp. 90-95.

Pantic, M. and L. Rothkrantz (2003). Toward an affect-sensitive multimodal human-computer interaction. IEEE 91(9), 1370-1390.

Park, K., H. Lee, Y. Kim, and Z. Bien (2008). A steward robot for human-friendly human-machine interaction in a smart house environment. IEEE Transactions on Automation Science and Engineering 5(1), 21-25.

Parke, F. (1974). A parametric model for human faces. Ph. D. thesis.

Pelleg, D. and A. Moore (2000). X-means: extending k-means with efficient estimation of the number of clusters. In Proceedings of the Seventeenth International Conference on Machine Learning, Volume 1, pp. 727-734. 
Picard, R. (2003). What does it mean for a computer to have emotions? Emotions in Humans and Artifacts. The MIT Press, Cambridge, Massachusetts, 213-235.

Plutchik, R. (1980). Emotion: A psychoevolutionary synthesis. Harper and Row, Nova Iorque.

Policastro, C., R. Romero, G. Zuliani, and E. Pizzolato (2009). Learning of shared attention in sociable robots. Journal of Algorithms, Cognition, Informatics and Logic 64, 139-151.

Prampero, P. (1998). Combinação de classificadores para o reconhecimento de padrões. Ph. D. thesis.

Quinlan, J. R. (1993). C4.5: Programs for machine learning. Morgan Kaufmann.

Rabie, A., C. Lang, M. Hanheide, M. Castrillón-Santana, and G. Sagerer (2008). Automatic initialization for facial analysis in interactive robotics. In Proceedings of the 6th International Conference on Computer Vision Systems (ICVS), Lecture Notes in Computer Science, Part VII, Volume 5008, pp. 517-526.

Rousseeuw, P. (1987). Silhouettes: a graphical aid to the interpretation and validation of cluster analysis. Journal of Computational and Applied Mathematics 20(1), 53-65.

Russell, J. (1980). A circumplex model of affect. Journal of Personality and Social Psychology 39, 1161-1178.

Saldien, J., K. Goris, S. Yilmazyildiz, W. Verhelst, and D. Lefeber (2008). On the design of the huggable robot probo. Journal of Physical Agents, Special Issue on Human Interaction with Domestic Robots 2(2).

Salichs, M., R. Barber, A. Khamis, M. Malfaz, J. Gorostiza, R. Pacheco, R. Rivas, A. Corrales, and E. Delgado (2006). Maggie: A robotic platform for human-robot social interaction. In IEEE International Conference on Robotics, Automation and Mechatronics (RAM 2006). Bangkok. Thailand.

Saragih, J., S. Lucey, and J. Cohn (2011). Deformable model fitting by regularized landmark mean-shift. International Journal of Computer Vision 91(2), 200-215.

Sarvadevabhatla, R., M. Benovoy, S. Musallam, and V. Ng-Thow-Hing (2011). Adaptive facial expression recognition using inter-modal top-down context. In ICMI' 11 Proceedings of the 13th International Conference on Multimodal Interfaces, pp. 27-34.

Scheller, E., C. Buchel, and M. Gamer (2012). Diagnostic features of emotional expressions are processed preferentially. PLOS ONE 7(7), e41792. 
Schyns, P., L. Petro, and M. Smith (2009). Transmission of facial expressions of emotion co-evolved with their efficient decoding in the brain: Behavioral and brain evidence. PLoS ONE 4(5), e5625.

Sebe, N., I. Cohen, T. Gevers, and T. Huang (2005). Multimodal approaches for emotion recognition: a survey. In S. R. Santini, S. and T. e. Gevers (Eds.), Proceedings of the SPIE: Internet Imaging VI, Volume 5670, pp. 56-67.

Shan, C., S. Gong, and P. McOwan (2009). Facial expression recognition based on local binary patterns: A comprehensive study. Image and Vision Computing 27(6), 803-816.

Sheerman-Chase, T., E.-J. Ong, N. Pugeault, and R. Bowden (2013). Improving recognition and identification of facial areas involved in non-verbal communication by feature selection. In 10th IEEE International Conference and Workshops on Automatic Face and Gesture Recognition (FG), pp. 1-8.

Shih, F., C.-F. Chuang, and P. Wang (2008). Performance comparisons of facial expression recognition in jaffe database. International Journal of Pattern Recognition and Artificial Intelligence 22(3), 445-459.

Sidner, C., C. Lee, C. Kidd, N. Lesh, and C. Rich (2005). Explorations in engagement for humans and robots. Artificial Intelligence 166(1-2), 181-186.

Sirovich, L. and M. Kirby (1987). Low-dimensional procedure for the characterization of human faces. Jounal of Optical Soc. Am. 4, 519-524.

Smith, M., G. Cottrell, F. Gosselin, and P. Schyns (2005). Transmitting and decoding facial expressions. Psychological Science, American Psychological Society 16(3), 184-189.

Spexard, T., M. Hanheide, and G. Sagerer (2007). Human-oriented interaction with an anthropomorphic robot. IEEE Transactions on Robotics 23, 852-862.

Tekalp, A. and J. Ostermann (2000). Face and 2-d mesh animation in mpeg-4. Signal Processing: Image Communication 15, 387-421.

Tian, Y., T. Kanade, and J. Cohn (2005). Handbook of Face Recognition. Capitulo 11. Facial Expression Analysis. Springer.

Tong, Y., J. Chen, and Q. Ji (2010). A unified probabilistic framework for spontaneous facial action modeling and understanding. IEEE Transactions on Pattern Analysis and Machine Intelligence 32(2), 258-273.

Valenti, R., N. Sebe, and T. Gevers (2012). What are you looking at? improving visual gaze estimation by saliency. International Journal of Computer Vision (IJCV) 98(3), 324-334. 
Valstar, M. (2008). Timing is everything: A spatio-temporal approach to the analysis of facial actions. $\mathrm{Ph}$. D. thesis.

Vanderborght, B., R. Simut, J. Saldien, C. Pop, A. Rusu, S. Pintea, D. Lefeber, and D. David (2012). Using the social robot probo as a social story telling agent for children with asd. Interaction Studies 13(3), 348-372.

Vapnik, V. (1995). The nature of statistical learning theory. Springer-Verlag, $2^{a}$ edição.

Viola, P. and M. Jones (2004). Robust real-time face detection. International Journal of Computer Vision 57(2), 137-154.

Wang, C., Y. Wang, and Z. Zhang (2010). Face detection in videos using skin color segmentation and saliency model. In Chinese Conference on Pattern Recognition (CCPR), pp. 1-5.

Wang, S. and S. He (2013). Spontaneous facial expression recognition by fusing thermal infrared and visible images. In Proceedings of the 12th International Conference Intelligent Autonomous Systems (IAS), Advances in Intelligent Systems and Computing, Springer, Volume 194, pp. 263-272.

Wang, S., S. He, Y. Wu, M. He, and Q. Ji (2014). Fusion of visible and thermal images for facial expression recognition. Frontiers of Computer Science 8(2), 232-242.

Wang, S., Z. Liu, S. Lv, Y. Lv, G. Wu, P. Peng, F. Chen, and X. Wang (2010). A natural visible and infrared facial expression database for expression recognition and emotion inference. IEEE Transactions on Multimedia 12(7), 682-691.

Wang, S., S. Lv, and X. Wang (2008). Infrared facial expression recognition using wavelet transform. In IEEE International Symposium on Computer Science and Computational Technology (ISCSCT 'O8), pp. 327-330.

Wang, S., P. Shen, and Z. Liu (2012). Facial expression recognition from infrared thermal images using temperature difference by voting. In IEEE 2nd International Conference on Cloud Computing and Intelligent Systems (CCIS), Volume 1, pp. 94-98.

Weiss, S. and N. Indurkhya (1998). Predictive Data Mining: A Practical Guide. Morgan Kaufmann Publishers Inc., San Francisco, CA.

Wessels, L., M. Reinders, A. Hart, C. Veenman, H. Dai, T. He, and L. van't Veer (2005). A protocol for building and evaluating predictors of disease state based on microarray data. Bioinformatics 21(19), 3755-3762.

Yang, Y., G. Wang, and H. Kong (2009). Self-learning facial emotional feature selection based on rough set theory. Mathematical Problems in Engineering, Hindawi Publishing Corporation. 
Yoshitomi, Y., K. Sung-Ill, T. Kawano, and T. Kilazoe (2000). Effect of sensor fusion for recognition of emotional states using voice, face image and thermal image of face. In Proceedings of the 9th IEEE International Workshop on Robot and Human Interactive Communication (RO-MAN), pp. 178-183.

Zeng, Z., M. Pantic, G. Roisman, and T. Huang (2009). A survey of affect recognition methods: Audio, visual, and spontaneous expression. IEEE Transactions on Pattern Analysis and Machine Learning 31(1), 39-58.

Zhang, J., X. Li, Y. Song, and J. Liu (2012). Fusiform face area is engaged in holistic, not parts-based, representation of faces. PLOS ONE 7(7), e40390.

Zhao, H., Z. Wang, and J. Men (2007). Facial complex expression recognition based on fuzzy kernel clustering and support vector machines. In Third International Conference on Natural Computation (ICNC), Volume 1, pp. 562-566.

Zhou, S., X. Liang, and C. Zhu (2008a). Exploiting lcsvc algorithm for expression recognition. In IEEE (Ed.), The 9th International Conference for Young Computer Scientists, pp. 1760-1765.

Zhou, S., X. Liang, and C. Zhu (2008b). Support vector clustering of facial expression features. In IEEE (Ed.), International Conference on Intelligent Computation Technology and Automation (ICICTA), Volume 1, pp. 811-815. 